Lola Zuckerman

Layla Zami

contemporary performemory Moving Through Diasporic Dancescapes in the $21^{\text {st }}$ Century

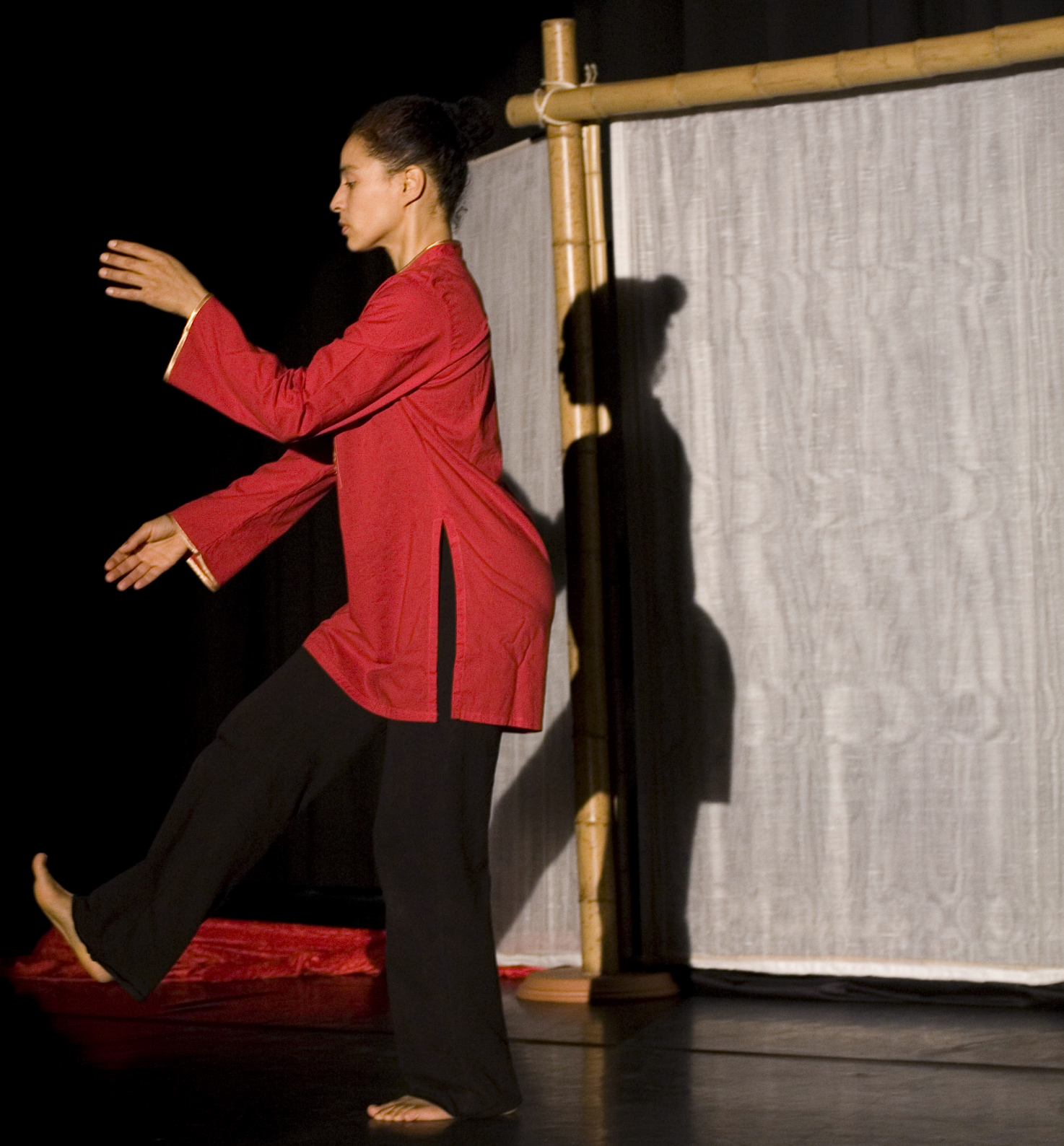




\title{
Contemporary PerforMemory
}

Moving Through Diasporic Dancescapes in the $21^{\text {st }}$ Century

\author{
Dissertation \\ zur Erlangung des akademischen Grades \\ Doctor Philosophiae (Dr. Phil.) \\ im Fach \\ Gender Studies
}

eingereicht am 11. April 2017

an der Kultur-, Sozial- und Bildungswissenschaftlichen Fakultät der Humboldt-Universität zu Berlin

von Dipl.-Pol. Lola F. Zuckerman (Layla Zami)

verteidigt am 24. Mai 2017

Präsidentin der Humboldt-Universität zu Berlin

Prof. Dr.-Ing. Dr. Sabine Kunst

Dekanin der Kultur-, Sozial- und Bildungswissenschaftlichen Fakultät

Prof. Dr. Julia von Blumenthal

Gutachten von:

Prof. Dr. Lann Hornscheidt

Prof. Dr. Marianne Hirsch, Columbia University 
This book is the fruit of research conducted from 2013 to 2017 as a Doctoral Candidate at the Center for Transdisciplinary Gender Studies, Humboldt-University Berlin, Germany. My study also involved international research stays as a Visiting Research Scholar at the University of California San Diego, Department of Theatre and Dance and at Columbia University, Institute for Research on Women, Gender and Sexuality (IRWGS); as well as field research trips in France, Martinique, Austria and Taiwan.

The research was sponsored by a Doctoral Fellowship (2013-2016) from the Jewish Talents Program (Jüdische Begabtenförderung) administered by the Ernst-Ludwig-Ehrlich Scholarship Fund (ELES), and funded by the German Federal Ministry of Education and Research (BMBF). This publication is made possible in parts by a grant from the Faculty of Humanities, Cultural and Social Sciences, Humboldt-University Berlin.

A documentary film is currently in production as an audiovisual complement to the book.

Watch Trailer here: http://vimeo.com/laylazami/memory2go

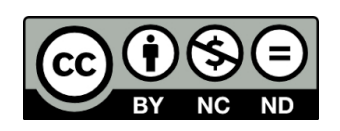

This work is licensed under a

Creative Commons Attribution-NonCommercial-NoDerivatives 3.0 License

Front Cover: Oxana Chi in Durch Gärten (Through Gardens), Berlin 2008

Photo by Annette Hauschild

Back Cover: Layla Zami, Jewish Music and Theatre Weeks, Dresden 2014 Photo by Sebastian Loeder

Book Cover Design: Doro Tops 
Table of Contents

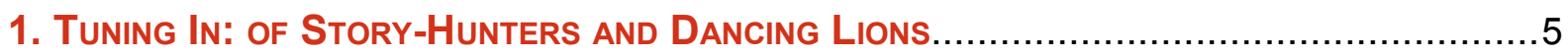

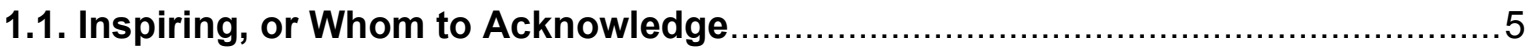

1.2. Imagining, or What an Academic and Artist Aims to Find Out about Dance and

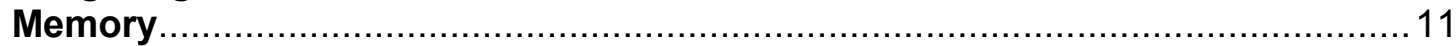

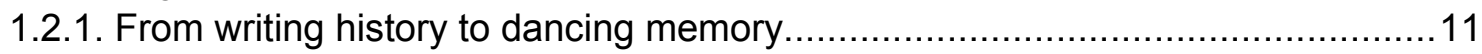

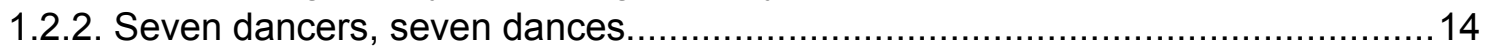

1.2.3. Jumping between the gaps of hegemonic narratives...................................... 18

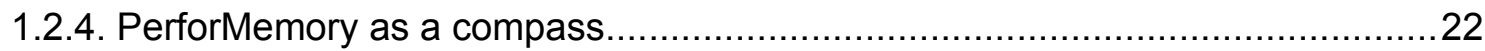

1.3. Innovating, or Which Contributions I Wish to Make to Existing Scholarship.....25

1.4. Investigating, or How Epistemology and Methodology Come into Play.............30

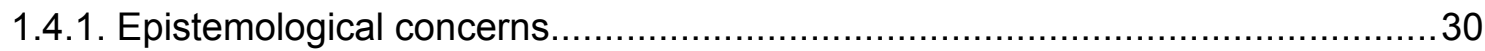

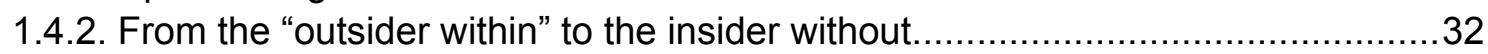

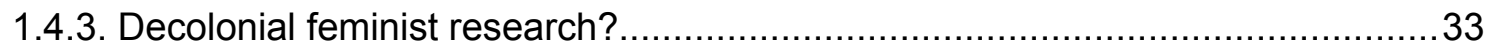

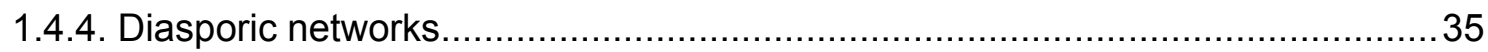

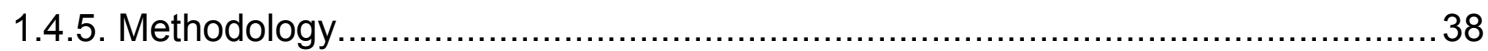

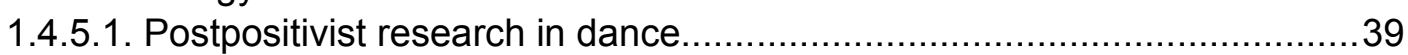

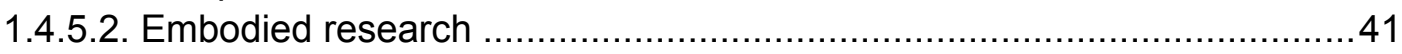

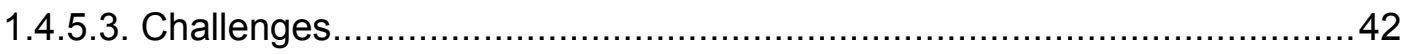

1.5. Inventing, or Whence the Outline Comes From ........................................... 44

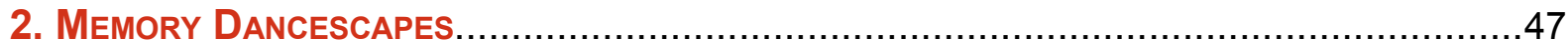

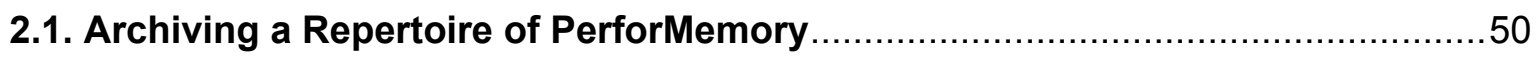

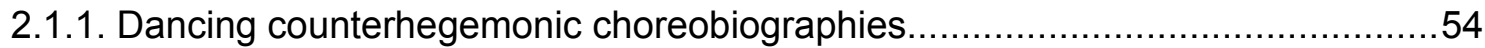

2.1.1.1. Through Gardens by Oxana Chi .....................................................56

2.1.1.2. They Call You Venus by Chantal Loïal ................................................60

2.1.2. Dancing after the ancestors: family, trauma and movement............................62

2.1.2.1. all about nothing by Zufit Simon .......................................................64

2.1.2.2. Digital Middle Passage by André M. Zachery.....................................68

2.1.3. Dancing without borders: geopolitical and physical islands.............................70

2.1.3.1. Impressions by Wan-Chao Chang ................................................... 73

2.1.3.2. Choc(s) by Christiane Emmanuel ..................................................... 76

2.1.3.3. Parole, Parole, Parole by Farah Saleh...................................................79

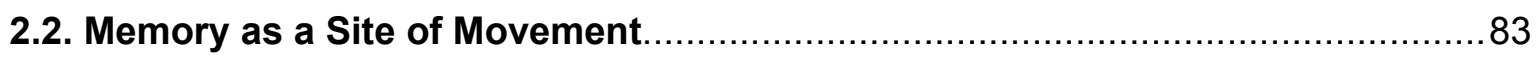

2.2.1. Performing memory in the age of Postmemory ........................................ 83

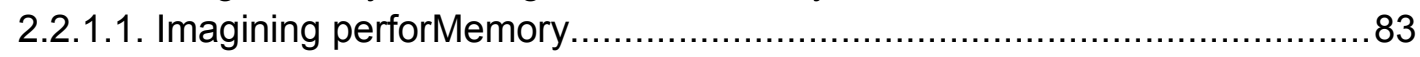

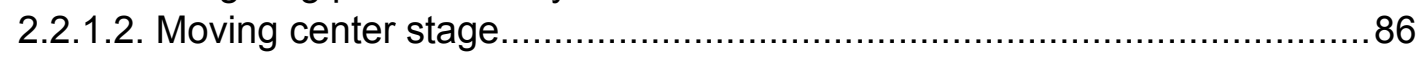

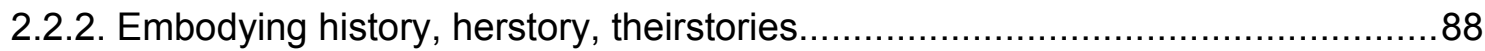

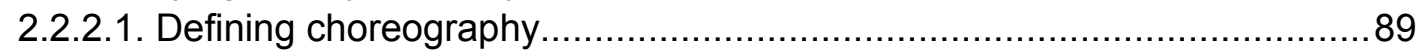

2.2.2.2. Between telling history and performing memory................................91

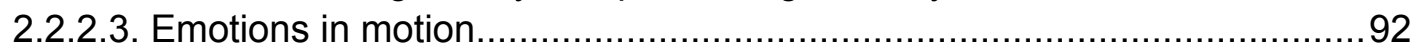

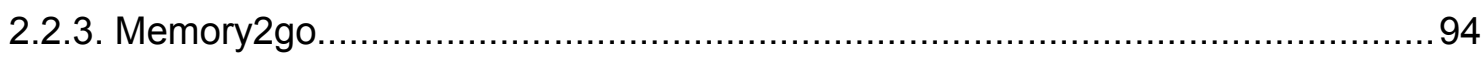

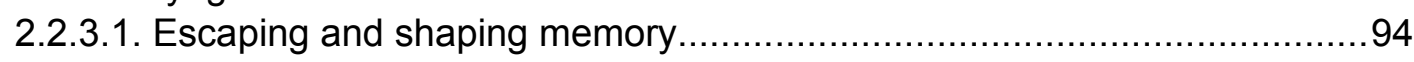

2.2.3.2. From the choreography of power to the power to choreograph ..............97 


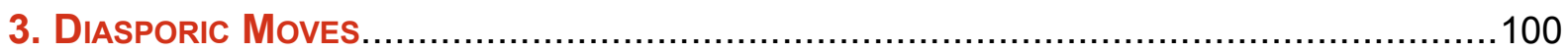

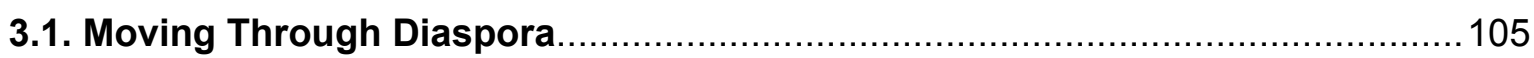

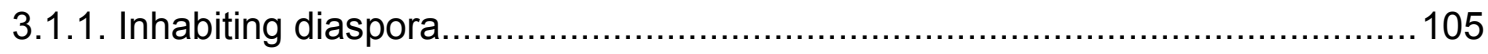

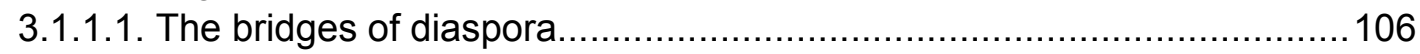

3.1.1.2. The multiple layers of diaspora space..........................................110

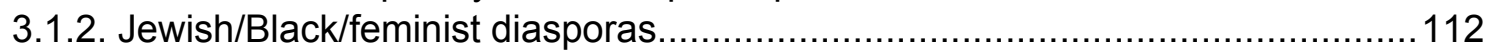

3.1.2.1. Diaspora, where do you come from? ................................................ 113

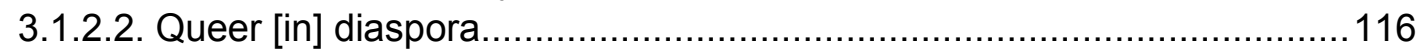

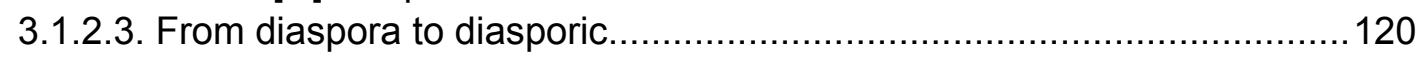

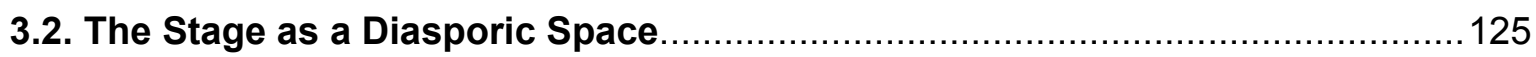

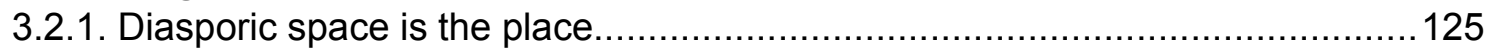

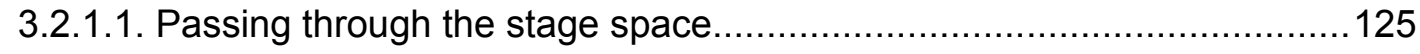

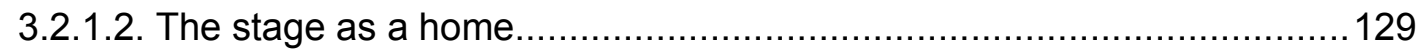

3.2.2. Finding a home space in the dance place?............................................... 131

3.2.2.1. The dancing body as a home.................................................... 131

3.2.2.2. The dancing body as a diasporic memory...................................... 136

4. Dancing the Past in the Present Tense.................................................... 141

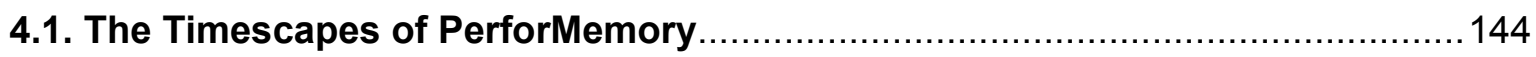

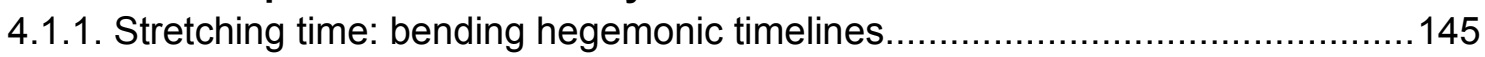

4.1.1.1. The pulse of time in all about nothing ................................................ 145

4.1.1.2. The suspension of time in Digital Middle Passage..............................147

4.1.1.3. Cyclic time in Through Gardens.................................................... 150

4.1.1.4. Instant time in Parole, Parole, Parole.................................................. 155

4.1.1.5. The ripples of time in They Call You Venus.........................................157

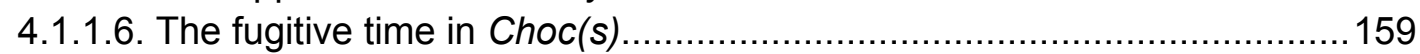

4.1.1.7. The swirling time in Impressions................................................. 161

4.1.2. The quantic dance of memory: moving through and beyond past, present and

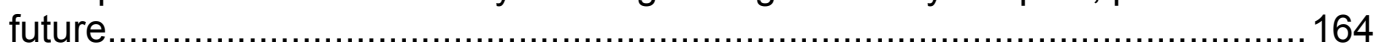

4.1.2.1. Dancing right here right now: from ephemeral to epiphenomenal time...165

4.1.2.2. Intensity as the spacetime of perforMemory .................................... 170

4.2. The Moves of PerforMemory: Shaping the Dancescapes........................... 174

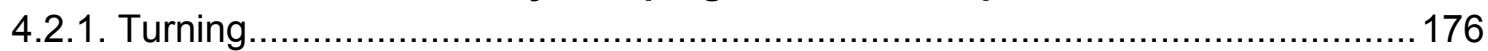

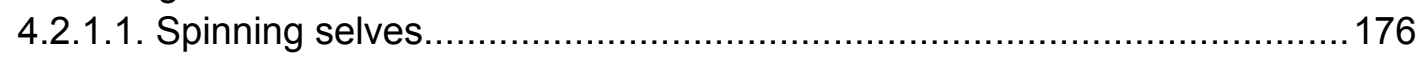

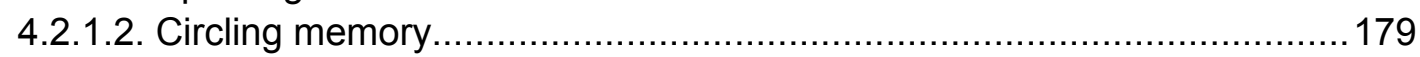

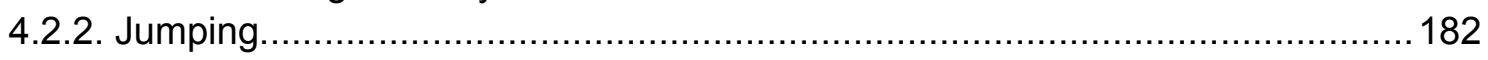

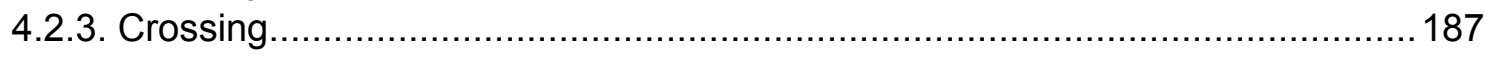

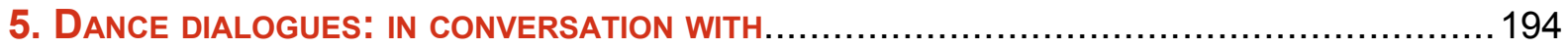

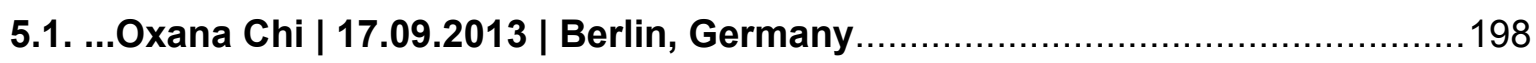

5.2. ...Christiane Emmanuel | 21.02.2014 | Fort-de-France, Martinique..................212

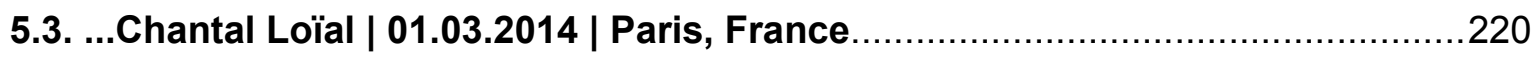

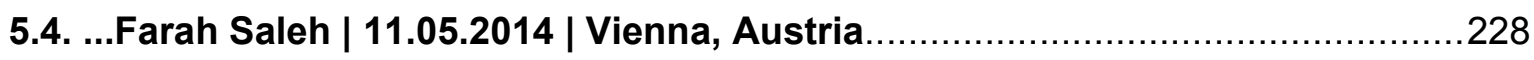

5.5. ...Zufit Simon | 30.06.2014 | Berlin, Germany..............................................238

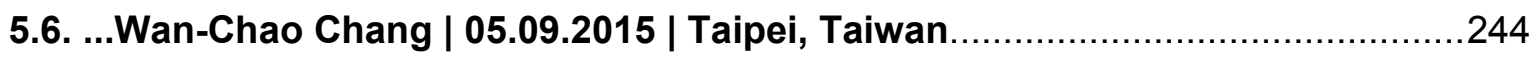

5.7. ...André M. Zachery | 01.12.2015 | New York City, USA................................254

6. Turning Out: Transforming the Body into a Spacetime of ResistDance............265

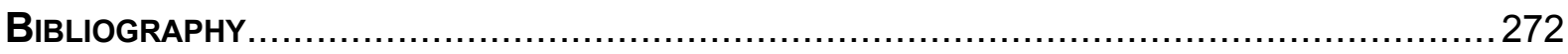




\section{Tuning In: of Story-Hunters AND DANCing Lions}

\subsection{Inspiring, or Whom to Acknowledge}

I developed a deep interest in the conscious linking of dance and diaspora, storytelling and struggles, bodies and battles, performance and politics, movements and memories, after being introduced to Oxana Chi's work in 2009 and working with her on stage since 2012. Like the figure dancing in the garden in the above quoted poem, it was the sight of Oxana Chi dancing her solo Durch Gärten (Through Gardens), that led me to follow this research path. My first encounter with the piece, in which Chi tells the powerful and tragic story of Jewish-Chinese-Latvian-Russian dancer Tatjana Barbakoff, took place on October 7th, 2009, at the Werkstatt der Kulturen Theater in Berlin, Germany. I was mesmerized by the impressive quality of the solo dance, by the astounding interplay between sounds and live-music, by the astute and emotional storytelling, by the alternating energies of tenderness and struggle embedded in Chi's moves. ${ }^{2}$

This piece originally awakened me to the tremendous power of dance art to perform memory. It also piqued my interest in the role of performance in preserving and re-creating memories of the past grounded in the present, and in imagining a future when and where persecution, discrimination, oppression and genocide are no longer imaginable. The experiences of the piece are the roots that nurtured my concept of perforMemory. However, at this time, I was far from knowing that I would collaborate with Oxana Chi, and even further away from imagining that I would complete a doctoral thesis on dance and memory. Between 2010 and 2014, I collaborated with Oxana Chi in the production of a feature-length documentary-fiction film about Through Gardens. The film, entitled Durch Gärten Tanzen

${ }^{1}$ Ayim, Blues in Schwarz-Weiss, 40 [My translation].

2 See Zami, "Tanzkunst als lebendige Erinnerung." 
(Dancing Through Gardens), was shot in Indonesia, Germany, and France. In the meantime I also wrote essays and journalistic articles about Through Gardens in English, French, and German.

In 2011, within the context of the exhibition Tanzende Erinnerungen (Dancing Memories) curated by Oxana Chi at the Galerie Gondwana, we commissioned the placement of a Stolperstein stone for Tatjana Barbakoff in the center of Berlin. Stolperstein literally means "a stone to stumble upon." The stones are a commemorative project by the artist and activist Gunter Demnig, who places them on sidewalks all over Germany to render visible the names of people who were deported during Nazi rule. ${ }^{3}$ The increasing presence of the stones throughout the country marks public space with a material, daily, individualized memory-reminder. While the stones are usually placed in front of the building where people had lived, we asked Demnig to place the Barbakoff stone in front of the Renaissance Theater where Barbakoff performed, thus shifting the focus from her place of residence to her place of work, in order to signify her major role in the cultural history of the city. The memory stones, like the perforMemory I define in this study, generate a dynamic remembering, situated in the present and negotiated by the movement of individual bodies within collective spaces.

By 2013, when I became a doctoral candidate at Humboldt-University's Cultural Studies department, I was an active member of Oxana Chi's Ensemble Xinren, participating as a musician and actress. I have been touring universities, theaters, festivals and conferences with her ever since, gaining artistic experience that has shaped my academic reflection on her work, as much as on the work of the six other artists discussed here. A central experience has been my involvement in the piece I Step On Air, a work for which Oxana Chi was commissioned by Dr. Natasha Kelly, who taught the May-Ayim-seminar at Humboldt-University at that time. I Step On Air is Oxana Chi's perforMemory of May Ayim, a Ghanaian-German author, activist, scholar and teacher, who was the Afro-German equivalent and friend of Audre Lorde.

May Ayim is the author of the quotation that opens this book. In the way they connect dream and motion, the words resonate with the piece Through Gardens, and especially with Tatjana Barbakoff's account of "dreaming herself into" the Chinese clothes of her mother as a child, in her first attempts to dance and choreograph. ${ }^{4}$ The layers of diaspora's costumes is a motif that resurfaces in this book. Through Gardens is a performance choreographed and interpreted by Oxana Chi in memory of Tatjana

\footnotetext{
${ }^{3}$ The artist started the project in 1996 in Berlin-Kreuzberg, defying the lack of municipal authorization. The city legalized the stones later, and by now Demnig has placed 50,000 stones all over Europe. Some cities such as Munich continue to forbid the stones, which continue to be placed individually by hand by the artistartisan, funded by private individual and institutional donors. http://www.stolpersteine.eu/en/

${ }^{4}$ Straus-Ernst, "Bei Tatjana Barbakoff"; Printed in Chi, Tanzende Erinnerungen, 2011, 15-17.
} 
Barbakoff (1899 Liepaja - 1944 Auschwitz). Barbakoff was a successful expressionist dancer-choreographer who inspired many artists in the 1920s/30s in Europe, yet is often unacknowledged in what pretends to be "the" western dance historical canon. The experience of Through Gardens, as well as the kitchen table conversations and office desk discussions with the dancer, made me realize the importance of documenting how memory is performed on stage. I deem it important to specifically challenge these issues in an academic context because universities devote material resources (funding, time, etc.) to historiographical and epistemological matters. My deepest gratitude for this project therefore goes to Oxana Chi, my life and work partner. I feel blessed and privileged for the path that we have walked together from Berlin to New York over Surakarta and Istanbul, and for the worlds I have encountered on the way.

I also want to express deep gratitude to the six other dancers-choreographers Zufit Simon, Chantal Loïal, Farah Saleh, André M. Zachery, Wan-Chao Chang, and Christiane Emmanuel, whose bodily work forms the core of my research. My heartfelt thanks go to all seven of you for taking precious time from your busy schedules, expressing enthusiasm and trust, sharing fascinating conversations and performances. Like a performance, this work required patience and perseverance to be materialized, and I thank you for understanding it. I admire your moving efforts to fill the stage and our hearts with beauty and complexity. Your inexhaustible discipline and creativity are the fuel that powers my research.

After Through Gardens, there were three other inspirational personal encounters. I met Chantal Loïal in Martinique in 2011, when I first attended the premiere of her solo On t'appelle Vénus (They Call You Venus), which deeply touched me and inspired my poeticjournalistic essay on dance as a means of reclaiming the body. ${ }^{5}$ I followed the evolution of the piece over the years, in various contexts, and attended dance classes and workshops with Loïal's company Difé Kako. 2011 also marks my encounter with Prof.ecs Dr.ecs Lann Hornscheidt, who later became my doctoral advisor at Humboldt-University. We first collaborated in the realm of the exhibition to dyke_trans | dis_visualizing re_locating de_silencing, and produced the short movie spuren legen_verwehen: a feminist videopoem together. I remember the rich and deep conversations we had on the topic of voices, privileges, visibility and creativity. Lann Hornscheidt described an imagery that has stayed with me ever since: the contrast between the rigidity of their family sitting on a fixed couch and the constant motion, across the globe and over the centuries, of my Jewish_Afro_Indian_Caribbean_Russian ancestors. Hopefully one day we will find the time to shoot this scene for our next video project. I am deeply grateful to Lann

\footnotetext{
${ }^{5}$ Zami, "Rendre sur scène son corps à Sawtche."
} 
Hornscheidt for recognizing the significance and vitality of my doctoral research, for helping me to access material resources to realize it, for allowing me to explore academic freedom, for encouraging me to follow intuition as a valid source of knowledge, and for widening my understanding of the field and purpose of "Gender Studies."

I am also very thankful to my second advisor, Professor Marianne Hirsch, Director of the Institute for Research on Women, Gender and Sexuality (IRWGS) at Columbia University, for her trust, curiosity and availability during my stay as a Visiting Scholar at IRWGS. It was truly an honor to have you on my thesis committee, thank you for traveling to Berlin for this special occasion and for supporting my project. Warmest thanks also go to Professor Tina Campt at Barnard College/Columbia University, for opening the heavy door to this prestigious institution, and for actually leaving your office door open at the Barnard Center for Research on Women (BCRW). Many thanks also to the staff at IRWGS and BCRW.

During my initial research stay in New York City in the summer of 2013, I indeed followed my intuition and attended a dance class by Ronald K. Brown (Evidence Company Director) at the Center for African and Diaspora Dance (CUMBE). After attending an Evidence show at NYU, I requested an interview and had the opportunity to attend and film rehearsals. Ronald was very accessible and shared intimate thoughts on his artistic process, and so did company member dancer Annique Roberts. I thank you for sharing time and knowledge, and although the circumstances did not allow this precious material to find its way into this dissertation, it is already integrated into my next research and publication project.

Later that summer, at the Brooklyn Library, I found the book Urban Bush Women Twenty Years of African American Dance Theater, Community Engagement, and Working It Out ${ }^{6}$ by Professor Nadine George-Graves, Chair of the Department of Theater and Dance at the University of California San Diego. I am glad that we got to meet and to discuss my work on the short diasporic islands of time whose shores we lingered on. I thank Nadine George-Graves for inviting me to come as a Visiting Research Scholar to her department. Many thanks also to graduate coordinator Marybeth Ward for her capacity to make it sunny on the administrative side of the street.

The writing phase was as challenging as it was enjoyable. When I started writing the dissertation, I benefited from precise and enthusiastic support from experts in the field of gender, dance and memory. In Berlin, Dr. Jacob K. Langford (Gender Studies) gave wonderful feedback on the second chapter. Her precise and committed advice was incredibly helpful, and I am looking forward to continuing our conversation as musicians in

\footnotetext{
${ }^{6}$ George-Graves, Urban Bush Women.
} 
the form of musical phrases. Professor Jill Strauss (City University of New York, Department of Theatre and Communication), dance expert Judy Pritchett (Frankie Manning Foundation, Board), Aradhana Hinds (New School, Doctoral Candidate), and Kerry Downey (MoMA, visual artist and educator) took up the torch in New York, gifting me with invaluable detailed edits and suggestions. In the preparation of this publication, I had the chance to work with professional writer and editor Fatin Abbas (Ph.D., Harvard, Comparative Literature) whom I thank warmly for her precious feedback and her careful attention to detail. I thank you all for taking time out of very full schedules to read, edit and comment on my work. For interview transcription and translation support, I thank dancerswriters Jaya Chakravarti (Berlin) and Nubian Néné (New York, Glasses \& Laces), for joining the diasporic dance of words.

It is no coincidence that I applied and received doctoral funding while I was intensely engaged in the rehearsal process for Oxana Chi's performance I Step On Air. I am grateful for having had the privilege of receiving a highly competitive Doctoral Fellowship from 2013 to 2016 from the Jewish Talents Program "Jüdische Begabtenförderung - Eine Geschichte mit Zukunft," administered by the Foundation Ernst-Ludwig-EhrlichStudienwerk (ELES) and funded by the German Federal Ministry of Education and Research (BMBF). They also provided additional funding for my stays as a Visiting Research Scholar at UCSD and at Columbia University (2014-2015), and for international presentations of my research. Special thanks go to my program advisors at ELES, PD Dr. Eva Lezzi and Dr. Dmitrij Belkin for their constant availability. I also deeply thank my mother Dr. Ketty Smith for encouraging me and sponsoring my research in the crucial final year. I thank my father Alex Zuckerman for covering some of my costs in the USA.

Warm thanks also go to Professor Michelle M. Wright (Northwestern University) for giving me insightful feedback at an early stage of my project during a workshop held at xart splitta e.V. in Berlin. I am also grateful to Prof. Dr. Claudia Bruns, Chair of the Institute for Cultural Studies at Humboldt-University, for showing interest and support as a first advisor during the early stages of this research. I also thank the Faculty of Humanities and Social Sciences for funding this publication, and for rewarding me twice with a Women's Fund grant that enabled me to present research and perform at Yeditepe University in Istanbul and at Goldsmiths University in London.

The Centre for Transdisciplinary Gender Studies ( $\mathrm{ZtG})$ at Humboldt-University also showed interest in my research, and included me in the faculty's course program. I thank the $\mathrm{ZtG}$ staff for recognizing the quality of my contribution and for reaching out to the Education Quality Program "Berliner Qualitätsoffensive für die Lehre" for additional funding. I am also grateful that my seminar "Performing Memory" was officially acknowledged as outstanding, and for receiving the Faculty's First Prize Teaching Award 
(Fakultätspreis für gute Lehre). I also thank all my students for their openness, their motivation, their constructive feedback and their will to learn, share and perform, and for ranking the seminar as Best Humanities Seminar across Germany. Special thanks to Stefanie-Lahya Aukongo, Toni Witzel, Jan Dammel, Vera Wirtz, Sophie Weber, Jumoke Adeyanju Omonga, Pia Vogel, Sarah Mouwani, Marie Springborn, Aria Tilove, Alex Dmitriou, Bea_Leander, and Jana Asmus for their commitment.

The defense committee members evaluated the dissertation with a magna cum laude. I thank them for their commitment to academic integrity and fairness, and for their challenging questions. Many thanks to my advisors Professors Lann Hornscheidt and Marianne Hirsch, Dean Professor Ulrike Vedder, PD. Dr. Bettina Bock von Wülfingen, Professor Susanne Gehrmann and Dr. Pepetual Mforbe Chiangong, as well as to my student Marie Springborn; and to my special guests Dr. Ika Hügel-Marschall and Dr. Dagmar Schulz, who were close friends of Audre Lorde and enriched the defense with their presence.

I am also grateful to my two grandmothers Friedel Zuckerman (1912-2010) - whose dance career was brutally disrupted in 1933 - for accompanying me in spirit, and Germaine Smith for making physical space for my laptop in her home in Martinique. I also had the opportunity to work at the Pratt Institute Library in New York City, and at the Gérard-Philippe-Library and O26 Bürogemeinschaft in Berlin. In Brooklyn, I felt an interesting energetic parallel in crafting my dissertation on performance at Pratt campus, while the institution was itself laboring on the creation of what has now become the Performance Studies MFA. For motivational support in Berlin, I also thank my dear friend AnouchK Ibacka-Valiente who often had more than an ear to listen to my doubts and more than a word of encouragement to follow my path.

Gratefulness to my ancestors and all the deities and spiritual beings twirling around the universe that help me to overcome, circumvent, crawl under, and jump over structural barriers of racism, antisemitism, genderism, classism, homo- and transphobia. Thank you for always carrying me into the crea(c)tive flow. 


\subsection{Imagining, or What an Academic and Artist Aims to Find Out about Dance and Memory}

The connection between traumatic cultural memory and corporeality has come to the fore in recent years, especially with the vanishing of the last generation of Holocaust survivors, and the digitalization of oral history - slave narratives, for instance. The role of performing bodies within collective and individual cultures of remembrance, however, has been contested. Memory scholarship has foregrounded the role of visual and literary arts in representing, reclaiming and recasting history. ${ }^{7}$ Feminism and performance scholars have argued that the body functions as an archive. ${ }^{8}$ Some scholars of African-American studies have situated Black $^{9}$ bodies as receptors and generators of culture, and highlighted how dancers perform and negotiate the intersections of race and gender on stage..$^{10}$ Yet to date, little research has thoroughly examined the function of dance as an epistemological practice of cultural memory in relation to historical trauma. Pursuing this research path represents a vital step in opening up new viewpoints on memory, and gaining new insights into the value and function of the body within the humanities.

\subsubsection{From writing history to dancing memory}

How can dancers embody the afterlives of traumatic pasts, in ways that render the sensation of the present meaningful, and the imagination of the future possible? This overarching question is the canvas on which I examine moving bodies as nodal points between cultural, performance and gender studies. My aim is to analyze how dance performances and cultural memory intersect in the $21^{\text {st }}$ century. I am interested in finding

\footnotetext{
7 See Bruns, Dardan, and Dietrich, Anette, Welchen der Steine du hebst; Hirsch, The Generation of Postmemory; Kelly, Afrokultur; Mandel, Against the Unspeakable; Landsberg, Prosthetic Memory; Rothberg, Multidirectional Memory; Tillet, Sites of Slavery.

${ }^{8}$ See Anzaldúa, Borderlands; Cvetkovich, An Archive of Feelings; Lepecki, Exhausting Dance; Taylor, The Archive and The Repertoire; Wehren, Körper als Archiv in Bewegung; Zenenga, "Power and the Body."

9 I use the word "Black" to refer to people of the African diaspora. I choose to capitalize the word "Black" to acknowledge the fact that Black is a proper name on par with Jewish, Latinx, or Irish. On this controversial question, see for instance Lori L. Tharps, "The Case for Black With a Capital B"; Kapitan, "Ask a Radical Copyeditor: Black with a Capital 'B."'

${ }^{10}$ See for example Dixon Gottschild, The Black Dancing Body; George-Graves, Urban Bush Women; Johnson and Rivera-Servera, Blacktino Queer Performance; Kusser, Körper in Schieflage: Tanzen Im Strudel Des Black Atlantic Um 1900; DeFrantz, Dancing Revelations: Alvin Ailey's Embodiment of African American Culture; DeFrantz and Tara A. Willis, "Black Moves: New Research in Black Dance Studies."
} 
out how selected works handle and generate knowledge about historical trauma in relation to current sociopolitical contexts. My research explores how movement and, more specifically, contemporary dance productions, may inform and transform access to traumatic pasts, current power relations and perceptions of (post)human futures at a personal and a societal level. Contending that corporeality is a site and a source of power, I ask what happens when bodies propel the past into the present, metaphorically and materially. By challenging the presumed ephemerality of dance,${ }^{11} \mathrm{I}$ contend that it can be read as a dynamic epistemology that mobilizes memory, in a way that has a long-lasting impact on the production and transmission of memory. Eventually, this book argues that dance as an epistemological medium functions as a fundamental tool for processing historical trauma in relation to current sociopolitical relations.

I hope to contribute to knowledge production located at the crossroads of gender studies, cultural memory studies, postcolonial studies, performance studies, and critical dance studies. Working towards the recognition of dance as a vital field for academia, I argue that it should be acknowledged as knowledge, thus rejoining dancer-scholar Ananya Chatterjea, who makes the case for:

[...] situating dance and choreographic work in the larger frame of cultural production as a potent source of information, analysis, and critique, linked intimately to the processes of sociocultural and political change. ${ }^{12}$

Here Chatterjea suggests that dance can, or even should be a matter of academic inquiry, and that interpreting dance works can lead to sociopolitical transformation. Knowing this, one may wonder about the absence of dance in cultural studies departments, such as the one at Humboldt-University, ${ }^{13}$ and the corollary absence of a dance/performance studies department. My thesis attempts to address this absence, and hopefully represents a small yet significant step in the humanities research landscape.

Years before reading Chatterjea or other dance theorists, it is live dance itself that sharpened my awareness of its crucial sociopolitical role. As mentioned earlier, a milestone experience was Oxana Chi's piece Through Gardens. She was the first dancerchoreographer whom I interviewed for this book in 2013. The connection between her role as a dancer, choreographer and historical storyteller, which we discussed in the interview, left a strong impression on me. Speaking about Through Gardens, the dancer emphasized her conscious intent to use dance as a medium to counter hegemonic storytelling and to use her body as a counterweight to mainstream historical narratives:

\footnotetext{
${ }^{11}$ See for instance the performance-as-disappearance paradigm of Peggy Phelan in Unmarked: The Politics of Performance; Schneider, Performing Remains, For arguments against the ephemerality of performance, see for example.

${ }^{12}$ Chatterjea, Butting Out, 30.

${ }^{13}$ There is no professor appointed for performance studies in the sense of a "Professur".
} 
[My work on] Tatjana Barbakoff led me to increasingly question: Who writes or is allowed to write history in Germany, in Europe, in the world? It then became clear to me how important it is, for contemporary artists like myself, to write history ourselves. And if I do not have the means to write a book, then I shall step on stage, and dance it out, this history. I must create alternatives to all this mainstream that actually, very intentionally, narrates a single story, which is, for my taste, extremely truncated.

[Meine Arbeit zu] Tatjana Barbakoff hat mich mehr und mehr dazu gebracht, zu hinterfragen: Wer eigentlich in Deutschland, wer eigentlich in Europa, wer eigentlich in der Welt Geschichte schreibt, oder schreiben darf. Dann wurde mir klar, dass es ganz wichtig ist, für zeitgenössische Künstler_innen wie mich, Geschichte selbst zu schreiben. Und wenn ich nicht die Mittel habē, ein Buch zu schreiben, dann muss ich mich auf die Bühne stellen und muss sie dort vertanzen, die Geschichte. Ich muss Alternativen schaffen, zu diesem ganzen Mainstream, der im Prinzip ganz ganz berechnend eine einzige Geschichte schreibt, die für mein Geschmack, sehr sehr beschränkt ist. ${ }^{14}$

Chi emphasizes her will to use her own body as a tool to challenge and displace hegemonic narratives. This does not mean that she rejects the practice of writing. Her own reflections on her work appear in self-published publications as well as in academic anthologies such as Sisters and Souls. ${ }^{15}$ What I read in the quotation however is the will to explore dance art as a corporeal alternative to conventional instruments of historiography.

Dance indeed enables the expression of stories, characters and imaginations that are otherwise marginalized, invisibilized, or erased in western narratives of the past, as we will see in this book. Focusing on the role of social categories in the production of historical narratives from a transnational feminist Afro-diasporic perspective, Samantha Pinto asks,

How do race, gender, and diaspora interact with the concept of 'history', both as it is constructed as a Western narrative of dominance and in counternarratives of resistance ${ }^{16}$

This book offers some responses through the lens of performance. I contend that because the categories of race and gender are constructed as bodily markers, the analysis of bodily engagements with history provides necessary tools to answer Pinto's question. I examine how selected choreographic works negotiate hegemonic conventions and definitions of memory, and how they contribute to reflecting upon concepts of diaspora, time, space, body and self. Dance does not only signify and represent meaning, it also enacts power dynamics on multiple levels, as pointed out by Susan Foster:

[...] as a cultural practice that cultivates disciplined and creative bodies, as a representational practice that explores rigorously strategies for developing bodily

\footnotetext{
${ }^{14}$ Chi, interview.

${ }^{15}$ Chi, "Von Hier Nach Dort - I Step On Air."

${ }^{16}$ Pinto, Difficult Diasporas, 78.
} 
signification, as a cultural endeavor through which cultural change is both registered and accomplished $[\ldots] .^{17}$

To analyze dance, one must therefore take into consideration the interplay of its cultural, representational, and interventional dimensions. Because my thesis focuses on artists who work outside of mainstream structures of cultural production, I found it particularly relevant to look at how they negotiate the stage as a strategic site for bodies to not only represent (themselves or others), but also to intervene by reclaiming visibility and agency. Consequently, my research scope does not encompass social dance, such as club dancing, or street dance. ${ }^{18}$ Rather, my study focuses on concert dance productions that were produced and performed by professional artists within a theatrical context for an audience, usually in a conventional stage setting. Although by focusing on stage performances, I intentionally did not go with the current stream of performance studies, I am also very interested in interactive performances, as in Farah Saleh's work Parole, Parole, Parole.

\subsubsection{Seven dancers, seven dances}

In the precious hours that I spent counterbalancing the academic activities of sitting/reading/writing, I encountered the eight limbs of yoga, a fundament on which a yogi is meant to build their home. My research material rests on seven limbs. (Seven is a great yogic number too, think of the seven chakras!). The book discusses seven works by seven dancer-choreographers who are currently active in the dance scene: Oxana Chi, Zufit Simon, Christiane Emmanuel, Chantal Loïal, Farah Saleh, André M. Zachery, and Wan-Chao Chang. Based in Germany, Taïwan, Martinique, Palestine, France and the USA, they are all positioned as cis-gender, able-bodied dancers. Their choreography sometimes relates to their genealogies located in Afro-descendent, Jewish European, Middle-Eastern and Chinese diasporas. I regroup these artists who highly vary in terms of style, location, race, age, and education under a broadly defined "diasporic dance" umbrella. Just as a dancer's pieces of work form a repertoire, this research is my own repertoire of perforMemory.

One of the parallels between these artists is their capacity to work both as dancers and as choreographers. As artists who interpret their own work, it was particularly interesting

\footnotetext{
${ }^{17}$ Foster, Corporealities: Dancing Knowledge, Culture and Power, xii [My emphasis].

${ }^{18}$ For an insightful study on identity and sexuality in both concert and social dance settings, see: Ramón $\mathrm{H}$. Rivera-Servera, Performing Queer Latinidad; Bragin, "Shot and Captured: Turf Dance, YAK Films, Nad the Oakland, California, R.I.P. Project."
} 
to conduct interviews and listen to their perspectives. Focusing on dancer-choreographers - rather than dancers or choreographers - also offered an additional insight into the power of agency I was interested in exploring in relation to perforMemory. The decision to write only about works I appreciate and admire is a natural pendant to the methodology described later. It echoes the approach of performing scholars such as Jill Dolan, who writes about "works that inspired [her] emotionally, intellectually, and politically."19 Moreover, the selection of the performances comes from a conscious will to acknowledge the works of artists who have received less exposure in academia, despite their active and important presence onstage.

During the research process, I decided to focus on solo works, meaning dances that the choreographers interpreted themselves on stage, sometimes with live-music, but without other dancers. This was not evident from the start, since most of these artists are prolific group choreographers, for instance Chantal Loïal is the Founder-Director of Difé Kako and André Zachery leads Renegade Performance Group (RPG). Also in my readings, most academic engagements with dance dealt with group choreographies. ${ }^{20}$ Here again, the key experience of the dance solo Through Gardens shaped my intent to spotlight single, individual corporealities dancing onstage, performing movements they created for their own bodies. Thus, the book concentrates on one solo work per dancerchoreographer.

In the desire to explore contemporaneity, this study highlights concert dance productions from the 21st century. All pieces discussed are original creations, and premiered between August 2008 and November 2015 in Germany, the USA, France, Martinique and Taiwan. Although I formally began doctoral research in 2013, I relate to live experiences of the works between 2009 and 2016. I conducted interviews between 2013 and 2016 in Berlin, Paris, Vienna, New York City, Fort-de-France (Martinique), and Taipei.

Although or because contemporary choreographic inquiries of the past are often reenactments of past works or events, I chose to highlight a less explored field, namely original creations that engage with the past. I limit the scope to recent works because my intent is to engage with dance productions which are currently part of the cultural landscape. This also works to bridge the gap between cultural productions and their inscription into academic knowledge production, and to generate knowledge in synchronicity with its societal surroundings. In order to provide a clear and concise overview of the seven performances, I present them in a chart on the next page.

\footnotetext{
${ }^{19}$ Dolan, Utopia in Performance, 33.

${ }^{20}$ For an interesting discussion of race and gender in solo theater pieces, and a dynamic collection of academic essays, artists interviews, and performance scripts, see the anthology: Johnson and RiveraServera, Solo/Black/Woman.
} 


\begin{tabular}{|c|c|c|c|}
\hline Performance Title & Creator & Topic & Premiere \\
\hline $\begin{array}{l}\text { Through Gardens } \\
\text { (Durch Gärten) }\end{array}$ & Oxana Chi & $\begin{array}{l}\text { A dance-music tribute to Tatjana } \\
\text { Barbakoff (1899-1944). The piece } \\
\text { depicts, in four acts, the great } \\
\text { successes and struggles of this } \\
\text { Chinese-Jewish-Latvian dancer in } \\
\text { Europe. Video Excerpt }\end{array}$ & $\begin{array}{l}\text { September } 2008 \\
\text { Berlin, Germany } \\
\text { Multipurpose Hall } \\
\text { Haus de r } \\
\text { Demokratie und } \\
\text { Menschenrechte } \\
\text { (Hous e of } \\
\text { Democracy and } \\
\text { Human Rights) }\end{array}$ \\
\hline $\begin{array}{l}\text { They Call You Venus } \\
\text { (On t'appelle Vénus) }\end{array}$ & Chantal Loïal & $\begin{array}{l}\text { The solo handles the story of } \\
\text { Sawtche, also known as Sarah } \\
\text { Baartman. It explores the } \\
\text { exploitation of her body as the } \\
\text { "Black Venus," as well as her Khoi } \\
\text { San origins. Video Excerpt }\end{array}$ & $\begin{array}{l}\text { January } 2011 \\
\text { Fort-de-France, } \\
\text { Martinique } \\
\text { Aimé-Césaire- } \\
\text { Theater }\end{array}$ \\
\hline $\begin{array}{l}\text { Choc(s) } \\
(\operatorname{Shock}(s))\end{array}$ & $\begin{array}{l}\text { Christiane } \\
\text { Emmanuel }\end{array}$ & $\begin{array}{l}\text { An assessment of body memory at } \\
\text { the confluence of political, } \\
\text { economic, physical and spiritual } \\
\text { shocks on a global and local scale. }\end{array}$ & $\begin{array}{l}2011 \\
\text { Fort-de-France, } \\
\text { Martinique } \\
\text { Atrium Theater }\end{array}$ \\
\hline Impressions & $\begin{array}{l}\text { Wan-Chao } \\
\text { Chang }\end{array}$ & $\begin{array}{l}\text { A corporeal retrospective on } \\
\text { Chang's "inner and outer journeys" } \\
\text { in search of artistic and cultural } \\
\text { identity. Video Trailer }\end{array}$ & $\begin{array}{l}\text { September } 2012 \\
\text { Taipei, Taiwan } \\
\text { Fringe Festival }\end{array}$ \\
\hline Parole, Parole, Parole & Farah Saleh & $\begin{array}{l}\text { The (im-)possibility of a } \\
\text { Gaza/Ramallah love story within } \\
\text { political-physical barriers. Video }\end{array}$ & $\begin{array}{l}\text { April } 2013 \\
\text { Palestine } \\
\text { Ramallah } \\
\text { Contemporary } \\
\text { Dance Festival }\end{array}$ \\
\hline all about nothing & Zufit Simon & $\begin{array}{l}\text { A body collage on trauma and } \\
\text { emotions, inviting the audience to } \\
\text { activate their own memories (from } \\
\text { the trilogy un-emotional). Video }\end{array}$ & $\begin{array}{l}\text { June } 2014 \\
\text { Munich, } \\
\text { Germany } \\
\text { Schwere Reiter }\end{array}$ \\
\hline $\begin{array}{l}\text { Digital } \\
\text { Middle Passage }\end{array}$ & $\begin{array}{l}\text { André M. } \\
\text { Zachery }\end{array}$ & $\begin{array}{l}\text { An exploration of the movements of } \\
\text { African-American diasporic identity } \\
\text { between past, present and future. } \\
\text { (from the Afrofuturism Series) Video }\end{array}$ & $\begin{array}{l}\text { November } 2015 \\
\text { New York, USA } \\
\text { Irondale Center }\end{array}$ \\
\hline
\end{tabular}


Not all the choreographers use the term memory explicitly in their performance synopses or choreographic statements-of-intent. Thus, it is my interpretation which frames their works as perforMemory. For the sake of clarity, capacity, intensity, and sanity, the written analysis focuses on one piece per dancer-choreographer. One always has to impose some kind of limits. However, when I conducted interviews with the artists, I systematically addressed other works, which led to riveting discussions included in the last section of this book. Therefore, the interview transcripts are a fundamental constituent of the book, which allow the reader to zoom out and to discern a broader picture of the choreographers' repertoire and their reflections upon it. Here you will find interesting contributions about others pieces dealing with other historical and contemporary migration, trauma and diaspora: Neferet iti and I Step On Air by Oxana Chi; Keep Her Safe, Please! by Wan-Chao Chang; The Inscription Project and Dapline! by André M. Zachery with his Renegade Performance Group; Ordinary Madness by Farah Saleh; and Noirs de Boue et d'Obus by Chantal Loïal. The film Memory2Go, which is currently in production and will later complement this book, will also include excerpts and discussions of several works by the artists, thus giving simultaneously a broader and a more precise impression of their performances of memory.

By no means do I attempt to give an evenly balanced discussion of each piece. It appears senseless to me, and in contradiction with the epistemological and methodological framework described in the next section. First, because the pieces vary greatly in terms of duration, for instance a full hour for Through Gardens, 27 minutes for Digital Middle Passage, or a miniature-length, less then 15 minutes for Parole, Parole, Parole. Moreover, my knowledge of the pieces and my proximity to the artists also vary greatly: I have followed closely over several years, and attended many times in various settings, the works of Oxana Chi. I am also quite familiar with the work of Chantal Loïal and her company, Difé Kako. In other cases, I was not so familiar with the artists and their productions. In the case of Christiane Emmanuel, I am familiar with her company's work, her dance studio and her work ethics, however I was only able to see the piece Choc(s) as a video recording. I found out about Farah Saleh through my online research, while trying to use internet technology to extend my scope to the Global South. I witnessed her work once at the Tanzquartier Vienna (in the west!). The research phases and interviews I conducted in Taiwan and Martinique (still a French colony) were the only opportunities I had to research outside the west. This disparity of perception infers a diverse engagement with the works. 


\subsubsection{Jumping between the gaps of hegemonic narratives}

The works presented above engage with different historical traumata, such as the European Holocaust, the Transatlantic Slave Trade, the Maafa, ${ }^{21}$ the Nakba, ${ }^{22}$ and other forms of colonial-racist violence. The dances explore tropes of displacement, migration, oppression, empowerment and resistance from the micro-level of the individual body cells to the meta-level of society networks. All the dancers-choreographers situate their dance practice in the now, meaning that their interest in knowing the past goes hand-in-hand with the desire to shape the present.

Through a reflection upon these pieces, my book examines how dance art intervenes in memory discourses and practices. My main research goal is to discover how dance can accomplish what bell hooks calls "a politicization of memory [...], remembering that serves to illuminate and transform the present." ${ }^{23}$ I discuss how the seven pieces share the capacity to politicize memory on stage, by embodying biographies, themes, and perspectives usually marginalized in dominant narratives of history. Thus, my research is also about political matters: the interaction between the power of performance and the performance of power. ${ }^{24}$

Institutional memory, as it is transmitted via official textbooks, media, and monuments, often does not adequately represent and address the perspectives of people of color $^{25}$ and/or marginalized groups. In the German context, Kien Nghi Ha calls "Ent_innerung"26 (dis_remembering) the active omission of certain perspectives on the history of nationalsocialism and colonialism, and argues that it is reflected in current racist discriminations. By analyzing the medial representation of the 1992 Rostock-Lichtenhagen pogrom directed against Vietnamese migrants, he shows how the failure to acknowledge the colonial-racist past pervades contemporary memory discourses and practices. ${ }^{27}$ On June $21^{\text {st }}$ 2012, when Kien Nghi Ha released an anthology on Asian-German diasporic presences, ${ }^{28}$ he invited Oxana Chi to perform Through Gardens as part of the book

\footnotetext{
${ }^{21}$ The term Maafa means "catastrophe" in Ki-Swahili. It was introduced by Marimba Ani to name the physical, economic, and psychological violence perpetrated against Afro-descendant bodies through imperial domination. See Ballé Moudoumbou, "Erste Annäherung zu Maafa."

${ }^{22}$ The word Nakba means "Catastrophe" in Arabic, and is used to refer to the forced displacement of approximately 750,000 Palestinians that began with Israel's establishment, and that continues to this day. Originally the term was used to call 1920 the "Nakba year", in reference to the colonial partition of the Ottoman Empire, which led to uprising in Palestine, Syria and Irak.. "Facing the Nakba."

${ }^{23}$ hooks, "Choosing the Margin as a Space of Radical Openness," 155.

${ }^{24}$ Zenenga, "Power and the Body."

${ }^{25}$ I understand "people of color," following Kien-Nghi Ha, as a generic, political term referring to racialized humans who possess either or many of these genealogical origins: African, Asian, South American, Arabic, Kurdish, Jewish, Indigenous, Pacific. Ha traces the origins of the words to a 1966 Black Panther manifesto. Without masking differences, the appellation aims to foster solidarity among people experiencing racialized discrimination. See Ha, "People of Colour."

${ }^{26} \mathrm{Ha}$, "Macht (T)raum(a) Berlin," 105.

${ }^{27} \mathrm{Ha}$, "Die Fragile Erinnerung Des Entinnerten"; Ha, "Rostock-Lichtenhagen: Die Rückkehr Des Verdrängten."

${ }^{28} \mathrm{Ha}$, Asiatische Deutsche.
} 
release event organized jointly with the Federal Agency for Civic Education. Ha expressed a strong emotional reaction to the piece, as an alternative way of engaging with diaspora, identity and memory. Chi, using her body to fill the gaps of dis_remembering, allowed space for the complexity of Tatjana Barbakoff's Chinese-Jewish-Latvian background and for the possibility of a story where success and persecution co-exist. The event served as a testament to the role of performance in remedying the epidemic disease of Ent_innerung or dis_remembering.

Similarly to Ha's dis_remembering, Diana Taylor speaks of a "percepticide," ${ }^{29}$ in regards to cultural memory in the context of the Americas. The word suggests the ongoing connection between genocidal violence and the epistemic violence of memory transmission. She also cites the word "dememorazido"30 used by the Peruvian performance group Yuyachkani for the equivalent of the German "Ent_innerung." Writing about the history of the Haitian Revolution, and engaging with such various memory sites as Holocaust historiography and Disney's plans for an amusement park themed around slavery in Virginia, Michel Rolph-Trouillot also argues that "any historical narrative is a particular bundle of silence." ${ }^{11}$ His Silencing the Past shares with $\mathrm{Chi}$, Ha and Taylor the attention to the relations between present power structures and historical narratives. All of them show how omissions are not haphazard occurrences, but rather major aspects of the storytelling game. While $\mathrm{Ha}$ and Taylor use nouns to name silencing practices, RolphTrouillot emphasizes the verb form:

By silence, I mean an active and transitive process: one "silences" a fact or an individual as a silencer silences a gun. One engages in the practice of silencing. ${ }^{32}$

What this strong imagery suggests is the intricacy of material and historiographic power: hegemonic violence operates not only through physical weaponry but also through epistemic practices of erasure. Moreover, like a silencer aimed at rendering the shot inaudible, historical silencing is a practice that renders invisible events, biographies and perspectives. The connection between the physical violence and the epistemic violence against people is also made by Oxana Chi in the film Dancing Through Gardens. At the end of the film, she walks to her daily rehearsal. The camera (in my hands) shows her crossing a bridge, historically a border between East and West Berlin, as she says: "Der Fluss hat nicht nur ihre Körper fortgespült, sondern auch Ihre Namen," which can be translated as "The river has not only flushed their bodies away, but also their names." This is especially true of female actors in history, and especially females of color, an aspect left

\footnotetext{
${ }^{29}$ Taylor, The Archive and The Repertoire, 28.

${ }^{30}$ Taylor, 209.

${ }^{31}$ Trouillot, Silencing The Past: Power and the Production of History., 26-27.

${ }^{32}$ Trouillot, 48.
} 
out by Rolph-Trouillot, although he mentions the role of gender, race, class and resistance. Thus, my book shows that dance, as a practice of re-membering, has the power to counteract hegemonic practices of historical erasure.

When dancers embody history on stage, they can bring to life, and into emotion, what would otherwise remain a numb text, or a lifeless number. As a practice, dance often works through the expression of emotion, as reflected in the Indian rasa or the German Ausdruckstanz. In the academic world, Sara Ahmed makes the relation between emotion, bodies and time particularly clear:

Emotions tell us a lot about time; emotions are the very 'flesh' of time. They show us the time it takes to move, or to move on, is a time that exceeds the time of an individual life. Through emotions, the past persists on the surface of bodies. Emotions show us how histories stay alive, even when they are not consciously remembered; how histories of colonialism, slavery, and violence shape lives and worlds in the present. The time of emotion is not always about the past, and how it sticks. Emotions also open up futures, in the ways they involve different orientations to others. ${ }^{33}$

Ahmed, whose work does not address dance, hints at possibilities for using emotions and body memory to transcend spatiotemporal boundaries. While all art forms can express emotional states, dancers channel emotions through their own bodies moving through space and time, or spacetime. If emotions tell history, then a body-in-motion-throughemotion is a strong vector of history. The dancers activate their bodies - and thus their emotional surfaces - in the present, and also use them to represent the possibility of transformation in the future. Bodies in movement can thus become, and be read as the location of re-emerging pasts, but also as the living nodes channeling a past, present, and future connection.

The quotation also resonates with Anita Gonzalez and Thomas DeFrantz's definition of diaspora in their introduction to Black Performance Theory:

Like skin, [diaspora] is porous and permeable, flexible and self-repairing, finely spun and fragile. And like skin on a body, diaspora palpably protects us. We wrap ourselves in its possibilities, and they remind us of impossible connectivities. In this reminding - this bringing into consciousness of the intangible experience of a mythic past-we wear memory on our bodies; we see each other in skins that go together or sometimes belong apart. ${ }^{34}$

Indeed these authors, like Ahmed, seem to understand bodily surfaces as the embodiment of past trauma and present connections. The duality of fragility and protection, past and present seem to be an attribute of emotions as well as of diaspora,

\footnotetext{
${ }^{33}$ Ahmed, The Cultural Politics of Emotion, 202.

${ }^{34}$ DeFrantz and Gonzalez, Black Performance Theory, 11.
} 
both of which are metaphorically conceived here as skins. If diaspora is like a skin on the body, what happens when diaspora becomes a dancing body? I would like to suggest that the body is the meeting point between various understandings of memory, identity, temporality, and spatiality. These signposts help to unfold the reflection as the book's journey moves forward.

Porousness, permeability and flexibility are also attributes of time. Temporality sustains both memory and dance, and is therefore also at the core of this book. I ask how the dancers negotiate emotional, temporal and spatial perimeters not only to represent, but also to enact, through their own flesh, alternative realities. By looking at the temporality of historical narratives and dancing narratives, I argue that dance can offer a compelling alternative to chronological approaches to the past. For instance, I discuss André M. Zachery's Digital Middle Passage as an example of other conceptions and realizations of time and identity-formation. I show how Zachery's work bears affinities with Michelle M. Wright's critique of the "Middle Passage Epistemology."35 Wright assesses western conceptions of linear time as they affect the production of historical and contemporary definitions of blackness.

Because the temporality of performance is the present spacetime, the art of dance is an appropriate medium to address the continuity between historical trauma and contemporary sociopolitical conflicts, between a "haunting past" and an "ongoing violence." ${ }^{36}$ While Nicola Lauré al-Samarai sees in visual art the possibility for Black German artists to "provide their own plot" ${ }^{37}$ to historical narratives, I am interested in how minoritized performing artists officiate the stage, and re-write the storyline of historical matter from a diasporic perspective, thus intervening directly into present power relations. Presence, which may be physical, political, historical, and charismatic, is thus also a main protagonist in my research. The dancescapes I strive to move through constitute the canvas for an alternative sketch of the body at the intersection of memory, self and agency. Asking how selected dance solos contemporize the past, how they stand in the present in the hope of a future, I demonstrate that the dancers embody and enact the past in relation to but also beyond their own current locations of race and gender.

\footnotetext{
${ }^{35}$ Wright, Physics of Blackness.

${ }^{36}$ Schwab, Haunting Legacies, 2.

37 "die Möglichkeit schaffen, ihre Geschichten und Gegenwarten mit einem eigenständigen Plot zu versehen" Lauré al-Samarai, "Inspirited Topography," 118.
} 


\subsubsection{PerforMemory as a compass}

In order to navigate these moving territories, I came to conceptualize perforMemory in order to better describe, understand and investigate the innovative ways in which the performances produce memory. PerforMemory can serve as "a compass that traces historical linkages that were never supposed to be visible," ${ }^{38}$ and orients the present research as it navigates through dance, memory, trauma and diaspora. Thus, the very selection of the performances draws such unexpected lineages. A concept that will unfold throughout the book, perforMemory is a form of expression and an intervention. It is both a performative process and a result which contributes to shaping the collective and individual landscapes of cultural memory. The idea of perforMemory shifts the focus to understanding memory as a site of movement: moving back and forth, and blurring the borders between past, present and future, between countering absence and performing presence, between understanding and imagining, between emotions and reflections, between science and fiction, between transformation and liberation, between knowledge and truth. PerforMemory foregrounds corporeality as a mode of production and transmission of cultural memory. Through my analysis of selected dances, I argue that perforMemory is a remedy to the epidemic silencing that erodes the memorialization of political trauma.

My research is situated chronologically and thematically after the "performative turn in memory studies," 39 which foregrounds agency and embodiment. The concept of perforMemory shares with Toni Morrison's "rememory" the capacity to be both a noun and a verb. In the novel Beloved, first published in 1987, Toni Morrison uses the word "rememory" 40 to describe how the trauma of slavery re-emerges in the lives and bodies of African-Americans in the $20^{\text {th }}$ century. Analyzing Beloved, alongside Jewish, Kurdish and Palestinian post-traumatic art, Marianne Hirsch theorized the paradigm of "postmemory," ${ }^{41}$ which allows for memorial identifications across boundaries of race, gender, family and generation. Hirsch works from a refreshing feminist perspective, applying it to literature and visual art that deal with historical trauma. While she asks why visual media has come to occupy the primary place in the field of memory studies, ${ }^{42}$ I pose the corollary question of why dance is marginalized in the academic memory stage. Furthermore, Hirsch identifies a challenge for postmemorial artists: to create work that reinvents the past from an affiliative, yet not appropriative perspective, and to engage with historical trauma

\footnotetext{
${ }^{38}$ Omise'eke, "Black Atlantic, Queer Atlantic," 208.

${ }^{39}$ Plate and Smelik, Performing Memory in Art and Popular Culture, 6.

${ }^{40}$ Morrison, Beloved: A Novel.

${ }^{41}$ Hirsch, The Generation of Postmemory.

${ }^{42}$ Hirsch, 6.
} 
without inducing re-traumatization. ${ }^{43}$ The dances of perforMemory presented here take on this challenge successfully, and negotiate traumatic memory in an empowering and healing way.

While I discuss specific works of perforMemory, there are certainly other artists and works that could be analyzed through this frame. Here I think for instance of Julian Carter's discussion of the piece Lou (2009), choreographed by Sean Dorsey in memory of the transgender activist Lou Sullivan, and interpreted by four dancers. Carter contends that Dorsey's work "stages the tension between the material reality of historical loss - the past as dead and gone - and the equally material reality of physical rememory - the past as embodied in the living present." ${ }^{4}$ The dynamic "tension" between loss and recovery, between countering absence and performing presence, is also at the core of this study. Furthermore, Carter suggests that choreographic engagements with time and space can help to illuminate gender transitioning as a permanent movement rather than a linear temporal progression. In embracing diasporic spatialities and non-linear spacetimes, the dances of perforMemory incite the audience to move away from western hegemonic timelines, and invite them to re-formulate notions of time, space, self, history and identity. The absence-presence of historical figures, stories and perspectives is a recurring duet, or a rope onto which dancers hold when they perforMemory. In my development of the idea of perforMemory, I will also speak of ideas such as choreobiography and memory2Go, in the ongoing search for an evolving language that matches the dynamism of its subject matter.

Ananya Chatterjea proposes a helpful definition of choreography as "a mode whereby history can be imagined or interpreted yet again through the interstices of the present enactments." 45 The dances of perforMemory enact this "mode." They perform the past from the standpoint of the dancer who is per se moving in the present. PerforMemory is a dancing presence that is bound to move forward, even when engaging with the past. The photography on the book cover, taken from the scene "The Journey" from Through Gardens, illustrates this idea. Contrary to the conventional western reading direction, dancer Oxana Chi moves from right to left, thus conveying a feeling of return. And simultaneously, her raised hands and feet, and especially the angle of her knees and elbows, unmistakably evoke motion, a march towards a new space or time. My study of perforMemory raises the following questions, which I address throughout the book:

- What is specific about dance as a form of perforMemory?

- How does perforMemory comment upon notions of home and diaspora?

\footnotetext{
${ }^{43}$ Hirsch, 86.

${ }^{44}$ Carter, "Embracing Transition, or Dancing in the Folds of Time," 132.

${ }^{45}$ Chatterjea, Butting Out, 21.
} 
- How does perforMemory negotiate western constructs of time and space, and how does this impact counter-hegemonic memory-making?

- If perforMemory is about movement, what are the movements of perforMemory? 


\subsection{Innovating, or Which Contributions I Wish to Make to Existing Scholarship}

Following Lann Hornscheidt, there is no such thing as a "neutral state of research," for any assessment of existing scholarship will inevitably be a selection process that promotes some sources and ignores others. ${ }^{46}$ Hornscheidt further argues that these selections, especially when they claim to form an academic "canon," often ignore and/or mask race, gender and class positionalities. A state of research thus always reflects what it leaves out. What Hornscheidt calls "EntNennung"47 (dis_naming) happens for instance in memory studies, when research is biased because of a predominantly androcentric perspective, and grants mostly publications by white cis-males canonical status. Dance research often suffers from the corollary omission, or what Lockward calls "EntErwähnen," 48 which blends out perspectives of choreographers and scholars of color. I would also add that any academic state of research usually obliterates productions from the Global South, and other forms of knowledge production such as artistic and activist research. Consequently, I do not attempt to position my work within a presumably "objective" state of research. Rather, I try to highlight how my research may extend, expand and enrich existing scholarship which I have found useful to engage with.

As discussed earlier, the landscape of cultural memory studies is populated with important works investigating the role of visual media and literature. Here I wish to bring dance to the forefront of the memory stage, an endeavor which has seldom been pursued so far. In Germany, for instance, Aleida Assman has made important contributions on memory transmission in relation to national-socialism, yet she does not consider the art of dance, and her sources are mostly androcentric. However it would be interesting to ask how Assmann's distinction between "Ich-Gedächtnis" (I-memory) and "mich-Gedächtnis" (me-memory), or between the "Spur" (trace) and the "Bahn" 49 (way) apply to performing arts.

I hope to make an important contribution to the growing field of what I would call feminist global memory studies. Here I think of the feminist groundwork buoys laid by Marianne Hirsch's work on postmemory, which I discuss in the book, and Claudia Bruns'

\footnotetext{
${ }^{46}$ Hornscheidt, "Postkoloniale Gender-Forschung," 223.

${ }^{47}$ Nduka-Agwu and Hornscheidt, Rassismus auf gut Deutsch.

${ }^{48}$ Lockward, "Diaspora."

${ }^{49}$ Assmann, Der lange Schatten der Vergangenheit, 129.
} 
research on the relation between the history of antisemitism and colonial-racism. ${ }^{50}$ In his articulation of "multidirectional memory," Michael Rothberg also points out the need to link Holocaust and postcolonial studies to memory, and discusses striking examples, such as W.E.B. Du Bois' 1949 trip to Warsaw, and his subsequent publication in a Jewish magazine. ${ }^{51}$ Although his work is quite androcentric, it offers a helpful metaphor for grasping the complexity of memory politics. Here one may also think of Rolph-Trouillot's Silencing the Past, quoted earlier, as an example of multidirectional memory. Other scholars also follow this path in their teaching. I know for instance of Christina Sharpe's Tufts University class called "Memory for Forgetting," in which students investigate how visual artists, authors and filmmakers handle the trauma of Holocaust and slavery. All these scholars create connections across conventional historical and geographic markers, without negating the specificity of each traumatic event and art work. Embracing this endeavor, I intend to bring in a new perspective. The specificity of perforMemory resides in its capacity to address the multidirectionality of memory not only as a metaphor, but also as a reality, as the dancers physically move in multiple directions on stage. Thus, my imagination of perforMemory is constituted by and contributes to conceptual multidirectionality.

Much of the scholarship that brings dance and memory/history into constellation focuses on the role of re-enactments. The main concern is not so much dance as a device for performing memory, but rather the choreographic re-enactment of historical pieces and movements, or the performative re-enactment of historical events. ${ }^{52}$ The re-enactment may also be a new interpretation of a novel, as in Bill T. Jones's work, sharply reflected upon by Salamishah Tillet in her Sites of Slavery. ${ }^{53}$ Considering all the gendered and racialized connotations and constructions of the body within hegemonic discourses that perpetuate western capitalism, it is an urgent matter to look at dancing bodies as alternative knowledge production sites. Therefore, my work draws on the strong legacy of innovative, feminist scholarship on memory, and shifts the center of gravity to the epistemological quality of dance.

In the field of gender studies, dance remains a distant, rarely visited relative. From Black feminist reflections on art as a form of resistance, ${ }^{54}$ to white feminist reflections on bodies and performativity, ${ }^{55}$ many important works do not address the capacity of dancers

\footnotetext{
${ }^{50}$ Hirsch, The Generation of Postmemory; Bruns, "Antisemitism and Colonial Racism."

${ }^{51}$ Rothberg, Multidirectional Memory; and Rothberg, "W. E. B. Du Bois in Warsaw: Holocaust Memory and the Color Line, 1949-1952"; See also Levy and Sznaider, Erinnerung im globalen Zeitalter.

${ }^{52}$ Hardt, "Engagement with the Past in Contemporary Dance"; Lepecki, Singularities; Schneider, Performing

Remains; Thurner and Wehren, Original Und Revival; Wehren, Körper als Archiv in Bewegung.

${ }^{53}$ Tillet, Sites of Slavery.

${ }^{54}$ For instance El-Tayeb, European Others; Lorde, "Foreword to the English Language Edition."

${ }^{55}$ See Butler, Bodies that matter; Butler, Gender Trouble.
} 
to perform and transform power relations. Scholars working at the intersection of gender and dance studies often focus on binary gender representations in dance, or on the impact of genderism on dance historiography. ${ }^{56}$ My research fosters an innovative connection between transdisciplinary decolonial feminist research, dance, and the analysis of memory discourses and practices.

This book is also situated within the exponential development of critical dance and performance studies. My approach resonates with the works of Brenda Dixon Gottschild, Diana Taylor, Jacqueline Shea-Murphy, Rebecca Rossen, Nadine Georges-Graves, Ann Cooper Albright, SanSan Kwan, and Ramón Rivera-Servera. ${ }^{57}$ These scholars often focus on cultural productions from the Americas, and usually on singular constructions of diaspora, such as "African-American," "Native," "Jewish," "Chinese," or "queer Latinidad" negotiations of identity. An inspirational transnational study was Ananya Chatterjea's discussion of "the production of culture in and through the body, itself produced through cultural constructions" 58 in the works of the African-American Urban Bush Women company and the Indian choreographer Chandralekha. In contrast, I focus on solo performances. Moreover, my research scope promotes a wider, diasporacentric approach that blurs conventional national and geohistorical divides. At the moment, I am not aware of a book that connects memorial approaches across the Black, Jewish and Asian diasporas in the field of performing arts.

If one leafs through the Routledge Companion to Theatre and Performance, ${ }^{59}$ one will see that the "dance" entry, meant to provide a general overview for undergraduate students, does not mention any performer of color. In the German context, works such as New German Dance Studies, or more recently Körper als Archiv in Bewegung ${ }^{60}$ barely acknowledge or completely ignore the works of contemporary Afro-German, JewishGerman and Asian-German choreographers. These are only a few examples of the workings of "Ent_Nennung", and "EntErwähnen" in dance and performance. The exclusion of choreographers of color often goes hand-in-hand with the appreciation and reiteration of the same handful of established dance-makers.

Counter-trends in the USA come from the above mentioned scholars. Brilliant investigations live at the crossroads between Africana studies and dance studies, and

\footnotetext{
${ }^{56}$ See Marquié, Non, la danse n'est pas un truc de filles!; Walkowicz, Die Kampfkunst-Tänzerin. Der Gender Diskurs Im Interkulturellen Vergleich Des Tanzes; Marquié, "Le genre, un outil épistémologique pour l'historiographie de la danse."

${ }^{57}$ Cooper Albright, "Embodying History"; Dixon Gottschild, The Black Dancing Body; George-Graves, Urban Bush Women; Ramón H. Rivera-Servera, Performing Queer Latinidad; Rossen, Dancing Jewish; Kwan, Kinesthetic City; Shea Murphy, The People Have Never Stopped Dancing; Taylor, The Archive and The Repertoire.

${ }^{58}$ Chatterjea, Butting Out, 75.

${ }^{59}$ Allain and Harvie, The Routledge Companion to Theatre and Performance.

${ }^{60}$ Wehren, Körper als Archiv in Bewegung.
} 
work towards connecting dance, race and gender. ${ }^{61}$ Here I think of the recent anthologies Oxford Handbook in Theatre and Dance, Black Performance Studies, and BlackTino Queer Performance. In terms of academic genealogy, a pathbreaking study was done by Brenda Dixon Gottschild, who demonstrated the role of Africanist dance in shaping the evolution of modern American ballet. ${ }^{62}$ Her work remedies the elision of this major aspect of dance historiography. The absence of certain cultural productions in academia or dance historiography is even more glaring given that many western choreographers owe their successful presence on stage to the rich influence of African, Asian, indigenous, and Jewish inspirations. By foregrounding works not yet, or rarely discussed in scholarly publications, my study wishes to counterbalance certain gaps in the critical discussion.

However, this claim too must be relativized, as some of the seven artists discussed here are becoming increasingly present in academic settings. In 2016, Farah Saleh was a choreographer in residence at Brown University and a Visiting Scholar at the Pembroke Center. Through Gardens has been included in the curriculum of Humboldt-University's Gender Studies department since 2016, and my discussion of it now appears in several academic publications. Since 2013, Oxana Chi's performances have increasingly been featured at universities, and her work has found resonance in international academic settings such as the NYU Tisch School of the Arts, Humboldt-University, Bielefeld University, Mainz University, Rutgers University in Philadelphia, the City University of New York, Yeditepe University in Istanbul, Tampere University Finland, among others. She has published her own reflections on her work in the academic anthology Sisters\&Souls. ${ }^{63}$ André M. Zachery recently published an article reflecting upon his Afrofuturism Series in the Yale Drama journal. ${ }^{64} \mathrm{He}$ was a guest faculty artist-in-residence at the School of Dance at Florida State University in the Fall of 2016, and is now a 2017-2018 Visiting Artist and Guest Professor at Virginia Commonwealth University (VCU).

As a queer feminist artist_academic of color, I am also inspired by the tremendous work that queer scholars and artists produce(d) on archive, memory, and utopia. In a field of history characterized by the absence of perspectives of people of color, queer people and performing bodies, perforMemory does leave a trace. Subscribing to Jill Dolan's claim that the time_space of theater is a place of realization for "utopian performatives," 65 perforMemory builds on the connected preoccupations and findings of gender, dance and memory studies, as well as on quantum physics and literature.

\footnotetext{
${ }^{61}$ See for instance George-Graves, The Oxford Handbook of Dance and Theater, DeFrantz and Gonzalez, Black Performance Theory; Johnson and Rivera-Servera, Blacktino Queer Performance.

${ }^{62}$ Dixon Gottschild, Digging the Africanist Presence in American Performance.

${ }^{63}$ Chi, "Von Hier Nach Dort - I Step On Air."

${ }^{64}$ Zachery, "Futurity and the Containment of Blackness in Twenty-First-Century Performance."

${ }^{65}$ Dolan, Utopia in Performance, 5.
} 
In the spirit of Ann Cvetkovich's Archive of Feelings, which is simultaneously an academic analysis of archival matter as well as an archive in itself, my research aims not only to analyze choreographic repertoires, but also to contribute to the archiving of a new performative "repertoire" of cultural memory. ${ }^{66}$ While Chi promotes the presence of Tatjana Barbakoff in the contemporary making of and writing about dance history, my work promotes, at a meta-level, the presence of seven counter-hegemonic performances in the landscape of contemporary cultural production. The book thus traces a full circle between the re-emergence of Tatjana Barbakoff's precious, yet often silenced dancehistorical legacy on stage in Through Gardens, and the re-surfacing of successful, yet often unacknowledged dance perspectives in contemporary academia.

${ }^{66}$ Cvetkovich, An Archive of Feelings; Taylor, The Archive and The Repertoire. 


\subsection{Investigating, or How Epistemology and Methodology Come into Play}

\subsubsection{Epistemological concerns}

Do you ever wonder how a squirrel finds the power to propel itself, how a spider wanders, how a cat tiptoes, or how a researcher moves through library catalogues and shelves? Sometimes, I stumble upon books in my library wanderings. I usually search the online catalogue, write down a reference, and make my way to finding (or not) the book. My eyes strive across the patterns, titles and shapes of books that surround the spot where THE book should be found. Besides working with catalogues and numbers corresponding to the library staff's order of knowledge, I always rely on intuition and kinetic sense.

Think about how Oxana Chi found out about Tatjana Barbakoff: through an exhibition catalogue in the fine arts department of the Amerika-Gedenkbibliothek (American Memorial Library, a major library built in Berlin after World War II as part of the US Marshall Plan). Had she stuck to the slim dance section, she would never have come across the catalogue which inspired her creation of Through Gardens. This story is told in our film Dancing Through Gardens, which by now, in 2017, is itself featured in the library's collection, and is currently showcased in the library's temporary exhibition "Themenraum Tanz."

Knowledge, especially in academic settings, is selected. Sometimes the selection implies that under the combined key words "dance," "Holocaust," and "postcolonial," no result appears in the Humboldt-University catalogue, and I hope my book will be filed under those keywords. Feminist artists and academics are often aware of the bias induced by the overrepresentation of cis-male, white, western, ableist perspectives in key positions in the arts and academia in Europe and the USA. A key preoccupation of Black feminist scholars has therefore always been to render visible the power dynamics dictating knowledge production. One of the factors impacting academic knowledge production is colonialism. Reflecting upon race, gender and epistemology, Grada Kilomba invites us to constantly ask:

What knowledge is being acknowledged as such? And what knowledge is not? What knowledge has been made part of academic agendas? And what knowledge 
has not? Whose knowledge is this? Who is acknowledged to have the knowledge? And who is not? ${ }^{67}$

Kilomba's questions resonate with the earlier cited reflection of Chi on power and historiography in Germany, and with Ha's definition of "Ent_innerung." Kilomba, Chi and $\mathrm{Ha}$ ask us to scratch the surface of knowledge, to uncover which social positionings affect its production. For instance in Germany, Jewish perspectives on the Holocaust, or Black women's perspectives on colonialism, are seldom part of German "academic agendas." And dance is rarely "acknowledged as knowledge" to repeat Kilomba's words. Yet dancerchoreographers such as the ones discussed here constantly negotiate epistemological issues, and anchor narratives of the past in the present subjectivities of their own selves.

The widespread absence of performance as a source of knowledge in European humanities is a legacy of colonial structures. My intent with this research and the publication of this book is to bring about the inclusion of diasporic dance as part of the academic agenda at my institution. Because feminist knowledge production is also an action, I have tried to apply this in my teaching as well. For instance, in my 2016 class "Performing Memory," I encouraged students to take part in Berlin cultural life. I also invited dancers into the classroom, and we even had a live excerpt performance of Oxana Chi's Psyche at the university. The fact that I was subsequently awarded the Faculty Teaching First Prize for this class, testifies to the university's openness to re-thinking access to knowledge, as much as it suggests the students' willingness to read not only books, but also dance as a valuable source of knowledge.

To hide one's positioning, or proximity to the research topic or the participants does not serve the quality of the research, but rather impedes critical reflection. Grada Kilomba advocates for "an epistemology that includes the personal and the subjective as part of academic discourse," ${ }^{\text {( } 8}$ while Patricia Hill Collins emphasizes "experience as a criterion of meaning with practical images as its symbolic vehicles." ${ }^{.9}$ My experience of the performances, my experience of doing research, and the dancer's experiences merge into the quest for a sense truth. Situated within the lineage of Black feminist epistemologies, my writing interweaves personal anecdotes and stories with academic theory, performance analysis and interviews.

\footnotetext{
${ }^{67}$ Kilomba, Plantation Memories, 27.

${ }^{68} \mathrm{Kilomba}, 31$.

${ }^{69}$ Collins, Black Feminist Thought, 258.
} 


\subsubsection{From the "outsider within" to the insider without}

One way of including the personal in the research is to engage with one's biography rather than repressing it. In my case, this means considering how my research benefits from my genealogical connection to the Jewish and Black diasporas. An inspirational work in this regard was the anthology Rites of Return, ${ }^{70}$ in which authors explore diasporic memory in relation to their own biographies, with such diverse examples as Lila AbuLughod's return to her father's Palestine and Jay Prosser's search for a music of return in the Jewish Baghdadi diaspora. This approach bears affinities with Patricia Hill Collins' sociological articulation of "outsiders within":

The approach suggested by the experiences of outsiders within is one where intellectuals learn to trust their own personal and cultural biographies as significant sources of knowledge. ${ }^{71}$

I came to understand myself less as an "outsider within" than an insider without. I am partly an insider to the embodied memory of trauma carried forth by some of the dancers, such as the European Holocaust and slavery. In this sense, my reading of the performances encompasses personal connections to the trauma of forced displacement, racialized oppression and resistance. During the course of my study, I also became an insider to the world of performing arts. Being a member of the Oxana Chi Company and accompanying her dance with music and physical acting gave me an onstage positioning that was even better than a first row seat among the audience. Yet, despite dedicating a regular amount of time to dance training and practice, I am "without" the experience of a formal dance education, or of working as a professional dancer or choreographer. My research therefore benefits from what I call the position of an "insider without."

I would also add that Black feminist epistemologies allow research to be more accessible to an audience that extends beyond a community of professors and graduate students. I do not think however, that this is limited solely to the perspective of Black feminism, but more generally applies to any researcher who takes feminism seriously. For instance, Doris Ingrisch, who works at the intersection of academic research, art, and gender, argues for the need to sensualize research ("sinnliche Wissenschaft"), ${ }^{72}$ namely, to invite into scientific processes the emotional senses inherent to artistic endeavors. This is a laudable and arduous task. Although I did not fully diverge from the conventions of writing and presenting a dissertation, I tried to subvert some of its most obstructive

\footnotetext{
${ }^{70}$ Hirsch and Miller, Rites of Return.

${ }^{71}$ Collins, "Learning from the Outsider Within," 122; On Afro-German identity construction, see also Wright,

"Others-from-Within from Without."

${ }^{72}$ Ingrisch, Wissenschaft, Kunst Und Gender, 22.
} 
features by telling a story that might lead the reader to move fluidly through the book. This also explains why I sometimes address YOU, the reader, or make parsimonious use of the "us" pronoun. ${ }^{73}$

\subsubsection{Decolonial feminist research?}

I recall meeting Professor Nadine George-Graves for the first time in her office at the Department of Theatre and Dance at the University of California, San Diego, in the spring of 2015. After a pleasant conversation about Afro-diasporic dance, I walked down the stairs to reach the Department's ground-floor office. There, outside the building, young Asian-American students were rehearsing hip-hop choreographies, using the wall's reflective textures as mirrors, and the open outdoor space as a dance studio. Their movements were obviously drawn from the iconography of mainstream African-American hip-hop culture. I wondered why they did not rehearse inside the dance studios, and found out that they were not registered as dance students. Dance, bodies, and knowledge, are compartmentalized into categories constructed by society.

Feminist approaches and gender studies help us to reflect upon these categories of race, gender, sexuality, class and ability. I adhere to a constructivist approach, and strive towards a broad understanding of gender studies that follows in Lann Hornscheidt's footsteps. Professor Hornscheidt devotes much attention to the deconstruction of gender as a normative category, and the related discrimination form which they call "genderismus" (genderism). ${ }^{74}$ They demonstrate how gender, and therefore gender studies, cannot be disconnected from the category of race, which is always at play, especially in the German context in which they write. Hornscheidt therefore proposes to re-name the field of "gender studies," and proposes the expression "postcolonial feminist studies." A corollary argument is that questioning the epistemological and ontological formation of historical knowledge formation is a legitimate field of inquiry for feminist research. ${ }^{75}$ Similarly, Marianne Hirsch argues that feminist research on the topic of memory does not necessarily involve analyzing gender as a category, for investigating the construction of memory discourses and practices is inherently a feminist research task. ${ }^{76}$

Thus, I understand my work as a decolonial feminist research, which attempts to question hegemonic historical narratives, to foreground marginalized epistemologies, to

\footnotetext{
${ }^{73}$ Thank you Lann Hornscheidt, for inciting me to question the universalistic fallacy of "us".

${ }^{74}$ See for instance the insightful constructivist critique of the various forms of gendered discrimination in Hornscheidt, feministische $w$ orte.

${ }^{75}$ Hornscheidt, "Postkoloniale Gender-Forschung," 218.

${ }^{76}$ Hirsch, The Generation of Postmemory, 18.
} 
inquire into the body as a site and source of knowledge production and transmission, and to connect feminist and decolonial perspectives. ${ }^{77}$ । deliberately speak of a "research" which infuses gender "studies" with dynamism. Rather then the word "postcolonial," I prefer the prefix "de" that marks an active process of moving beyond or countering coloniality. ${ }^{78}$ Decoloniality bears affinities with María do Mar Castro Varela and Nikita Dhawan's definition of postcolonialism as an attempt to move beyond the historical power structures of imperialism and racism that determine(d) the scientific disciplinarity of knowledge. ${ }^{79}$ However, the very use of the words "colonialism" or "colonial" arises out of a fallacy, as I learned from Marianne Mballé Moudoumbou in the realm of collective research on intersectionality, for the word can be traced to Latin roots which mean "to take care." This explains why the word is hardly appropriate for referring to centuries of racialized violence. Mballé Moudoumbou recommends the use of the word Maafa to name not only the subjugation of African bodies, souls and soils, but also any other form of genocide and violence against Afro-descendant people prior to and post-slavery, including South African apartheid and US segregation, or even ongoing police violence against Black bodies. ${ }^{80}$ The word Maafa helps to un-think historical trauma in terms of a linear chronology, a point I discuss in my chapter "Dancing the Past in the Present Tense." In the context of this thesis however, the word Maafa also does not adequately cover the trauma of the Holocaust, or imperial violence affecting indigenous and Asian-diasporic people.

My research is grounded in interdependent thinking, a term I coined earlier in German a s InterdepenDenken. ${ }^{81}$ It refers to an intersectional research practice which requires researchers to continuously reflect upon their positionings in terms of constructed social categories, and how this impacts their framing of the research. ${ }^{82}$ The verb is a neologism, a German play on the words "Interdependenzen" (interdependencies) and "denken" (to think). Applied to my research, it involves naming my positionalities as an able-bodied, Jewish, queer, nongender conforming womyn, academic and artist of color socialized in the west, and recognizing how they influence my epistemological choices, my formulation of interview questions, the structuring of my thesis, and my writing.

\footnotetext{
${ }^{77}$ The term decoloniality is often attributed to Aníbal Quijano and Walter D. Mignolo, although it is not clear where it actually originated. See Quijano, "Coloniality and Modernity/ Rationality"; Mignolo, Local Histories/Global Designs.

${ }^{78}$ On coloniality in Germany, see Kelly, Afrokultur.

${ }^{79}$ Castro Varela and Dhawan, "Europa Provinzialisieren? Ja, Bitte! Aber Wie?," 9-10.

${ }^{80}$ Ballé Moudoumbou, "Erste Annäherung zu Maafa," 127.

${ }^{81}$ I coined the term at a working group that collectively co-edited an anthology on intersectionality. See AK Forschungshandeln, InterdepenDenken.

${ }^{82}$ For suggestions on the InterdepenDenken paradigm as an epistemological and methodological tool, see Hornscheidt, "Aber wie soll ich das denn machen? Interdependenkend forschen: Methodologische und Methodische Handlungsvorschläge."
} 
One of the major biases in an ableist western perspective is to define vision as a superior sense when it comes to relating to the world, in contrast to other senses. Oyèrónkẹ Oyěwùmí argues that the Eurocentric "worldview" is restrictive, compared to the multidimensionality of an Africanist "world-sense." ${ }^{83}$ Dancers certainly expect to be seen. However, to attend a live performance, and to (re-)view it as a video, is an entirely different experience. There is an abysmal gap between the emotions and reflections one goes through as an audience member, and the mediated experience of a dance video, suggesting that live performance works through more channels than the visual one. In interpreting the performances, I pay attention to how other factors affect me, such as the sound, or the energy. For instance, when I investigate how selected works negotiate temporalities and movements of perforMemory, I go beyond a visual engagement with the pieces, in search of a holistic, multisensorial experiencing of dance art.

\subsubsection{Diasporic networks}

The research scope is intentionally wide in terms of geographic locations, choreographic styles, dance techniques, thematic contents and artistic intents. The goal is not to compare the performances, but rather to contemplate kindred meanings among the works, to map out the diasporic networks of perforMemory. Thus, I adhere to Hirsch's defense of a "connective rather than comparative approach" 84 to memory studies. In a sense, my work responds to Ella Shohat's call for "multichronotopic" research:

[Transdisciplinary gender research] would require a multichronotopic form of analysis, particularly in terms of the ways space is imagined and knowledge is mapped within academic institutional practices. It would ask us to place the often ghettoized histories, geographies, and discourses in politically and epistemologically synergetic relations. It would require showing how variegated pasts and presents, 'locals' and 'globals' parallel and intersect, overlap and contradict while also analogizing and allegorizing one another. ${ }^{85}$

The juxtaposition of performances, topics and people not usually brought into convergence fosters precisely the "synergetic relations" pointed out by Shohat. By bringing together various geohistorical subject matters into one research field, I trace connections between the traumatic historical sites of the Holocaust and the Middle Passage, between past trajectories and contemporary migrations, between AfroEuropean, Taiwanese, Jewish, Caribbean, Palestinian positionings and resistances. Most

\footnotetext{
${ }^{83}$ Oyěwùmí, The Invention of Women, 2-3.

${ }^{84}$ Hirsch, The Generation of Postmemory, 8.

${ }^{85}$ Shohat, Taboo Memories, Diasporic Voices, 15. My emphasis.
} 
importantly, the geographic amplitude is paired with the large choreographic breadth of the works. The seven pieces step through multiple stylistic territories, from traditional Javanese dance to Afrofuturism, from ballet and contact improvisation. Rather than sorting the works into neat boxes, I search for converging threads of meaning, affect and narrative. The challenge resides in doing justice to the various choreographies, choreographers and themes in all their diversity, whilst also detecting convergences and resonances between them. ${ }^{86}$ The key is to acknowledge differences (of sociocultural context, geographical location, political stakes, corporeal technique), rather than eliding them, to unearth how those differences may shape a multichronotopic, multidirectional, multilayered, and multidimensional picture of perforMemory.

I argue that the dance pieces are themselves "multichronotopic" works of perforMemory, thus necessitating a "multichronotopic" analytical approach to appropriately understand and address the performances. I would even suggest that Chi's current repertoire as a whole is a "multichronotopic" work, with geohistorical topoi stretching from the European Holocaust (Through Gardens, Killjoy); the colonial looting of African cultural objects (Neferet iti); the Afro-German feminist biography of May Ayim (I Step On Air); and Black transgenerational body memory (Psyche).

Drawing inspiration from Elliot Fox's idea of "diasporacentrism," ${ }^{87}$ I advocate for a diasporacentric approach to bring together various performers and performances who all share a more or less explicit identification with diaspora. I consciously expand Fox's Afrodiasporic concept, to account for a plurality of diasporic identities and solidarities, and to renew definitions of diaspora beyond the center-margin paradigm. Fox situates diasporacentrism in relation to African-American instrumental jazz, and infers its definition as a positive force:

Diasporacentrism therefore is not a focus on loss or dilution; its emphasis is on struggle, survival, rebirth, the creation of new (albeit floating) 'centers. ${ }^{188}$

In diasporacentrism, the diaspora paradigm thus shifts from the fragmentization of identity-formation to the creativity of identity-making. Diasporacentrism fosters an empowering definition of diasporic subjectivity. Arguably, taking the quotation seriously allows for a definition of diasporic identities which extends beyond specific racialized constructions.

Rather than naming the artists diasporic, I choose to look at how they embody and enact diasporic resistance to hegemonic storytelling in terms of race and gender. The

\footnotetext{
${ }^{86}$ Chatterjea, Butting Out, 12.

${ }^{87}$ Fox, "Diasporacentrism and Black Aura Texts."

${ }^{88}$ Fox, 369.
} 
dissertation is diasporacentric in terms of the constellation of selected performances, the plurality of theoretical sources, the variety of narratives, and the multiplicity of dance movements. I argue that in challenging not only Eurocentric perspectives, but also Afrocentric or other forms of -centricity, the performers operate diasporacentric movements: for instance, when Wan-Chao dances the complexity of migrations, when André Zachery re-shuffles the temporality and spatiality of the Digital Middle Passage, when Oxana Chi embodies a Chinese-Jewish-Latvian biography from an Afropean perspective, and when Chantal Loïal creates a virtual and physical affiliation between her body and Sawtche's story. What I also find enticing in this idea of "diasporacentrism" is the emphasis on survival. Through Gardens, for example, emphasizes the struggle and performs the rebirth of Tatjana Barbakoff. They Call You Venus portrays the survival of Sawtche's spirit. Digital Middle Passage embodies the struggle and survival of Black bodies in the Americas. The dancescapes of all seven artists perform tales of memory, of pain, of hope and of resistance.

The desire to address the contemporaneity and vitality of diasporic performance art compels me to search for new paradigms and perspectives. Similarly preoccupied, Ananya Chatterjea coined the term "alternative postmoderns" to describe the choreographic "practices of mobile intersectionality and of resistance to inscription by and in the terms of the metanarrative of Euro-western dominance, from a positioning in alterity." ${ }^{89}$ She argues that choreographers of color also produce postmodern works, although they have not been acknowledged as such in the historiography of the Judson Church, for instance. In my view however, the term "postmodern" re-produces the western colonial narrative of linear history, which is why I attempt to coin alternative terms. Yet by now, Movement Research at Judson Church possesses a dynamic Artists of Color Council that contributes to ensuring visibility of performers of color. And at the time of the publication of this book, Oxana Chi was opening the Fall Season for Movement Research, in front of a large and enthusiastic audience at Judson Church, on September 18th, 2017.

Performing artists who move outside of mainstream productions and expectations are often described as "off" the performing scene. The appellation "off," however, evokes a marginalization, an outsider-ness that hardly seems appropriate in qualifying those trendsetting artists. It also does not reflect the scope of their careers in terms of awards and tour history. Although they may perform "off-Broadway," or off-"off-Broadway," they surf on the winds of artistic experimentation and innovation, producing avant-garde works which are ahead of their times, and which inspire many other performers and institutions.

\footnotetext{
${ }^{89}$ Chatterjea, Butting Out, 104.
} 
A live experience illustrating this point: visiting my mother in Paris, France, I attended the piece En Filigrane in a small theater. It is an original creation by dancer-choreographer Ibrahim Sissoko and cellist Ophélie Gaillard. The piece uses an innovative blend of west African moves, hip-hop techniques, classical European and Roma music. After returning to Berlin, I discovered a few months later that a mainstream public theater had plagiarized the concept and aesthetics of the hip-hop dancer moving around the cellist. So why continue to label these artists or this scene as "off"? Language needs to remedy this upsetting trend and to renew appellations. These dancers do not play outside of cultural platforms, they are at the heart of them. They are not off, they are on stage and on the move.

\subsubsection{Methodology}

This research led me on a transdisciplinary journey along which I reaped from branches as various as cultural memory studies, dance and performance studies, gender studies, postcolonial studies, literature, critical race theory, queer studies/queer of color critique, historiography, theology and quantum physics. The book blends these various sources together in a transdisciplinary, ${ }^{90}$ and at times postdisciplinary fashion. Doing postdisciplinary feminist research is, according to Nina Lykke, the goal to achieve:

[A] mode of organizing scholarly knowledge production that, on the one hand, can pass as a discipline and claim the academic authority that goes with that status but, on the other hand, which also maintains a transversal openness and a dialogic approach towards all existing disciplines, and which points beyond the traditional, monodisciplinarily organized university. ${ }^{91}$

While fulfilling the standard requirements for a doctoral dissertation at HumboldtUniversity, I also adopted this "transversal openness" by engaging in a nuanced, differential knowledge production. The factors that impede a transdisciplinary or postdisciplinary approach methodology are in my view: monodisciplinarity; the masking of the researcher's choices and positions; canonization processes; the hierarchization of sources; and the repression of poetics, politics and humor. This is why I refrained from containing theory within a specific chapter. Instead, academic literature surfaces throughout the book, as I bring it into resonance with the performers' interviews, and with my own interpretation of the performances.

\footnotetext{
${ }^{90}$ See Hornscheidt and Baer, "Transdisciplinary Gender Studies."

${ }^{91}$ Lykke, "This Discipline Which Is Not One," 138. My emphasis.
} 
In addition to academic literature, my sources include live performance experiences, video recordings, press reviews, interviews with the choreographers, and their own publicity materials, such as artist statements, publications, flyers, and websites. My interpretation of the works reflects my own reading, and does not always correspond to the choreographer's intent. I do not try to read the dance performances in light of a specific theory, but include the performances as theoretical sources. Here, I also think of Ketu Katrak's call for "deriving theoretical insights from the creative works," ${ }^{22}$ in order to re-define what theory is, and to generate a critical conversation between multiple artistic and academic sources. I show how the performances carry meaning in themselves, and emphasize resonances between my discussion of selected academic knowledge sources and my interpretation of the dances.

\subsubsection{Postpositivist research in dance}

My approach is also dictated by the subject of my study, dance. In her own work as a dancer-choreographer, Oxana Chi evokes the affinities between dance-making and research:

To me, dance is a very, very complex matter [...] akin to the soul. It is almost impossible to grasp. I wish to grasp it, of course, but it is impossible to grasp. And so it is important to constantly keep researching, like a scholar $[\ldots]^{93}$

In an earlier publication on Through Gardens, I discuss and describe her work as a dynamic process of Wissensschaffung (science-making), in contrast to "Wissenschaft."(science). ${ }^{94}$ Conversely, academics can use artistic methods to enrich their research. With the moving matter of dance as an object of inquiry, I felt compelled to use creativity at various stages of the research: conception, reflection and formulation. I applied a "postpositivist research methodology in dance," as defined by Jill Green and Susan W. Stinson, according to whom:

[The research] must be created as the researcher goes along, in the context of this particular piece of research. In this sense, the researcher shares much in common with the choreographer, remaining open to emerging patterns and meanings and to forms that are appropriate for them. Just as in the case of the choreographer, the postpositivist researcher allows the form of the final product to arise from the process. ${ }^{95}$

\footnotetext{
${ }^{92}$ Katrak, Contemporary Indian Dance, 2; See also the notion of "theory-in-practice" in Ramón H. RiveraServera, Performing Queer Latinidad.

${ }^{93} \mathrm{Chi}$, interview.

${ }^{94}$ Zami, "Oxana Chis Tänzerische Wissensschaffung."

${ }^{95}$ Green and Stinson, "Postpositivist Research in Dance," 95; On feminist methodology in dance studies, see also Desmond, "Engendering Dance: Feminist Inquiry and Dance Research."
} 
Although it may sound abstract, Green and Stinson also propose concrete forms of the post-positivist methodology in approaching dance. In particular, applying the methodology led me to: ${ }^{96}$

- search for "coherence" in selecting the performances

- express my personal positioning in the introduction and throughout the text

- use subjectivity to approach truth, for instance in assessing the performances

- identify resonances between a multiplicity of scholarly and artistic sources

- formulate specific questions for each artist, and conduct open-ended interviews

- interweave the discussion of academic theory, performances, and literature

Within this methodological framework, the authors identify three research profiles: "interpretative," "emancipatory," and "deconstructionist." those profiles. First, I adhere to the "interpretative" research mode through my strong relationship to the performances and performers; the use of participant observation; the use of autobiographical impressions and reflections, the conducting and transcribing of interviews; and the collection of material from the dancers, such as videos, flyers, press, photographies.

Second, my research aims to be "emancipatory" through its attempt to question the power relations in the context of which the research takes place, and to empower the persons involved. I circulated the interview transcripts among the dancers in order to give them a chance to revise them, and to make sure that they feel comfortable with them. In my view, however, the emancipatory research profile is also biased because of its assumption that the researcher can "help" the participants. I rather think the reverse may be true, since the researcher may draw intellectual and financial gains from doing the research! In any case, I understand emancipatory research as the will to respect and appreciate the works I write about.

Finally, "deconstructivistist" researchers, according to Green and Stinson, acknowledge that their account is incomplete and biased, and are aware that their research may be oppressive to the persons at stake, no matter how critical they consider themselves to be. Nonetheless they strive to "create multiple interpretations of some dimension of the dance experience." 98 Just as a theatrical light change alters the dramaturgical atmosphere, each chapter highlights a new dimension of the dance interpretations. I start with a focus on the performances' themes; then revisit them through a diasporic lens; and finally inquire into the time and movement dimensions of the pieces.

\footnotetext{
${ }^{96}$ Green and Stinson, "Postpositivist Research in Dance."

${ }^{97}$ Green and Stinson, 100-112.

${ }^{98}$ Green and Stinson, 113.
} 
Green and Stinson even invite their readers to assess their own methodology, and to come up with a research profile of their own. I would suggest speaking of Expressive Conscious Re-Search. The processual aspect of my research is best reflected in my writing. By including intermittently personal stories that situate me in my research environment, the writing reveals the journey that led to its constitution. It weaves together the "patterns" that have appeared since 2013: home, diaspora, displacement, trauma, power, movement, spacetime. Like the art of dance, this research required me to be flexible enough to move between phases of writing, phases of interviews, and phases of reading. Therefore I did not work in a linear timeline that separated reading, field research, and writing. Rather, I opted for a multimodal circular working process consisting of several spheres: reading, attending/viewing performances, interviewing, writing. The spheres were like circles which sometimes overlapped as I moved along them in a concentric way. Although it was often challenging, my research certainly benefited from a constellation in which each working sphere delivered input for the other spheres. This felt particularly appropriate to the dance world that surrounded me.

I also wish to note at this point that I occasionally chose to use multiple languages when quoting, in order to address readers who are multilingual as much as those who may understand English only, and to expand the research perspective. Therefore, I offer both the original and my translation of the quotation within the main body of the text, when I feel that the original language adds another dimension to the meaning. Although this practice may seem surprising at first, it is not totally unusual in feminist scholarship. ${ }^{99}$

\subsubsection{Embodied research}

Another aspect of my methodology involved not only the full engagement of the mind, but also of the body in the research process. George-Graves calls this "involved embodied research." 100 Movement praxis provided me with a healthy counterbalance to time spent on the computer, expanding my body activity beyond eyes and finger muscles. But foremost, it enriched my research by allowing me to grasp the issues I was reflecting theoretically on another, corporeal, level of knowledge. Taking dance classes, attending rehearsals and performances, and especially working as a member of Chi's company since 2013, provided me with a way to engage myself fully in this research.

It was thus not surprising to meet George-Graves, who was my advisor at one point, at a dance studio in Brooklyn. We both took a dance class with Pat Hall, a former member of the Urban Bush Women company that George-Graves has written about. There we were,

\footnotetext{
${ }^{99}$ See for instance the use of bilingualism in Anzaldúa, Borderlands.

${ }^{100}$ George-Graves, Urban Bush Women, xi.
} 
two scholars shaking body parts, releasing energy, jumping across space. Decolonial feminist researchers should not be fearful of including their own selves within their research conception, implementation, production and communication. During my time as a Visiting Research Scholar, I also met fantastic dance-makers, such as Maria Bauman, former Associate Artistic Director of Urban Bush Women, who now runs her own dance company MBdance. Oxana Chi and I performed I Step On Air on a split bill with MBdance at the Bronx Academy of Arts and Dance (BAAD!). Their company's motto is "Sweat your truth!" This precious dance incentive is as important as the need to trust one's sweat. My book attempts to merge an infinite number of emotional truth drops into an ocean of corporeal writing.

\subsubsection{Challenges}

In the personal conversation I recorded with André M. Zachery on the subject of dance, diaspora and memory, he asked:

Who is the person that's doing it? Who is the person that's telling it? The story is going to sound totally different and have [a] totally different meaning from each person and experience that is allowed to get on the mic, or get on the dance floor, or get behind the computer and do the work. ${ }^{101}$

Echoing the dialectic of storytelling lions and hunters, and the above mentioned epistemological reflections by scholars and dancers such as Oxana Chi and Grada Kilomba, Zachery interrogates the relation between knowledge and power. As a researcher, I do not sit in a safe place that saves me from asking myself these very questions. In the awareness that my positioning shapes my research content and form, I believe that the fact that I am "telling" the research story impacts the following aspects, which I find important to emphasize here.

As stated earlier, my knowledge of each choreographer's repertoire varies greatly. Moreover, I have a different personal relation to each dancer-choreographer: intimacy, friendship, distance, etc. Therefore, the dissertation necessarily reflects my elastic relations to the pieces and their makers, in compliance with the epistemological concerns expressed earlier.

Additionally, my research reflects the very predominant influence of US-American academic productions, because of my research location, and because the field of feminist postcolonial research and critical dance studies is much broader in the USA than it is in Europe, especially Germany, in terms of publications. Yet, I tried to use my fluency in

\footnotetext{
${ }^{101}$ Zachery, interview.
} 
three languages in order to expand my literature sources, and use also sources written in German and French. I am aware that my research is strongly biased by a western perspective because of my positioning and socialization in the west. ${ }^{102}$ However, I include the works of dancers-choreographers who are currently not based in the west, such as Farah Saleh (Palestine), Wan-Chao Chang (Taiwan) and Christiane Emmanuel (Martinique, a French department which is arguably still a French colony). Also, ableism and class are not emphasized as categories of analysis. Furthermore, I am aware that most of my sources and most of the interviewed dancers are cis-gendered persons.

The major challenge I confronted was translating dance into words. Susan Foster advocates for the choreography of writing, which becomes a necessity when writing about dance, so that one can address "how the activity of writing is conceptualized in relationship to the activity of performing, and how that relationship will be represented in the text." ${ }^{103}$ Departing from this reflection, I acknowledge the limits of the writing medium, no matter how well choreographed it may be, to reflect upon perforMemory. This consideration motivates my current production of a documentary film that will eventually enrich the book, in order to supplement the writing with an audiovisual expression and impression.

What I hope to evoke through the writing are nuances, as in a concert where the sound of each instrument modulates the total listening experience. In my research arrangement, each performance, and each dancer refines the melody of perforMemory with subtle and sometimes unexpected tones, and voices, which I bring into resonance with each other.

\footnotetext{
${ }^{102}$ On feminism and the categories of "geography" and "nations", see Sirri, "Führt geografische und religiöse Positionierung zu Ausschluss?"; Küppers-Adebisi, "Nationalisierung interdepenDenken."

${ }^{103}$ Foster, "Choreographies of Writing."
} 


\title{
1.5. Inventing, or Whence the Outline Comes From
}

\author{
"Dance is a barometer of culture - and a measure of society." 104 \\ Brenda Dixon Gottschild
}

As we know, a barometer is a tool that scientists use to measure atmospheric pressure, which helps in forecasting the weather. Today, even smartphones have built-in digital barometers. The idea of measuring the weight of the air in the atmosphere resonates with an ethereal imagination of dance. Whether dancers use a rather grounded or airy technique, the moving body always plays with weight and balance as it moves through the venue's atmosphere. Dixon Gottschild's metaphor of the barometer makes clear the powerful role of dance as a tool to assess and understand sociocultural politics. Just as we need tools to understand the movements of the weather, the moves of bodies dancing on stage can enlighten and deepen our knowledge of our social environment. And the dance barometer can indeed deliver precious information about sociopolitical pressure.

In my book, each chapter works through an overarching environmental metaphor whose energy may invigorate the chapter as a whole. Here you can also think of Chinese astrology, where the individual's past, present and future are interconnected, and related to, let's say the element (e.g., wood, metal, etc.) in one's birth chart, or in the stars' alignment. The literary quotations that open the chapters introduce the reader to the environmental motif.

The first chapter sets the grounds of inquiry by defining memory as a site of movement. Engaging with critical theory and literature, it opens up reflections on dance, choreography, trauma, and power, and introduces the pieces that constitute my repertoire of perforMemory. Here, I look at how selected performances negotiate the absence and presence of stories, perspectives, and bodies in hegemonic and counter-hegemonic narratives of the past. I develop the concept of perforMemory, and invent the notion of choreobiography to express the link between a choreographic and a historiographical process. Because perforMemory requires the effort to dig deep into the grounds of memory, to turn the self upside down, this chapter stands at the footstep of volcanic

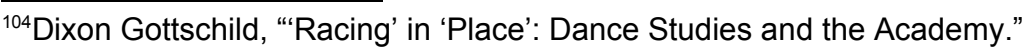


trauma. PerforMemory emerges out of the depths of the performances, reaching to the surface in eruptions. The magma of perforMemory is characterized by the earth element.

Diaspora, the motif of chapter two, is oceanic. In the Yoruba language, people from the diaspora are called "tokubo", meaning "the one who came/went over the sea." ${ }^{105}$ Not only in the Black Atlantic is diaspora associated with watery metaphors. Diasporic journeys undertaken across the spaces of nations, stages and stories sometimes move in wavelike patterns. The diasporic condition can be envisioned and understood as an oceanic movement - be it inner or outer, of back and forth between real or imagined roots, between past and current positionings. The currents of diaspora flow with the water sign, as I connect three spaces of definition for diaspora: academia, stage and body. The water element in this chapter signifies the fluidity of memory as it is constituted and transmitted individually and collectively. Water may be threatening, swallowing migrating bodies and sometimes drowning them in the void of white supremacist patriarchal capitalism. Water may also be the vivifying source of life, energizing, a carrying force, suggesting the vitality of an everflowing diaspora. By centering diaspora, this chapter asks how, given the legacy and contemporaneity of "colonial dismemberment,"106 the stage, and eventually the body may become a space of diasporic remembrance.

The third chapter, "Dancing the Past in the Present Tense," explores how perforMemory moves through time and space. To perforMemory may help to pulverize stiff conceptions and conventions of time, and this in turn happens through motion. Air is the element breathing through the third chapter. The exploration of time and the questioning of its shape within and beyond western norms, moves as a wind or storm. In the first part of the chapter, I examine the performances through the lens of spacetime definitions, and ask how selected works contemporize the past. I explore how choreographic strategies of perforMemory bend linear conceptions of "history," time, space, and emotions on the diasporic stage. I argue for instance, that pieces perform time in ripples, cycles or waves. I embed the discussion of the works in a broader reflection on memory and time. The second part of the chapter spotlights a set of movements, and connects the physical and conceptual aspects of perforMemory. Spinning, jumping, crossing the grounds of memory, this chapter may recall wandering. It is a space of memorial blossoming, suggesting dance as the possible, imperative revival that may, that should occur after traumatic histories, or more recently the passing of a hurricane.

The last part of my thesis is a book within the book. It contains the full transcript of the seven interviews I conducted with each artist between 2013 and 2016. Here the artists

\footnotetext{
${ }^{105}$ Küppers-Adebisi, "Nationalisierung interdepenDenken," 137.

${ }^{106}$ Taylor, The Archive and The Repertoire, 209 Here Taylor analyzes the work of the theater group

Yuyachkani as a strategy of "re-membering."
} 
reflect upon the solos, but also upon other works as molded in my framing of the questions. ${ }^{107}$ This chapter is a conversation, an encounter between a researcher's preoccupations and the artists' perspectives. As you will see, the interviews are not a mere appendix to a doctoral research, rather they are an integral part of the body of work. I hope this challenges the conventional distinction between "primary" and "secondary" sources, which often implies a hierarchization between academic knowledge production and other forms of writing or speaking. The interviews enrich the dissertation and convey some of the intents and perspectives of the dancers on the topic of dance and memory.

As the elements influence each other in a circular, or even spiral pattern, the book shall come full circle, the Earth sign spiraling back to the volcano, and the research excavating memory as futurity. With these geoastral, geohistorical and literary-physical threads, I hope to provide the readers with a rope to hold on to as they climb up and down through the dancescapes of perforMemory, where they may encounter story-hunters and dancing lions. ${ }^{108}$ The title of this introduction is namely a play on the famous quote:

Until the lions have their own historians, the history of the hunt will always glorify the hunter.

This west African proverb suggests how power relations shape historiographical narrativization. It explains why so the history of chattel slavery is seldom told from the perspectives of those who escaped plantations and lived in quilombos, or why Holocaust studies rarely highlight organized struggle against fascism in ghettos and concentration camps. Although the saying is often attributed to specific male writers, it is a very old wisdom transmitted orally throughout African societies. It was first passed on to me, orally, more then ten years ago, when I was working as an intern at the headquarters of the AfricAvenir Foundation in Douala, Cameroon. Whether I may have been a hunter and/or a lion in previous lives, I now thrive to be a storyteller who uses creative and academic words, music, sounds, video and movement to tell a story. This story shall hopefully move you, if you join the dance.

\footnotetext{
${ }^{107}$ For an interesting combination of artist interviews, academic essays and performance scripts in the field of theater, see Johnson and Rivera-Servera, Solo/Black/Woman.

${ }_{108}$ The film that will accompany the digital and print publication will feature images representing a sense of movement through environment and a sense of these elements, besides the interviews and performance excerpts.
} 


\section{Memory Dancescapes}

We are on a volcano, and we are volcanos. On the margin of borders, we are those without borders. In questions without answers, we are the question. We are the answer. [...]

We exist, we ask, we reclaim, we contest, we question history's questions and we tame history's pain.

(Nous sommes sur un volcan, et nous sommes volcans. En limites de frontières, nous sommes les sans frontières. En questions sans réponses, nous sommes la question.

Nous sommes la réponse. [...] Nous existons, nous demandons, nous réclamons, nous contestons, interrogeons les questions de l'Histoire et nous domptons les douleurs de l'Histoire.)

Widad Amra ${ }^{1}$

Let's travel through memory as a site of movement. I love this quotation by Palestinian-Martinican author Widad Amra, for it subverts conventional dichotomies. It expresses so deeply the paradoxical condition of humans who produce counter-hegemonic narratives. I recall deep conversations with Widad Amra at her home on the island of Martinique: about absence, about the entanglements of diasporas and the entanglements of familiar and historical traumata and configurations. The phrase to "question history's questions" resonates with ears attuned to feminist voices, and it also carries the echoes of the choreographers' voices, as they ask, reclaim, contest why and how they arrived here. First and foremost, they exist on stage, working with explosive topics and forms, producing performances of political eruptions in volcanic settings. They move back and forth between the volcano as historical setting and the volcano as a well of stories from which they draw pain, doubt, hope, euphoria, fear, contemplation. PerforMemory here is a dancescape, a site of political and emotional mobility.

Whether it is Oxana Chi spinning festively, Chantal Loïal sustaining and collapsing the spine, Wan-Chao Chang pulling energetically on a scarf, Zufit Simon rolling onto the stage, Farah Saleh walking on her hands, André Zachery flying high and low, Christiane Emmanuel

\footnotetext{
${ }_{1}$ Amra, Le Souffle Du Pays. Nabd El Jayzirah, 34-35 [My translation].
} 
racing in the air, all of the artists perform memory through movement, moving through historical figures and contemporary times. Their works invite us to move with them, without rising from our seats. PerforMemory can make the audience travel back in time while remaining in the present. What is deeply moving is the presence the performers radiate on stage. In solo or group constellations, they fill the stage with stellar energies, telling stories of quest and loss, inviting us to travel in stillness, yet also actively through memory as a site of movement.

Defining memory as a site of movement, perforMemory may then be understood as a process and as a result. It enacts the will to counter or acknowledge absence and to embody and perform presence. This understanding resonates with bell hooks' definition of memory as a "site of resistance." 2 PerforMemory connects memory, movement and resistance, contending that memory can become a site of moving resistance, or resistance through movement.

This chapter examines how the performances orbit around memory, and how they negotiate absence and presence in diasporic spheres connected with various sites of trauma such as the Holocaust, the Transatlantic Slave Trade, or the Nakba. Asking how memory is shaped through dance, I start by delineating the borders, in order to describe in successive chapters what it feels like to move through these memory dancescapes. In a sense, this second chapter maps out the dancescapes of perforMemory, sketching the silhouettes of stories, perspectives and bodies that are alternately and simultaneously absent and present. The first section is conceived as an archive, in which I sort through and introduce thematically my repertoire of perforMemory. I will provide information about the theme and structure of each piece. For biographical information on the dancerschoreographers, please refer to chapter 5 , in which each one of the seven interviews is preceded by a short vita. In the second section of the chapter, I return to reflections about memory as a site of movement, which I touched upon in the introduction, by interlacing creative and academic literature with concrete examples of perforMemory.

The pieces, although they are fundamentally diverse in terms of choreographic vocabulary, movement techniques, dramaturgic construction, aesthetics and themes, share several features. First, they all relate more or less explicitly to a diasporic journey, as discussed in chapter 3 . Second, they perform memory in a timespace that moves beyond past, present, and future distinctions, as discussed in chapter 4 . Third, one could say that the seven pieces express auto_biographical journeys, or at least a journey across the gap between auto and biography, between life and choreography. They constitute a 
kinesthetic knowledge through a process I conceptualize as choreobiography, ${ }^{3}$ to denote the intertwined processes of choreographing and (auto)biographical storytelling. ${ }^{4}$

Choreobiography allows dancers to put a name and a face to the body of memory, to zoom in on an individual within the broader picture of history, to search for personal ancestors or artistic soulmates through choreography. To choreograph a biographical piece, centered on one individual who is named and embodied, is in itself a strong political statement. Choreobiography may additionally stir up the status quo of the past, in relation to the preoccupations of the present. Like a literary biography, a choreobiography tells a biography from a contemporary perspective, but through movements rather than words. Audre Lorde called her autobiographical novel Zami ${ }^{5}$ a "biomythography," a new genre blending history, biography and myth. Dancers who are also choreobiographers work through myth to perform their own biographical legends into history. Choreobiography thus is a pivotal genre of perforMemory. It applies particularly to the repertoire of Oxana Chi, with pieces such as Neferet iti and I Step On Air. Chantal Loïal's They Call You Venus, as well as Wan-Chao Chang's Impressions, also intensely enmesh the choreographic process with the more or less abstract telling of an individual biography, be it historical (Sawtche) or their own (Chang).

Scholarship at the intersection of critical dance studies and cultural studies conceives of dance as Meaning in Motion. ${ }^{6}$ Looking at signifying bodies moving through memory dancescapes, this chapter generates the idea of perforMemory as a form of memory2go: a tensile memory, whose content is transferable to others - if they are willing to connect. PerforMemory brings into existence a remembering anchored in the present. It reveals the powerful weight of dance as a "counterhegemonic cultural practice"7 that may transform how we understand the past, stand in the present, and leap into the future.

Performative memory opens up worlds connected to, but divergent from, literary and visual engagements with memory. With a focus on embodied power as a key feature of performance, I draw connections between the material power of stage performance and the metaphorical power to re-write or challenge historical narratives. A question that guides this first step of the inquiry is: how do postmemorial artists choreograph interventions into hegemonic narratives?

\footnotetext{
3 Zami, "Oxana Chis Tänzerische Wissensschaffung."

${ }^{4}$ On the connection between Black women's autobiography and dance, see Conyers, "Shedding Skin in ArtMaking."

${ }^{5}$ Lorde, Zami: A New Spelling of My Name.

${ }^{6}$ Desmond, Meaning in Motion: New Cultural Studies of Dance.

${ }^{7}$ hooks, "Choosing the Margin as a Space of Radical Openness," 153.
} 


\subsection{Archiving a Repertoire of PerforMemory}

Every long journey requires taking one step at a time. In Berlin, you can stumble over archival memory, as discussed earlier. Sometimes you can also fly over memory at a height of 39971 feet, and at a speed of 518 miles per hour. I crossed and re-crossed the "grey vault," ${ }^{8}$ the Atlantic's burial chamber, on airplanes flying between Berlin and New York City, on the many journeys that I undertook for this research. Memory feels as porous as the time zones separating the feeling of a Berlin evening from New York City's afternoon light, or separating the city of the Reichskristallnacht from the city of the African Burial Ground. Over the years, I hopped from one place to another, and assembled pieces of dance into patterns of perforMemory. What the seven solo pieces have in common is their contribution to innovative forms of remembering, and to what Aïcha Diallo describes as a "living archive":

The Living Archive understands itself as an imaginary archive that blurs the boundaries between past, present, and future; between written and alternative transmission forms; between the visible and the invisible; and interweaves them anew with each other. ${ }^{9}$

Diallo's definition attends to the critique of linear time conceptions, and to the multiplicity of the senses and realms of remembering, which will resurface in the next chapters. Interestingly, the imagery of interweaving threads evoked by Diallo's statement resonates with Oxana Chi's understanding of her choreographic process, which she compares to the task of "knitting" a rope, or a fisher's net. ${ }^{10}$ Chi's description suggests that she uses her body to channel a connection between the memory of a historical biography (in this case May Ayim, in other cases Tatjana Barbakoff or Claude Cahun), and the contemporaneity of her dance.

Similarly, this book knits together a tapestry using threads from academic theory and from the "theory-in-practice" 11 of the dancers. The archive lives on in the moving bodies of these artists who transmit and perform memory in innovative and creative ways. How do the performances perform an imaginary archive, and how does my archiving of the pieces

\footnotetext{
${ }^{8}$ Walcott, "The Sea Is History," 137.

9 Diallo commissioned me to write an article about Oxana Chi's Neferet iti dance for this anthology. Diallo and MID Redaktion, The Living Archive [My translation].

${ }^{10}$ Chi, "Von Hier Nach Dort - I Step On Air," 203.

${ }^{11}$ Ramón H. Rivera-Servera, Performing Queer Latinidad. The author argues that performers also generate theory with their bodies.
} 
challenge conventional temporal, geographical, artistic and thematic boundaries? In this first section, I dwell on the repertory of seven innovative choreographers and introduce their dance pieces, which I define as works of perforMemory. A dance repertoire that is also a memory repertoire in the sense of Diana Taylor, ${ }^{12}$ perforMemory counterpoints the disproportionate attention granted to archival memory transmission. Reflecting upon the workings of collective memory transmission, Taylor conceptualizes a tandem, non-binary memory paradigm. She makes a convincing case for overcoming the usual dichotomy between written and embodied cultural transmission, and between literary and performative knowledge. Besides other modes of transmission - such as digital and visual modes - she prefers to distinguish between the archive and the repertoire, which often go hand-in-hand. The author emphasizes the role of performance in general, not only theatrical but also social performance, in the processing of historical traumata:

How do the archive and the repertoire combine to make a political claim? How does performance participate in the transmission of traumatic memory? ${ }^{13}$

I argue that perforMemory demonstrates how integral dance performance is to political remembering of traumata. PerforMemory counters the idea that dance is the art of the ephemeral, in a similar move to Taylor's point, which calls attention to the dangers of admitting only written knowledge transmission as durable and valuable. ${ }^{14}$ Taylor highlights those dangers in the American context, revealing how revealing how the valorization of written knowledge transmission has served to oppress and repress Native cultures and history. She smashes the myth of an enduring, rock-like archive. Instead, she values the repertoire of "performances, gestures, orality, movement, dance, singing - in short, all those acts usually thought of as ephemeral, nonreproducible knowledge."15 Her research demonstrates how in performance the body not only transmits, but actually enacts memory. Her argument is strongly relevant within the context of gender studies, for it incites us to unveil the bias induced by imperialism, white supremacy, capitalism, heteronormativity, and patriarchy (to paraphrase bell hooks), and to consider how such bias affects institutional archival processes. It also incites us to reappraise the strong, long-lasting impact of performative memory production and transmission. ${ }^{16}$

The seven pieces of my repertoire attend to Taylor's deconstruction of the archive and its limits, and her appraisal of the repertoire as an enduring memory tool. Sometimes they

\footnotetext{
${ }^{12}$ Taylor, The Archive and The Repertoire.

${ }^{13}$ Taylor, 54.

${ }^{14}$ Taylor, 193.

${ }^{15}$ Taylor, 20.

${ }^{16}$ However, Taylor suggests that the repertoire is not per se counter-hegemonic, since colonialism in her view also works through the performance of violence. See also Scolieri, Dancing the New World: Aztecs,

Spaniards, and the Choreography of Conquest.
} 
use both the archive and the repertoire to generate memory transmission. Through Gardens and They Call You Venus circumambulate archival matter, and perform "a history written with and against the archive." ${ }^{17}$ For instance, Oxana Chi's publication Tanzende Erinnerungen, as well as the documentary Dancing Through Gardens, reproduce some of the archived information on Tatjana Barbakoff, in the form of press excerpts and letters. ${ }^{18}$ The publication and the movie are now part of the archive in several institutions such as the National German Archive Tanzarchiv Köln, the Israel Museum in Jerusalem, the Fondation pour la Mémoire de la Shoah (FMS, Paris) and several university libraries.

Conversely, the piece Through Gardens is the performative repertory result of Oxana Chi's interest in and negotiation of the archive of Tatjana Barbakoff. Besides performing the solo at international venues and festivals, Chi has performed it at her yearly event series, "Salon Qi, a Femmage to Tatjana Barbakoff," in Berlin and Paris. By doing so, she perforMemoried marginalized aspects of dance history and the history of artist discrimination and resistance in $20^{\text {th }}$ century Europe. The artist transforms the archival knowledge on Tatjana Barbakoff - which she accesses through regular communication and cooperation with the historian Günter Goebbels ${ }^{19}$ and through her own research - into an embodied repertory piece, a repertoire of perforMemory. While archival material on Barbakoff is full of ellipses, inevitably filled with the imaginings of those who have collected it, and biased with their social positionings, the repertoire piece invites the audience to use their own imagination to generate meaning. Contrary to some archival claims, Through Gardens does not pretend to nail down a full, irrefutable account of Tatjana Barbakoff's biography. Rather, it choreobiographes her story, framing it in a historical context, and yet it remains open and abstract enough to offer a more differentiated story of what her life may have been from a contemporary perspective. ${ }^{20}$

Chantal Loïal also moves at the intersection of the archive and the repertoire. They Call You Venus is a performative intervention into the hegemonic narrative of Sawtche, as told in historical textbooks and archived in European institutions. The solo demonstrates how the perforMemory of Sawtche is no less resilient than the presumed archival knowledge extracted out of her physical remains. The physical "archive" of Sawtche, by contrast, appears very malleable depending on whose hands hold her bones. Sawtche's actual bones did not resist temporal and spatial transfers throughout the $20^{\text {th }}$ and $21^{\text {st }}$ centuries. Pseudo-scientists objectified her body, experimenting upon it, alive and later

\footnotetext{
${ }^{17}$ Here the author refers to another Venus story. See Hartman, "Venus in Two Acts," 12.

${ }^{18}$ Chi, Tanzende Erinnerungen, 2011; Chi and Zami, Durch Gärten Tanzen (Dancing Through Gardens).

${ }^{19}$ Drenker-Nagels, Goebbels, and Reinhardt, Tatjana Barbakoff, Tänzerin und Muse; Goebbels, Tatjana Barbakoff.

${ }^{20}$ On the relation to the audience's interpretation, see Oxana Chi's e-mail to her musician Laszlo Moldvai (01.01.2010), in Chi, Tanzende Erinnerungen, 2011, 12.
} 
dead, even going so far as to display the mold of her genitals at the Parisian Musée de I'Homme until 1974! Later, her bones were to become objects of ritual, buried in South Africa in a grave that is now a national heritage site. Thus the value and meaning of Sawtche's archive, depending on which hands hold it, reside in the context, and serve political purposes. The story of Sawtche's display, as a living and as a dead body, evokes a colonial display of power. Like a dance repertoire, the museum's archive is bound to its space-time of existence. The solid archive generates an evolving knowledge and is no more reliable or immutable than a performative, embodied one.

In this sense, I find that both Through Gardens and They Call You Venus resist what Marisa Fuentes calls the triple "physical, archival, and epistemic" violence that affects simultaneously "the body of the archive, the body in the archive and the material body." 21 Fuentes is critical of the tendency of historical knowledge produced about enslaved women in the Caribbean to re-produce slavery's violence. The choreobiographies of Oxana Chi and Chantal Loïal counter the epistemic re-production of violence that occurs when dance historiography omits, or dis_remembers the importance of Tatjana Barbakoff in the 1920s and 1930s; and when French coloniality re-asserts itself in the archiving of Sawtche's story and body. They are repertoires of memory that extend and expand archival knowledge. The pieces perform the possibility of an afterlife full of dignity, more so at a meta-level in the case of Oxana Chi, who revives Tatjana Barbakoff in the dancer's own field of expression, the stage, but also in the case of Chantal Loïal's use of display. A dancer's repertoire thus may "account for the palimpsest of material and meaning" 22 that go missing in the archive. It can perforMemory, generating memory as a repertoire colliding and colluding with the archive.

One of the major aims of this research, which is published through HumboldtUniversity, is to make space on the academic shelves for a new repertoire filling an archival gap...and fulfilling a pledge. The works demonstrate the enduring resonance of performative memory, and its potential to subvert archival transmission and domination. The following repertoire, structured in thematic overviews, shall give you an impression of each piece. Seen and sewn together, through one lens of analysis, it constitutes a mosaic of memory as a site of movement. To facilitate the reader's access to each piece, I use headings that draw circles of meaning in which I place the performances. These are not intended to mark hermetically sealed epistemological boundaries, but rather serve as signposts as you circumambulate the shifting tides of perforMemory. Moreover, the circles of meaning are not watertight. Rather, they are spheres with permeable borders, allowing fluid theorization and multiple positionings of the pieces. For instance, all of the pieces are

${ }^{21}$ Fuentes, Dispossessed Lives, 6-7.

${ }^{22}$ Fuentes, 6. 
choreographies of history in a way. They all deal with migration and displacement. And all of the pieces are rooted in autobiographical inspiration and imagination, as suggested by the interview transcripts. I could also have imagined other headings such as "gestures of war and love." Or I could have drawn distinctions between Afro-diasporic and Asiandiasporic perforMemories. Luckily, however, I am not writing in permanent ink, so you, the reader, are invited and incited - like audiences of perforMemory - to weave in shifting threads as you move through these memory dancescapes.

\subsubsection{Dancing counterhegemonic choreobiographies}

Through Gardens and They Call You Venus (re-)inscribe a historical female figure into collective memory by deploying performative knowledge. Not only do they "call names" 23 to resist erasure, they recall the bodies, and perform in their names, embodying stories and impersonating the bodies of women of color too often buried under tons of other names and stories. PerforMemory comes into being: powerful and challenging, it does not minimize historical tragedy but maximizes possibilities to deal with it. As the dancers stand firm on their feet, presence stands out in their choreobiographies. In their moves, terrestrial gravity exists side-by-side with ethereal grace.

${ }^{23}$ hooks, Yearning, 116. 


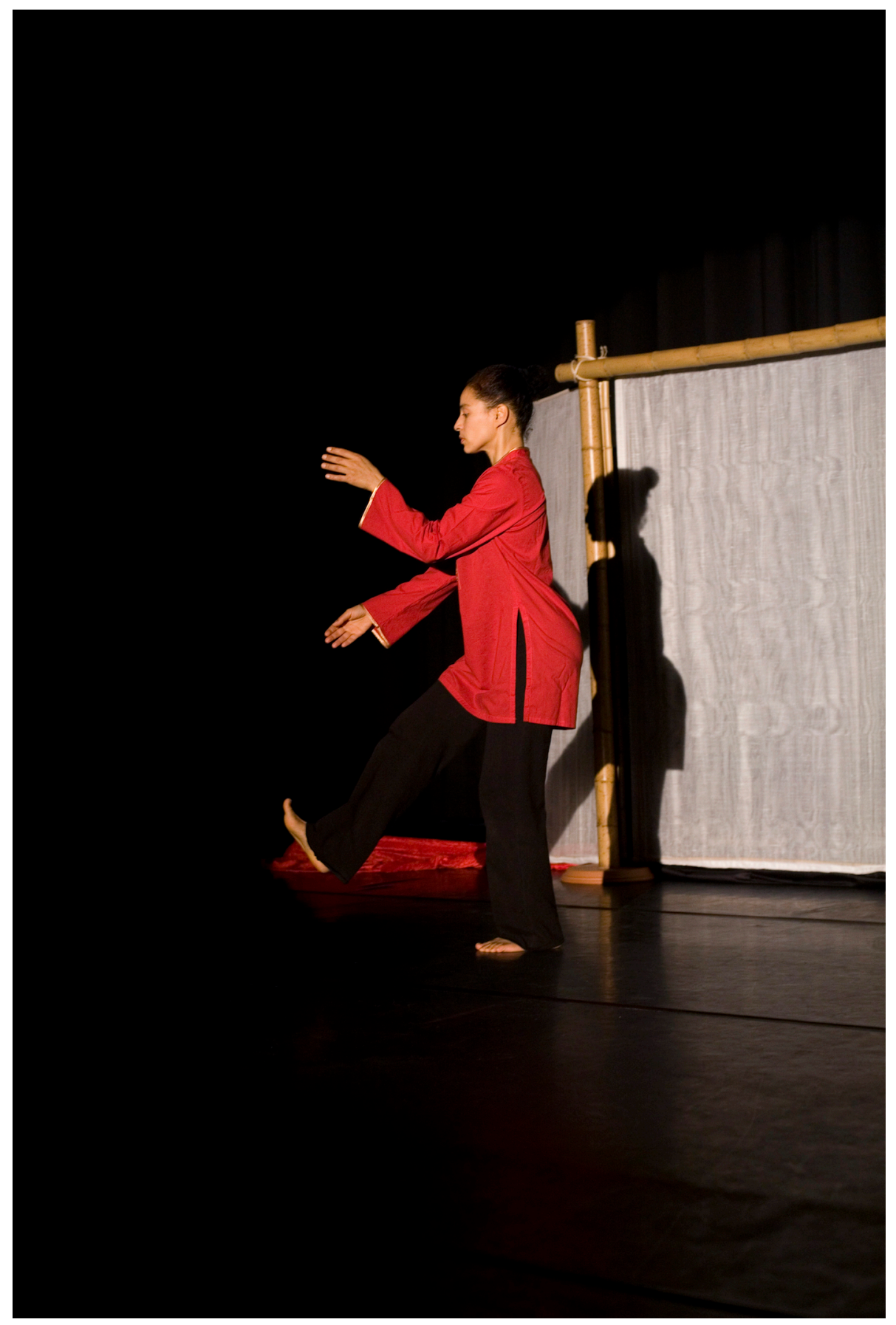

Oxana Chi in Through Gardens, "The Journey"

Werkstatt der Kulturen Theater, Berlin, Germany, 2008.

Photo: Annette Hauschild @ Oxana Chi 


\subsubsection{Through Gardens by Oxana Chi}

Through Gardens, the main inspirational piece for this book, is dedicated to the aweinspiring story of Tatjana Barbakoff. ${ }^{24}$ She was a solo expressionist dancer and choreographer from Russia (now Latvia), of Chinese-Jewish descent, who was very successful in 1920s/30s Europe. Historical archives suggest that her work was often cited and discussed in the press. Because of the institutionalized persecutions of the Nazi regime, she fled from Germany to France, where she continued to dance in spite of all adversities. In 1944, she was arrested in French Nizza, deported three days later, and killed immediately upon arrival in Auschwitz.

Barbakoff was also a muse. Many famous artists produced paintings, photographies and sculptures of her: Yva, Otto Dix, Kasia von Szadurska, Willy Maywald, Minya Dührkoop, Gert Wollheim, Nini and Carry Hess, Waldemar Flaig, Sasha Stone, and Helen Dahm. Most artists were persecuted for being Jewish and/or political protesters. Although many artworks were destroyed by the NS-regime, and some of the artists such as Yva were also assassinated, the legacy that remains hints at the important role of the dancer in the art world. Interestingly, many of these artists were, like Barbakoff, independent working women*, who defied the gendered restrictions of their times. ${ }^{25}$

Named after one of Tatjana Barbakoff's solos, the contemporary dance Through Gardens is not a re-enactment of her work, but a gripping choreobiography choreographed, interpreted and directed by Oxana Chi. The choreographic architecture has four timespaces: Die Geburt (Birth), Das Fest (Celebration), Der Kampf (Struggle), and Der Neumond (New Moon). In between the main acts, the dancer performs short interlude scenes. The mix of linear and circular dramaturgy, which I will return to later, generates a fascinating decoding of western historical temporality and geographic spatiality.

The piece merges various techniques from European ballet, Chinese WuShu, Javanese dances and west African movements and expressions into the dancer's selfnamed "fusion" style. It also corresponds in my view to what Zenenga terms the "Africanist paradigm" of Total theater aesthetics, ${ }^{26}$ with a harmonious aggregation of dance, livemusic and theatrical expression. The choreography germinated from Chi's decades of training and performance in Europe, Southeast Asia and the USA. The technical precision

\footnotetext{
${ }^{24}$ For more information on T. Barbakoff's biography, see Goebbels, Tatjana Barbakoff; Drenker-Nagels, Goebbels, and Reinhardt, Tatjana Barbakoff, Tänzerin und Muse.

${ }^{25}$ For a feminist reading of Tatjana Barbakoff's biography see Zami, "Tanzkunst als lebendige Erinnerung"; and the movie Chi and Zami, Durch Gärten Tanzen (Dancing Through Gardens).

${ }^{26}$ Zenenga, "The Total Theater Aesthetic Paradigm in African Theater."
} 
of fast-paced pirouettes lives side-by-side with a proficiency in the slow-motion energetic flow of Qi-based arts. The movement quality is supported by the carefully designed costumes. Video projections round up the scenography. The photograph above, taken during one of the first iterations of the piece, shows the dancer in front of a bamboo folding screen, the backdrop against which she offers a live perforMemory of Tatjana Barbakoff. The dancer steps forward with movements reminiscent of Southeast Asian puppetry (Wayang Kulit), which Chi encountered during her formation in Indonesia. Barbakoff was also photographed holding a Wayang Kulit figure in her hands. As evoked in the introduction, I read the picture as a metaphor of perforMemory, with an interesting tension between the dancer's determination to move forward, and the walk orientation from right to left, that denotes a re-turning towards the past.

As a solo dancer, Chi usually performs with live-music composed and performed by an evolving ensemble. Her Ensemble Xinren regroups varying and varied musicians, brought together specifically for each piece. This is an emblematic feature of her work, which I have had the chance to participate in. The choreography stems from a movement research preceding the musical input. Once the musicians enter the rehearsal process, they compose and improvise in dialogue with the dance. The choreographic process continues, like a flexible frame within which the movements' pace and intensity may vary according to the musical elements. Through Gardens exists in various, innovative musical constellations: with piano and hang; with accordion, e-guitar, and hang; with cello and Chinese drum. Chi explains her will to keep the work in movement, like a life or an environmental process:

The working process on Through Gardens equals a life. There is nothing sealed off and static that could not be changed during the performance timeframe. It is an ongoing process of experimenting and choreographing. It would be beautiful, if a luxuriant vegetation arose out of the manifold performance variations, always letting new bursts of buds.

(Die Arbeitsweise an Durch Gärten gleicht einem Leben. Es gibt nichts Abgeschlossenes, Feststehendes, was nicht während der Aufführungsdauer verändert werden könnte. Es wird immer weiter experimentiert und choreographiert. Es wäre schön, wenn eine üppige Vegetation aus vielen verschiedenen Performance-Variationen entstehen würde und immer neue Knospen hervor sprießen ließe. $)^{27}$

The first movement seed was planted in Oxana's memory garden in 2007, after she encountered a catalogue dedicated to Tatjana Barbakoff. It was the catalogue of an exhibition held at the August Macke Haus in Bonn in 2002, curated by the museum's

${ }^{27}$ Chi, Tanzende Erinnerungen, 2011, 5 [My translation]. 
director Klara Drenker-Nagels, along with Hildegardt Reinbrandt and Günter Goebbels. ${ }^{28}$ Goebbels is a former engineer who devotes himself to the excavation of "forgotten biographies," and has conducted extensive international research on Barbakoff for decades. He is very involved in the process of keeping her memory alive through exhibitions and publications. Barbakoff, however, is blatantly missing in contemporary dance historiography, in contrast with other historical figures.

Inspired by Barbakoff's memorial presence in the art world, Chi wishes to bring her memory back on stage....and her life back into movement. Journalist Sophie Lespiaux describes Oxana Chi's presence in Through Gardens as follows:

Thus, Oxana Chi's presence on stage becomes at times solid and dense, almost telluric, in full control of inner energy and slow motion, and at times fluid and aerial, in a gracious moment.

(Aussi la présence d'Oxana Chi sur la scène se fait-elle tantôt massive et compacte, presque tellurique, toute en maîtrise de l'énergie intérieure et du mouvement dans la lenteur, tantôt fluide et aérienne, lors d'un gracieux instant. $)^{29}$

When Oxana encountered Tatjana's story, it was the first time she felt able to identify with a historical figure from European dance history. Indeed, their lives and styles reveal many salient parallels: diasporic origins; use of performance to criticize sociopolitical power relations; ${ }^{30}$ solo interpretations of their own choreographies; collaboration with live musicians; expressive and poetic aesthetics and inspiration from several cultures, including Indonesian dance styles; and residence in Dusseldorf, Berlin, and Paris. ${ }^{31}$ The piece tells Barbakoff's biography from a contemporary perspective, and travels through themes of migration, discrimination, resistance and performance. Through my personal, embodied engagement with the piece, I gained a lot of insight into the workings of dance and memory. Thus, Through Gardens is the choreobiographical keynote in my perforMemory composition. It epitomizes the shift between archival digging and repertoire dancing, between "history" and perforMemory.

\footnotetext{
${ }^{28}$ Goebbels, Tatjana Barbakoff.

${ }^{29}$ Lespiaux, "Durch Gaerten, une performance musicale et chorégraphique d'Oxana Chi." [My translation].

${ }^{30}$ Already in 1925, Tatjana Barbakoff had to report to the police office after a show deemed too critical by the city's authorities in Königsberg. See Chi and Zami, Durch Gärten Tanzen (Dancing Through Gardens).

${ }^{31}$ On the parallels between T. Barbakoff and O. Chi, see Zami, "Mit Oxana Chi Durch Gärten."
} 


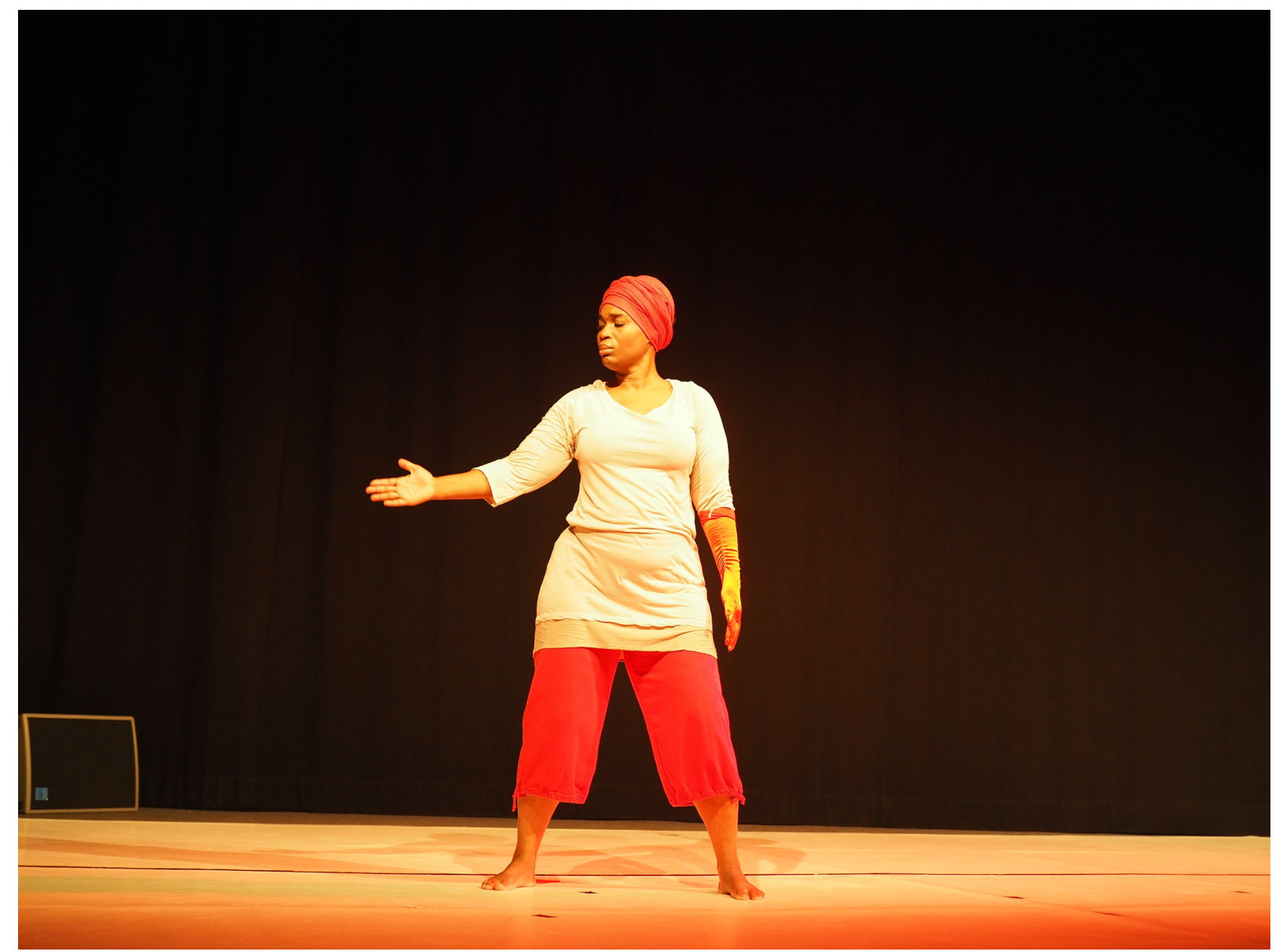

Chantal Loïal in They Call You Venus

Moving Memory International Symposium-Festival, Berlin, Germany, 2016.

Photo: Layla Zami 


\subsubsection{They Call You Venus by Chantal Loïal}

Another Afro-European choreographer who performs an arresting one-womanbiographical solo is Chantal Loïal. Yet her themes, trajectory and aesthetics are very different from Oxana Chi's. They Call You Venus is the first and only solo in Chantal Loïal's repertoire. She choreographed this piece with the artistic support of Philippe Lafeuille and Paco Decina. The narrative is inspired by the biography of a Khoi woman originally named Sawtche or Ssehoura, also known as Saartjie or Sarah Baartman. Her story has been inscribed in historical archives under a variety of racist and exoticizing names. In the early 19th century, her family was massacred, and she was enslaved in Cape Town and deported to Europe, where she was forced to display her naked body at racist exhibitions and forced into prostitution. ${ }^{32}$ Through her anatomy, her body and self were discursively constructed as representing the African "Other," and she was the target of racist-genderist violence: an object to be gazed at, despised, and brutalized, as many other human beings from Africa, Asia, the Pacific and the Americas were. Between her death and her burial, centuries passed. When Nelson Mandela was elected president of South Africa in 1994, he requested that the French government return what was left of Sawtche's remains, in an attempt to restore dignity to the body, to return it to its rightful place after centuries of displacement. South Africa had to wait until 2002 for the French Parliament to pass a law for Sawtche's remains to be transferred back "home."

Ever since attending the premiere at the Théâtre Aimé Césaire in Martinique in January 2011, I have followed the piece. In my 2011 critique, the first of what later became a long list of international press reviews by diverse journalists, I described the feeling of witnessing how Loïal symbolically gave Sawtche her body back, through dance. ${ }^{33}$ This visceral work of perforMemory felt like an intervention, a reclaiming of the embodiment so crucially lacking in most historiographical projects.

Dramaturgically, the solo is divided in two parts: the first one evokes Sawtche's persecution in Europe and the second one celebrates her posthumous return to South Africa. Even though this may seem like a chronologically linear divide, it can be interpreted as an emotional dramaturgical split, or as the reunion of pain and exile with a scene of home and celebration. The movements also carry traces of Loïal's experience

\footnotetext{
${ }^{32}$ Loïal, "On T'appelle Vénus - Dossier de Diffusion" It is very difficult to write about Sawtche's biography, since what are officially recognized to be facts stem from the accounts of the persons who have brutalized her and her people. I refute the assumptions that she travelled willfully to Europe, (and ask how "will" is defined when one is in the position of an enslaved human). Thus, I am cautious of the fact that even Chantal Loïal's discourse may sometimes re-produce the violence of racialized and gendered normativity constructions.

${ }^{33}$ Zami, "Rendre sur scène son corps à Sawtche."
} 
both as a dancer in the European "contemporary" dance scene and as a dancer touring with west and east African companies. They also carry the dancer's personal repertory of Afro-Caribbean styles, marked by a mastery of isolation techniques.

Chantal Loïal's piece follows in a long lineage of artistic engagements with Sawtche's biography. For instance, the Urban Bush Women choreographed Batty Moves with the intent to "re-imagine her [Venus] as a whole self," ${ }^{44}$ centering the buttocks at the core of the dramaturgy. Conversely, after Chantal Loïal's preview performance in Lille in 2010, other choreographers based in Europe approached this particular biography. In the synopsis, Loïal emphasizes that she wishes to question western processes of Othering which persist up to the present, rather than re-enacting the story ("rejouer le drame"). She wants to depart from the "official Black Venus" narrative in order to "offer her a victory over history." ${ }^{35}$ The performance also features a text spoken by Loïal, and written by a white cis-man, Marc Verhaverbeke. The text is not written in the first pronoun, but in the third one, conveying the outsider perspective of a voice which is trying to invest itself into the historical biography.

The piece choreobiographes Sawtche's story through Loïal's corporeal perception. Finding out about Sawtche through historical narratives, the dancer felt a connection to her personal experiences as a Black woman who had arrived in France at a young age and later toured with the company Montalvo-Hervieu. ${ }^{36}$ In her artist's statement, Chantal Loïal explains how she reads the story from a personal perspective embedded in her socialization:

Beginning with the theme of the Hottentot Venus is an occasion for me to dive into a work on the body, a body displayed, mutilated by the Western gaze, a body expressing more than any other, Otherness/Othering. Being myself a descendant of West Indian societies with pregnant cleavages, generated in historical violence on the bodies [...].

(Partir du thème de la Vénus Hottentote est l'occasion pour moi de plonger dans un travail sur le corps, un corps exposé, mutilé par le regard de l'Occident, un corps exprimant mieux que tout autre l'altérité. Etant issue moi-même d'une société antillaise aux clivages prégnants, engendrée dans une violence historique et sur les corps $[\ldots].)^{37}$

The artist's statement expresses the impossibility of fully differentiating the historical protagonist from the artist's own autobiography in her dancing narrative. Yet, one must also note the challenge faced by the dancer as she navigates the troubled waters of epistemological violence. When she plays with the display of the Black female body, she

\footnotetext{
${ }^{34}$ George-Graves, Urban Bush Women, 59.

${ }^{35}$ Loïal, "On T'appelle Vénus - Dossier de Diffusion" [My translation].

${ }^{36}$ Cadeau, "Chantal Loïal - La diversité par la mise en danse du corps."

${ }^{37}$ Loïal, "On T'appelle Vénus - Dossier de Diffusion” [My translation].
} 
runs the risk of re-producing the historical genderist-racialized violence against it. Also, the title of the piece (as do most engagements with this historical biography), hints at the fact that "Venus" was a derogatory name imposed upon her, and yet it contributes to associating the story with this name.

They Call You Venus, like Through Gardens, was produced with the clear intention of inscribing marginalized female perspectives into historiography. If these works perform what André Lepecki calls a "choreopoetic proposal for a political meditation on European historical amnesias," ${ }^{38}$ can they heal audiences? Lepecki refers to a solo I find problematic in terms of racial positioning. In contrast, in the case of Oxana Chi, I often overheard audience members thanking her after a show for "healing" them through her dance. Oxana Chi and Chantal Loïal may offer Afropean perforMemory as a choreobiographic therapy: a powerful and "natural" remedy against the voluntarily political Alzheimer's that affects Europe.

\subsubsection{Dancing after the ancestors: family, trauma and movement}

The two following pieces were choreographed respectively by Zufit Simon, a European Jewish artist who does not however define her work as "Jewish," ${ }^{39}$ and André M. Zachery, an African-American artist whose artistic intents are strongly grounded in Black diasporic subjectivity. ${ }^{40}$ In contrast to the two previous pieces, they do not evoke a specific historical biography, and use less theatrical dramaturgy, adopting instead a more experimental approach to performance. They revolve around the performers' current biographical itinerary through emotionality. In their solos, Zufit Simon and André M. Zachery orbit around their emotional selves, occasionally dwelling in the galaxies of their genealogy. Both performers draw from their family history, and research using body language, inquiring into how they may be injured, inspired, empowered, influenced by generational traumata. In my view, these postmemorial perforMemories traverse what Hirsch calls "a structure of inter- and transgenerational return of traumatic knowledge and embodied experience." ${ }^{41}$ These solo dances seem to be less interested in what happened in the past than with the effect and affect of ancestral pasts on their descendants' present.

\footnotetext{
${ }^{38}$ Lepecki, Exhausting Dance, 107.

${ }^{39}$ Simon, interview.

${ }^{40}$ Zachery, "Futurity and the Containment of Blackness in Twenty-First-Century Performance."

${ }^{41}$ Hirsch, The Generation of Postmemory, 6.
} 


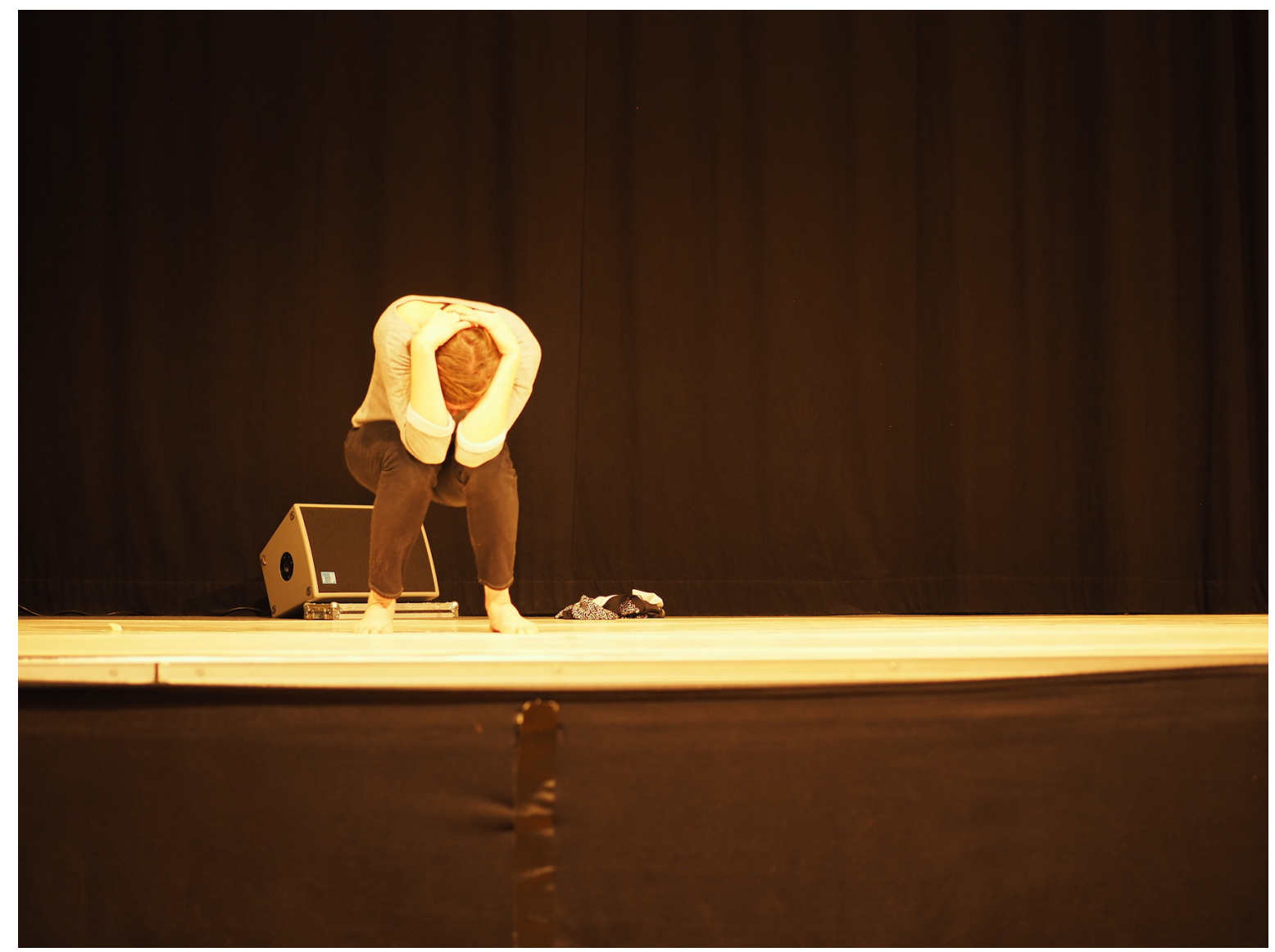

Zufit Simon in all about nothing, trilogy un-emotional

Moving Memory International Symposium-Festival, Berlin, Germany, 2016.

Photo: Layla Zami 


\subsubsection{1. all about nothing by Zufit Simon}

Zufit Simon spent two years producing the trilogy un-emotional, through which she investigates the interrelation between body language and emotional expression. The piece all about nothing constitutes the second section of the trilogy. According to the artist's synopsis, the solo is a collage made up of her personal memories, which requires the audience to project their own emotions and memories onto it. ${ }^{42}$ Emotions, traumata and movement seem to be the triangle within which Zufit Simon moves in this trilogy and in other works. As a matter of fact, she also choreographed a piece entitled Meine Mischpuche, in which she deals with the emotional "chain reaction" of memory transmission within family relationships. In the interview which you will find in chapter 5 , Simon expresses her concern for postmemorial beings, and the ways our lives are influenced by the decisions and movements of the generations before us, including voluntary and forced migrations. Simon's body of work clearly emerges from a selfquestioning process that deals with family relationships: the relationship between individual family members, the one between her family and the geohistorical site "Germany," and the relationship between her family's past and her own contemporary experience in Europe. These relationships materialize on stage in a corporeality marked by shifting positionings, fragility and humor.

I attended all about nothing twice: at the schwere reiter theater in Munich in 2014, where the dancer performed with the live-electronic mixing of musician Roberto Merdo, and at the Berlin Technical University for the closing of Moving Memory. ${ }^{43}$ Sitting among the audience in Munich, I met Simon's parents, who had travelled from Israel to attend the premiere. After this intense and painful piece, I wondered how they felt about witnessing their daughter performing at a venue in Dachauerstrasse, located on the route from Munich to the former concentration camp of Dachau, given their own history of flight. The tango of memory and emotion is omnipresent in Zufit Simon's work as a whole. Memory in her view is a heavy emotional weight that individuals can never get rid off, almost a burden:

Memories are like a bag of emotions that we carry everywhere, no matter where we go, whether we are sleeping or awake...[Memory] is what we always take with us, that which influences our character, how we act, react. That is something one can never let go of, never get rid of.

\footnotetext{
${ }^{42}$ Simon, "All about Nothing."

43 "Moving Memory" was an international transdisciplinary academic symposium and performance festival held from October 20th to 22nd at the Technical University in Berlin. I initiated and co-chaired the event together with Oxana Chi. See "Moving Memory - International Symposium-Festival."
} 
(Erinnerungen sind wie ein Sack von Emotionen, die wir überall tragen, egal wohin wir gehen, egal ob wir schlafen oder wach sind, das ist etwas das wir immer mitnehmen und das beeinflusst unser Charakter, wie wir agieren, reagieren. Das ist etwas, dass man nie loslassen kann, nie loswerden kann. $)^{44}$

Zufit Simon's choreographic identity is marked by a dynamic appropriation of the stage space, a minimalist aesthetics and a physical body language drawing from European modern and contemporary dance. Although thoroughly crafted, the choreography seems to allow enough room for improvisation, in terms of how long and how intense each sequence becomes. all about nothing courageously embraces the asymmetry between "our own fragile corporeality and a constructive engagement with the fragile corporeality of others," ${ }^{45}$ as Naomi Mandel calls it in Against the Unspeakable: Complicity, the Holocaust, and Slavery in America. At the beginning and at the end of the piece, the performer makes use of a prop: a microphone on a stand. The contrast between the utterance of the words "I am so happy to be here," "I am so glad you all came," and the expression of the body (collapsing, crying, shaking), and constantly changing facial expression, demonstrates that the texture of emotions is indeed unspeakable. When she returns to the microphone at the end of the piece, about to speak, it is now clear that everything has been said, albeit not through words. Maybe the body can speak better than the voice? Surely Simon makes the unspeakable dance-able.

After attending the Munich premiere on June $26^{\text {th }}, 2014$, I wrote these lines in my research diary. Allow me to share them in my own English translation, followed by the original German text:

pain, pain, PAIN! is what Zufit danced tonight, in her solo all about nothing. The painful movements of the body: spasms, never-ending staccato that shake the solar plexus and the body as a whole, the tearless crying... What I saw was trauma, traces of trauma, archived on the body and directing the whole piece. How deep, how wide, how far, how close - in terms of time - were these trauma coming from?

The performance transmits the feeling of a disturbed society, which represses its disorder by brutalizing its bodies. Simon did not seem to repress her feelings, rather she perforMemories them to the outer edge. She reveals the dishonesty of our daily environment. The spasms on her face also remind me of the workings of medicine, and of a system that drowns its issues in anti-depression-cocktails. I see a face that can only smile for a fraction of a second, a smile that seems merely mechanical, like everything else in our automated era, a smile that is merely machinery, like the deportations in this very place a few decades ago.

\footnotetext{
${ }^{44}$ Simon, interview [My translation].

${ }^{45}$ Mandel, Against the Unspeakable, 24.
} 
At first the dancer sat on the side of the stage and watched us in the audience as we stepped into the performance space. She reversed the gaze by observing those that had come to observe. Suddenly, she took off her jacket and erupted into the performance. She placed a microphone on stage, which she would only use at the end of the piece. Was she expressing what Kien Nghi Ha calls the 'aufgedrückte Schweigen' (silence pressed onto) the German society? Or the limitation of words in relation to a deeper, clearer, moving, inner bodily expression through dance?

The dancer externalizes internalized emotions through her embodied perforMemory. In the program notes, she invites the audience to complete what they see with their own memories. Which memories come to my mind, my body sitting still while she is dancing at high-speed?

(schmerz, schmerz, SCHMERZ! tanzte Zufit heute abend, in dem solo all about nothing. Wie schmerzhaft die Bewegungen den Körper bewegten. Die Spasmen, die unaufhörlichen staccato, die mal die Brust mal den gesamten Body durchzuckten, tränengeschüttelt. Die Spasmen erinnerten/erinnern mich auch an Traumata, wie eine kette von unkontrollierbaren spuren, Trauma, die im Körper archiviert sind und die gesamte Handlung durchziehen. Wie tief, wie weit, wie fern, wie nah - zeitlich gesehen - liegen die Trauma zurück ? Es ist unsagbar.

Der Tanz vermittelt mir eindrücke einer gestörten Gesellschaft, die ihre Brutalität im Körper be_drückt. Diese gefühle unterdrückt Zufit nichts, ganz im gegen teil, sie performt sie, stellt sie zur extremen dar. Sie offenbart ausserdem die Verlogenheit unserer alltagsweltlichen. Die Spasmen in Zufits Gesicht verraten auch eine Andeutung auf Medikament-süchtige Systeme, die ihre Probleme in Antidepressiven zu ertrinken versuchen. Ein Gesicht, welches nicht länger als eine Fraktion von Sekunden lächeln kann, ein lächeln, welches nur noch mechanisch ist, wie alles in dieser automatisierten zertalter und wie damals auch die Abtransporte.

Am Anfang hat Zufit rasch ihre Jacke ausgezogen und explosiv losgetanzt nachdem sie von der Bühne aus sitzend beobachtete, wie das Publikum eingelassen wird und Platz nimmt. Sie stellt ein mikro- auf, welches sie aber erst viel später im stück verwendet. Drückt sie somit das 'aufgedrückte Schweigen' der deutschen Gesellschaft wie es Kien Nghi Ha nennt? Oder die Begrenztheit der wörtlichen Sprache gegenüber eine viel tiefere, klare, bewegende, innige Körpersprache?

Zufits verkörpert verinnerlichten Emotionen live, sie lädt laut Programmzettel das Publikum ein, ihre Darstellung mit eigenen Erinnerungen aufzufüllen. Welche Erinnerungen kommen in mir hervor, die so still sitze während Zufit im Höchsttempo tanzt?) ${ }^{46}$

${ }^{46}$ Zami, "Research Diary - Unpublished Manuscript” Munich, 28.06.2014. 


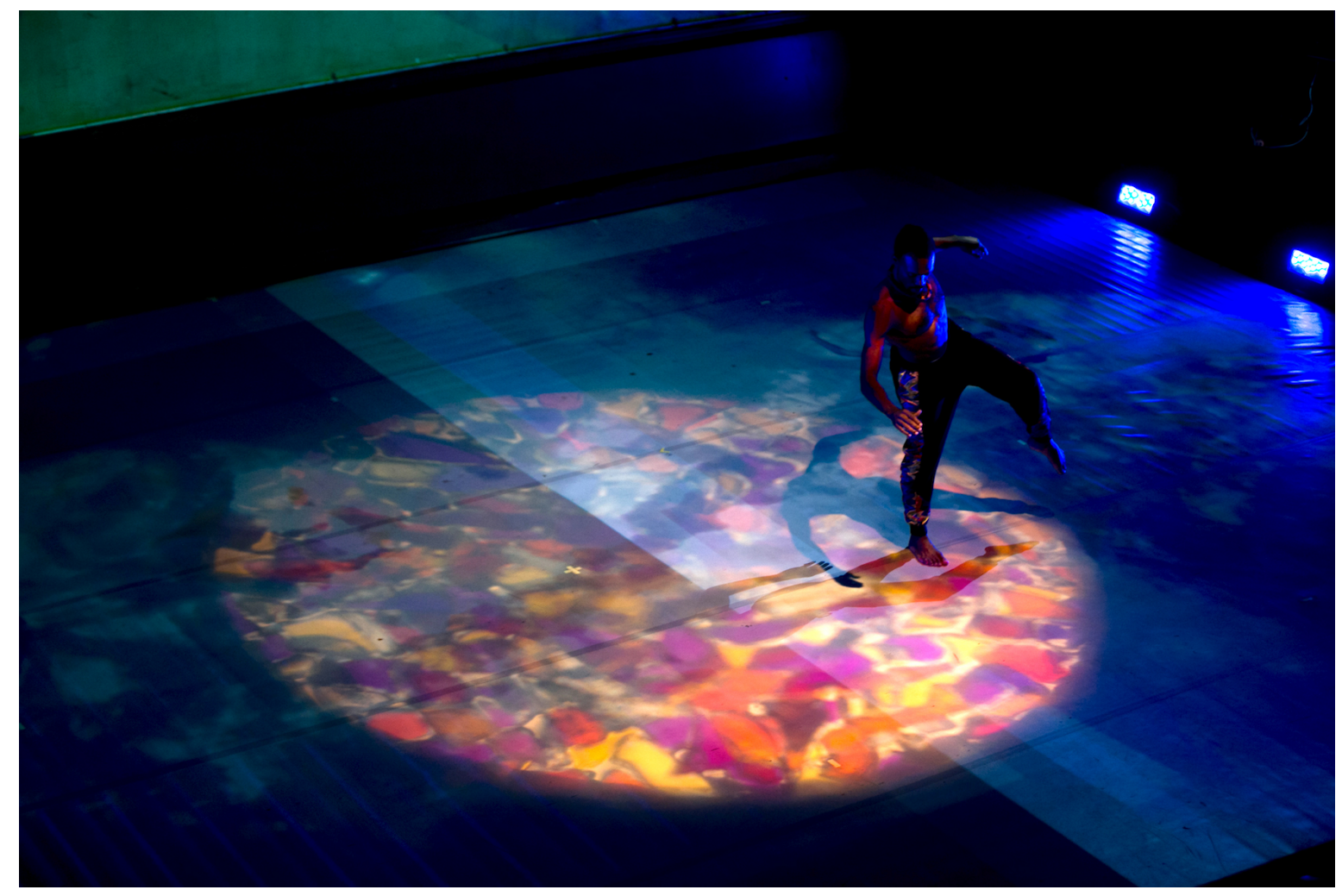

André M. Zachery in Digital Middle Passage, Afrofuturism Series Irondale Center, New York, USA, 2016.

Photo: Kearra Gopee @ $\odot$ André Zachery 


\subsubsection{Digital Middle Passage by André M. Zachery}

When Zachery dances with his Renegade Performance Group (RPG), the cast often consists of agile performers identifying as Black women/women of color, such as Nehemoyia Young and Candace Thompson. In another piece, Dapline!, created in collaboration with visual artist LaMont Hamilton, Zachery worked with six Black cis-men of various backgrounds in terms of class, formation and age. The piece aimed "to show how at the root of dapping [a practice associated with Black masculinity], there is a constant response of intimate understanding and connection in the face of oppression." ${ }^{47}$ In both cases, Zachery challenges hegemonic gender representations, by departing from the gendered roles usually assigned to female* and male* bodies in the contemporary dance world. Instead, RPG's dances often convey the power of the Black female body, as much as they allow for a Black-male-identified body to embody vulnerability, or same-sex solidarity and affection.

In his solo Digital Middle Passage, Zachery departs from his signature group choreographies, and travels alone through Black diasporic presence as a site of movement. The piece moves through watery metaphors across spacetime boundaries, revolving around the malleable orbit of blackness. As the title suggests, the dance recreates, re-imagines and re-traverses the Middle Passage between the African and the American continent. The word "Digital" signposts a location in the 21 st century, reflected in the use of contemporary digital technology in music composed by Yvonne K. Paredes and for media projections devised by the choreographer himself. André M. Zachery is both a dancer-choreographer and a multimedia artist. He conceived the piece as part of the Afrofuturism Series, whose purpose he describes as follows:

As an interdisciplinary artist, I have developed an interest in investigating the presence of the Black body as a medium of political and artistic expression through performance and technology. In what ways could one reimagine and recontextualize the images, legends, myths, symbols, lineages, practices, and stories of blackness (or, more specifically, Africanism) through dance and performance? Do we need permission to remix these materials? What new questions are we asking? In what new ways are we asking the questions? Are we excited to use technology? Can we use technology to express or reflect our spiritual and ancestral connection? What can be gained by using technology? What will be lost? ${ }^{48}$

When I attended the premiere, the solo was part of the Untitled Distances program, in between two group works choreographed by RPG. The music was performed by a cellist

\footnotetext{
${ }^{47}$ Zachery, "Renegade Performance Group."

${ }^{48}$ Zachery, "Futurity and the Containment of Blackness in Twenty-First-Century Performance," 64-65.
} 
and an electronic sound designer. The performance indeed materialized a multimedial and multisensorial dancescape. It felt rather surreal to watch the performer evolve through a dancescape inhabited by his multimedial projections projected onto the ancient walls of the Irondale Church in Brooklyn. The feeling of "going under" in order to re-emerge, as he later explained in the interview, ${ }^{49}$ strongly came across to me as an audience member.

Zachery surfaces on the dance stage the submerged history of Afrodiasporic mobile resistance, which re-emerges in various contexts, even in the widely popular zumba and dancehall in today's dance studio. Although RPG's contemporary dance aesthetics do not at all bear affinities with popular dance, parallels can be traced in terms of cross-temporal connections. For instance, in dancehall, single moves simulate shuffling with the arms or walking with chains, thus revealing a genealogy that can be traced back to the Transatlantic Slave Trade. The Caribbean "limbo" dance emerged from what is still known today as the "slave-ship dance." It testifies to the long history of moving resistance, and of the use of movement already on the unstable vessels crossing the ocean, a search for balance that becomes visible in Zachery's movements. Geneviève Fabre explains how the slave-ship dance combines improvisation and intention to physically imagine what it may mean to escape from the "prison of history." ${ }^{0}$ In her account, this dance is imbued with agency and empowerment. The historical performance "was a creative and daring act that proclaimed, with the sovereignty of the body, the vibrant intensity of one's imagining power."51

This description bears affinities with the spirit of Digital Middle Passage. André M. Zachery uses the power of imagination to re-imagine the power that his ancestors deployed to survive the slave ship journey, leading to his existence in the age of technology. Digging up ancestral memory, he seems to gain an unyielding power to jump up. A press article summarizes the piece as follows:

In twenty minutes, Zachery moved across the stage embodying the horror of the Middle Passage, displaying signs of power and agency and later, struggle and capture. ${ }^{52}$

The piece reflects the dancer-choreographer's taste for physical performance. It shows the artist work through a conceptual dance score requiring strong technique and the will to improvise. Despite its abstract body language and the use of contemporary techniques such as Flying-Low, ${ }^{53}$ and his own derived technique of Physical Propulsion, the performance is anchored in representations of the Middle Passage. However, it flows

\footnotetext{
${ }^{49}$ Zachery, interview.

${ }^{50}$ Fabre, "The Slave Ship Dance," 42.

${ }^{51}$ Fabre, 44.

${ }^{52}$ Tighe, "Middle Passage in Twenty Minutes: The AFROFUTURISM Series."

${ }^{53}$ Zambrano, "Flying-Low - Dance Technique."
} 
alongside mainstream depictions of this era, producing an Afrofuturistic experience that is, in the dancer's own words:

a self-exploratory work that was a true linking of past, present and future ideologies, [...] and concepts surrounding my own cultural heritage and my own experiences from traveling, researching, and interactions with experiences of blackness around the globe, and what that means moving forward. ${ }^{54}$

Rather than resting on a linear narrative, Digital Middle Passage moves through dramaturgical ebb and flow, alternating high energy sequences and slow moments of mindfulness. Zachery occupies the whole stage, while simultaneously crossing the stage from right to left in a directional orientation. He thus moves across the western conventional sense of reading from left to right. He surely does not seem to move backward. Is he returning to a Black future?

\subsubsection{Dancing without borders: geopolitical and physical islands}

The three remaining pieces I wish to introduce here are paradoxically grounded in displacement. Here, the movements explore what it means to transgress geopolitical, physical and cultural borders. While displacement is a leitmotiv in Digital Middle Passage, and all other solos, it takes on a peculiar shape in the following pieces, in which the performers experience the alienation of living on an island, be it a geographic or a political one. In Wan-Chao Chang's words, these performances express "how physical displacement can transform people and their surroundings." 55 The displacement takes various shapes: Wan-Chao Chang deals with her experience of being a more or less voluntary migrant, a nomad traveling from her place of birth, Taiwan (itself the home of displaced Chinese people) to Indonesia (to where her parents emigrated), and the USA (to where she emigrated as an adult). Christiane Emmanuel identifies herself and her dance with the creolized experience, with the desire to erase geocultural borders, and to blend her Caribbean-European-African cultural heritages into one tiny spot: the island of Martinique. Farah Saleh, a Palestinian citizen who has lived in Jordan, Syria, Italy, France, translates onto her body what it means to "be the border," in the words of Widad Amra quoted at the beginning of this chapter. Saleh asks how physical walls and checkpoints impact such fundamental human needs as love. The three solos are strongly

\footnotetext{
${ }^{54}$ Zachery, interview.

${ }^{55}$ Program Notes to the performance at Cowell Theatre San Francisco in October 2010. See Chang, "WanChao Dance."
} 
affected by the political context of the places in which they were produced. They are informed by and transform geographic notions of space and place. In my interpretation, they embrace dance as a means of leapfrogging physical and mental feelings of containment. 


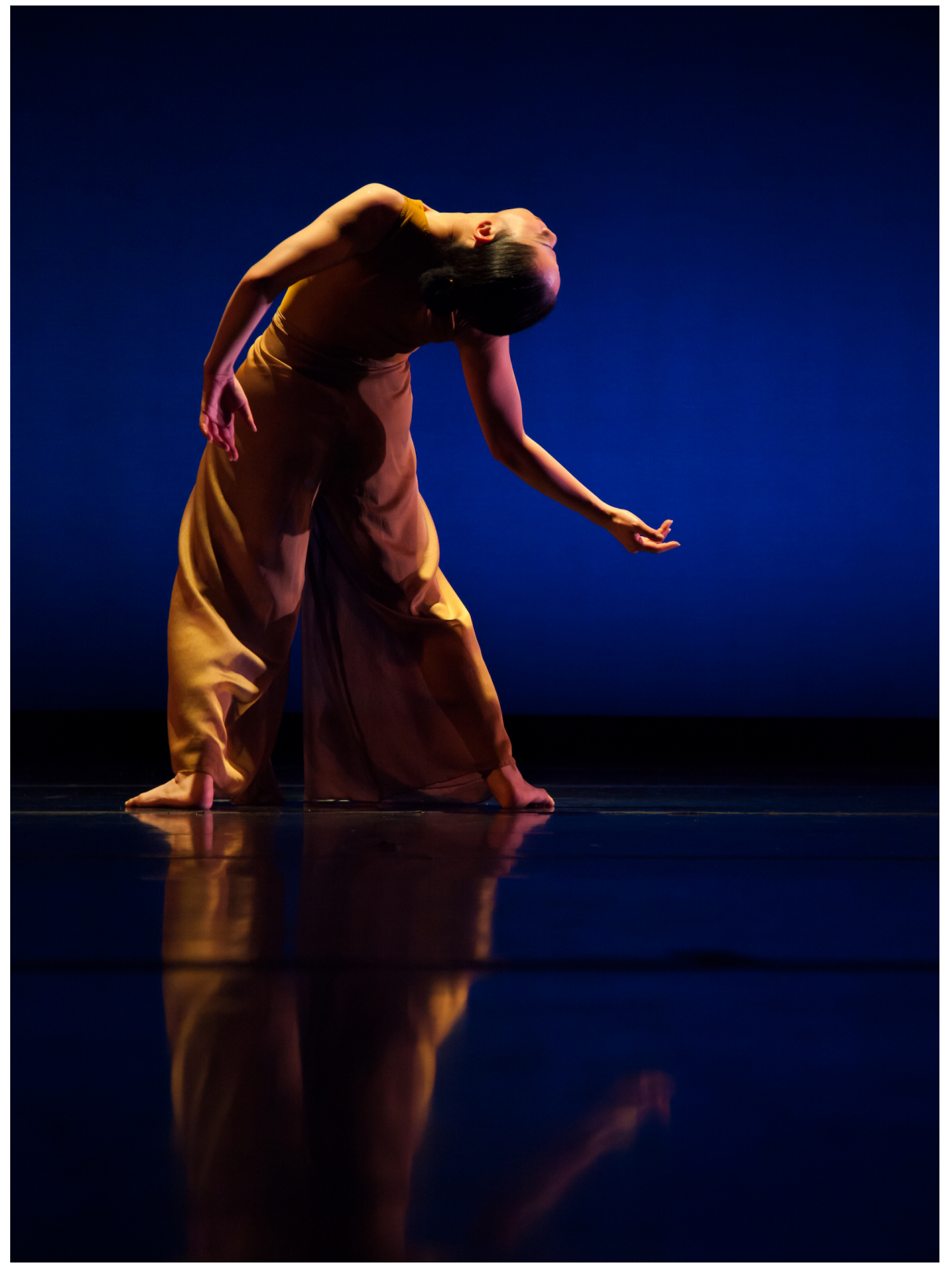

\section{Wan-Chao Chang}

Cowell Theater at Fort Mason, San Francisco, USA, 2010.

(c) Shalon Mormsby 


\subsubsection{Impressions by Wan-Chao Chang}

Dancer-choreographer Wan-Chao Chang produced Impressions upon returning to her place of birth, Taiwan, after having spent 15 years in the San Francisco Bay Area. The piece is truly diasporacentric, reflecting Chang's personal approach to mixing Indonesian, Chinese, West Asian, Balkan and American dance vocabularies. As explained on her website, the solo "describes the inner and outer journey one has to make when seeking one's cross-continental roots." ${ }^{56}$ The dancer wishes to translate into movement the multisensorial, disorientating experience of returning to one's home place. Landmarks shift, or vanish; and locational and temporal stability is missing, or shaking, as evoked in her artist's statement in English and Chinese:

\section{繁忙的台北街頭, 蜂擁車陣人潮, 不間斷的車聲人語。她，獨自佇立街頭。 曾經懷抱夢想而離鄉探索, 走過舊金山, 行吟巴爾幹, 著迷於印尼的多面, 終在西亞 流連徘徊。不同的臉孔川流而過, 最後卻再也分不清誰是誰... 再回到故鄉, 已認不清身在何處。只想撥開層層吵雜的策幕找塊安靜的地方落腳, 卻 壓不住腦海中一幕幕過往神遊的畫面, 起身再度漫遊...}

The crowds, noises, lights, the smog of Taipei! I am foraging my hometown for a quiet place to settle, but sequences from my past journeys keep coming back before my eyes...And then I find myself: once again I am walking toward the unknown... ${ }^{57}$

Chang performed the piece to a combination of live-music and computer-generated sounds, both composed and performed by Klaus Bru. Diasporic re-search, nomadic (in)stability and identity-formation form the core of her concert dance productions. The dancer conceived Impressions as a choreographic family album in which she recalls images from her past homes and migrating trajectories. Thus, it handles her own migrations to Java and her 15 years' stay as a migrant in the Bay Area (where she taught at the San Francisco State University), and her return to Taiwan. While in the group work Keep Her Safe, Please!, she blurred the boundaries between her own life and her parents' experience of migrations through Taiwan and Indonesia, here she zooms in on her solo life and movements. The choreographer consciously grapples with her complex relationship towards Taiwan, where she no longer feels - or never felt - at home. Her work also registers her complex relationship to Java, a place where her family experienced discrimination but which is simultaneously a place of deep inspiration for her dance art. ${ }^{58}$

As a solo dancer, Chang's stage presence is elegant, delicate and swift, as noted by journalist Renée Renouf:

\footnotetext{
${ }^{56}$ Chang, "Impressions."

${ }^{57}$ Chang.

${ }^{58}$ Chang, interview.
} 
[...] the graceful arms and gestures of Wan Chao Chang illustrated the narration via silhouette, torso reclining, swaying in memory, compliant, yearning [...], Wan Chao emerged once or twice, moving with her characteristic slender grace. ${ }^{59}$

Chang uses these aesthetics to address the recurrent question that seems to haunt her work: "Where is my home?" When words cannot provide an answer, Chang dances the worlds opened up by this question, and inhabits the stage as a world worth living in. 


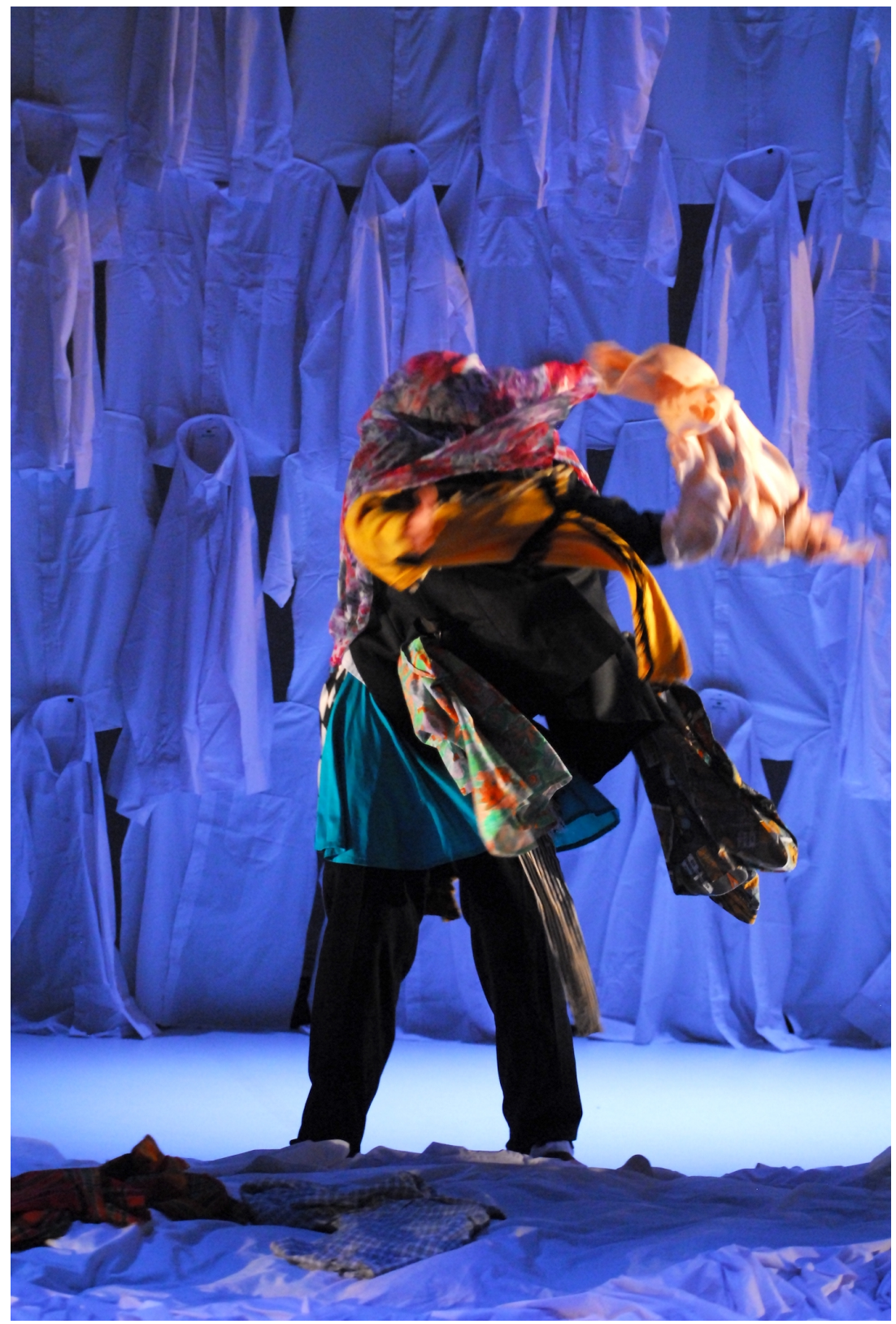

Christiane Emmanuel in Choc(s)

Atrium Theater, Fort-de-France, Martinique, 2010.

Photo: Wilfrid Tereau (c) Christiane Emmanuel 


\subsubsection{Choc(s) by Christiane Emmanuel}

This solo work is a gem in the repertory of Christiane Emmanuel. Here again, traveling through displacement seems to be the leitmotiv. The piece "questions the memory of the body, its present and creates its evolution." ${ }^{60}$ In her artist's statement, the choreographer reflects upon the relation between the tremors that shake the earth materially and metaphorically. Her standpoint is the volcanic island of Martinique, where her practice is anchored:

As our planet oscillates between economic turmoils, societal crisis and human clamors, these events make me question the evolution of our world and more specifically of Martinique, island enamored of the wind breeze and which no longer smells beautifully of vanilla. [...] I am crossing through my memory and thinking of all the big dates of history and to all of those who fought, so I am clinging on.

(Alors que notre planète oscille entre bouleversements économiques, crise sociétale et crise de l'humain, ces événements m'interpellent sur le devenir de notre monde et plus particulièrement celui de la Martinique, île amoureuse du vent et qui ne sent plus bon la vanille. [...] je traverse ma mémoire et je pense à toutes ces grandes dates de l'histoire et à tous ceux qui se sont battus, et je me raccroche. $)^{61}$

What $\operatorname{Choc}(s)$ makes clear is that to perforMemory is to undertake an existentialist task. The dancer literally clings onto a piece of cloth hanging from the ceiling, and later dances through and dwells in piles of shirts in a resourceful scenography devised with the complicity of Martinican artist Valérie John. Using aerial work, Afro-Cuban and Martinican dance vocabulary, as well as contemporary imagery by David Gumbs, electronic music by Jeff Baillard, and live percussion by Daniel Dantin, Micky Télèphe and Marc Séraline, the piece condenses in a single event the plurality of economic, cultural, emotional, geotemporal shocks experienced by Emmanuel in the $21^{\text {st }}$ century.

Choc(s) was created in the context of the general strike, when the island was literally shut down in protest against French (neo)colonialism and Euro-American imperialism. The strikers protested against the astronomical prices of food and housing and the lack of professional prospects and agency for Black people. They aspired to reclaim control of the land and other resources still mostly in the hands of the former slave owners' descendants. The strike, taking place simultaneously in the neighboring country of Guadeloupe, was violently repressed by French military forces sent out to Martinique to ensure that the islands remained their private turf. In $\operatorname{Choc}(s)$, the dancer begins the piece high up in the air, and ends in a firm relationship to the ground, executing Cuban rumba

\footnotetext{
${ }^{60}$ Emmanuel, "Choc(s) - Artist Statement."

${ }^{61}$ Emmanuel [My translation].
} 
steps. In this evolution, I saw the tension between the will to move forward, to envision other possibilities and realities, and the necessity of remembering the past and knowing one's roots.

Awarded the regional Utopia Prize for Choreographic Creation in 2011, the piece reveals a visionary aspect of Emmanuel's dance art. Like Zachery and Loïal, Emmanuel is usually known for her group choreographies. A prolific artist, she has created several productions dealing with diverse topics, and sometimes entailing a memory aspect. For instance, Jazz Dousss is a piece dedicated to the jazz icon John Coltrane, in which a hiphop dancer encounters two contemporary dancers. An Kabel pou Lam is an ode to the painter Wifredo Lam which sets his work into motion, and bears affinities with West African dance-theater. These pieces, like $\operatorname{Choc}(s)$, live through a diasporacentric approach. In a context of physical and political confinement, the performances celebrate dance as the art of mobility. They affirm contemporary Caribbean identity as a diasporic reunion. African-American jazz dance, a Martinican folk dance tradition called bèlè, Cuban rhythms and contemporary European aesthetics coexist. In our personal conversation, Emmanuel summed up the essence of her practice as a choreographic negotiation of diasporic identity:

At the end of the day, I think that I choreograph our way of being, our way of being in Martinique, ways of moving...I think that unconsciously, it is inscribed in my choreographic dreams and creations...well, maybe it used to be unconsciously, but now I am conscious of it, because it is a recurrent theme! It all depends on the topic, if I am given a topic where one must dance an "i" letter, I think I would swing the "i," because we can not be a straight "i." We have too much to express! Our walk is musical, our body is an orchestra, whether you look at the hips, the feet, the knees, the positions, the posture, the head nods, the gestures, the placing of the hands...we are a complete orchestra, it is all about putting it in symbiosis to make a choreography out of it. ${ }^{62}$

Whether or not Emmanuel's statement can be read as essentialist, it touches upon the potentially empowering relation between bodily expression and political expression, between body memory and intellectual aspirations. Eventually, there is a circular dynamic between the choreographing of bodies defined as Martinican, and the use of choreography to define what Martinican identity means.

${ }^{62}$ Emmanuel, interview [My translation]. 


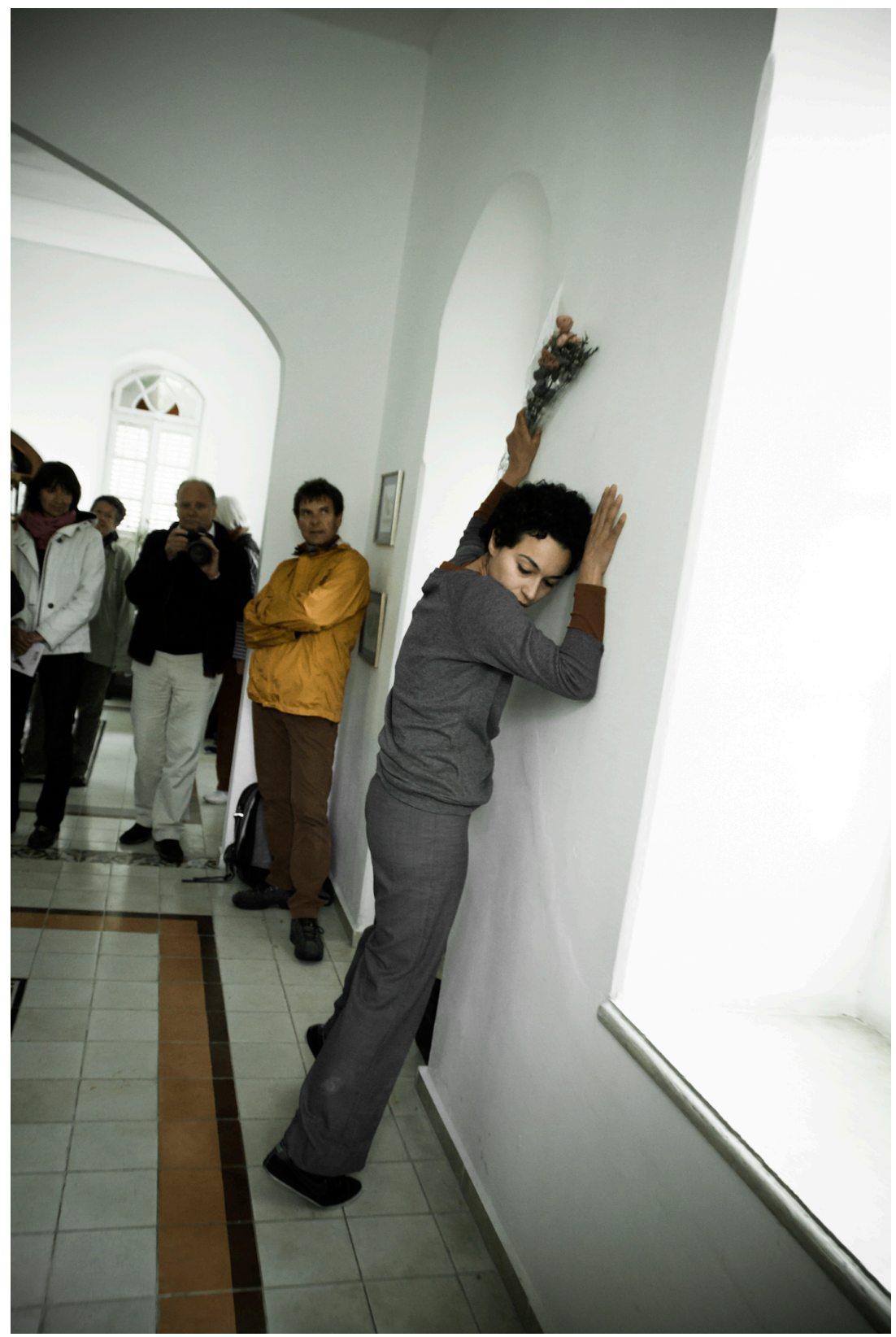

Farah Saleh in Parole, Parole, Parole

Miniatures Officinae Project, Ramallah, Palestine, 2013.

Photo: Nabil Darwish 


\subsubsection{Parole, Parole, Parole by Farah Saleh}

Farah Saleh's art is animated by the belief that dance can be "a daily form of resistance," as suggested by the title of the lecture she gave at the Tanzquartier in Vienna on May $9^{\text {th }}, 2014$. The lecture was preceded by her "miniature" (meaning a very short piece) performance called Parole, Parole, Parole. Saleh uses dance to represent the Palestinian experience of geographical and psychological dislocation resulting from the Occupation. This piece, her first solo work, which originally premiered in Ramallah, is not performed in a conventional stage setting.

As the audience walked into the performance venue, I observed the dancer standing in a corner of the room, trying to make eye contact with some of the guests. The border between performer and audience is abolished. This brings us back to the words of Widad Amra which open this chapter, about borders and questions without answers. Maybe because the performer engages with an ongoing conflict, memory was not a keyword in the personal conversation I held with her. The historical trauma of the Nakba is still ongoing, and therefore the memory performed is a daily, present memory. According to Saleh, war in Palestine is a daily concern, never only a past memory but always simultaneously an ever-present challenge. She also addresses this in other pieces, such as Sandwich Labné, evoking in a non-narrative way the story of two girls killed in the Gaza war, or Ordinary Madness. It is through my internet research, and my encounter with a press review about Ordinary Madness, that I encountered Saleh's work.

The choreographies of Saleh emphasize gestures, theatrical expressions and what is usually called task choreography in performance studies. ${ }^{63}$ She also explores gestures in dance video installations such as Cells of Illegal Education. ${ }^{64}$ Commenting on another piece, Ordinary Madness, she explains:

So that's why we use a lot of gestures from greetings, and daily life moments and relationships that are very distorted sometimes. And of course we talk in a very subtle way also about political divisions, internal political division and also the Israeli Occupation $[\ldots]^{65}$

Like Ordinary Madness, the solo Parole, Parole, Parole is situated in the timespace of the Israeli Occupation and moves through Palestinian experiences of it. The performance epitomizes and personifies the search for sanity and stability in the context of physical,

\footnotetext{
${ }^{63}$ Foster, Reading Choreography: Bodies and Subjects in Contemporary American Dance.

${ }^{64}$ During the First Intifada, the Israeli military called "Cells of Illegal Education" the civil disobedient groups who were resisting the closure of all schools and universities, and gathering to learn and teach. See Saleh and Bindler, Free Advice and an Interview with Farah Saleh.

${ }^{65}$ Saleh, "On Art Production as a Form of Daily Protest."
} 
psychological, intellectual and emotional pressure and fragmentation. Raja Shehadeh describes how "Saleh tried to express through movement how everything around us is changing and how we are becoming accustomed to it - or not." ${ }^{" 6}$ This comment is relevant to both pieces in my view.

Indeed, movement seems an appropriate medium to express constant change. The atmosphere shifts quickly, for instance, as a gesture born out of love may turn into a frantic, aggressive one. Or as a gesture of war such as throwing something over a wall is turned into a tender act of love. On the wall, there is a reprint of a stencil graffiti in which a person wearing a Palestinian scarf throws flowers instead of stones. Saleh's movements play with synchronicity, dynamism and tenderness. Embodying what it means to move through Palestinian daily life, she stands on her head, looking at her surroundings from a new perspective. 
The diversity of the seven artists' cultural heritages, from African-American to AfricanEuropean to Palestinian, to Southeast Asian and Jewish, and foremost the diversity of their artistic reflection and practice, does not preclude connections between their performances. In order to generate new knowledge on the topic of memory, I have intentionally associated works and artists seldom brought together within hegemonic aesthetic, choreographic, geohistorical or political delimitations.

Since dance requires the subtle coordination of the body-mind-soul triad, and works with specific attention to the self's movements through space and time, it is an art form particularly well-suited to handling displacement. This first section reveals that, regardless of the diverging contexts and aesthetics of the works, each work of perforMemory grounds the past in the present, and literally brings to the body and stage surfaces that may otherwise be buried in the archives. The repertoire of perforMemory can be archived.

The performances share the capacity to perform fragmented identities and trajectories, and to address them through the ability of the individual body to dance, in solo. Fabre argues that the historical slave ship dance "reenacts the tragedy of dismemberment and dislocation, [and] it stages the possibility of transformation through recollection, reassembly and movement." ${ }^{67}$ Similarly, perforMemory can be defined as a simultaneous embodiment of traumata and healing, of political oppression and rebellion. To perforMemory means to recollect within the single dancing body the fragments of recalled, imagined, and transformed memories, and to assemble divergent facts, emotions, and visions into the convergence of movement.

One of the strongest impressions I was left with from my own experience of being on stage as part of Oxana Chi's work of perforMemory, was the electric sensation one feels in the shift from the closed intimacy of rehearsal to the exposure to the audience's presence, regardless of the size of the venue. And in archival debates, presence matters. Let us return to the discussion of The Archive and the Repertoire which opened this section. For Taylor, presence is what singles out the repertoire and differentiates it from the archive:

The repertoire requires presence: people participate in the production and reproduction of knowledge by 'being there', being part of the transmission. [...] The repertoire both keeps and transforms choreographies of meaning. ${ }^{68}$

Besides the metaphorical use of the word "choreography," I find the emphasis on presence particularly relevant to my analysis. What is presence? First, it is the presence of dancers filling the stage with their magnetic energy and complex choreography.

\footnotetext{
${ }^{67}$ Fabre, "The Slave Ship Dance," 43.

${ }^{68}$ Taylor, The Archive and The Repertoire, 20.
} 
Second, it is the presence of an audience which makes the performance possible. Presence does not travel on one-way roads, rather it moves in loops, back and forth between the perfomer(s) and the audience. ${ }^{69}$

PerforMemory thus exists through presence and produces presence. In perforMemory, the dancer's repertoire overlaps with the historical repertoire of memory. A presence countering the absences of dis_remembering coexists with the contemporary presence of the dancer in their body, and on the stage. Presence is the common denominator to WanChao Chang's danced displacements, André Zachery's crossing of a digital Transatlantic axis, Christiane Emmanuel's multifaceted shocks, Oxana Chi's postmemorial choreobiography, Farah Saleh's artistic activism, Chantal Loïal's decolonial pride, and Zufit Simon's memory-emotions. PerforMemory begins and ends with the presence of the performer and its experience thereof by the audience, be it on stage or even off-stage, as in Farah Saleh's performance. Without the presence of the performer, there is no repertoire, neither a dance nor a memory.

Stage presence may unleash the magmatic force necessary to dig perforMemory out of absence. To dance is therefore to assert one's presence, an essential preoccupation for artists of color, especially queer ones. James Baldwin concludes his bewitching novel Just Above My Head by emphasizing the link between (counter)hegemonic power, history and presence:

To be forced to excavate a history is, also, to repudiate the concept of history, and the vocabulary in which history is written; for the written history is, and must be, merely the vocabulary of power, and power is history's most seductively attired false witness. And yet, the attempt, more, the necessity, to excavate a history, to find out the truth about oneself is motivated by the need to have the power to force others to recognize your presence, your right to be here. ${ }^{70}$

The word "excavate" evokes an earthy imagery that captures the spirit of my chapter. The quotation suggests the limits of archival, written history, to account for the past. It highlights the correspondence between power relations, mediums of memory transmission, and the search for historical and contemporary truth. The dancerschoreographers do not oblige audiences to see them, rather they offer them the possibility of experiencing their live arts. Rather than resorting (only) to conventional historiography, they use and create a kinesthetic vocabulary to perforMemory.

\footnotetext{
${ }^{69}$ See performance scholar Erika Fischer-Lichte on "autopoietische feedback-Schleife" in Fischer-Lichte, Ästhetik Des Performativen, 75.

${ }^{70}$ Baldwin, Just above My Head, 512 [My emphasis].
} 


\subsection{Memory as a Site of Movement}

\subsubsection{Performing memory in the age of Postmemory}

\subsubsection{Imagining perforMemory}

Reading Baldwin's Just Above My Head as a young teenager was a transformative experience. I had put it back on the shelf twice after getting through just a couple of pages, overcome by the difficulty of reading in my third language, English. One day - I cannot remember if it was a bright or a cloudy one - Baldwin's main protagonist, the gospel singer Arthur Montana, knocked at the door of my mind. His candid uncertainty brought our worlds - apparently so distant from one another - into proximity, obliterating spatial, temporal and social distances. Without Skype, we connected across the Queer Black Atlantic. Today, I may feel far more critical of or distant from the novel, however in that time and context, reading an openly Black gay author felt liberating. Arthur's story is narrated through the memories of his brother and work partner Hall Montana. Towards the end, Hall, burdened by the loss of his beloved brother, questions the function of memory:

I wonder, more and more, about what we call memory. The burden - the role - of memory is to clarify the event, to make it useful, even, to make it bearable. But memory is also what the imagination has made of the event. ${ }^{71}$

PerforMemory is a site of movement that one can navigate by using the currents of imagination. During and after the performance, the audience will re-imagine what the dancer "has made" of the historical event. Postmemorial artists use their imagination on a daily basis to transform events into stories, traumata into accounts, to counter absence and to perform presence. ${ }^{72}$ Restoring life to the past, they make every effort to render it accessible yet challenging, clear yet interlinked, bearable and possibly empowering.

If imagination seems to be the ground on which postmemorial artists move, it is also the oxygen that animates perforMemory. Imagination plays a particularly important role in choreographic process. In relation to corporeality and social transformation, dance is an inherently appropriate mode to imagine other selves, as noted by dancer-scholar Hélène Marquié:

\footnotetext{
${ }^{71}$ Baldwin, 567.

${ }^{72}$ Hirsch, The Generation of Postmemory, 18.
} 
To imagine is not to dream, but to feel/sense and experiment, to give oneself the possibility to be. [...] To dance, thus, is to become whom you imagine.

(Imaginer n'est pas rêver mais ressentir et expérimenter, se donner la possibilité d'être. [...] Danser, c'est donc devenir ce que l'on imagine. $)^{73}$

Consequently, dance can be a spacetime in which performers realize utopian futurities, a point we will return to in the chapter on time. Furthermore, Marquie notes that performing artists have resorted to dance to transform and transcend categories of identity, including gender, independently from and in parallel to critical theory such as queer studies. ${ }^{74}$ Considering that memory transmission, including transmission of historical memories, can best be understood as a construction of the imaginary, I find it particularly fascinating to look at dance performances that connect the imagination of other selves to the investigation of the past. Believing that the body is the site where traumatic memory is archived, it becomes even more compelling to look at the dancing body as a resourceful channel to re-imagine chronicled and prospective realities, what was and what is can be.

PerforMemory belongs to The Generation of Postmemory as defined by Marianne Hirsch. Like postmemory, the notion of perforMemory conceptualizes artistic embodiments of traumatic histories from a connective and affiliative perspective. It also shares with Hirsch's concept an extensive research scope, which brings together the European Holocaust, the Transatlantic Slave Trade or Maafa, the Nakba and other catastrophic experiences of (dis)humanity in order to better explain the workings of traumatic memory. Hirsch is interested in the memories transmitted intergenerationally within the family or through society at large:

Postmemory's connection to the past is thus actually mediated not by recall but by imaginative investment, projection, and creation. ${ }^{75}$

My analysis of perforMemory does not distinguish between "recalled" and inherited or appropriated memories. For instance, Farah Saleh's Parole, Parole, Parole solo does not necessarily stem from a remote time_space, but could just as well represent memory of everyday life in Palestine. Wan-Chao Chang performs her personal diasporic trajectories from Taïwan to the USA via Indonesia and back to Taïwan as well as the traumatic experiences of her parent's migrations as inherited through storytelling. Haïtian-AfroAmerican performer André M. Zachery activates ancestral memory of the Middle Passage while re-mixing it in the digital age and thus invites us into the process of his own contemporary experiences.

\footnotetext{
${ }^{73}$ Marquié, Non, la danse n'est pas un truc de filles !, 100 [My translation].

${ }^{74}$ Marquié, 101.

${ }^{75}$ Hirsch, The Generation of Postmemory, 3.
} 
Through Gardens and They Call You Venus are luminous examples of performances that re-imagine both historical biographies and the performers' selves. Both choreographers identify autobiographically with the figure they embody on stage, as you can sense from their interviews. Loïal identifies with the story of a Black woman who was excluded and discriminated against through western body norms, and with her struggle for corporeal and political freedom. Chi identifies with the art and story of a solo expressionist dancer, and with her struggles and success as a female artist of color, striving for visibility, recognition, and professional development in a difficult political context. She describes her dancing encounter with Barbakoff as follows:

What I noticed, and had already noticed earlier, was that dance historiography only accounts for certain persons, however humans with whom I can not identify. With this work Through Gardens, I could identify with a [historical dance] figure for the first time, namely Tatjana Barbakoff.

(Was mir aufgefallen ist, und mir aber auch schon früher aufgefallen ist, dass auch in der Tanzgeschichte es immer nur bestimmte Personen gibt, Menschen mit denen ich mich aber nicht identifizieren kann. Mit dieser Arbeit zu Durch Gärten konnte ich mich zum ersten Mal mit einer Figur identifizieren, nämlich mit Tatjana Barbakoff. $)^{76}$

What is at stake here is the role of sociopolitical power relations in general historiography, and more specifically in the formation of "dance history." Chi's work intentionally counters the "Ent_innerung," Although both pieces deal with a traumatic historical subject matter, their perforMemory is celebratory. Through her work of perforMemory, Chi shapes for herself the role model that institutional memory denied her. Crossing the line between autobiography, genealogy and historical memory, Through Gardens and They Call You Venus exemplify and generate what Marianne Hirsch calls "non appropriative identifications," which Hirsch identifies as a major challenge for "postmemorial artists":

$[T]$ o find the balance that allows the spectator to enter the image and to imagine the disaster, but that simultaneously disallows an overly appropriative identification that would make distances disappear and thus create too available, too easy an access to this particular past. $^{78}$

Both Loïal and Chi, for example, blur boundaries between their own and portrayed selves, and leap across the auto/biographical slash, yet trace distance with clear references to historical biographies in the program notes, the dramaturgy and their pre- or post-show discourses. Distance is also materialized in the theatrical settings and in the demarcation

\footnotetext{
${ }^{76}$ Chi, Oxana Chi [My translation].

${ }^{77} \mathrm{Ha}$, "Die Fragile Erinnerung Des Entinnerten."

${ }^{78}$ Hirsch, The Generation of Postmemory, 161.
} 
between audience and stage. "Balance," as Hirsch calls it, is also the physical and metaphorical feat devised by all dancers. (Dis-)equilibrium pervades both Christiane Emmanuel's Choc(s) and André Zachery's Digital Middle Passage, whose dances seem to search for a ground to stand on. Emmanuel does so by descending down from several feet above the stage. Zachery's spiral kinesthetics pierce across the stage, assembling the energies of capoeira-like movements to his very own technique of jumping.

Visual art and literature offer cultural lenses that may be applied to performance. For instance, Hirsch's discussion of the materiality and tactility of photographic family albums evokes for me Zufit Simon dancing her Mischpuche on clay eggs, and Wan-Chao Chang's piece, which creates the impression of family albums in movement. ${ }^{79}$ The notions of displacement, cropping, ellipses and repetition also exist in choreographic practices, as we will see in the chapter on time_space narratives. In dance, essentially the art of dis/placing bodies through space and time, choreographic dramaturgy nourishes itself through ellipses and repetitions. ${ }^{80}$ Pieces like Through Gardens condense centuries of history and gigantic memory dancescapes into one or several moving bodies. PerforMemory exists in this realm, and challenges one to reconsider magmatic explosions of memory. At this point two questions arise, which will be addressed throughout the book: if perforMemory is a form of postmemory, what is then specific to perforMemory? How does the focus on concert dance influence perforMemory?

\subsubsection{Moving center stage}

Memory is above our heads, behind our backs, at our feet and in front of us. I share with Jill Dolan the belief that the theater is the space where performance brings utopia into existence. ${ }^{81}$ The dancers discussed in this study diverge from dominant norms in terms of either/or gender, race, sexual identity and class. Their artistic processes and products also do not aspire to replicate dominant models. While utopia and performance can (co-)exist outside of the theater (as astutely suggested, for instance, by Queer Latinx scholars such as Muñoz and Rivera-Servera), ${ }^{82}$ I focus on the stage space by analyzing the moving research matter of concert dance. The stage is no ordinary space to occupy, as I know from my own experience as a live performer. Dance can display and enact tension, release, balance, accents, pace, coherence, fragmentation, emotionality and multiplicity in ways that diverge from other art worlds through its visceral embodiment.

\footnotetext{
${ }^{79}$ Chang, "Impressions."

${ }^{80}$ On patterns, archive and African diaspora, see Campt, Image Matters, 2012.

${ }^{81}$ See introduction. Dolan, Utopia in Performance.

${ }^{82}$ Muñoz, DISIDENTIFICATIONS. Queers of Color and the Performance of Politics; Ramón H. Rivera-Servera, Performing Queer Latinidad.
} 
Hence, dance on stage potentially performs memory in a very distinctive mode, a corporeal one. What is striking and decisive is the interaction between the "expressive" and "liberating" potential of moving bodies on stage, ${ }^{83}$ and what it implies for the writing of historical narratives.

As explained in the introduction, I focus on performances that take place in theatrical venues. Because I look at bodies that carry long and ongoing legacies of enforced invisibility that persists in the present spacetime, ${ }^{84} \mathrm{I}$ am particularly interested in the negotiation of visibility happening in concert dance. I am interested in performances that consciously move center stage and contest how the past is being written and the present is being ruled. In this I refer to the work of Nadine George-Graves, who writes about the Urban Bush Women dance company:

I argue that by creating characters who exist in alternate realities and characters who represent entire populations, the company is attempting to rewrite master narratives. ${ }^{85}$

This argument can be made for the performances discussed here as well. For instance, in their respective works, Impressions and Digital Middle Passage, Chang and Zachery create an alternate reality constituted by their ancestral and/or family memories. In this reality, they are the only presence on stage. As leading-roles, they guide us through the story that unfolds as they dance it. Zachery re-inscribes American history from a Black, cis-male perspective, and his single performing body crossing the stage expresses the condition of millions of diasporic subjects. Farah Saleh dances a character who represents the Palestinian people, and the im-possibility of living a normal life. In another work, Ordinary Madness, Saleh and her performers perform the checkpoint situation, transforming it into an emotional roller coaster, where gestures expand ad absurdum. In Choc(s), Christiane Emmanuel performs an endless circular trajectory (tourner en rond), materializing physically her vision of the island's political situation.

In the realm of drama, Harry Elam developed the concept of "(w)righting history" in reference to German-African-American playwright August Wilson and his cycle of plays on several eras of African-American history. ${ }^{86}$ To (w)right history is to refute "master" narratives, and to imagine other ways of assessing and telling history. PerforMemory "(w)rights" history "within the space and through the agency of performance" 87 at the prime level of its making: the human body and its motion. In Through Gardens and They Call You Venus, the protagonist's body dances beyond its own death, thus generating an

\footnotetext{
${ }^{83}$ Zenenga, "Power and the Body," 66.

${ }^{84}$ See also Chatterjea, Butting Out.

${ }^{85}$ George-Graves, Urban Bush Women, 72.

${ }^{86}$ Harry J. Jr Elam, The Past as Present in the Drama of August Wilson, 3-4.

${ }^{87}$ Harry J. Jr Elam, 14.
} 
alternate reality in which there is an afterlife of motion after oppression. In the German context, Through Gardens contests the "master narrative" of the Holocaust - which minimizes or negates the agency of both perpetrators and victims, and objectifies the people who were deported. The choreographer re-inscribes women of color out of erasure. In all of her recent repertoire, Chi embodies a leading protagonist who exists in an alternate reality but is connected to existing power relations. In Neferet iti for instance, Chi plays with the codes of museum display, shifting the audience's gaze to itself, returning the gaze, blurring the boundaries between the objects and subjects of the gaze. Her beginning pose evokes for a moment the ubiquitous display of non-western art and culture in museums in the west. The pose sets itself in motion, and the statue begins to trace a solar trajectory with outstretched arms. It could be the hours of a day or a century passing as visitors pass by the statue of Neferet iti. The statue comes to life, the representation of the pharaoh becomes the pharaoh, the dancer becomes Neferet iti. The usual one-sidedness of museum displays is transformed into an encounter, the usual immobility of the displayed is infused with movement and the figure even sets down her crown on the head of one of the audience members. Constantly embodying a story moving away from "history," she becomes a center stage character full of agency, verve, fragile yet energetic, resourceful and open.

All of the performances embody personal stories related to collective histories. Moving beyond the mere representation of history, they create memory on stage, mourning absence and illuminating presence, refusing to let their characters - and thus their selves, drown in mainstream narratives of history.

\subsubsection{Embodying history, HERstory, theirstories}

If you think of the connection between dance, history, and memory, depending on the generation and location you belong to, you may think of Opiyo Okach's Cleansing. Choreographed for his Compagnie Gaarà, the piece premiered in Nairobi in 1997 and was performed by Okach with German-Ethiopian dancer Afrah Tenambergen and Congolese dancer Faustin Linyekula. While Linyekula is now quite famous within the European dance scene, most people ignore this foundational moment in his career. Opiyo's intent was to perform and question three realms of "cleansing": cleansing as a daily practice, as a spiritual ritual, and "as a quest for "purity" in such various contexts as the genocides in "Nazi Germany, Rwanda and Bosnia." ${ }^{88}$ The piece's innovative mix of contemporary and

${ }^{88}$ Okach, "Cleansing." 
traditional African performance art generated widespread interest from audiences and the media, and yet it remains absent from what is understood as the world dance history canon in the west. By bridging the distance between historical genocides usually thought of as remote from one another, Cleansing performs highly politicized memory.

Okach's whole repertoire, including his recent solo works such as Body Evidence and Border Border Express, articulate his consistent exploration of relationships between identity, space and world politics. I experienced Border Border Express at the HAU Theater in Berlin in 2013, shortly after having begun work on this research project. The dancer slowly wraps himself, in a circular motion, in a red-white plastic banner similar to those used in road construction to set boundaries. The gradual, almost indiscernible transformation of a stage prop into a spiritually infused costume reveals the capacity to use the body-in-movement to tell tales of migration, to cross imaginative and real borderlines and borderlands, to transport the audience into a spacetime that is located so intensely in the "now," beyond chronology and topography. I describe this image as a metaphor for the intertwining of presence, memory and choreography that occurs in the dances discussed here. Okach, like the other dancer-choreographers, possesses a powerful way of embodying presence on stage. To perforMemory can be understood as an interlacing of the threads of corporeal meaning, emotions, reflections, stories through movement.

\subsubsection{Defining choreography}

The idea of an enlacing choreography echoes Aimée Meredith Cox's definition of choreography as:

[...] embodied meaning making, physical storytelling, affective physicality, and an intellectualized response to the question of how movement might narrate texts that are not otherwise legible. ${ }^{89}$

In her study about the Choreography of Citizenship in , Cox discusses choreography as a metaphorical, sociological or anthropological analytical tool to read social contexts outside of the performing arts. Yet, her definition, perhaps because she herself is a trained dancer, is also relevant to the actual process of dance choreography. Her definition appeals to the essence of perforMemory, and more specifically the pieces discussed here, in their capacity to address and redress dominant historical narratives and memory discourses and practices.

${ }^{89}$ Cox, Shapeshifters, 28. 
In this definition, embodiment, physicality and movement are at the core of the choreographic process. By anchoring the story in the body and at the same time subverting bodily boundaries, choreographed movement expands the frame of interpretation by allowing for multiple meanings. Choreography makes it possible to embody history, telling unspeakable trauma without speaking, inscribing unwritten memories without writing, contesting points of view without being contentious. The ability of dance(rs) to perform feelings, realities, and imaginations that may otherwise not be expressed is evoked in Lou Straus-Ernst's 1933 interview with Tatjana Barbakoff during her exile in France. Straus-Ernst admires Barbakoff's ability to perform "a dancing expression for an inner truth which could not be told in other ways." 90 Today, Chi's perforMemory of Tatjana Barbakoff enacts this embodiment in the present. Embodying the story on stage, she sets history into motion, actually enacting the story as she performs it. In our personal communication, she expressed her will to challenge what I would call the casting in the (hi)storytelling movie:

I deemed it important to keep on researching and to find out: how does 'history' work in Germany? Who tells 'history'? How, when, and where is 'history' told? ${ }^{91}$

Thus, Through Gardens is a tribute, or a "femmage," a term she uses to disrupt the androcentrism of the word "hommage." Indeed, Oxana Chi's femmage-tribute to Tatjana Barbakoff tells a story outside of dominant history and performs the memory of a forgotten figure of dance historiography. The contextualizing information plays an important role in understanding a story without words. When I traveled to Indonesia in 2010, accompanying Chi's tour with a video camera, I was touched by the lively reactions of the audience and the strong interest from the press. She performed Through Gardens to an audience of 5000 at the open air festival Solo International Performing Arts, held on the volcanic island of Java. The hosts introduced the show in English and in Bahasa Indonesia with a succinct summary of the story of Tatjana Barbakoff. Although the Javanese audience surely knows about German history, they may frame it differently than people located in Europe, especially in Germany. Despite the apparent distance from their own histories, the audience's intense attention suggested their strong connection to the performance. Even if the plot might seem remote from their own history, body language leaps over spoken language barriers. The celebratory, meditative and dramatic aspects of the performance resonated for audiences at home with performed storytelling. As I was later to experience, dance occupies a pivotal position in Javanese culture, in which the stage is a popular setting for collective history and sociopolitical critique. Whether in Java, Paris or

${ }^{90}$ Straus-Ernst, "Bei Tatjana Barbakoff"; printed in Chi, Tanzende Erinnerungen, 2011, 16-19.

${ }^{91}$ Chi, Oxana Chi. 
Berlin, I witnessed people stirred by the core of choreography as defined earlier: Through Gardens used movement to transmit meaning beyond language, and beyond factual storytelling. The meaning embodied by the choreographer took on added dimensions as it reached each audience member and moved them to project onto the story their own meanings and memories. Thus, perforMemory invites a new perspective on the past, and incites a transformative experience of and in the present. Just as the shift of tectonic plates has repercussions on the earth's surface, the digging up of forgotten or silenced memories may impact the outer borders of memory itself, namely the social relations that shaped it.

\subsubsection{Between telling history and performing memory}

Women stand firmly on the ground, bent slightly forward. Standing upright with obliquely curved spines, chins parallel to the floor and gazing towards the horizon, they seem to be frozen in their march or movement. Ananya Chatterjea and Uttara Coorlawala interpret this choreographic sequence Sri, by Chandralekha, very differently. While Chatterjea reads the scene as a portrayal of gendered submission, Coorlawala sees powerful women demonstrating "an extreme exercise of strength, flexibility and willpower." ${ }^{22}$ The capacity of this scene to raise such divergent interpretations suggests the role of subjectivity in movement analysis. Both interpretations can be found in the dance studies reader moving history / dancing cultures, edited by Ann Dils and Ann Cooper Albright. In her own essay in this anthology, Albright asks what it would "mean to reinscribe history through one's body?"93

This question opens up reflections on diaspora, space, and time. The seven soli inscribe history onto the dance floor where they leave the trace of their bodies' movements. Dance carries the weight of agency. With this premise in mind, I argue that when choreographers tell stories inspired by the past (as known or imagined from books, stories, collective representations and individual memories), they do not merely represent a so-called history, they enact memory. This is where perforMemory lives: its very existence is bound to movement. Memory in this case does not exist outside of its performance. Echoing Albright, Lepecki asks:

Where does history rest, if at all? And how is history reawakened and put into motion? How is it that it finds its grounding, its pacing, its anatomy? ${ }^{94}$

\footnotetext{
${ }^{92}$ Coorlawala, "Ananya and Chandralekha," 399

${ }^{93}$ Cooper Albright, "Embodying History," 439.

${ }^{94}$ Lepecki, Exhausting Dance, 106.
} 
Lepecki wrote this in reference to a performance which seems problematic in terms of racial positionings. Yet, I find the imagery of historical anatomy quite fitting for the works of perforMemory. The pacing and movement anatomy will be surveyed in the chapter on time and movements. For now, l'd like to emphasize a choreohistoriographic approach to dance and memory. History as a word or concept, may sound like a classical western patriarchal capitalist heteronormative melody, which sounds a grating tune. Its tonic sound is the attempt to be "objective" that has characterized the field for so long. In contrast, the word "memory" is in deeper harmony with the body and allows for a range of complex, multilayered and non-competitive stories and positionings. Oxana Chi, as quoted in the introduction, feels compelled to produce dances that widen the "narrow radius" of what is usually called "history." Other feminists criticize the possessive "his," replacing it sometimes with terms such as "herstory" (which troubles androcentrism but still reproduces binary genderism). ${ }^{95}$ On this battlefield of history, Black feminists have constantly contested the white supremacist monopoly on the writing of history, just as Afro-centric activists have invited us to listen to how lions tell stories of the hunt. They have searched for the narratives that were buried, erased, or submerged. The task of perforMemory is to invest the body as the site of recuperation of these stories, and the site of production of new stories.

\subsubsection{Emotions in motion}

Queer theory recognizes the role played by emotions in allowing us to access personal memories and to engage with memory on a societal level, especially in relation to traumatic pasts. bell hooks, for instance, speaks of "the intertwinings of psychohistory," ${ }^{96}$ a term that accounts for the coexistence of facts and emotions. Working on embodiment and emotions, Sarah Ahmed scrutinizes - in the language of her title - the "cultural politics of emotions" such as fear, love and pain, and colors the "canonized" white pages of phenomenology with a queer of color critique. ${ }^{97}$ In her Archive of Feelings, Ann Cvetkovich redefines archival practices and materials, advocating for the inclusion of emotionality and ephemerality. By claiming that trauma "raises questions about what counts as an archive [and] what counts as a public culture," opens the door to new forms of documenting and understanding the past, and to new ways of rendering it meaningful for the present.

\footnotetext{
${ }^{95}$ For a detailed critique of genderism, see Hornscheidt, feministische w_orte.

${ }^{96}$ hooks and Mesa-Bains, Homegrown, 110.

${ }^{97}$ Ahmed, The Cultural Politics of Emotion.

${ }^{98}$ Cvetkovich, An Archive of Feelings, 10.
} 
Artists, and indeed dancer-choreographers, queer or not, have been working this out on stage before academics arrived at theorizing it on paper. Zufit Simon asks us to face fake, or contradictory emotions. What is particularly striking about Oxana Chi's embodiment of Tatjana Barbakoff is the emotional quality with which she invests movements and facial expressions, in the tradition of expressionist dance. Also, when Chantal Loïal performs the pain experienced by Sawtche and the postmortal joy of her remains returning to her ancestral land, she sets emotions into motion even while allowing space for interpretation. Both solos perforMemory other stories, what I prefer to call theirstories rather than history, namely by embodying historical women figures in works in which "subversion and critique are braided with celebration and creativity." 99

In her study of contemporary Aboriginal stage dance, Jacqueline Shea Murphy describes a similar embodied research process, in which the dance moves beyond the representation of historical events and becomes itself a historiographical process:

Rather than only recounting history through dance, this choreographing and choreography also presented itself as historical research tool and document. [...] a way of researching, an epistemological 'way of knowing', with theoretical insight and historical legitimacy, and as itself embodied documentation, with archival value. ${ }^{100}$

This description supports my claim that perforMemory can take the form of a choreobiography or choreohistoriography. The understanding of dance as a precious form of knowledge is deep-rooted among indigenous populations whose cultures have always been embedded in the correlation between life, art and knowledge transmission, as Shea Murphy notes. When I speak of perforMemory as a choreohistoriographic device, entwining choreography and historiography, scientific and artistic research, ${ }^{101} \mathrm{I}$ aim to highlight how dancers invite the past to flow into our present, in a way that is specific to their live art. Dancers themselves emphasize the "insight" and "legitimacy" of their practice, and challenge the assumption that only scholars theorize. They are also keen to translate body knowledge back into words, and deploy kinesthetic knowledge, as well as an acute awareness of the historical and emotional forces at play in their work, as the riveting interview transcripts demonstrate. For instance, André M. Zachery commented upon the link between choreographic imagination and bodily epistemology in his Digital Middle Passage:

I was actually more imagining that I had to re-submerge to almost get permission from the ancestors that were lost, on the voyage, in the sense that I had to literally

\footnotetext{
${ }^{99}$ Chatterjea, Butting Out, 187.

${ }^{100}$ Shea Murphy, The People Have Never Stopped Dancing, 10.

${ }^{101}$ Wehren, inspired herself by prior works, speaks of choreography as a historiographical practice, however she focuses here on dance historiography, not on memory in general: on the re-enactment of ancient choreographies through contemporary choreography. See Wehren, Körper als Archiv in Bewegung.
} 
almost drown myself, to find their spirits under the water, to then get permission to move forward. And so that's literally what the piece is about in a nutshell... and how literally we, I, collectively are preparing, getting ready to now move, to move forward. ${ }^{102}$

One could say that dancer-choreographer-André (Zachery) here responds to the above cited scholar-André (Lepecki). When history rests in movement, the choreographer reminds us, it is never at rest. Put into motion by dancers, it catalyzes a mixture of intricate choreographic composition and preparation and danced improvisation on stage. As Zachery articulates with such clarity, embodied epistemology sets shifting and interlocking (volcanic) layers of being into motion, enacting connections rather than divisions. Thus, for instance, the choreography-spirituality-history triad weave together inextricably in the works and words of so many of the choreographers in this study. Loss, and journeys of spiritual recovery, are leitmotivs in all seven pieces. ${ }^{103}$ So we spiral back to the beginning of this section. As bodies move on stage, they not only represent but perform contemporary and historical stories, spiritual connections and political feelings. Beyond interpreting how selected dancers embody "history," my research rather asks how they perform memory and how this may in turn impact power relations.

\subsubsection{Memory2go}

\subsubsection{Escaping and shaping memory}

Survivors of traumatic events, such as Child Survivors of the European Holocaust, often seem to travel through memory as a site of movement, and to envision it as a moving and movable "being." In their accounts, I often read about the distance required to re-member and translate their traumatic memories into an artwork, such as a literary novel, or a work in another medium that may be understood as art in the present time. For instance in Je me souviens, Boris Cyrulnik, who hid in France during the Nazi period, talks about the artistic process as a "détour," a roundabout way to produce "a representation that may now be shared" so that "we may now inhabit the same world." ${ }^{104}$ The détour is also a key concept in the work of Edouard Glissant on post-slavery Caribbean societies, ${ }^{105}$ in which the détour is an alternative to the impossibility of retour (return). This vision of

\footnotetext{
${ }^{102}$ Zachery, interview.

${ }^{103}$ On spirituality in the work of Ronald K. Brown, see Paris, "Reading 'Spirit' and the Dancing Body."

${ }^{104}$ Cyrulnik, Je Me Souviens, 80 [My translation].

${ }^{105}$ Glissant, Le Discours Antillais.
} 
memory as a world that may be inhabited is also inherent to Ruth Klüger's concept of "Zeitschaften":

Ortschaft, Landschaft, landscape, seascape - there should be the word timescape to transmit what a place is within time, to a certain time, neither before nor after.

(Ortschaft, Landschaft, landscape, seascape - das Wort Zeitschaft sollte es geben, um zu vermitteln, was ein Ort in der Zeit ist, zu einer gewissen Zeit, weder vorher noch nachher. $)^{106}$

PerforMemory is located afterwards and afterwords. Performance takes place in a specific timescape as much as it creates one. Klüger coined the word timescape - which, as far as she knew, did not exist in the German language - to assert the impossibility of conceiving of the concentration camp as a "place," as well as the impossibility of putting this traumatic experience into words afterwards. The dancescapes of perforMemory are also timescapes through which the audience moves, on a journey led by the dancer-choreographers.

The dancescapes of perforMemory, like Ruth Klüger's Zeitschaft, connect spatial and temporal realms. Dancescapes function metaphorically and materially. Zufit Simon fills the stage with clay eggs, building a landscape of fragility populated with shapes that may be seen as obstacles or supporting figures. Her bodily research investigates how the past trauma of her Jewish parents impacts her present. Digital Middle Passage transforms the stage into a wide seascape that Zachery traverses within the span of 30 minutes. Pulled irresistibly towards the ground - or the depths of the ocean - he dives into a maritime timescape, trying to "update" centuries of American slavery into his body moving in the Digital Age. Farah Saleh choreographs the timescapes of love when a Skype chat presents the only possibility of meeting, and overcoming checkpoints. In her Impressions, Wan-Chao Chang creates a physical border out of a red cloth, a boundary that she moves with, against and around as she recalls her own and her parents' geographic and cultural migrations.

Coming back to the topoi of the concentration camp, which appears in one scene of Through Gardens... I I I I । । । The blinking mouse on my laptop screen arrests my attention. As the clock ticks, I realize that I, too, am struggling to find words to write about this topos. After going out for a breath of fresh air, I come back to the writing, realizing that the words concentration camp, $K Z$, prevent me from moving forward. Recalling the agility Oxana Chi deploys in Through Gardens, I am struck once again by the contrast between my immobility and this moving memory. ${ }^{107}$ I start conceiving of perforMemory as a memory in movement, a memory2Go that I as a spectator can in turn take home with me. In this

\footnotetext{
${ }^{106}$ Klüger, weiter leben, 78.

${ }^{107}$ On mobility and disability, view the swimming pool example in Hornscheidt, feministische w_orte, transdisziplinäre genderstudien:189.
} 
iteration of perforMemory, the dancer reaches the very limits of breath, swings her arms energetically in a circular motion, and employs strategic kung fu kicks as she faces invisible enemies arriving from all directions at unexpected moments. As a descendent of people who had to flee Germany in 1933, and having several relatives who were deported and murdered, I relate to the piece, performed by someone who carries other kinds of body memory within her, but nevertheless connects to the experience of oppression, and resistance to it.

The idea of memory2go also prompts the image of disconnection. The disconnection may also be the cultural production of memory remote from one's personal or family past. Alison Landsberg addresses this type of memory, which she calls prosthetic memory. Her analysis focuses on multiple sites of memory in the USA, including Holocaust memory and slavery memory as represented in comics, film and interactive museums. For Landsberg, prosthetic memory is characterized by mediation, (bodily) experience, commodification and usefulness. She defines it as the "production and dissemination of memories that have no direct connection to a person's lived past, and yet are essential to the production and articulation of subjectivity." 108 Although controversial, her thesis produces an innovative understanding of cultural meaning-making. Landsberg's central argument which is also helpful in understanding perforMemory - is that some forms of memory may raise empathy across lines of race, class and gender, although each person will respond from a subjective position. Such forms of memory may awaken political consciousness and stimulate counter-hegemonic alliances. She emphasizes the value of learning about the past through experience and interpretation, rather than through learning the "facts."

Interestingly, Landsberg did not include dance in her research scope, although it is a mode of expression that provides just such a possibility as it transmits memory through experience and interpretation. In her solo Through Gardens, Afro-German artist Oxana Chi handles the memory of Tatjana Barbakoff, to whom she does not have a genealogical or ethnic connection. However, Chi extracts stories of success, struggle and hope in Barbakoff's pasts which resonate with her present. Achieving a narrative which is much more nuanced and complex than a factual history lesson, she engages with an individual destiny rather than leaving it hidden behind a nameless mass of numbers. Through Gardens reveals the possibility to perforMemory mediated, embodied experiences, and to share them with audiences, who can in turn take the memory2go and connect it to their personal memory universe. Like a USB-stick ${ }^{109}$ connecting to a computer, memory2go exists in the encounter between the dancer, whose body is the medium of storytelling, and

\footnotetext{
${ }^{108}$ Landsberg, Prosthetic Memory, 20.

${ }^{109}$ And it is indeed a brand for USB-devices as I just found out!
} 
the audience's receptive capacity. What distinguishes a memory device from a dancer's corporeality however is the agency that the artist puts into the work.

PerforMemory thus also moves beyond the distinction between cultural and communicative forms of remembrance (kulturelles Gedächtnis and kommunikatives Gedächtnis), ${ }^{110}$ for it allows them to coexist in one space - the stage. To erase memory, as Brenda Dixon Gottschild reminds us, would "act as a roadblock to empowerment" for Afro-descendent and Jewish people, because for them "facts of history" are "facts of life." ${ }^{111}$ Therefore, perforMemory is potentially empowering - and this is precisely where its analytical power resides.

\subsubsection{From the choreography of power to the power to choreograph}

It is not only people's rulers who know that historical and contemporary power relations are (also) a matter of performance. Scholars in gender studies and performance studies, as well as those working on their intersections, have demonstrated extensively that historical and contemporary power relations are (also) a matter of performance. ${ }^{112}$ The reverse is also true: dancers perform power, and dance historiography tells much about the history of power. Negotiating Black women's power for instance, is a key aspect of Urban Bush Women's choreographies, as shown in Nadine George-Graves's extensive research about the company. She extends Judith Butler's notion of performativity by superimposing a "meta-theatrical" level, where "an aesthetic use of performativity in a performance site implies awareness and agency." ${ }^{\prime 13}$ Stage, body and memory are each layers that constitute a site of performativity.

Power is at stake here, rebounding power, always landing on both feet: political memory. The power residing in the act of performing contains the power that molds social relations, and therefore memory. To politicize memory therefore means to acknowledge memory as a location where power struggles take place. These struggles can happen on the stage, where power may be wrapped in various costumes, as described by Praise Zenenga:

For example, within the Zimbabwean context where I come from, mainstream theatre and dance depend on the power of the body to express different kinds of power, such as political power, intellectual power, spiritual power, physical power,

\footnotetext{
${ }^{110}$ Assmann, Erinnerungsräume.

${ }^{111}$ Dixon Gottschild, Digging the Africanist Presence in American Performance, 6.

${ }^{112}$ For a comparative analysis of performativity in gender and performance studies see for example Gebske,

"Performativität zwischen Zitation und Ereignis."

${ }^{113}$ George-Graves, Urban Bush Women, 40-41 [My emphasis].
} 
social power, and even economic power. The speaking, dancing, and acting body not only expresses but also wields these forms of power. ${ }^{114}$

I would extend the reach of this quotation beyond the Zimbabwean territory. Western academia often resists acknowledging the body, and even more so the dancing body, as a source and generator of power. The performances, as do their makers' reflections upon them, convey the idea and materiality of corporeal power, more so because in this case, the performers dance their own creations. Our conversations articulated a clear awareness of all forms of power dancing bodies can represent and enact on stage.

Farah Saleh, for example, advocates dance as a form of daily resistance, in her art as well as in her educational practice. This is materialized in the solo Parole, Parole, Parole, which I witnessed at the Tanzquartier Vienna in 2014. Her lecture-performance shifted immaterial borders between daily movements, audience interaction and informative talk. "Parole," the French word for "speech," is absent at first. The dancer watches the audience walking into the theater space. The dancer and the audience coexist within one space where conventional borders have been erased. Saleh transforms embodied memories of what she calls Ordinary Madness of daily life in Palestine into choreographed and improvised movement. In a geopolitical context such as Palestine, where mobility cannot be taken for granted, dance may bring with it a sense of overcoming boundaries and it can foreground political and economic power and autonomy. Clearly, Saleh and all the other dancers discussed here are political performers. They are what Ananya Chatterjea calls artists as cultural activists, who articulate through choreography "complex critiques of hegemonic sociopolitical phenomena marking the contexts in which they live and work." ${ }^{115}$ PerforMemory proves that artists can perform cultural memories, challenging historical narratives and contemporary settings, swimming against the mainstream, and thus eschewing racist and genderist cliches while keeping a broad audience in sight.

In this second chapter, I asked how memory is shaped through dance. My thesis and more specifically this chapter, maps an alternative cartography, where memory is a dancescape, and perforMemory a compass. I tried to sketch the outer borders of memory dancescapes in order to be able to describe in succeeding chapters what it feels like to move through them. The thematic focus of the performers works towards inscribing memory in political ink. If we embrace dance as an enduring form of transmission, eschewing the ephemerality paradigm, we may envision memory dancescapes as worlds inhabited by moving beings. Whether they contain hermetic or permeable borders, these dancescapes constitute sites of memory that are full of movement. Choreographing memory using postmemorial aesthetics, the performers intervene both as choreographers

\footnotetext{
${ }^{114}$ Zenenga, "Power and the Body," 65.

${ }^{115}$ Chatterjea, Butting Out, 35.
} 
and dancers in hegemonic narratives of history. Not only do they embody history, they perforMemory a form of memory that is a memory2go, full of presence and power.

The vital contribution of literary and visual artists to remembering traumatic pasts lives side-by-side with performative engagements with storytelling. I argue that perforMemory is as powerful as these other forms of memory with which most academic discussion occupies itself, certainly in terms of library shelf space. For now, I have sketched the décor of memory dancescapes, which will be set into relief as you move deeper into the thesis to eventually stand at the doorstep of perforMemory. Now that we know what the dancescapes may look like, let's advance a step further, identifying how diasporic forces influence the dancescapes of perforMemory. 


\section{DIASPORIC MOVES}

You may shoot me with your words

You may cut me with your eyes [...]

But still, like air, I'll rise.

Out of the huts of history's shame

I rise

Up from a past rooted in pain

I rise

I'm a black ocean, leaping and wide, Welling and swelling I bear in the tide.

Bringing the gifts that my ancestors gave I am the dream and the hope of the slave I rise, I rise, I rise

Maya Angelou ${ }^{1}$

I have travelled across the Atlantic many times, within a child and within an adult body. Moving to the Americas seems to be in the family, and my ancestors arrived across the generations, over centuries, from Russia, from Africa, from India...displaced voluntarily or involuntarily. Some stayed, some went back. In 2015, the Jewish Foundation Ernst-LudwigEhrlich-Studienwerk (ELES) in Berlin, which sponsored my thesis, granted me with funding to spend a year as a Visiting Research Scholar in the United States. A substantial part of the text you are reading was written during that year, in the diasporic space of the USA. After a stay at the Department of Theatre and Dance at the University of California San Diego, I transferred to the Institute for Research on Women, Gender and Sexuality (IRWGS) at Columbia University. This change in coastal location provided me with direct access to the diasporic hub and dance metropole of New York City. My new research home became the Arts and Healing Center, to which I was affiliated through a summer artist residency program that hosted Oxana Chi's company. The center belongs to choreographer Marlies Yearby, a Bessie-Award winner, who lives on the third floor. We stayed and worked onsite, on the first floor, sharing a flat and a rehearsal space with Laurie Carlos, a senior writer, playwright and actress. Carlos became famous through her innovative work in jazz theatre style, and as an early influential member of the dance company Urban Bush Women. Once again, my academic readings took shape in real life, through encounters, rehearsals, performances.

\footnotetext{
${ }^{1}$ Angelou, And Still I Rise, 42.
} 
The figure of Laurie Carlos, mentioned in the anthology Solo/Black/Women, ${ }^{2}$ was my housemate, who would casually ask me, "do you need anything from the bodega?" 3 before stepping out for her daily walk. We bonded over the fact that we both grew up in Black-Jewish-mixed households, and that we were now in Crown Heights, itself a historic landmark where Black and Jewish Americans have lived side-by-side for decades, though with little communication or interaction. The Black social landscape of the neighborhood is made up of African-American inhabitants, and more recent Caribbean migrants and their US-born children. Crown Heights, and more generally New York City, is a diasporic space through which people of variegated cultural heritages, inspirations and aspirations pass. Each group carries its own baggage, filled with different histories, and leaves its own footprints on the US-soil. It seemed to me that no one could claim New York to be home, and yet everyone inhabited the space as though it were a home. The Lenape peoples, however, who originally walked through Manhattan long before Broadway was built, seemed blatantly absent. ${ }^{4}$ No footprints, not even a whisper. And yet, when we began to pay attention, Oxana Chi and I would encounter cultural signposts such as Indigenous Day, which commemorates resistance to European conquest, rather than celebrating the conquest of America officially marked by Columbus Day. Or we would encounter the powerful performance of Two-Spirit ${ }^{5}$ dancer Sheldon Raymore at the Theater for the New City. So I began asking myself whether Natives were absent from the cityscape, or whether it was a matter of horizons, and how our socialization and expectations determine what and how we acknowledge presence.

Real life experiences in turn shaped how I read theory and interpreted performances. In that academic year of intense travel between the USA, the Caribbean, and Taiwan, my understanding of diaspora became indistinguishable from motion. My working schedule in New York consisted of a productive and agreeable balance between library time for research and writing, training time with dance icons such as Pat Hall - former Artistic Director of the Cumbe Center for African and Diaspora Dance - and rehearsal time with Oxana Chi. At that time, dancer Candace Thompson invited me to join the freshly launched Dance Caribbean Collective's Scholarship Team. At the DCC festival and meeting, diasporic connections were again omnipresent. A broad understanding of what

\footnotetext{
${ }^{2}$ See Sharon Bridgforth's interview in Johnson and Rivera-Servera, Solo/Black/Woman.

3 "Bodega" is a Spanglish diasporic word for the corner shops run by Spanish-speaking migrants.

${ }^{4}$ Cole, Open City.

${ }^{5}$ The term Two-Spirit stems from Indigenous American cultures to account for what is usually called $L G B T^{\star} Q$ identities in the West. Across Native tribes, indigenous words exist to refer to two-spirited persons and/or transgender persons. Prior to colonization, persons positioned as two-spirited often played a special role (e.g. healers, visionaries) in society, and were already in their childhood acknowledged and respected as cross- or transgender humans. I take this historical and contemporary information on the role of Two-Spirit in American First Nations from personal conversations and from the blog post Laframboise and Anhorn, "The Way Of The Two Spirited People."
} 
Caribbean identity may mean, and how it can be preserved, performed or imagined through movement, seemed to constitute the common ground, the ocean harboring individual and collective islands of creativity.

Stepping through these New York dance spaces was a memorable, challenging and refreshing experience. It was even more fascinating to become myself part of its dancescapes. My first appearance with the Oxana Chi Company in New York in July 2015 took place as a result of an invitation extended by André M. Zachery, who curated a threeday festival at the University Settlement Theatre on the Lower East Side. Oxana Chi's piece Neferet iti opened the festival. Later, when we toured the piece in Indonesia and Taiwan, my physical participation expanded. Besides playing saxophone and ocean drum, I performed a few capoeira movements, including a headstand. When I think of it today, I am reminded of the insider-outsider's perspective discussed in the introduction.

In this piece, Oxana Chi embodies the Egyptian statue stolen by Germans, which until today is displayed on Berlin's museum island, and which is a huge tourist draw. More generally, Neferet iti denunciates the colonial looting of cultural objects, as well as the hegemony of genderist and racist discourses about migrants, as exemplified in Berlin's marketing campaign about the historical Pharaoh Queen. ${ }^{6}$ A diasporic quest for origins, the dance entails a multitude of cultural influences. Legendary dance critic Eva Yaa Asantewaa attended the show in New York, and summarized her first impressions of Oxana Chi's fusion dance:

A chart of her dance background would look like a spinning globe - from ballet and Cunningham and jazz to Javanese and Egyptian dance. Her Solo Neferet iti [...] dares to draw visual and kinetic elements from different cultures, too, in a quilt-like, multi-textured performance. Her Central American plumed headdress, her yellowgold harem pants, her hip thrusts and shimmies, her archer's bow draws, Masai jumps, capoeira maneuvers, vogue hands and dervish spins add up to a heady mixture. She believes it all works - you can see that - and makes it work. A somewhat delicate presence, she is, nevertheless, a woman writ large, claiming concert dance space for a diverse and teeming world, blessing that space. ${ }^{7}$

The journalist appreciates the dancer's unique dance aesthetics, characterized by the borrowing from and mixing of multiple kinesthetic idioms from Europe, Africa, Indonesia, and Brazil. As Asantewaa suggests, it is through the process of fusion that these elements come to "work," because the performer "makes it work" - a term associated with voguing vocabulary. The writer recognizes the specific "shimmy" technique of the Egyptian Raks

\footnotetext{
${ }^{6}$ See Chi, "Neferet iti - Reloaded"; and Zami, "Oxana Chi von Zopf bis Fluss: Transkulturelle Tanzkunst und alternative Geschichtsschreibung."

7 Asantewaa, "Hamilton and Zachery at University Settlement's Performance Project". We actually toured this version of the piece on the diasporic spinning globe, and during my time as Visiting Research Scholar, I enjoyed being part of the performance at Dixon Place Theatre in NYC, upon invitation by curator Sangeeta Yesley. I also had the privilege to travel to accompany Oxana's solo at the Youth Government Auditorium in Taipei in August and September 2016.
} 
Sharki dance style, often misunderstood as "belly dance." In the anthology, Taboo Memories, Diasporic Voices, Ella Shohat explains how this appellation, stemming from the French "danse du ventre," originates from and participates in a colonial fragmentation of the body, and how the label misses and minimizes the feat of a sophisticated, full-body performance technique. Shohat also refers to colonial exhibitions and how the so-called belly dancers were used in the colonial project rather than being praised as artists. ${ }^{8}$ So it is striking that today, Chi re-frames this technique in order to de-construct the colonial mis-use of Neferetiti's bust. By juxtaposing ancient pharaoh iconography, colonial history and Raks Sharki, her performance intervenes in hegemonic western narratives. ${ }^{9}$ Shohat goes on, criticizing teleological world conceptions that "segregate" temporality and spatiality, and put the global "South" historically "behind." She argues for a vision that sees all "worlds" as coeval:

The spatiality and temporality of cultures as scrambled, palimpsestic in all the worlds, with the premodern, the modern, and the postmodern coexisting and interlinked globally. ${ }^{10}$

Oxana Chi's performance brings about these coeval worlds, as she challenges the conventional inscription and restriction of culture within markers of space and time. The "spinning globe" evoked by Eva Yaa Asantewaa mirrors a dynamic understanding of diaspora in interaction with dance. To be "claiming concert dance space for a diverse and teeming world" is to perform diaspora and to diasporize performance. Interestingly, the critic reads the piece through the lens of her own African-American cultural heritage, by referring to the practices of voguing and quilt-making. The making of quilts is inherently a palimpsestic handicraft. It was historically used by African-American women to literally compose stories, to record and to transmit memory of the past to the next generations. ${ }^{11}$ Thus, when the journalist compares Oxana Chi's dance-making to quilt-making, she appropriately touches upon perforMemory as understood in my research: a diasporic assemblage of diverse choreographic materials, gathered in expressive patterns of storytelling. What Chi calls "fusion," or what Shohat calls "polycentric aesthetics" is essentially a diasporic process. Diasporic strategies contest the European monopoly over artistic creation, and counter the meta-narrative of art history, as noted by Shohat:

\footnotetext{
${ }^{8}$ Shohat, Taboo Memories, Diasporic Voices, 50.

${ }^{9}$ Chi's intervention corresponds for instance to the strategy discussed in Karentzos, "Postkoloniale Kunstgeschichte" "Die postkoloniale Kritik richtet ihr Augenmerk nicht nur darauf, wie diese Objekte als Trophäen des Kolonialismus fungierten, sondern insbesondere auch auf die Grenzziehungen und Auschlussmechanismen, mit denen solche Exponate als 'andere', von der 'eigenen', europäischen Kunstproduktion getrennte markiert wurden."

${ }^{10}$ Shohat, Taboo Memories, Diasporic Voices, 15.

${ }^{11}$ hooks, Yearning, 116.
} 
While a Euro-diffusionist narrative makes Europe a perpetual fountain of artistic innovation, one could argue for a multidirectional flow of aesthetic ideas, with crisscrossing ripples and eddies of influence. ${ }^{12}$

Indeed, Oxana Chi's current repertoire flows in multiple directions, and takes as its source a plurality of cultural influences and techniques, as gracefully described by Asantewaa. The multiple textures of her dance are the result of several decades of training and inspiration gathered in over 40 countries. What is born of this fusion is a multilayered vocabulary of perforMemory. The "black ocean" sung by Maya Angelou could function as a metaphor for Oxana Chi's dance, for its ability to incorporate many continents.

The diasporic dancespaces are now taking shape, be they volcanic, or oceanic. Diasporic artists dance in multiple directions in search of alternative artistic currents. The "diasporacentric" quality of the dances fuels my "diasporacentric" research, to return to the notion highlighted in the introduction. If diaspora is indeed, to follow Fox, a "permanent intervention,"13 dance as a medium that is mobile per se seems to be an optimal site of creation for diasporic identities and practices. The magma of perforMemory resides in its painful archeology, and the dancers use their very bodies as tools to excavate stories that have been buried, overseen, forgotten, ignored. PerforMemory can be described as a movement in which the dancer combines the backward looking twist of the Sankofa bird's head, with the feet strongly grounded in the present, as in ballet's first position, and with the torso's anticipation of the next movement to come, such as a jump into the future.

In the previous chapter, I asked how postmemorial choreographers use imagination to perform counter-hegemonic interventions. The idea of a memory2go that was discussed in the previous chapter takes on new significations and implications when wrapped in diasporic layers. I will now explore how selected performances negotiate the interrelation between diaspora and memory. The physicality of memory's movement becomes amplified by conceptual movement inherent to diasporic transformations. I now continue on this path, and engage with Jewish, Black and feminist definitions of diaspora, distinguishing between "diaspora" as an entity and "diasporic" as a process. In this chapter, I engage with diaspora in multiple spaces: the theoretical space of academia, the physical space of the stage and eventually the corporeal space of the body. ${ }^{14}$ I wonder: Which meaning(s) does perforMemory take on when dressed in a diasporic costume?

\footnotetext{
${ }^{12}$ Shohat, Taboo Memories, Diasporic Voices, 79.

${ }^{13}$ Fox, "Diasporacentrism and Black Aura Texts," 368-69.

${ }^{14}$ See also Zami, "Dancing the Past in the Present Tense."
} 


\subsection{Moving Through Diaspora}

\subsubsection{Inhabiting diaspora}

Carefully picking up a green Chinese silk dress, cradling it in her arms, Oxana Chi gently drags herself into it, and begins a magical, nostalgia-imbued dance. The scene is reminiscent of dancer Tatjana Barbakoff's own memories. In a conversation with Lou Straus-Ernst during her Parisian exile in 1934, Barbakoff recalls how as a child, she used to improvise with the Chinese clothes of her mother, and how she enjoyed letting the cloth textures lead her movements. ${ }^{15}$ On another level, this moving tableau in Through Gardens suggests the absence of Tatjana Barbakoff in today's dance historiography, and reflects the mindful way Chi embraces Barbakoff's cultural legacy. The absent body of the past dancer becomes present in the performative timespace, blurring the historical and physical boundaries between Barbakoff's diasporic search in the $19^{\text {th }}$ century and Chi's diasporic dance and political message in the $21^{\text {st }}$ century. I particularly enjoy the versions in which Chi performs to a hang instrument. The venue fills with serene soundscapes, and the dancer moves through the vibrations as if they were silk. Her hands caress the air, inspired by the Chinese kinesthetics of Tai Chi Chuan, and borrow from Javanese classical dance, with its elaborate finger choreography and mindful poses. Yet, the slow flow is sometimes punctuated by tragic staccato, as exemplified in the interludes of shaking hands. Chi's diasporic perforMemory of Barbakoff embeds the appreciation of her Chinese genealogy within her own fascination for and training in Javanese dance. At the end of the scene, Oxana Chi returns to the back right corner of the stage, steps out of the dress and places it back in its original place, as if waking up from a dream...or dropping off a memory.

The choreobiographic Through Gardens performs "the diasporic world we now inhabit," as defined by Hirsch and Miller in their Diaspora Poetics. In this world, intimate and public relations coexist and inform one another. Diasporic actors perform what the authors call Rites of Return:

\footnotetext{
${ }^{15}$ Straus-Ernst, "Bei Tatjana Barbakoff”; printed in Chi, Tanzende Erinnerungen, 2011, 16-19.
} 
For some, return is an act of undoing - a counterfactual effort to imagine a world before disaster and displacement. That act of imagination can also become an act of repair, however tenuous. [... $]^{16}$

Through Gardens, especially its first half, performs a rite of return to pre-World War II Europe. Indeed, we are projected into a time before Tatjana Barbakoff's flight and exile. Pieces of knowledge about the 1920s and 1930s are woven together, as Oxana Chi imagines and remedies the loss of historical figures, and presents them through performative presence. This dancescape materializes the diasporic movements required to travel through time, space and dance historiography. Chi shifts from Barbakaoff's geographical origins to her cultural journeys. The audience encounters memory as a space to be inhabited and traversed.

\subsubsection{The bridges of diaspora}

In Kinesthetic City, Chinese-American academic and choreographer SanSan Kwan explores the relationship between urban space and concert dance in five sites of Chinese diasporas: Taipei, Hong-Kong, Los Angeles, Shanghai and New York City's Chinatown. She evokes how diasporic Chinese born outside of Mainland China are called "huaquiao,"17 in which "hua" stands for "Chinese" and "quiao" means "bridge":

When indeed [would I return], considering I have never really known the other side of the bridge? Still, for the huaqiao the bridge is always there; there is always the assumption of return. It is never a matter of simply leaving but always of going and coming, shuttling across the bridge, continually circling back - even if only in the imagination. ${ }^{18}$

What strikes me here is the dynamic quality of the diasporic condition, and its connection to a permanent state of transition through the verbs "going," "coming," "shuttling," "circling." Also, the idea of a bridge, and to a greater extent, the linguistic translation of the space of diaspora, is appealing because of its malleability. It can also be found in the writing of feminists of color, who metaphorically describe their back, or their home as a bridge. ${ }^{19} \mathrm{I}$ am inclined towards a materialization of diaspora in space through the structure of the bridge, which by essence is a constructed site, a place of mobility between worlds, where stagnation is not allowed.

\footnotetext{
${ }^{16}$ Hirsch and Miller, Rites of Return, 18.

${ }^{17}$ Kwan, Kinesthetic City, 3; See also Lin, "Kinesthetic City."

${ }^{18}$ Kwan, Kinesthetic City, 3.

${ }^{19}$ Anzaldúa and Moraga, This Bridge Called My Back; Anzaldúa and Keating, This Bridge We Call Home.
} 
Dancer Farah Saleh also spoke of a bridge metaphor: the border between Palestine and Jordan, called "the bridge." ${ }^{20}$ But also, the idea of "building cultural bridges" between Palestinian and Israeli people, an idea which Saleh is suspicious of, because she argues that an uneven bridge connecting two unequal levels is counterproductive. However, her dance Parole, Parole, Parole creates choreographic bridges that might otherwise be lacking between Europe and Asia, Africa and America, daily sanity and constant oppression, as does André Zachery's Digital Middle Passage, and Christiane Emmanuel's Choc(s). For instance, when Zachery takes the thirty minutes of his solo to traverse the stage, he transforms the waters of the Black Atlantic into a walkable route, a cultural itinerary of oceanic memories, a dance-able bridge. More so, because he traverses from right to left, he moves against the tide of the conventional reading direction of western languages, thus conveying a feeling of return. Similarly, Christiane Emmanuel transformed her family home into a diasporic hub for Afro-diasporic dance production and transmission.

Chantal Loïal performs the body as a bridge - between South African and French history and politics, between Afro-Caribbean and European movements, between the factual and the emotional storytelling of Sawtche. Choreographer Wan-Chao Chang is a "huaqiao" diasporic Chinese, whose work constantly transpires the imaginative and physical coming and going between the Asian and American continents. From I Thought Here Is My Home to her Impressions solo, she walks along a diasporic path, striving to connect her multiple diasporic experiences in Indonesia, Taiwan and the USA. In the interview, Chang spoke extensively about her personal questioning of the idea of (not) belonging, and of return. The conversation, and the performances reflect what I would call nomadic melancholia, inspired by the cultural theory of Nathalie Etoke and José Esteban Muñoz on "melancholia" in reference to diaspora. Both authors claim melancholia as integral to diasporic subjectivity. In Melancholia Africana, Etoke praises a "flexible" diasporic consciousness. For her, the pain of not belonging, rather than impeding diasporic beings, empowers them to be free:

Diasporic consciousness is a feeling of belonging that contributes to existential fulfillment. It keeps memory alive by putting it through a blues-riddled archeology. The past grinds the present. The past forces the present to face its responsibilities. A present which is itself built on the ruins and steles of that which survived destruction, that which is born out of destruction.

(La conscience diasporique est un sentiment d'appartenance qui contribue à une plénitude existentielle. Elle entretient la mémoire en la soumettant à une archéologie criblée de blues. Le passé triture le présent. Le passé place le présent devant ses

${ }^{20}$ Saleh, interview. 
responsabilités. Présent lui-même établi sur les ruines et les stèles de ce qui a survécu à la destruction, de ce qui est né de la destruction. $)^{21}$

For Etoke, this applies to the specific context of African and Afro-descendent people. Her definition of melancholia africana echoes bell hooks' work on "yearning"22 as a feature of blackness: the aspiration to counter the silencing of one's voice or history. Indeed, the Afro-diasporic dancers Chi, Loïal, Zachery, and Emmanuel, do perform soli of deep melancholia. The violence inflicted upon Black people throughout the centuries, be it the deportation of Sawtche/Venus to Europe, of Africans to the Americas, or the European Holocaust, appears in their pieces not (only) as a source of mourning over the past, but also as a well of creativity for the present. As in the volcano metaphor discussed in the previous chapter, the dancers perform a choreographic archeology, transforming each stratum of the past into a movement's sequence. Memory2go lives in this melancholic, nomadic, diasporic interstice between history, geography, memory and futurity.

Melancholia is also at the core of Muñoz's articulation of queer of color subjectivity:

I am proposing that melancholia, for blacks, queers, or any queers of color, is not a pathology but an integral part of everyday lives. [...] It is this melancholia that is part of our process of dealing with all the catastrophes that occur in the lives of people of color, lesbians, and gay men. ${ }^{23}$

Like Etoke, Muñoz defines diaspora as a feeling, or rather a state-of-being that should not be rejected or repressed, but embraced, for it constitutes the ground on which people of color, and more specifically queer people of color may perform, or dance their daily remembrance and resistance. It is thus not surprising that what I call nomadic melancholia suffuses the work of queer Afropean dancer Oxana Chi, as described in the above-mentioned scene of the Chinese dress. A strongly melancholic mood also pervades Christiane Emmanuel's going-in-circles in Choc(s) and Farah Saleh's search for a place to stand on her hands among the audience in Parole, Parole, Parole. A diasporacentric approach allows us to extend the scope of melancholia beyond the territory of race.

Retuning to Chang's diasporic search through the lens of my own personal background, as a queer person born in France of Jewish-Caribbean descent and living in the Euro-American space, I realized that Chang was putting into words and movements a feeling I experience in my own meanderings. Her choreography seems to seek what Hirsch calls a "mutual imbrication [...] between a desire for roots and an embrace of

\footnotetext{
${ }^{21}$ Etoke, Melancholia Africana: L'indispensable Dépassement de La Condition Noire, 33 [My translation].

${ }^{22}$ hooks, Yearning.

${ }^{23}$ Muñoz, DISIDENTIFICATIONS. Queers of Color and the Performance of Politics, 74.
} 
diasporic existence." ${ }^{24}$ Furthermore, we can see this in the juxtaposition of dance styles which work towards finding a place in relation to each other, like the coexisting aspects of her identity. In Impressions, she uses dance techniques from Indonesia, China, the Balkans, and West Asia. In contrast to Oxana Chi, she does not define her dance as a "fusion." She calls her dance "ethno-contemporary," a word locating the work in a contemporary, global timespace. Although the term ethnic may sound problematic, the term seems to signify a search for the contemporaneity of traditional techniques. Her choreographic practice reflects the desire to knit together through movement the diasporic pieces of herself:

Also when we go abroad, people ask us "Show your cultural dance. Show your culture," and then I start to struggle. My culture? Should I show Chinese dance? Well, I'm ethnic Chinese. But I'm not really coming from China, right? Should I show the Taiwanese aboriginal? Well I'm coming from Taiwan but I'm not aboriginal! Where's my culture? So it was a struggle at that time for me, because I'm still searching for the root, and there is a stage where I recognized that, well - how do you define culture, actually? It's the environment I grew up with. [...]

There is my home is the beginning of the process, because I feel that I've always been an "alien". At that time I was searching, where is my home? ${ }^{25}$

I Thought Here Is My Home could be the title of the conversation I had with the dancer, since we kept returning to the theme of cultural belonging and geographical orientation. This solo was the embryo from which the group piece Keep Her Safe, Please! was born. Chang's dancescapes englobe a multitude of worlds. Depending on the reading, one may draw a different interpretation from them. On the surface, the dance is about the conflicts between Chinese migrants and Javanese residents, as experienced by the choreographer's parents in the sixties and as reproduced in 1998. The choreography draws from the experience of her Chinese parents called "new migrants" in Taiwan, because they emigrated (from Indonesia) to Taiwan after the 1950s main wave of migration from mainland China; and narrate her own experience as a so-called "alien" in the USA. The original title, Keep Her Safe, Please! was later complemented with the space-time marker Jakarta 1998, which may have to do with the marketing concerns of the US-based festivals that programmed the piece. The choreographer consciously grapples with her complex relationship to Java, a place where her family experienced rejection, but which is simultaneously also a place of deep inspiration for her art. This inspiration is particularly visible in this piece, in which Javanese dance movements and gamelan music alternate with Chinese drums.

\footnotetext{
${ }^{24}$ Hirsch and Miller, Rites of Return, 2.

${ }^{25}$ Chang, interview.
} 


\subsubsection{The multiple layers of diaspora space}

Wan-Chao Chang performed I Thought Here Is My Home at the "Festival of the Silk Road" in San José, California. ${ }^{26}$ Dancers $^{27}$ form a circle around an individual. Disappearing as swiftly as they appear, they resemble the roaming limbs of an itinerant family that assembles, disassembles, reassembles. The movements alternate between Javanese techniques - bending the legs, shaking the isolated shoulders - and European "modern" dance vocabulary - hands rising up and down in mimicry of waves. The group surrounds one dancer, who soon steps out of the circle, walking across the stage to the front right corner. Later the dancers will form a line of gracefully aligned, standing bodies, whose heads fall to the side as if pulled by a puppet string, and whose upper bodies regularly seem to collapse to the beat, through a rolling of the spine. The circle of women may epitomize protection, a temporary shelter that dissolves into the whirling movements of the white clothes held by the dancers. They may also personify a threatening force restricting one's mobility, while the dancer in the middle seems to attempt to grab something in the air, as if trying to find something to hold on to.

Cloth is also a leitmotiv in Wan-Chao Chang's 2012 solo Impressions. In the prelude, a wide red ribbon is tied to a pillar. The dancer holds it behind her, and appears to be tied to the ribbon, which prevents her from stepping forward. Suddenly, she releases herself, or is she released by the ribbon? Simultaneously, the music starts abruptly, and the piece begins. Is Wan-Chao holding onto Chinese culture, symbolized by the particular color of red? Is the diasporic relation to her Chinese heritage impeding her, or giving her the impetus to dance and to move forward?

When I first viewed this scene of displacement, I could not help but think of the beginning of Through Gardens as I first experienced it live in 2009 at the Werkstatt der Kulturen in Berlin. Although they are completely different in terms of aesthetics and techniques, both scenes share the use of a red cloth, reminiscent of the navel string to which the dancer/protagonist is attached. In the scene of "The Birth," Oxana Chi rests on the ground, a solitary figure wrapped in velvet red. Her shape does not reveal a human figure, until she starts moving, accelerating and intensifying her moves to the sound of the quickening heartbeat of the electric guitar, played by Hannes Buder. She repeatedly moves between the floor and the air, a flexible spine allowing her to reach down and rise up with outstretched arms at a very quick speed. Then she bursts out of the velvet cloth, revealing her human face, the mouth open, gasping for air, her arms spread out as if to welcome life's embrace, and the beat stops. Tatjana is born, and reborn in Oxana's

\footnotetext{
${ }^{26}$ See the video Chang, I Thought Here Is My Home.

${ }^{27}$ Wan-Chao Chang, Aliah Najmabadi, Tara Pandeya, Jade Raybin, Hannah Romanowsky, and Kristen Sague.
} 
dance. Throughout this scene, the dancer will move within the velvet cloth, which is now a mysterious costume. When she slowly leaves the stage, she pulls the rest of it behind her, attempting to drag with her what seems like a heavy weight. With patience and endurance, she manages to carry it away, as if rolling the navel string back up. Even when she is already out of sight, we continue to watch the cloth follow after her, a diasporic node tied to her movements. The intensity of this scene is emblematic of the expressionist aspect of Chi's dance style. She persistently pulls her own costume's extension after herself. Here, I think of my recent conversation with dancer Zufit Simon, in which she states that we all pull a "bag of emotions" behind us all of our lives. Is this cloth a bag of emotions which Chi gracefully pulls to her? Explaining why she prefers to work as a solo artist, Chi says:

My body is African, and my energy comes from many places. It's African, but also Eastern European, Asian...many energies come together, and build up, generate my individual energy. I also need to care for this energy in a certain way. I call this 'housekeeping.' [...] So, I have always noticed that these energies absolutely do not fit within the mainstream, and also do not fit within a white, western, male-dominated society. It simply does not fit. Therefore, I work at my own rhythm and at my own pace. $^{28}$

She moves diaspora to a different level of consciousness, moving fluidly through geographic markers of spaces. By envisioning a distinction between body genealogy and body energy or performative energy, between inherited identity and "affiliative selffashioning," ${ }^{29}$ the dancer creates diaspora spaces which she may inhabit and in which she can perform. The diaspora spaces are also within her and exteriorized out towards an audience through the performance. This "theory-in-practice" ${ }^{30}$ brings us back to Hirsch and Miller's understanding of diaspora as worlds to inhabit. As suggested earlier, dancescapes are also worlds to inhabit, and perforMemory is a mode to live within them, by constantly shifting and re-imagining their boundaries.

Both Chang's and Chi's articulation of diaspora through perforMemory can help us to understand Avtar Brah's theorization of diaspora space, a critical conceptualization and conceptual critique of diaspora. For Brah, a diaspora space is characterized by "relational positioning" and "multi-locationality across geographical, cultural and psychic boundaries." ${ }^{31}$ Applying Brah's concept of diaspora space to the stage means considering which boundaries surround the stage physically and metaphorically: geographical boundaries between in/outside; between the stage and the audience; cultural and psychic boundaries between an imaginative performer and more or less receptive, open-minded

\footnotetext{
${ }^{28}$ Chi, interview.

${ }^{29}$ Nelson, "The Factness of Diaspora," 25.

${ }^{30}$ Ramón H. Rivera-Servera, Performing Queer Latinidad.

${ }^{31}$ Brah, "Diaspora, Border and Transnational Identities," 625.
} 
audiences; financial and technical opportunities which provide support as much as they can constitute limitations. What does it mean to enact multilocationality on the stage?

The multilocationality of diaspora takes on a new meaning in the digital age, which in turn influences memory cultures. For instance, in the blog post "Archive and Aspiration," Arjun Appadurai reflects upon the new possibilities for migrant "minorities" to connect "neuro-memory and social memory" online, and to find or build virtually the space they may be denied in the physical world, and asks how this in turn may shape the "materialities and architectures" of memory. ${ }^{32}$ One does not necessarily need to disconnect digital memory from corporeal memory. In this matter, André Zachery's choreographic work connects a raw type of physicality to a multilayered use of projection and sound technology in Digital Middle Passage, as I will discuss later, and as he mentions in the interview.

The dances I regroup here under a widely extended diasporacentric umbrella, have in common the will to move in spite of and beyond the white, western, (cis)-masculine patriarchal capitalism which takes on different names in Oxana Chi's or bell hooks' words. Regardless of their various positionings within geographic, racial, social and physical worlds, and regardless of their public recognition within worlds of dance, all the choreographers do not belong to hegemonic identifications. Their performances live at the crossroads of dance, memory and diaspora. They create a space for diaspora to exist, to be performed and re-imagined. When Oxana Chi holds onto the velvet costume of her own design, or Wan-Chao Chang holds onto the Javanese Gambyong dance cloth, they inspire me to ask: what is this diasporic condition humans strive to hold on to? How can it be defined?

\subsubsection{Jewish/Black/feminist diasporas}

In the postscript to Other Germans: Black Germans and the Politics of Race, Gender, and Memory in the Third Reich, Tina Campt reflects upon Avtar Brah's work and offers a retrospective theorization of diaspora in cultural studies. Campt invites us however to "engage this concept [of diaspora] with an awareness and articulation of its limits [...],"33 and to also pay attention to Black identity formations that may not correspond to USbased diasporic definitions, for instance in the Afro-German context. Herself an AfricanAmerican scholar, Campt resists the idea of using African-American contexts as prototypes of Black diasporic experiences and maps out the tense relationship between

\footnotetext{
${ }^{32}$ Appadurai, "Archive and Aspiration."

${ }^{33}$ Campt, Other Germans, 174.
} 
memory and diaspora for Afro-German populations. I would add that the idea of diaspora should also not serve to flat iron identities such as Jewish, queer and other notions that constitute the diversity and diversality ${ }^{34}$ of diaspora. What is particularly interesting in Campt's articulation of a "crowded space of diaspora," inspired by her encounter with Afro-German survivors of the Holocaust, is the role of memory in the formation of diaspora:

This complex technology of memory as an act of both remembrance and commemoration engages strategic forms of forgetting imposed institutionally from without as well as individually and collectively within specific communities. In this way, it is important to recognize that memory provides the source of the defining tension of diaspora and diasporic identity: the dynamic play of originary and imaginary homes, and the complex networks of relation forged across national, spatial, and temporal boundaries. ${ }^{35}$

If we read this quotation in light of Through Gardens, produced and performed by an AfroGerman choreographer, we may understand perforMemory as the site of creation of this "dynamic play." Moreover, if we agree with Campt that the Afro-German sociocultural context lacks certain forms of collective memory transmission usually found among other Black diasporic populations, then perforMemory appears particularly crucial. Although Campt does not refer to dance art, her reflection is relevant to all solos described and examined here. As suggested earlier, these performances of dis_placement interweave notions of memory and imagination, roots and utopias, and create new timespaces which are no longer bound to geohistorical boundaries. Impressions, Digital Middle Passage, and Through Gardens not only cross these boundaries, but actually challenge how they are traced. And if memory is indeed the "defining tension of diaspora," perforMemory works through the physical tension of muscles dancing diasporas.

\subsubsection{Diaspora, where do you come from?}

It is beyond the realm of my research to mention all coexisting and conflicting definitions of diaspora, ${ }^{36}$ however it is useful to reflect upon Black, Jewish and feminist diasporic genealogies and positionings in relation to memory. The term diaspora has become a landmark in cultural and postcolonial studies, irrespective of whether it is deemed relevant or obsolete. Diaspora's etymology is often constructed in reference to persecution, displacement and geohistorical origin-destination dynamics. In the Greek

\footnotetext{
${ }^{34}$ On "diversalité", diaspora, memory, history, and colonial power see for example Bernabé, Chamoiseau, and Confiant, Eloge de La Créolité, 37-39; Glissant, Le Discours Antillais, 126-61.

${ }^{35}$ Campt, "The Crowded Space of Diaspora," 101 My emphasis.

${ }^{36}$ Here I also think of the important, but androcentric contributions of theories of Stuart Hall, Homi K. Bhaba, James Clifford, among others. See for instance Hall, "Cultural Identity and Diaspora."
} 
language, speirein means "to disperse, to scatter," and dia means "through." In the introduction to Diaspora and Transnationalism: Scapes, Scales, and Scopes, Ato Quayson narrates "the polysemy of the historical context from which [the term diaspora] first emerged," ${ }^{37}$ in relation to Jewish history. Judith Butler offers a contemporary definition of diasporic Jewishness, in which the self cannot be thought independently from the "Other" in Jewish philosophy, theology and ontology. Departing from this, Butler contests Zionist definitions of Jewishness and more importantly argues for the right to define Jewishness as distinct from, against or beyond Zionism. ${ }^{38}$ Other Jewish diasporic definitions are proposed by Daniel and Jonathan Boyarin, who challenge normative conceptions of nation, religion and lineage and acknowledge the Powers of Diaspora. ${ }^{39}$ Like Butler, they are skeptical of a presumed western universalism and suggest a definition of diaspora which is broad, has space for multilayered identities, and is critical of genderism and Zionism, because according to them both subvert what they understand as Jewish ethics. In both Butler and Boyarin's work, ${ }^{40}$ diaspora is not (only) related to territory or land, it is a more or less chosen genealogy and a way of being in the world. The idea that diaspora is not only fraught with risks, but is also a source of power, is particularly fitting for performance analysis:

This is the paradoxical power of diaspora. On the one hand, everything that defines us is compounded of all the questions of our ancestors. On the other hand, everything is permanently at risk. Thus contingency and genealogy are the two central components of diasporic consciousness. ${ }^{41}$

Interestingly, envisioning diaspora as power is also an idea prevalent in Africanist theorizations of diaspora, as suggested earlier in the discussion of the notion of diasporacentrism. In the above-mentioned essay, for instance, Tina Campt refers to Audre Lorde and her foreword to Showing Our Colors: Afro-German Women Speak Out (the English language edition of Farbe bekennen). ${ }^{42}$ For Audre Lorde, Afro-descendant citizens share an African cultural heritage that is a source of strength. Whether Jewish or Black, this understanding of diaspora echoes André Zachary's perception of Afrodiasporic ancestral connections, as described in his commentary on Digital Middle Passage. And at a metalevel, my research itself regularly jumps between Jewish and Black diasporic consciousness. Or maybe they are interwoven into a vast net of interconnected performative meanings. Whether or not they explicitly evoke the term "diaspora," I find a

\footnotetext{
${ }^{37}$ Quayson and Daswani, "Introduction - Diaspora and Transnationalism: Scapes, Scales, and Scopes," 8.

${ }^{38}$ Butler, Parting Ways.

${ }^{39}$ Boyarin and Boyarin, Powers of Diaspora.

${ }^{40}$ For a nuanced comparative critique of Butler and the Boyarins, see Cooper, "A Diasporic Critique of Diasporism."

${ }^{41}$ Boyarin and Boyarin, Powers of Diaspora, 4.

${ }^{42}$ Lorde, "Foreword to the English Language Edition."
} 
powerful diasporic consciousness pervades all the performances. As reflected in the interviews, the choreographers dig into cultural legacies of struggle and strength to create a work that can speak to any audience. Here, risk is intrinsic to the choreographic process: the risk of disclosing one's diasporic self and the risky opportunity to challenge social power relations.

The Boyarins warn against the risks of grouping under the one umbrella-word, diaspora, contexts that are too diverse (e.g. Black diaspora, Chinese diaspora, etc.). Although I understand where these worries come from, I argue for a renewed conception of diaspora, which allows for multiplicity without masking diversity. While the authors consider "the repeated experience of rediasporization"43 to be a specific feature of Jewish identities and itineraries, I contend that all diasporic communities may experience constant and/or continuous diasporization. Palestinian dancer Farah Saleh's account of her biography and the shuffling across countries offers such an example of permanent "rediasporization." Wan-Chao Chang for instance, deals with the multiple diasporic experiences of being a Chinese in Indonesia, a Taiwanese in the USA, and a newcomer in her birth country Taiwan, as reflected in her words and works. This to-and-fro materializes in her use of space in Impressions, and the (eventually released) tension of the cloth that binds her to the pillar, always pulling her back like a magnet, or like the memory tension that forms and informs her diasporic identity, to come back to Campt.

I hope it is clear by now that I understand "diasporic dance art" as a form of connection, a tool of analysis that supersedes the plurality of geographical locations or sources of diasporic or racialized identity (Caribbean, Afro-German, Afro-American, Palestinian, Chinese, South East Asian). This is also reflected in the plurality of words that the choreographers use to define their work: Oxana Chi's "fusion" of diverse influences, WanChao Chang's "ethno-contemporary," ${ }^{44}$ Chantal Loïal's "laboratory." Moving alongside the choreographers, I often observed how people begin by asking them "What kind of dance do you make?", as if every dance could be defined within the perimeter of one or two words or the timespace of one or two minutes. The question, rather, may be what researchers and audience members make out of the dances which the choreographers make. Labeling a dance, especially in an academic context, is an ongoing concern in my work. Muñoz contends that a process of "world-making" is at work in pieces produced by

\footnotetext{
${ }^{43}$ Boyarin and Boyarin, Powers of Diaspora, 11.

${ }^{44}$ With this term, Chang refers to a contemporaneous renewal and transformation of various traditional forms of dance. For a critique of the label "ethnic", see Foster, "Worlding Dance," 2"The substitution of 'world' for 'ethnic' at UCLA and in various labeling practices, such as the music industry and arts programming, has worked euphemistically to gloss over the colonial legacy of racialized and class-based hierarchizations. [...] Yet through this relabeling, the colonial history that produced the ethnic continues to operate."."
} 
performers of color. ${ }^{45}$ Scholars writing about performance indeed also create worlds, they trace boundaries and create maps in their writing, delineate performances and performers in space and time and assign interpretations, which may be in resonance or dissonance with the artists' intentions regarding the dances. Researchers should therefore ask themselves, as does Susan Foster: "What kind of worlds do we as scholars create for a given dance when we undertake to describe and analyze it?"46 The word/world I "create" for now is a diasporic one, where diaspora is the texture out of which I weave my analysis of perforMemory. And when I choose to write or speak of "diasporic dance," rather than "Black Dance," ${ }^{47}$ I open diasporic worlds, characterized by the mobility of dance as a vector for shifting identities and diasporacentric performances, rather than diasporic dancing subjects.

\subsubsection{Queer [in] diaspora}

One of my most memorable experiences of New York's diasporic dancescapes involved spending time at the Bronx Academy of Arts and Dance (BAAD!). Oxana Chi performed there twice, in a lovely theater run by two queer Latino artists: dancer Arthur Aviles and writer Charles Rice-Gonzalez. The first time, in 2015, I sat in the last row among an enthusiastic and attentive crowd, and videotaped the premiere of Oxana Chi's solo Psyche at the BlackTinX Performance Festival. At the front of the theatre, my doctoral self discovered a couple of shelves of dance theory and magazines. I bought a book entitled Performing Queer Latinidad. The second time, in 2016, I found myself on stage in Chi's piece I Step On Air. In the context of the yearly women's month festival, we shared the evening with Black lesbian dancer-choreographer Maria Bauman, whose company motto I mentioned in the first chapter: "Sweat your truth!". To me, it expresses with such humor and accuracy the physicality of the knowledge generated by dancers, the materiality of their work and the corporeality of their social engagement. This incentive has stayed with me ever since, as I sit typing these words, as far as I could possibly be from sweating, sipping some more yogi tea to restore the body heat swallowed by the machine, looking back at my yoga set of the morning and looking forward to going to dance class tonight. With every drop of the dancer's truths, the stage becomes a flowing river of knowledge about the past and what it means to our present.

Acting and playing music in I Step On Air that night, in accompaniment to the dance solo, I felt how in the space of performance, Oxana Chi and I were creating a queer

\footnotetext{
${ }^{45}$ Muñoz, DISIDENTIFICATIONS. Queers of Color and the Performance of Politics.

${ }^{46}$ Foster, "Worlding Dance," 3.

${ }^{47}$ On the question of (not) defining Black dance, see: Allen, "What Is Black Dance?"; Dixon Gottschild, The

Black Dancing Body; and George-Graves, Urban Bush Women.
} 
diasporic space of remembering for May Ayim that was simultaneously accessible to the US-based audience, their aspirations and imaginations. The BAAD! Venue felt like a queer diasporic home because of the staff and artists, their energies and performances. Later at home, I was to start reading the book I had bought there, enjoying Ramón $\mathrm{H}$. Rivera-Servera's discussion of choreographies of queer latina/o resistance at BAAD!, and other "counterpublicspaces" where identities of queer latinidad are realized in and through performance. The author argues that:

[...] performance functions as a site where marginalized communities, such as queer Latinas/os, make home by participating in embodied experiences with others in the midst of travel to collectively devise strategies of being and being together. ${ }^{48}$

That night we performed at BAAD!, I felt indeed a sense of togetherness through movement. I was also touched by the programmers and audience's expression of gratitude for a performance that made them feel empowered - as Black lesbians, as artists, as people of color - but also people bonding in humanity across boundaries of race, age or gender. \#grateful was also the hashtag used by dancer Maria Bauman in a Facebook post from March 29, 2016, in which she thanks her crew, BAAD!, and ends with the words "Oxana Chi and Layla Zami were inspirational. Watch out for more split bills from us!" Indeed, a few months later, she invited us to be a part of her program at NYU Jack Crystal Theater, in which Oxana Chi participated, while teaching obligations for my "Performing Memory" class kept me in Berlin. In my experience, the performance I Step On Air contributed to creating a diasporic space of collective remembrance and resistance. The audience strongly identified with May Ayim's biography - evoked by Oxana Chi's movements - and May Ayim's poem "Gegen Leberwurstgrau für eine bunte Republik," ${ }^{49}$ which I performed in its English translation. Chi, as an Afro-German performer commemorating and celebrating the Afro-German historical feminist Ayim, fashioned through dance a diasporic storytelling that made sense across definitions and populations of diaspora. Performing Psyche and I Step On Air, she inscribed her perforMemory into the dancescape of New York City. Not only did BAAD! become a temporary space for Oxana Chi's perforMemory, but her own act of dancing became the dynamic site of a memory2go that a plurality of individuals could take home that night.

The idea of diaspora is inextricably embedded in paradigms of migration and gender, and an expanding field of queer diasporic studies challenges diaspora studies to move beyond heteronormative understandings of migration movements, family and exile. ${ }^{50}$ For

\footnotetext{
${ }^{48}$ Ramón H. Rivera-Servera, Performing Queer Latinidad, 29.

${ }^{49}$ Ayim, Blues in Schwarz-Weiss.

${ }^{50}$ See, for example, Ellis, Territories of the Soul; Hayes, "Queering Roots, Queering Diaspora"; Johnson and Rivera-Servera, Blacktino Queer Performance; Gopinath, Impossible Desires; Boyarin, Itzkovitz, and Pellegrini, Queer Theory and The Jewish Question.
} 
example, Fatima el-Tayeb uses diaspora "to describe a population that does not share a common origin - however imaginary it might be - but a contemporary condition." 51 Moreover, she defines "queering ethnicity" as a strategy of diasporic citizens, the "strategy of claiming a space within the nation by moving beyond it." ${ }^{52}$ Reminiscent of strategic essentialism's adherence to the nation framework, the definition simultaneously takes a deconstructionist step out of the nation-state category. Again, I am reminded of dancer Chang's dialectical holding onto the red ribbon, which pulls and pushes her. I may also think of Saleh's performance of Parole, Parole, Parole at the Tanzquartier in Vienna. The dancer progressively claimed a space within the room: when she moved around and between the audience members, who were scattered around the room, the attendees created a half circle, which I interpreted both as a desire to grant her enough space to move, but as spatial distancing from the performer's body. There she was, a Palestinian citizen reclaiming space within an Austrian cultural venue, and eventually coming close to the Vienna audience, attempting to ignite a connection to people who were trying to understand what they saw.

Oceanic forces sometimes carry diasporic entities, as evoked in Maya Angelou's poetry which opens this chapter. In Black Atlantic, Queer Atlantic, Natasha Tinsley Omise'eke criticizes the androcentric bias of Black studies scholars and their failure to account for queerness, while she regrets the widespread absence of blackness in western feminist theory, e.g., in Butler's work. By "reading for Black queer history and theory in the traumatic dislocation of the Middle Passage," ${ }^{53}$ she anchors Black queerness in Afrodiasporic history and rejects polarized accounts of queer and diasporic themes in academia. Omise'eke's vision of Queer Africana studies emphasizes the potential role of metaphors to "provide conceptual bridges between the lived and the possible that use language queerly to map other roads of becoming." 54 She wants her essay "to perform the oceanness that it thematizes." ${ }^{25}$ In perforMemory, the performance of energies is inherent to the treatment of a specific topic, as is the case in Zachery's performance of oceanic migrations and interrogations. In perforMemory, the dances per se perform and transform the topic, issue, question, or mood they handle.

Black queer author Michelle M. Wright identifies the use of the autobiographical genre in literature, artistic and activist activities as a "diasporic strategy" ${ }^{56}$ used by Afro-

\footnotetext{
${ }^{51} \mathrm{El}-\mathrm{Tayeb}$, European Others, xxxv; See also more recently her analysis of Othering processes of Roma/Sinti, Muslim, and Black citizens, in relation to antisemitism and Holocaust memory in: El-Tayeb, Undeutsch.

${ }^{52}$ El-Tayeb, European Others, xxxiv.

${ }^{53}$ Omise'eke, "Black Atlantic, Queer Atlantic," 193 I found about out this article through Vanessa Agard-Jones'.

${ }^{54}$ Omise'eke, 212. I see parallels with the previously cited works by Lann Hornscheidt on language as epistemic violence.

${ }^{55}$ Omise'eke, 212.

${ }^{56}$ Wright, "Others-from-Within from Without."
} 
Germans. I believe that this "diasporic strategy" can be extended beyond the Afro-German context. However, instead of searching for the diasporic roots of the choreographers, I am more interested in examining the resonances between their work. As noted earlier, the seven solos proceed into what I call choreobiography, embedding autobiographical sources with historiographic quests and choreographic creativity. This may echo with the above cited diasporic works of Fatima el-Tayeb, Michelle M. Wright, and Natasha Tinsley Omise'eke and their theorizing of artistic expressions. Yet, dance is always missing in their approaches, as well as in other landmark works analyzing the power dynamics of identity constructions such as Mythen, Masken, Subjekte. ${ }^{57}$ Knowing all the difficulties inherent in the gendered, racialized, capitalized, ableist connotations of the body within hegemonic discourses of western heteronormative patriarchal capitalism, it is particularly interesting to look at how choreographers perforMemory in ways that present queer conventional representations of memory. I argue that the stage is a site where hegemonic spaces are referred to, while the dancers imaginatively and actually move beyond them. So, diasporic and queer strategies come together with performance strategies that share the challenge to "move beyond," ${ }^{58}$ negotiating steps which walk the path they are trying to leave.

Another intersection between Black and Jewish diasporas is their relation to forced dispersal and trauma, which in turn emerges in all performances. I reflected upon this in an autobiographical experimental piece of creative writing "Ein all_zu_täglicher Tag*,"59 published in the academic anthology InterdepenDenken dedicated to intersectionality. The story, merging years of experiencing discrimination in Germany into the density of a single day, attempts to render a sense of constant mobility that paradoxically is the only way to obtain stability and safety as a diasporic subject in the west. Scholarship located at the interstice between performance studies, queer studies and critical race theory demonstrates that positionalities of race, gender and sexuality are not only displayed by, but also performed by the body. ${ }^{60}$ For instance, in my view, Through Gardens offers a queer-feminist reading of Tatjana Barbakoff's diasporic trajectory from the perspective of Oxana Chi. Embodying Barbakoff as a strong diasporic female subject, distant from cismasculine and heteronormative assumptions, the piece performs diaspora as possibly queer, without representing queer sexuality. ${ }^{61}$ In the context of performance, dance art as an ontologically mobile expression permits new relations to trauma and diaspora. In her

\footnotetext{
${ }^{57} \mathrm{Ha}$, "Macht (T)raum(a) Berlin."

${ }^{58} \mathrm{El}-\mathrm{Tayeb}$, European Others, xxxiv.

${ }^{59}$ Zami, "Ein all_zu_täglicher Tag*."

${ }^{60}$ See, for example, Ramón H. Rivera-Servera, Performing Queer Latinidad.

${ }^{61}$ Zami, "Oxana Chis Tänzerische Wissensschaffung."
} 
discussion of diaspora in relation to queer archives, trauma and feelings - which also does not include dance - Ann Cvetkovich writes:

The presence of geographic dislocation in a range of trauma histories suggests the intersections of trauma and migration. For example, the trains to the concentration camps play a significant role in Holocaust testimony and memorial, and have additional resonance in the context of the Jewish diaspora. Ships figure prominently in the production of cultural memory about the Middle Passage, the traumatic process of transport from Africa to Americas. ${ }^{62}$

I n Through Gardens as in Digital Middle Passage, neither trains nor ships are represented. The performances deliberately renounce these iconic objects, using bodies instead as vectors of mobility. It seems that the dancers have the power to physically and emotionally relocate what has been "dislocated": memories, feelings, ambitions.

\subsubsection{From diaspora to diasporic}

The point where these Black, Jewish, and feminist definitions of diaspora and diasporic dances meet is in the affirmation of diaspora as an empowering force. Although fraught with obstacles, diasporic identity-formation entails the power needed to exist, subsist and resist in the "crowded space of diaspora." ${ }^{63}$ This space is not a clear blue sky. It may be a multi-textured horizon, constantly shifting according to the current position of the clouds of race, class and gender, and depending on one's standpoint. As one dives deeper into diasporic realms, more layers appear, constantly changing tone, as in the transformations of a long sunset. As mentioned earlier, diaspora has been extended far beyond its etymological origin to become a key concept, for instance in the fields of Africana studies. Edouard Glissant, a leading theorist of the Créolité movement, reminds us that the African diaspora is by no means only the transatlantic one. Mobility on and outside of the African continent began long before the arrival of Europeans, and continues until today. In an interview with Mantha Diawara, Glissant speaks about memory and defines diaspora:

It's the moment when one consents not to be a single being and attempts to be many beings at the same time. In other words, for me every diaspora is the passage from unity to multiplicity. ${ }^{64}$

The conversation was actually recorded on a boat traveling across the Atlantic...Glissant argues for the use of diaspora beyond the Jewish trope, reclaiming the term for the description of dispersal and mobility in other cultural and geo-historical contexts. The

\footnotetext{
${ }^{62}$ Cvetkovich, An Archive of Feelings, 120.

${ }^{63}$ Campt, "The Crowded Space of Diaspora."

${ }^{64}$ Diawara, "Conversation with Edouard Glissant Aboard the Queen Mary II (August 2009)," 59.
} 
ability to perform - and to be - several beings within one performance is the key to the most powerful performances. Dancer-choreographers train on a daily basis to realize this feat. They can render the complexity of historical figures, of contemporary inner and political conflicts within one performance or throughout their repertoire. To dance is in a way to become many beings at once, if they attempt to endorse multiple identities on stage. Chantal Loïal performs a historical narrative of Sawtche as much as she embodies her own story. Oxana Chi embodies Tatjana Barbakoff, May Ayim or Neferet iti...yet even as she inhabits them, she fills their narratives with her own self. Farah Saleh is all of her generational selves, and is any enamored Palestinian living in the situation she describes. Wan-Chao Chang is herself, is her parents on a diasporic journey, is the migrant person that watches her piece and identifies with her tale. Zufit Simon pushes to the extreme the coexistence of beings, shifting, changing, transforming within seconds from a welcoming smile to a breaking down in shivers. In this sense, I prefer to speak of a diasporic process than of diaspora as an entity. Particularly when it comes to the performing arts, the adjective offers more flexibility than the noun.

In this regard, Nadine George-Graves offers a definition which is more flexible than the roots narratives originally preponderant in theorizations of diaspora. She defines "diasporic spidering" as:

[...] the multidirectional process by which people of African descent define their lives. The lifelong ontological gathering of information by going out into the world and coming back to the self. ${ }^{65}$

What strikes me in George-Graves' formulation is the corporeality of the diasporic process at stake. Her rendition of "diasporic spidering" evokes a protagonist physically stepping in multiple directions on the stage, gathering and generating knowledge through movement. Knowing that a performance scholar coined this concept allows me to ask what it means if the metaphor is twinned with a material reality like the corporeality of dance. Moreover, this quotation suggests that the rediasporization invoked by the Boyarins may be as true for Jewish as for Black diasporic subjects. While Marianne Hirsch asks "what postmemorial practices, what alternate histories, are enabled by the tremendous capacities offered by the World Wide Web as an archival space?", ${ }^{66}$ Nadine George-Graves asks how spidering as a paradigm can pertain to performative and digital diasporic processes. This resonates with a pattern I found in all seven personal conversations I held with the artists. Each one of them reflected upon the way they connect the information found on their journey "out into the world" and how they process it

\footnotetext{
${ }^{65}$ George-Graves, "Diasporic Spidering," 33.

${ }^{66}$ Hirsch, The Generation of Postmemory, 228.
} 
within themselves. Yet, the shuffling between self and world is a circular, uninterrupted dynamic, and when the dancers perforMemory, they re-send information, diasporically processed, I may say, out to the world in the form of movement.

Nadine George-Graves was the research sponsor who officially invited me to conduct research at the Department of Theatre and Dance at the University of California San Diego, where I arrived in spring 2015. Destiny however led me to a new destination: New York City. Dr George-Graves assured me that we would meet on the East Coast, where she often has professional engagements in the performing arts world. By some diasporic spidering magic, we met sooner than expected, at the Bushwick Starr Theatre in Brooklyn, as we both attended the festival "Imagining Justice for the Dark Divine," curated by Jaamil Olawale Kosoko and Kate Watson-Wallace. I did not yet know that she had been involved in the works presented. On that opening night, the event ended with the performers gently throwing a big roll of thread to the audience. As they unrolled it, they invited each of us to pass it around. The thread connecting the audience members symbolized and materialized the "diasporic spidering" and its ongoing connective trajectories between diasporic subjects. There I was, holding onto a slim but nevertheless strong diasporic string that linked me to the dancers on stage, to Oxana Chi sitting next to me, and to my doctoral sponsor sitting behind me, among others: all of us were holding onto the diasporic condition.

Is this the feeling that Katja Petrowskaja strives to describe in her essay Vielleicht Esther (Maybe Esther), in which she narrates the quest for truth at the intersection between her family's story and narratives of Shoah history? ${ }^{67}$ The narrator describes her physical, geographic search for more information, the constant back and forth between the information collected from others and the implications of her own reflections. Petrowskaja wants to know the story of her grandmother, in a troubling territory where she cannot even ascertain her grandmother's first name, hence the book title. When the author uses the word "spinnen," evoking the German for spider, she refers to the activity of spinning yarn. She aims to find the lost threads ("verlorene Fäden") and stories that resist linearity, ${ }^{68}$ yet she lacks the appropriate tools to knit the story backwards. The spinning metaphor is reminiscent of the African-American women's quilt memory evoked earlier. What Petrowskaja's storytelling suggests is the fragility of the diasporic condition and the difficulty of any attempt to reconstruct the past.

Digital communication plays a role both in Petrowskaja's search for a Jewish past and George-Graves' theorization of Black diasporic practices. In the digital age, when not only diasporic threads, but also wireless networks connect us through the air, diasporic

\footnotetext{
${ }^{67}$ Petrowskaja, Vielleicht Esther.

${ }^{68}$ Petrowskaja, 134.
} 
spidering moves at the junction between the motif of crawling found in the traditional African myth of "Anansi," and the modern technology of web networks. The European essayist-journalist and the US scholar-dramaturg, each in a completely different cultural setting, shared a sense of diasporic identity as a process that is performed at multiple levels, rather than a fixed identity. Moreover, both quests revolve around the present in which diasporic memory is being fashioned. For George-Graves, "African diaspora (and Black identity) in this sense becomes also a contemporary active process - an act, a performative." ${ }^{\text {"99 }}$ This proactive aspect of identity-formation becomes particularly interesting in relation to the performing arts. For instance, for the dance They Call You Venus, Chantal Loïal collected "Black Venus narratives" as much as building on her own personal assumptions about what Sawtche's biography may have felt like. When she dances around the accessory of the skull, or liberates herself from a cloth bound around her chest, she accesses the performative truth that lies in-between what has been written about Sawtche and her own biography and biographical identification. Similarly, in Through Gardens, Oxana Chi switches back-and-forth between historical archives detailing Tatjana Barbakoff's story and her own process of choreobiographing Tatjana Barbakoff - accessing a story of her, a possibility of a story - through choreographic investigation and imagination. Wan-Chao Chang's dance threads around three islands from Java to California and Taiwan. Farah Saleh anchors her work in the dialogical relation between a permanent nomadism and a strong connection to the space of Palestine as a homeland.

I argue that the notion of "diasporic spidering" outlined above is relevant not only to the four Afro-descendant dancers, but to all seven artists discussed here. While in the next chapter, I will specifically come back to the relation between performativity, time and identity, for now I want to highlight the interconnections between diaspora as a conceptual umbrella, the stage as a diaspora space in Avtar Brah's sense, and performance as a mode by which diaspora as motion, diasporic motion can be created. I may say that all the choreographers included in my research do share a contemporary condition as artists dwelling on their multilocational cultural heritages to perform alternative visions of presentrelevant memories, and this is how I wish to bring them together, regardless of the nationalist and geohistorical factors that might separate them.

Here I define the dances as diasporic, because I contend that through their dance performances, the dancers fill diaspora with meaning. The result is not diaspora as an essence inherited through genealogy or geography, but diasporic motion as constantly reimagined on stage, through the body. At the beginning of this section, I asked: "What is

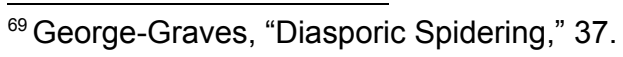


this diasporic condition we hold onto?" A possible answer can be found in conceiving of the diasporic condition as a string indeed, created in the dance for us and the dancers to hold onto. If the diasporic condition is a string, it is the texture of perforMemory, generated, like silk, by living and moving bodies. PerforMemory, like silk, is originally bound to the body that creates it, yet it can be collected and processed without harming its creator. When dancers release diasporacentric dances to gift us with their silky perforMemory, they offer us a chance to transform it, to receive a piece of cloth that we can try on at home. 


\subsection{The Stage as a Diasporic Space}

I sit in the Pratt Library, Brooklyn campus, my eyes temporarily resting from the blue light emanating from the laptop screen, looking out the window onto the green. I remember flying over the Transatlantic axis, and physically shifting my working environment from Europe to the USA. I reflect upon other beings who crossed the Atlantic, at other times, by other means, think about the strenuous Middle Passage and the diasporic webs it unfolded. Obviously and luckily, my flight is in no way comparable to the shipping of bodies several centuries ago, some of whom may have been my African and Indian ancestors arriving in Martinique. I keep thinking about what binds diasporic descendants of the Middle Passage to each other, knowing that it is so much more complex than it often seems.

My thoughts rewind to a few days earlier when, after completing my writing routine at Pratt, I took a walk to the Irondale Center where the Renegade Performance Group (RPG) was to debut its performative "Afrofuturism series." I was excited to finally view the work live after having followed their virtual evolution online. Now I even feel like a remote part of their galaxy because I responded to their call for donations to support the series. RPG Founder and Artistic Director, André M. Zachery is a choreographer, dancer, and multimedia artist, whose passion incites respect. He performed a powerful solo entitled Digital Middle Passage. The ebbing and flowing movements executed to a restless live-music were often propulsive, sometimes tender. The video technology designed by himself, as well as his choreography, disclose cyclic patterns. Circumambulating on stage, sometimes on the floor, sometimes in aerial jumps, the dancer's body draws the picture of an ever-present Middle Passage, not bound to spatial or temporal limits. The mostly Black audience seemed to travel with him to a realm where they could re-imagine the past in the hope of a future. ${ }^{70}$

\subsubsection{Diasporic space is the place}

\subsubsection{Passing through the stage space}

Digital Middle Passage epitomizes the driving force behind diasporic movements of memory. In my view, it thematizes contemporaneous forms of violence against Black bodies in the public space as much as it does the historical mistreatment of African bodies

\footnotetext{
${ }^{70}$ Zami, “Research Diary - Unpublished Manuscript” Brooklyn 10.11.2015.
} 
and their forcible displacement to the American continent. It connects ancestral spidering to digital web networks in the contemporary diaspora. Performing Digital Middle Passage, Zachery imagines and experiences what it may be like to return to a place and time to which you have never been. This piece, a part of his Afrofuturism Series, is nevertheless embedded in ancestral memories of a Caribbean-African heritage, as you can tell from his interview. The performance confers a physical reality to the paradigm of "culture as a site of travel." ${ }^{71}$ PerforMemory lies and lives at the crossroads of memory as a site of movement and diasporic motion. The above quoted excerpt from my research diary, written at the end of 2015, connects the diasporic condition evoked in this chapter to memory and movement. While perforMemory may not be solely a diasporic matter, diasporic stories can sometimes only be transmitted and archived through perforMemory. For the Generation of Postmemory ${ }^{72}$ that blossomed on the graves of their ancestors' trauma, the body becomes a site and source of historical archive in the diaspora. Embodying diaspora, history, home and trauma, and performing them on stage, helps to convey a sense of historicity and meaning-making in the present. Diasporic dance performances in the $21^{\text {st }}$ century can stage alternate narratives of and perspectives on the past, offering perforMemory as a tool to understand and transform the present. The performing-spidering, not only in the space of the World Wide Web, but in a wide array of worlds brought onto and created on the stage space, transforms the stage into a diasporic space.

Drawn to Afrofuturism, Zachery is animated by the will to find alternative definitions and forms of existence for living in a Black body carrying past experiences of the Middle Passage and present experiences of migration:

So I am now asking: well, how do we remix that experience [of the Middle Passage] to reconsider that moment of transformation for this idea of Afrofuturism? In the sense of relating it to Sun Ra's Space is the Place (the movie where he leaves Earth and he finds another planet to exist in liberation), this solo is about a speculative experience for blackness in the present moment. What is it that, where is it that we can metaphorically go from this state of constant, you know, resistance and revolution within our bodies and in our psyche, to a space where we can define a landscape, or planet, galaxy, atmosphere of an existence independent from whatever circumstances that we had prior, meaning on Earth, or in the United States or wherever you're from in this realm of the diaspora. ${ }^{73}$

If for Zachery and others, diasporic space is the place, diaspora may be the solar center around which the dancescapes orbit in a diasporacentric fashion. Circling is a key movement of perforMemory, as I will show in the last chapter. The stage may well be the

\footnotetext{
${ }^{71}$ Clifford et al., "Travelling Cultures," 3.

${ }^{72}$ Hirsch, The Generation of Postmemory.

${ }^{73}$ Zachery, interview.
} 
place where choreographers are in control of the atmosphere. Rather than performing Blackness, Jewishness, Europeanness or performing Chineseness, it seems to me that Oxana Chi, André Zachery, Wan-Chao Chang and others perform a kinetic search for belonging within the spaces of diaspora. Because they sculpt diaspora within rugged dancescapes, their performances epitomize physical mobility and personify emotional and political mobility.

The Anansi-spider story is also constructed as a story about the spider deity leaving Earth, reaching beyond the realm of human knowledge, and coming back to it. The trickster god, sometimes held to be the creator of the world, and commonly known as Anansi in the West African geocultural space, lives in the storytelling that brought her/him/them all the way to the American continent. Somewhere in the diasporic time space travel, Anansi's name and identity changed. Today, African-American and Caribbean stories tell of the superpowers of Aunt Nancy or Brother Nansi. What the dancers share with these diasporic spiders is the power to create diasporic worlds. While Anansi is seen as having the power to reach the realm of God, dancers connect with ancestors, with spiritual forces, to create, choreograph and dance, as expressed by Chi and Zachery in their interviews. No matter how futuristic their pieces may be, they resonate with a centuries-old tradition among Black, Jewish or Chinese diasporas, of passing down memory through arts and storytelling. Today, as Anansi is embodied in a modern animation blockbuster, Zachery offers an alternative tale without words, performing his version of the Middle Passage and transition. To do so, he may be using traumata recorded in his body cells as much as his creativity and computer skills. The result is a modern tale, accessible across generations without the necessity of mastering a specific language, such as English or French. It transmits not the statistical memory of the Middle Passage, but the impressions of it as they may have left their imprint within bodies. On stage, dancers may acquire the capacity to "define the landscape" and "the atmosphere," as evoked by Zachery. Regardless of the analysis that may be produced on their works thereafter, they create worlds of their own, and let the audience travel with them.

Sometimes dancers work together with scenographers to actually shape the use of space. For instance, Christiane Emmanuel collaborated with Valérie John to achieve the spectacular scenographic décor of the piece Choc(s). Valérie John, also a Martinican artist, usually works with visual arts. Much of her work is centered on themes of "déplacement" (displacement) and "dépaysement" (which can be translated as a disorientation produced by a change of country - le pays - or place). Speaking of displacement in art, John describes a patchwork approach to art as both an action and a result: 
The artist does patch work in order not to get lost. [...] The artist transports what s/he accumulated over the journeys which s/he compels her/himself to undertake outand inside the art work. The artist wants to be the sea for its multiple transformations, and more so, the backwash, the undertow of waves on themselves after they hit an obstacle or the riverside.

(L'artiste rapièce pour ne pas se perdre. [...] L'artiste transporte ce qu'il a accumulé lors des voyages qu'il s'impose hors et à l'intérieur de l'oeuvre. L'artiste veut être la mer à cause de ses multiples transformations et plus encore le ressac, ce retour des vagues sur elles-mêmes après avoir frappé un obstacle ou un rivage. $)^{74}$

I find striking similarities between John's vision of her visual work and Zachery's commentary about and the reality of his choreography, in which he spins on himself, and seems to constantly have to face the backwash that rolls him backwards to the right of the stage. In this Afrofuturist Middle Passage, I witness all of these elements, the patchwork, the backwash, the ocean and Maya Angelou's exhortation to "rise" above a sometimes painful, biased and painfully biased historiography. In Zachery's journey through watery perforMemory, I see and experience sometimes sequentially, sometimes simultaneously, the transtemporal flesh of Christina Sharpe's multiple definitions of the "wake."75 The wake can be "the track left on the water's surface by a ship; the disturbance caused by a body swimming or moved, in water" or a "state of wakefulness." It can also be the memorial spacetime "grief" and "celebration" in which a ritual is held for the death. ${ }^{76}$ Therefore Zachery's perforMemory of the Middle Passage across space and time may bear affinities with Sharpe's ontological reflections on Black beings.

Patchwork is also the leitmotiv used by Valérie John in her design of the scenography for Christiane Emmanuel's Choc(s). Hundreds of white shirts cover the back wall of the theater, while dozens of others are piled up in a big bundle occupying the center of the stage. Later, the dancer will search through this pile, and find pieces of colorful clothing, which she will put on, resulting in a surrealist patchwork costume. The initial disorientation, effected by the white shirts, disembogues into a re-structuring of the space, and now Emmanuel moves with confidence. The solo actually starts with the dancer hanging high up in the air, stepping, running, reaching for an invisible goal, later she will run around on the floor stage, actually traveling through the piece. Both $\operatorname{Choc}(s)$ and Digital Middle Passage share a generous occupation of the whole stage as a space to be traversed, be it from above as Emmanuel, or rolling over the floor as Zachery. In both soli situated in the de-layed wake of slavery, the performer's quest, sometimes in slow-motion, sometimes in high-speed tempo, is a quest for space, a will to occupy multiple locations and find stability on moving grounds.

\footnotetext{
${ }^{74}$ John, "De lieu en lieu(x)," 131 [My translation]..

${ }^{75}$ See Chapter 1 in Sharpe, In the Wake: On Blackness and Being.

${ }^{76}$ Sharpe, 21-36.
} 


\subsubsection{The stage as a home}

Walking in the air, five meters above the stage, Christiane Emmanuel makes me think of a surreal nightwalker in the dreamlike beginning sequence of $\operatorname{Choc}(s)$. When it comes to dreams and space, Christiane Emmanuel fulfilled what she calls "the biggest dream of her life," which was to turn her ancestral family home into a dance center. In the interview, she explains how she created a performance space on the rooftop of the house:

By the way when I created this place, and when I started doing projects in this space, I chose the title "setting dreams into motion," simply because for over 20 years it has been my dream to build, to turn the roof deck into a dance space... Things went quickly, and now the deck of the Red House, the House of Arts is actually the family house that I was born and grew up in. ${ }^{77}$

Space matters to Christiane Emmanuel. Her work strives to expand notions of spatiality and to shape space through movement - an approach which is in turn influenced by the space the dancers occupy. Diving into her work (process), space seemed omnipresent: while viewing her performances, while conversing with her at her studio in La Maison Rouge/Maison des Arts, and while listening to her presentation at the Habitation Clément (a former plantation turned into a museum and cultural center). In the interview, Emmanuel emphasized how working with space is at the core of her practice as a choreographer, and compared the dance practice to architecture. She is herself indeed an architect of dance and a dancing architect, especially since she initiated the architectural transformation of her parent's house to accommodate her dance practice center. Visiting her dance studio, one experiences kinesthetically the intricacy of personal and professional spheres. On the ground floor, one observes that the reception hall and office are steps away from the home's kitchen. And to reach the studio on the highest floor, you pass the floor on which her mother lives, a mother appeasing the space with the energy of a woman taking rest after having raised ten children. The choreographer puts the Maison Rouge at the center of her working process, thus reversing the process by which the socalled "ultra-marins" (overseen citizens from the French oversea departments) are pushed out to the periphery of France. The space of France, where she experienced both success and racial marginalization during her tours, is no longer a center for Christiane Emmanuel, but a periphery which is faraway from her home/dance/island center, and therefore no longer central to her work. When I interviewed her, she was just returning from a festival in Ouagadougou, Burkina Faso, where she had performed upon an invitation by curator dancer Irène Tassembédo. She explained how francophone Africa festival structures exclude Caribbeans, thus impeding the exchange between Caribbean and African

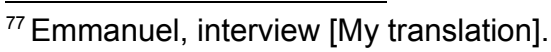


choreographers, who are neither financially nor structurally encouraged to work with each other. By traveling to the "root" continent, she managed to counter this hegemonic relation and to create a new relational space, where Martinican dancers performed for an international audience in Burkina Faso, among other African artists and audiences. Also, through her residency program (which I witnessed in 2014 as an observant-participant when Oxana Chi was in residency), Emmanuel herself regularly invites artists from the Global South and artists of color based in the west, to work in the studio space.

The transformation of her childhood home into a home for dance allows Emmanuel to occupy a stage, where she is in charge of the landscape, the timescape, and the dancescape. This does not prevent her from working in various spaces with her dancers, when the choreography requires it. For instance, when she created the piece Mangrove, commissioned by the Regional Office, and inspired by Wifredo Lam's iconic "Jungle" painting, the choreographer asked her dancers to rehearse and experiment in the open air to help them integrate a feeling for the Caribbean environment into their motion. In order to work with dancers on the bodies-as-cane-reeds depicted in the painting, she felt the need to improvise with them outdoors, on the theme of verticality, in the Martinican forest. $^{78}$

What André Zachery calls "defining the landscape" can also be shaping the home, and occupying the stage as one's home. Let us move from forest to gardens, to explore the relation between stage, environment and spatiality. Especially when I witnessed Through Gardens "from within," as one of the cast's musicians in Dresden and Berlin, I felt that Oxana Chi also occupied the stage space as a home. Not only does Oxana Chi inhabit the biography of Tatjana Barbakoff, she also seems to transform the dance space into a house where she lets the audience in. When she choreobiographes the story of Tatjana Barbakoff, it is as if she is decorating the house of memory, hanging the painting of memory2go on the walls. This happens regardless of the venue size, from a huge openair festival stage in Solo, Indonesia, to the intimate space of the Societätstheater at the Jewish Festival in Dresden. The dancer-choreographer needs to adapt the choreography to the spatiality, which in turn has impact on the timing of the music, the pace and the sequencing. For instance, crossing the stage from the back left corner to the front left corner will take much less time if the piece is performed on a smaller stage. Just like diaspora space and the multiple positionings it requires, the choreography evolves with the context, as the dancer sculpts space by moving through it. In the scene of the Chinese Dress described earlier in this chapter, the stage also becomes a diasporic home where multiple identities, imaginings and belongings can coexist without entering into conflict or

\footnotetext{
${ }^{78}$ Emmanuel, "Rencontre."
} 
collision. When she picks up the dress and inhabits it, slowly bringing it back to life through her movements, she creates a melancholic atmosphere, inviting us to enter the memory of Tatjana Barbakoff through the memory of Tatjana's appreciation of her mother's silk clothes. ${ }^{79}$ In this space of multiple diasporic identities, the stage offers the possibility to re-play history and to perform a new memory.

In Parole, Parole, Parole, Farah Saleh actually transforms the stage into a place that feels like home, since she invites the audience to witness a private Skype conversation. Is the stage also a home to Farah Saleh, or to Wan-Chao Chang, who relate of their nomadic condition and diasporic routine? Or for Chantal Loïal, who grew up between Guadeloupe and metropolitan France? What is the relation between occupying the stage as a physical home, a center where one is grounded, and turning this stage-home into a home for perforMemory, a place where the dancers and/or audience can attain a sense of home because of their own existence in the space - or to represent other's existence on stage?

PerforMemory unfolds itself in real spaces which themselves function as the scenery of the imagined spaces arising in the interaction between kinesthetic storytelling and the audience's interpretations. In a context in which independent dancers have limited access to resources for scenographic design, choreographers devise resourceful ways to produce intense pieces relying solely on the dancers, and which can be adapted to various stage sizes. Thus, the narrative, message or energy conveyed is not bound to specific physical surroundings. The stage spaces invested by the dancers do not necessarily tell stories in themselves, but they can be transformed by the performances and become a projection area for the embodiment of memory.

\subsubsection{Finding a home space in the dance place?}

\subsubsection{The dancing body as a home}

The question of (not) belonging to a cultural, geotemporal and artistic framework appears in all the seven conversations I held with the dancers, regardless of their geographical and genealogical positionings. Despite the fact that each artist has a very distinct choreographic style and repertoire, parallels in terms of intentions, preoccupations and processes emerge from the dancers' voices captured on paper in the final chapter. Particularly in relation to diaspora, one may see convergences between them, for example

\footnotetext{
${ }^{79}$ Chi, Tanzende Erinnerungen, 2011.
} 
between André Zachery's investigation of Black diasporic experiences in the USA, and Wan-Chao Chang's (a former "alien" citizen in the United States) search for a place and a culture to feel at home with. On October 11th, 2009, Chang performed a solo entitled I Thought Here Is My Home at the COUNTERpulse Festival in San Francisco, where she also participated in a public discussion about "dancing diaspora." The title in itself expresses the intricacy of diasporic trajectories and identities. Which "here" does the artist refer to? Is it Indonesia, a place her parents grew up in, and left? Or the USA, where despite all her successes, she could not shed her "immigrant status"? Is it Taiwan, to where she returned, yet which also did not feel like "home"?

Can the diasporic space of the stage become a space where the dancer will feel at home no matter where she goes? Or is the home bound to the dancing body and its movement in the performative here and now? In my understanding of Chang's words and works, especially in Impressions, the perforMemory space seems to offer the dancer a temporary relief, a shelter for questionings about identity and belonging. To perforMemory is not always to answer these questions, rather it may be to express the questions differently, like moving from discordance to concordance in a musical harmony. In the solo I Thought Here Is My Home, the body is at home in the scarf-like cloth wrapping the dancer's waist. But the cloth slips away from her, as swift as a letter may drop from a word. And there is no more space to call a home, to inhabit as a home but one's body. ${ }^{80}$

The body is at home

The body is a home

The absence of a single letter, or of a prop, inflects the meaning of the sentence. Similarly, in the seven works of perforMemory, there is an epistemic proximity between occupying the stage as a home for the dancing body, and inhabiting the body itself as a diasporacentric home. This spirals the argument back to the metaphor used by DeFrantz and Gonzalez, and evoked earlier in the introduction, according to which diaspora is akin to a "flexible and self-repairing" skin that both makes us vulnerable and safe. ${ }^{81}$ To inhabit the body as a home may be a rare constant parameter in a diasporic dance environment marked by movement, transition, and transformation.

Searching for a place to call home can be a collective endeavor. In a group piece, entitled Keep Her Safe, Please!, which also draws from I Thought Here is My Home, WanChao Chang blends Chinese-Taiwanese and Indonesian cultures and movements. Yet amidst the group choreography, Chang sometimes remains alone with her movements. At one point a circle of dancers breaks apart, and she becomes a soloist on stage. A long white cloth bound around her waist supports the dramaturgy. Twice, the dancer attempts

\footnotetext{
${ }^{80}$ For interesting developments on the body as a home in relation to race and gender, see Cox, Shapeshifters.

${ }^{81}$ DeFrantz and Gonzalez, Black Performance Theory, 11.
} 
to cover herself with it. She picks it up from the floor and delicately covers her shoulder, as if it were a scarf. But as soon as she starts to move in it, as if to enjoy the soft touch of it, it drops to the floor. She picks it up again, this time with a different energy, faster paced, almost anxious, she spins on herself and then throws the cloth on her upper body. But once again, she fails to find a long-lasting way to move with(in) the cloth, for it immediately falls to the ground against her will. Like the diasporic skin mentioned earlier, the cloth seems to represent the nerve-racking fragility and ephemerality of "home" in the diaspora. A simple accessory frames the movements of a diasporic identity, exteriorizing the unstable and precarious layer we carry within us, the fleeting and changing notion of belonging. The dancer then engages in multiple twists and finally leaves the stage with the cloth on the floor. This very focused moment of the performance is followed by a group choreography in which the dancers constantly change positionalities, crossing the material and metaphorical diaspora space of the stage with movements both vertical and horizontal. The multilocationality of diaspora theorized by Avtar Brah, and the process of "homing diaspora and diasporising home" ${ }^{22}$ can be achieved on stage. Moreover, in this diasporic space of the stage, the performing body becomes a locational space in itself, which is able to "continually challenge the minoritising and peripheralising impulses of dominance" ${ }^{\prime 3}$ by moving center stage. Avtar Brah also asks:

When does a location become home? What is the difference between "feeling at home" and staking claim to a place as one's home ${ }^{84}$

When choreographers and dancers coming from marginalized sociopolitical locations transpose the space of the margins to the center of the stage, they potentially enact a huge effect on hegemonic relations. At least in the time-space frame of the event in which they perform, they move from the margin to the center, not only transposing themselves to the center (of the stage, the narrative, the performance) but actually transforming what a center is. Dancers travel through space and time, materially on stage and metaphorically. So maybe their diasporic journeys are about settling down their imagined and imagining selves in the instantaneity of the performed moment, and furthermore inscribing their narratives into history, through perforMemory.

Dancing allows for a shifting conception of home, which can be claimed in any space as long as the dancer is alive. Dancers share with vocalists the singularity of an art that resides within the embodiment of their selves, independently from any accessory such as a canvas or an instrument. Defining dance (space) as home means challenging

\footnotetext{
${ }^{82}$ Brah, "Diaspora, Border and Transnational Identities," 623.

${ }^{83}$ Brah, 633.

${ }^{84}$ Brah, 623
} 
conventional inscriptions of home in terms of geographical boundaries and ascriptions of bodies according to historical-cultural norms. When scholar Chandra Talpade Mohanty asks if home is "a geographical space, a historical space, an emotional, sensory space?" 85 my answer, in this case, is yes, yes, yes and yes. The confluence or overlapping coexistence of geography, history, emotions and kinesthetics within the dancing body is a strong argument that emerges from my interpretation of the works and from the conversations I held with the choreographers.

The focus on solo performances invigorates the sense of the body as a home. For most of the choreographers I discuss, the solo form is rather exceptional. Oxana Chi, by contrast, is a choreographer who usually works as a solo dancer-choreographer, although she collaborates with other artists to incorporate live-music. She explains why she prefers to work and perform alone:

So when I dance, I try to pour myself more and more into the dance, and my body...to give everything that is possible to give. And if I must work with other dancers, I won't be able to give on stage what I would like to show. And I won't be able to develop myself the way I want to develop myself, because...I am a seeking person. I seek much in my own self. I can not manage that when I work with other dancers. ${ }^{86}$

In this conversation, the dancer comments upon the interrelation between artistic, financial and personal choices. Although or because she has worked with bigger ensembles, and despite a few solos such as The Journey interpreted with Christiane Emmanuel, Oxana Chi seems best able to channel her message and energy when she occupies the stage alone. Interestingly, she attributes this personal approach to performance to a process of individual development, whether artistic, spiritual or another form of growth. The image of the dancer "pouring" herself into the dancing body, the kinesthetic approach to creation rejoins the metaphor and reality of the body as a home. When Oxana dances-becomes Tatjana, she seems to actually bring her home on stage. Knowing that Barbakoff's body was destroyed, pulverized in Auschwitz concentration camp, the task taken on by Chi takes on a poignant meaning: to return to her (Barbakoff), or to her_story, a performative home through the stage presence of a performing body.

Brenda Dixon-Gottschild, who founded the Coalition of Diasporan Scholars Moving (CDSM), argues that "dance is a message in a cultural envelope," ${ }^{87}$ namely the body, which can take on different appearances. Sometimes dancers transcend the physical markers of the body to express another story, sometimes they actually play on

\footnotetext{
${ }^{85}$ Mohanty, "Crafting Feminist Genealogies," 487.

${ }^{86} \mathrm{Chi}$, interview.

${ }^{87}$ Dixon Gottschild, "Dance Is a Message in a Cultural Envelope."
} 
identification and similarity (as when Oxana Chi embodies Tatjana Barbakoff). ${ }^{88}$ It is also true in the case of Chantal Loïal, when she performs what she calls the story of the Black Venus. Here, the performance lives through Chantal's identification with the bodily features of Sawtche, and how they were exploited in a discourse and practice of western normativity, from which some-bodies are excluded. In the second part of They Call You Venus, the celebratory Africanist jumps, taking their strength from the ground, and performed to South African gumboots music, epitomize the diasporic, posthumous return "home" through the body of the contemporary dancer and her diasporic dance. The performance represents a powerful intervention in the context of France, a location characterized by a geohistory of colonial imperialism. In her discussion of French hip-hop dance culture, Felicia McCarren argues that "dancing simultaneously gives us an identity and a location yet allows us to bypass or outstrip these." 89 She finds that precisely this tension between displaying and moving the body within markers of race, class and gender, and moving the body beyond it, constitutes the attraction of dance as a form capable of commenting upon and challenging sociocultural and political norms:

While hip hop dancers are broadly thought to represent themselves, in a socialrealist dance form linked to its political-social program, in fact dance allows dancers to present their bodies, in all their embodiments, as something other than themselves. While staging the question of visible difference, dance performance remains an art of the visual rather than the entirely visible; it poses a challenge to reductive categories. ${ }^{90}$

The dances of perforMemory illuminate this strong counter-hegemonic power of dance. Experiencing and traveling through the works, one is invited to focus on a single dancing body, and its capacity to transcend restrictions or assumptions of racialized, gendered, and class-based identity. The visual is not always visible, and the visible suggests through motion, rather than words, what home, diaspora, resistance, and memory may mean.

When the choreographers deal with racism, genderism and other factors that influence how history is made, such as classism and ableism in their works, they politicize the performance of memory. However, they transmit a corporeal message that, precisely by being physical, can make the body's outer self not so relevant anymore. Journeying through their dancescapes of perforMemory, the audience gets the chance to encounter history, but eventually to encounter a performing human body, an individual and emotions which everyone may have experienced: hope, fear, loss, panic, mourning, courage, joy...This leads me to argue that the diasporic dancescapes shape home as a space in

\footnotetext{
${ }^{88}$ See Zami, "Mit Oxana Chi Durch Gärten."

${ }^{89}$ McCarren, French Moves: The Cultural Politics of Le Hip Hop, 85.

${ }^{90}$ McCarren, 85.
} 
movement, constantly reinventing itself at the intersection of body, geography, culture, history and emotion.

\subsubsection{The dancing body as a diasporic memory}

DeFrantz and Gonzalez estimate that in diaspora, "we wear memory on our bodies." ${ }^{91}$ I argue that perforMemory is more than an outer surface, it is an inner organ, sometimes even a full-body movement. The dancers of perforMemory create memory as a living entity, almost a living being. They infuse narratives of the past with a sense of contemporaneity anchored in the presence and present of the dancing body. In their works, I read subversions of hegemonic narratives in the alternative embodiments of the past into the present. In a context when diasporic subjects are usually pushed to the margins of society, literally moving on the stage center confers visibility and reality to bodies and their perspectives on trauma and empowerment. The notion of diaspora and the action of dance as outlined in this chapter shape the realization of perforMemory.

Sometimes the interaction between diaspora, dance, and representation is spatially visual. I remember arriving in Dresden and finding the streets filled with posters of the large annual festival Jüdische Theater- und Musik Woche 2014. The Afro-European choreographer Oxana Chi was portrayed next to Jewish cultural icons, in a city known in the media as a Neo-Nazi haven hosting racist PEGIDA demonstrations. Already in the physical space surrounding the performance venue, the geographic location of the performance, the programming of Oxana Chi and her work impacted the city, its spatiality and its relation to history. Dance shaped the material and metaphorical topography of a city - and country - struggling with its antisemitic past and present.

To understand the need, still vital, to modernize the representation of "culture" in Germany, we can learn from Afro-German scholars. Nicola Lauré al-Samarai, for instance, analyzed how Afro-descendant artists from Germany root their search for memory. Describing the work of Afro-German poets, sculptors and musicians, she speaks of an "inSpirited topography" which she defines as:

[...] a moving cartography [...] which, through the amalgamating and merging of seemingly disparate contexts, enables [one] to trace the hidden ruptures of history, and to look into them through [one's] own geopolitical views.

([...] eine bewegliche Kartographie [...] in der das Ineinandersetzen und Verschmelzen scheinbar nicht zusammengehöriger Kontexte es erlaubt, den

\footnotetext{
${ }^{91}$ DeFrantz and Gonzalez, Black Performance Theory, 11.
} 
versteckten Rissen der Geschichte nachzuspüren und diese mittels eigenständiger geopolitischer Lesarten in den Blick zu rücken. $)^{92}$

Although she leaves dance out of the variegated art practices in her analysis, her concept is relevant to diasporic choreographic practices, especially since it brings the motion factor into focus. Using perforMemory as a compass, I have started to sketch diasporic dancescapes as they comment upon, challenge, inform and transform the transmission of cultural memory in their respective geopolitical contexts. At a meta-level, my research in itself traces such a "moving cartography" that juxtaposes contexts not usually brought into proximity.

In this sense, my aim is also to contribute to what Natasha Kelly has defined as a necessary "program change" for German culture and media representations. Kelly argues that Germany finds itself in a "permanent cognitive coloniality." Referring to the concepts of "Ent_Nennung" and "Ent_Wahrnehmung," Kelly deconstructs the formation of historical discourses that exclude Black stories and perspectives from the dominant collective memory as inscribed in history books and cultural agendas. In her dissertation, published under the title Afrokultur als Wissenskultur - ein Programmwechsel, (Afroculture as knowledge culture - a program change), Kelly argues that in order to acknowledge the fundamental role of Black culture as knowledge, Germany needs to "change the program." ${ }^{25}$ Her dissertation connects the legacies of W.E.B. Du Bois, Audre Lorde and May Ayim, whom she calls a "change agent." The program change - which also evokes an association with the realm of technology - means allowing for minoritized discourses to find space in the transmission of memory. Self-positioned as Black Feminist academic-activist, Kelly actually strives to contribute to this program change by giving a platform to Black German artists, among others Oxana Chi, for instance when she commissioned her to create the piece I Step On Air in 2012. The fact that the piece has toured many universities since then, both in Germany and abroad, has contributed to bringing dance into academic spaces such as Bielefeld University, the City University of New York, Yeditepe University Istanbul, and Rutgers University, thus activating the program change called for by Kelly.

All the performances discussed here contribute to "program change," and share the will to encounter history through feminism and/or decoloniality, in my interpretation. In contrast to the "cognitive coloniality" criticized by Kelly, they counter absence and perform memory as presence, demonstrating that emotions and motion are viable sources and forms of

\footnotetext{
92 Lauré al-Samarai, "Inspirited Topography," 126-27 [My translation].

${ }^{93}$ Kelly, Afrokultur, 161 [My translation].

${ }^{94} \mathrm{Cf}$ Chapter one. Here Kelly refers to Nduka-Agwu and Hornscheidt, Rassismus auf gut Deutsch.; Lockward, "Diaspora."

${ }^{95}$ Kelly, Afrokultur.
} 
knowledge. PerforMemory breathes through these interstices, allowing the audience to sense them by witnessing the body as home, located in the present but reaching into to the past. The living body, moving through space, becomes a diasporic memory transmitted to the audience, at the intertwinings of history, corporeality, geography and culture. Not only is the dancing body a home, it is the materiality of perforMemory and the tool or kinesthetic software used by the artists to change the "program" of hegemonic memory.

Oxana Chi's whole repertoire has contributed to changing the memory program, both at the level of the use of dance as a form of knowledge, and through the content of the performances as discussed in the second chapter. Besides impacting the visual cityscape as described earlier, her continuous efforts to perform alternative storytelling of the past, to counter the absence of perspectives of women, especially women of color, happens in several spaces: theaters, universities, conferences. Through Gardens for instance, inscribes a Chinese-Jewish-Latvian expressionist dancer into dance history, and into the current programming, reclaiming her heritage and demonstrating how she impacted both the dance and visual art worlds of Europe in the 1920s and 1930s.

I also see a memory program change in Zufit Simon's repertoire, which brings Mischpuche into German theaters and re-vitalizes the role of contemporary Jewish artists in Germany's cultural landscape. Simon also changes the programming of gender norms through a non-gender conforming body and performance. Chantal Loïal also performs a new program that diverts from the one told by French institutions: she re-tells the story of Sawtche, challenging the racialized and gendered projections that have been imposed on her body, and replacing the absence of a Black female body with the strong, energetic presence of a contemporary Black female performer. Her perforMemory shifts the cliché which frames a large Black woman's body as a sexualized object, to a body as subject and in charge of its own story. Farah Saleh circumvents the impossibility of contact between Palestinian citizens across the Israeli territory. She performs the possibility of reaching out, and also changes the program of a western dance space by including the audience in the performance, making it borderless (remembering Widad Amra's opening quotation in the last chapter). Christiane Emmanuel changes the political program of the Martinican island, representing the "tourner en rond" of the status quo, but resolving to dance her liberated, Native Caribbean body. Wan-Chao Chang performs the bridge across Asia and America, changes the program of nationality as constructed in Taiwan, the USA and Indonesia. She dances diaspora as a presence, and evokes other imaginings of being across geocultural spaces. André M. Zachery actually uses digital programming to record and project his own movements, resulting in an Afrofuturist 
program change. The Digital Middle Passage surely is a new way of confronting the traumatic colonial past, differing from the conventional program as taught in school.

When the dancing body becomes a diasporic perforMemory, the memory program changes. Memory2go is a response to the need for a program change. Just as an actual change of software impacts the work place and work processes in the economy, the program change that perforMemory brings about can revolutionize the cultural ecology of western memory spaces. Staying with the watery metaphors of this chapter, I am reminded of what Christina Sharpe calls "the weather," namely the afterlife of slavery that is omnipresent in our present environment. Yet Sharpe notes how Black beings respond to a difficult climate, and create "new ecologies." ${ }^{16}$ This chapter on diaspora leads to the conclusion that perforMemory is an alternative ecology, in which the dancing body does not only transform the location of the stage into a home, but actually creates a new shelter and stakes claim to the body as a home, and as a site of a memory in movement.

In this chapter, I demonstrated that the stage can become a diasporic space, the shelter for a moving home that is dance. Sketching the outer reliefs of perforMemory's dancescapes, I invited the reader to come a step closer, to feel what moving through diasporic dancescapes may be like. If memory is a site of movement, it exists through a constant wind of change. Diasporic motion is the core of perforMemory. Just as wind shapes sand sculptures in the desert, or traces wave patterns on the ocean, diaspora as a concept shapes and shifts memory's movements. The political and emotional mobility evoked earlier work through/orbit around diasporic constellations. Thus, contemporary perforMemory as I define and approach it here, is molded by diaspora. This is not to say that perforMemory does not exist outside of diasporic relations. However to frame memory performances within diaspora, or to pinpoint diaspora within memory dancescapes, compels us to search for the connections between memory discourses, counterhegemonic storytelling, and movement. To understand what it means to find a home space in the dance place, I find it relevant to reflect upon this quotation by Sara Ahmed:

Being grounded is not necessarily about being fixed; being mobile is not necessarily about being detached. ${ }^{97}$

To dance is to be grounded and mobile, dynamic and centered. Diaspora is movement, be it the ocean sung by Maya Angelou as welling and swelling, or Kazim Ali's poetic "breath that swirls around and returns." ${ }^{98}$ Angelou, in the poem "Still I Rise" ${ }^{99}$ cited at the

\footnotetext{
${ }^{96}$ Sharpe, In the Wake: On Blackness and Being, 205.

${ }^{97}$ Ahmed et al., Uprootings/Regroundings, 1.

${ }^{98}$ Ali, Orange Alert, 68.

${ }^{99}$ Angelou, And Still I Rise.
} 
opening of this chapter, evokes the treasure in one's backyard, in her case the pride she takes from her cultural heritage, the capacity to rise above a painful, traumatic past. All the solos eventually seem to reveal that dance may help to retrieve something. It may be that one comes back from a world journey only to find that the treasure so dearly searched for lies in one's own backyard, or that the way is the destination, as is the core belief of Taoism. All these texts connect the space of home to the being of one's self. Although I do not dance on stage, I relate strongly, through performing experience, personal genealogy, and academic research, to the understanding of the dance space as a home place, as the home place. Also, traveling through diasporic dancescapes is as difficult as it is promising, as expressed by dancer Wan-Chao Chang:

I force myself to come out - to keep my memory for a certain stage and move on to find different things. It's...not an easy journey, but when you find something different that belongs to yourself, I think it's a treasure..$^{100}$

PerforMemory harbors a treasure trove waiting to be uprooted and unearthed, or waiting to emerge out of oceanic depths. As I write this chapter's conclusion, I find myself on a diasporic journey, spidering, spiraling, searching for a part of my ancestry. An invitation to perform I Step on Air in New Delhi with Oxana Chi, has given me the opportunity to travel to Tamil Nadu, where I am searching for the East Indian roots of my West Indian genealogy. This journey is full of diasporic surprises and treasures, such as the fact that "Zami" a family name found on my mother's island of birth, Martinique and throughout the Caribbean, and a book by Audre Lorde, but is also found in ancient historical texts to refer to a women community in India. Reminiscing on the hours of travel that took me from the performance venue in North India to a mountain top in South India, I can feel the complex intersection of diaspora, memory and movement. I can feel how as a diasporic subject, I am bound to a nomadic melancholia and a melancholic nomadism.

Diaspora and memory do not only circle around issues of spatiality, they are embedded in definitions and questions of time. In a constructivist approach, the movement of time and space are not given entities. Rather, they are variables in the search for the interrelation between remembering the past, and aspiring to understand, and change the present and to make the future a possibility. Consequently, the next chapter shall explore the dimension of time as it relates to perforMemory, in order to fully grasp the complex and subtle ways in which memory moves through spacetimes, and how time conceptions in turn inform expressions of cultural memory.

${ }^{100}$ Chang, interview. 


\title{
4. Dancing the Past in the Present Tense
}

\author{
there are millions of places around us \\ there are millions of years before and after us \\ there are millions of crossroads \\ at the crossing of reincarnation \\ and here, at this table \\ in this exact moment \\ we share \\ a tea \\ are we attending an appointment \\ that we scheduled in our prior lives? \\ (il y a des millions de lieux autour de nous \\ il y a des millions d'années avant et après nous \\ il y a des millions de croisements \\ sur le carrefour de la réincarnation \\ Et ici, à cette table, \\ en ce moment précis, \\ Nous partageons \\ un thé
}

Sommes-nous venus à un rendez-vous pris dans nos vies antérieures?)

Chung Hing ${ }^{1}$

I enjoy morning tea time: slowly dropping a teabag into a cup, observing the spreading color and aroma, waiting for the water temperature to cool, feeling warmth flowing down my throat with each sip. My tea routine is flexible, varying according to seasons and emotions, and includes a broad range of teas, from herbal mixed teabags to a specific loose green tea from Taiwan. My time management during this routine is also flexible, and varies from gulping the tea down quickly while checking e-mail, to savoring it at a zen pace. Today, my daily tea routine involved an echinacea tea from the "Yogi Tea" brand. The company prints a quotation on each bag (it is not clear to me whether these quotations originate with

${ }^{1}$ Chung-hing, Chants de Thé, 17 [My translation]. 
Yogi Bhajan, whose face is also printed on the package, or from the packaging factory staff, or from a computer-managed anthology of poetry). My appreciation of the quotations is as variable as my tea ceremony. This morning, the words struck me with their poetry and accuracy. They felt so deeply in tune with my concern of the day, namely, how to structure this chapter on time within a poetic stance on dance, and with my current readings on the dance of quantic matter. ${ }^{2}$

As the teabag evanesced into the hot water, the other end of the string waving outside of the cup carried this tiny quotation: "Each single heartbeat dances to the rhythm of the soul." The quotation evoked for me the interconnection between corporeality, time, and movement. I remembered and reflected on the way the dancers move their bodies not (only) to a paced tempo of recorded or live music, but also to their own rhythm, their own sense of being in the moment, their own pace of remembering. The imagery of a heart dancing, rather than beating, suggests a body that moves outside, beyond normative conventions of time and space. If the heartbeat dances "to the rhythm of the soul," its movement may vary in pace according to the emotional and intellectual fluctuations of the soul. The teabag also transported me back to the first scene of Through Gardens, in the first version that I attended. At the very beginning of the piece, under a dim light, a shape wrapped in a red velvet cloth lays on the ground. Its movements match the sound of a heartbeat, produced live by the guitarist on stage, at first low and slow, then increasingly quick and loud. The heartbeat lets us know that we are witnessing the birth of an individual, a performance, a story, a perforMemory. The heart and its magical triad also punctuate Oxana Chi's interview about dance and memory:

Dance really is simply body, soul, heart. All of those are needed, otherwise one can't dance. $^{3}$

This is how perforMemory re-emerged through the shimmering surface of my morning tea. The tea became, as in Chung-Hing's above quoted poem, a spacetime at the crossroads of time, space, memory and humanity, where the common teatime opens the possibility to embrace the multiplicity of temporalities and positionings that surround and inhabit us. PerforMemory reaches out through geohistorical timelines, and transforms the stage into a crossroads of history, geography, emotion, and memory.

On this thesis journey, we have encountered memory as a site of movement, and we have stepped through the stage as a diasporic space where dancing bodies find and create a home by performing memory. After the volcano and the ocean, the dancescapes now take the shape of a storm that swirls past traumata into the present, a hurricane of

\footnotetext{
${ }^{2}$ Rovelli, Reality Is Not What It Seems.

${ }^{3}$ Chi, interview.
} 
displacement, but also a regenerating breeze, a wind that displaces entities, travels across space and time. In this fourth chapter, I look into the timespaces and the movements of perforMemory.

The purpose of this chapter is to explore how the performances challenge western conceptions of history, time, and space. Here, I ask how selected works "contemporize" the past, and how they connect the physical and conceptual realms of perforMemory. I start by returning to the repertoire outlined in the first chapter, and propose a reading of each work's temporality as a narrative structure and a device to perform memory. Then I reflect upon the interconnection between performance, time and memory, and weave together threads pulled from critical race theory, quantum physics, performance studies, gender studies and history.

The second part of this chapter engages with the movements of perforMemory in a material-literal and metaphorical sense. I select three sets of movement - spinning, jumping, and crossing - and argue that they not only reflect, but also enact conceptual movements: to turn around perspectives, to bridge gaps and to transgress boundaries. In this process, my research advances further through these dancescapes, reflecting upon the counterhegemonic apprehensions, aspirations and inspirations that inform the ecology of perforMemory. 


\subsection{The Timescapes of PerforMemory}

Time breathes and breezes, time runs and roams, time flies, flees and foams, time sweats and sneezes, time crawls and curls, time evaporates and evacuates, time leans and leads, time rests and ripples, time spins and swirls, time tiptoes and tips, time ticks and twists, time ticks...time moves. A timescape is an anagram of timespace. Like the word dancescape, it evokes the intricacy of time paces and places. In a timescape, time unfolds into space, time unfolds as space. Time and space are not distinct from each other, rather they move in relation to one another, shaping a landscape that may be the décor for memory. You may hear the echo, carried by the wind, of Ruth Klüger's Zeitschaft mentioned in the first chapter. Ruth Klüger writes about the concentration camp as a non-place, or a place that only exists in relation to time and history; the timescapes of perforMemory may be conceived as times in place, or places moving in time. Discussing the specificity of theatrical time and space, Jill Dolan emphasizes the role of the present time in the space of the theater, and how it brings about what she calls "utopian performatives":

The very present-tenseness of performance lets audiences imagine utopia not as some idea of future perfection that might never arrive, but as brief enactments of the possibilities of a process that starts now, in this moment at the theater. ${ }^{4}$

Interestingly, the word utopia is anchored in spatiality, for it also means a non-place or a place not yet existing. By defining u-topia as a spacetime (although she does not use that word), Dolan defines a performative moment that exists within the venue of the theater and within the temporality of the performance. Although the performances mentioned here do not necessarily attempt to perform "future perfection," they do enact narratives that move away from linear time, and embody narratives that challenge the production of historical spacetime. Subscribing to the idea of present-tenseness allows us to understand how perforMemory may "illuminate and transform the present," ${ }^{2}$ to come back to my main research hypothesis.

\footnotetext{
${ }^{4}$ Dolan, Utopia in Performance, 17.

${ }^{5}$ hooks, "Choosing the Margin as a Space of Radical Openness," 155.
} 


\subsubsection{Stretching time: bending hegemonic timelines}

In this section, I revisit the repertoire of perforMemory through the lens of time, and ask: how do the seven solos perform time? How do their sense and uses of time collide and collude with western notions of linear temporality? I argue that choreographers stretch time, and thus generate a perforMemory that moves aside, away from, and beyond the traditional idea of "history." When encountering historical matter, the performers often circumvent chronology, and perform memory within other processes of narration. This non-chronological epistemological endeavor bears affinities with Alexandro Murguía's reflection upon the process of writing history:

I am not writing history per se; instead I am unraveling the strands of time/space/memory that define my presence here. I propose a history based not on 'objective' Western epistemologies, which are not objective anyway, but on intuition, memory and landscape; not on linear chronological time, but on circling the events till they become understandable to me. ${ }^{6}$

To unravel "the strands of time/space/memory" resonates with the imagery of the quilt evoked in the previous chapter, and equally signifies the multiple layers of intuition, memory and landscape merging in the dancescapes of perforMemory. Indeed, each performer seems to ground a performing presence in the "present-tenseness" of the show, connecting time, space, and memory to produce a new form of engaging with the past. At a meta-level, the structure of the thesis is analogous to the vision cited above. My goal is to circle the performances as the performers circle past, present and future events. Engaging intuition and memory to illustrate epistemological dancescapes, the chapter challenges historical chronology and nation-based geography.

\subsubsection{The pulse of time in all about nothing}

Doors open, the audience walks into the performance space, everyone calmly takes a seat. Performer Zufit Simon is already on stage. She sits at the back, in front of an emergency exit door. In contrast with the classic scenario - in which the artist enters the stage to an already seated audience - the performer waits for the audience to come in. Certain spectators notice this, become slightly irritated (did we enter too early?), others appreciate the dramaturgical irony, still others focus on choosing a seat to occupy for the hour to come. When the audience quiets down, the dancer rises, but does not start to dance immediately, again countering some expectations projected upon her body. She walks in an energetic, resolute manner towards the audience, reaches the left side of the

\footnotetext{
${ }^{6}$ Murguía, The Medicine of Memory, $\mathrm{x}$.
} 
stage where she grabs equipment, as if she were one of the technical staff. Zufit Simon is determined but takes her time, like someone who refuses to surrender her body to the hurry she is in. She sets up a microphone stand and a microphone at the front of the stage, then takes her jacket off, and hangs it to the side of the stage. Now she walks resolutely towards the microphone, ready to speak...but instead of words, a swift popping moves her body, a slight but intense contraction of the torso. She moves away from the microphone and starts to dance, choosing the movements over the words, the corporeal over the verbal expression. Later on in the piece however, she will use the microphone, speak, and perform the gap between a statement as expressed in words and facial expression (e.g., "I am so glad you are all here") and the deep emotional state transpiring through the body, in this case sadness, despair, anger.

This was the version of the show I experienced in Munich on June $28^{\text {th }}, 2014$, when Simon premiered it at the end of her artist residency at Blauer Reiter. I had first encountered her work through Oxana Chi's curation for TANZnews Berlin. Two years later, on October 21 $1^{\text {st }}, 2016$, Oxana Chi and I invited Simon to perform at the closing of the Moving Memory Symposium Festival. This time, she began by speaking into the microphone. At the very end of the piece, as her energy filled up the wide space of the Freiraum Theatre at Technical University, Zufit Simon returned to the mic, gathering herself to speak...only to abruptly turn around and leave the stage, conveying the feeling that everything necessary had already been uttered. Both versions of the piece mold time, stretch dramaturgy and bend linear timelines. The simple play with timing, such as the fact that the performer sets up after the audience has been let in, shifts the conventional time markers of concert dance.

In this piece, the choreographer expects audience members to project their own, personal memories onto her performance, as noted earlier. Thus, she hopes to create a collage that melds her memory with the audience's. This takes us back to Diana Taylor's definition of the repertoire in relation to traumatic memory encountered in the second chapter, and in which the presence of an audience is fundamental to memory transmission processes. Performance activates memory within the performative timespace, as the audience attends and experiences the event, albeit internally. Taylor further writes that the "body responds to and communicates a violent occurrence that may be hard to locate temporally and spatially." Almost throughout the whole dance solo, the dancer shakes incessantly, moved by an uncontainable shuddering. The movements are impressive, since they require a complex technique of control over body muscles at the microscopic level. As a narrative tool, the shuddering, shaking, palpitating body evokes a

\footnotetext{
7 Taylor, The Archive and The Repertoire, 203.
} 
sense of timelessness. The body seems to communicate both a memory of violence, and the violence of memory as it pervades the present. As an audience member, I wanted it to stop, I waited for it to stop, and yet the shaking went on and on, whether the performer stood, or lay on the floor, sat curled up, held her knees in her arms, or was in the process of getting up and going down, continuously shaking. Not the heartbeat, but the fast, intense shuddering marked the passing of time. The shudder became a timeframe, a time measure, like a heart or a drumbeat. Her sequences extended in length, to the point of exhaustion for the performer - and the audience. And yet the courageous decision, and the precision of the constant shuddering never felt boring, rather it transmitted the electrifying sensation of time, when each second seems to implode the very notion of time.

Moving her body in a constant state of contraction - that's what shuddering is, dancetechnically speaking - Simon lets the audience understand, or imagine, or re-imagine the traumatic memory stored in the body and expressed on the stage. Linear time is not relevant in this performance, neither are distinctions between a pre- and post-traumatic moment. In the last chapter I referred to Mohanty's analysis of home as emotional, sensory, historical and geographic; and so is time here: inherently emotional, sensory, marked by the motion of the body from one emotional state into another, from one physical movement to another. Dolan's "present-tenseness" becomes a tensed present, and a presence full of tension. Experiencing all about nothing, I felt deeply a sense of time passing, and with each second of shudder, I could sense a year, or a generation passing through the artist's body. The pulse of time stretches throughout the piece, and challenges the sense of how time passes in a theater, sometimes making two minutes feel like an eternity. The shuddering inflected the dramaturgy with a feeling of conflict: Zufit Simon tried to move, perform, express something that was being overlapped, overrun by the motion of contraction, of shuddering. In this here and now, time felt dolorous, like a pain that is neither increased nor reduced by the passing of time.

\subsubsection{The suspension of time in Digital Middle Passage}

If diasporic space is the place, how does it interact with diasporic times? The solo Digital Middle Passage attends to the relationship between Black identity and notions of time and space, or what a journalist described as condensing the Middle Passage within twenty minutes. ${ }^{8}$ The Renegade Performance Group's website explains how the piece focuses on spacetime: "Time and space in regards to Black existence is suspended

\footnotetext{
${ }_{8}$ Tighe, "Middle Passage in Twenty Minutes: The AFROFUTURISM Series."
} 
between two realms: one familiar and the other foreign." ${ }^{9}$ This description reflects an interest reflected throughout André Zachery's repertoire: the will to explore Black diasporic subjectivity through performance, and more generally to envision and enact new ways of moving through time and space, eventually moving around the very categories of time and space. By juxtaposing millennial technology and the historical name marker of the Transatlantic Slave Trade, the title already intervenes in the linear progression of time as constructed in the west. Suggesting that the digital realm can be used to access the history of the Middle Passage is innovative. Indeed, the artist uses both his skills as a dancer-choreographer and his expertise in 3D-technology to explore the past from a contemporary position. When his physical body dances across the stage, simultaneously with its digital reproduction, and transformation (projected onto the screen), he performs a multidimensional Black existence, that seems to exist in several layers of spacetime simultaneously. In a recent publication, Zachery described the intention behind the use of projections:

By creating a visual landscape with projections responding via delay to onstage movements, I was attempting to acknowledge, rather than fixate on, gaze: the image of my body bent and warped as if being pulled through dimensions while leaving traces of my real self in fragmented form. ${ }^{10}$

The synchronicity of moving bodies hints at the complexity of diaspora, inviting us to transcend the usual divide between time and space. The dancer lives and moves in these multiple realms. Is he a contemporary citizen connected through digital communication? Or just any human traversing the Atlantic? A Black diasporic subject moving between the African past and the American present...or all at once? Zachery's performance occupies many diasporic spaces at the same time, as he moves and lives, simultaneously on stage and on screen.

In this, he reminds us of the complexity of what searching for memories of the Middle Passage means. Let's take the historical case of Olaudah Equiano as discussed by Michelle Wright. While historians debate(d) whether or not Equiano was a Middle Passage survivor, Wright argues for the possibility of multiple true narratives to coexist. Drawing on particle physics, according to which a particle may be in several places at the same time, Wright states that Equiano may live simultaneously in the various epistemologies of his self. Thus, for Wright, the narratives of his story should no longer be seen as contradicting one another, but rather understood as juxtaposed truths. ${ }^{11}$

\footnotetext{
9 Zachery, "Untitled Distances."

${ }^{10}$ Zachery, "Futurity and the Containment of Blackness in Twenty-First-Century Performance," 75.

${ }^{11}$ Here Wright refers to the "principle of superposition" in particle physics and to the differing versions of Equiano's biography. While he wrote in his autobiography that he was born an lgbo (in what is today Nigeria), some historians have later attempted to locate his birth in the USA, thus contradicting his narrative
} 
I would add to her argument that this notion does not only stem from particle physics, but is very much in tune with a broad array of cosmologies, including some found in West African cultures. ${ }^{12}$ Asked to write a history of Black dance, Brenda Dixon Gottschild chose to produce a geography of the Black Dancing Body, in the soul and the spirit belonging to the body's geography. ${ }^{13}$ In the interview I conducted with him, André Zachery, like Oxana Chi, Ronald K. Brown and Christiane Emmanuel, emphasized the role of spirituality within the work. All hinted more or less explicitly at the presence of spiritual powers - ancestors, spirits, natural forces - guiding and influencing their dance. Zachery explained that he felt the need to "literally dive," to reach out to the ancestors and ask their permission to move. ${ }^{14}$ I see this translating in his intense use of floor work, when his body, lying parallel to the ground, slowly spins on its own axis with the help of a swift rotation of the outstretched arms that induces a full rotation of the torso. Even when he leaves the ground, he seems to be pulled back towards it, as his hands adhere to the smooth surface of the marley. The dancer coexists not only with his digital self, but also with his genealogy, in an extensive timespace liberated from historical chronology and geography, and a flexible approach to its coordinates:

Time and space for me are truly malleable, and it's not something where I'm interested in giving exact counts or placement of movement. ${ }^{15}$

When Zachery moves to the music, he indeed departs from a classical synchronization between movement and sound. He collaborates with an electronic musician who uses a lot of improvisation (similar to Zufit Simon, mentioned above). Both Zachery and Simon seem informed by contact improvisation, and they allow the dance and the music to be realms of their own making. The choreography does not necessarily determine the length of a musical sequence, rather at times it may be the contrary. In the case of Zachery, the practice often departs from Black rhythmic traditions of matching the dance steps to the beats.

While Simon's time pulses, Zachery's time seems to hold its own breath - in suspension between what he terms the familiar and the foreign, or between the embodied traumata of slavery and the incarnation of Black survival. He shuffles time around, from diasporic journeys into the past to present political concerns; from the torso spiraling up to a rocket-speed to the gradual, barely perceptible movement of a hand touching the

about surviving the Middle Passage. Wright, Physics of Blackness, 24..

${ }^{12}$ When I lived in Douala, Cameroon, as an intern in training with the AfricAvenir Foundation at their headquarters, some of my colleagues talked about the possibility for a soul to travel out of the house at night, while the body would seemingly remain in bed.

${ }^{13}$ Dixon Gottschild, The Black Dancing Body.

${ }^{14}$ Zachery, interview.

${ }^{15}$ Zachery. 
ground. After approximately ten minutes, music elongates, as the dancer lies on the floor, stretching his spine backwards, hands and feet reaching towards the ceiling - or sky. Time is in slow motion, as the projection of the performer on the wall lets his bodies dissolve into each other, vanishing, in an imagery evoking death. There is another moment, at about 18 minutes, when he freezes, and then jumps in a deftly executed touren-l'air, evoking a complex ballet technique. He seems to perform and enact liberation from physical, emotional and any other type of constraint.

The solo actually epitomizes the artist's proficiency in his own technique of "Physical Propulsion," itself inspired by the Flying-Low work codified by David Zambrano. Zachery describes his technique as "dynamically engaging the cranial-sacrum connection for seamless floor vocabulary, intelligent shifts in body weight, and fierce aerial movement."16 There is an interesting parallel between the post-injury context (at the small-scale of the body) in which Zambrano developed his Flying-Low technique, inspired by a Brazilian jump roper and a kung fu practitioner, ${ }^{17}$ and the post-traumatic spatio-temporal surface (at the large scale of American spacetime) in which Zachery uses his "Physical Propulsion" to traverse the Digital Middle Passage on stage. Digital Middle Passage rests on the performer's intense connection to the ground from which he briefly departs and to which he returns, with indeed seamless motion across the floor. This solo, which belongs to the Renegade Performance Group's Afrofuturism Series, realizes "AfroFuturist narratives in which time collapses into a single plane [that] are not necessarily unconcerned with history," ${ }^{18}$ to use Alondra Nelson's words. On the contrary, the choreographer's strong concern for history as a field to be explored and re-mixed, shapes this solo in which time seems suspended. With knowledge of the contemporary violence against Black bodies in the United States, the solo makes clear that its scope reaches beyond the memory of slavery as a past trauma, but actually encompasses the present tensions inherent to being present in a Black body in the Americas.

\subsubsection{Cyclic time in Through Gardens}

In the dance piece Through Gardens, choreographer Oxana Chi structures the narrative in a theatrical dramaturgy consisting of four main acts: the Birth (Geburt), the Celebration (Fest), the Struggle (Kampf), and the New Moon (Neumond). Each act or scene paints a tableau of Tatjana Barbakoff's life. The Celebration and the Struggle are the longest sequences. The dance bears affinities with four seasons: the festive, colorful,

\footnotetext{
${ }^{16}$ Zachery, "Physical Propulsion."

${ }^{17}$ Zambrano, "Flying-Low - Dance Technique."

${ }^{18}$ Nelson, "AfroFuturism."
} 
warm summer mood of the Celebration; the blue, white, winter void of the Struggle, the autumnal nostalgia of the Chinese Dress interlude, and the spring-like renewal energy of both The Birth and the New Moon. At first, the narrative appears embedded in a chronological temporality that takes the audience along Barbakoff's biographic timeline. Yet at closer review, the piece implodes any notion of linear time, in my view most clearly through the final scene of the New Moon. The audience witnessed the birth, successes, resistance, deportation, and death of Tatjana Barbakoff. Oxana-Tatjana now lies motionless on the floor. One may think that the piece has ended - as would be the case in a conventional narration of Holocaust biographies - but the live-music continues. After a few minutes, the dancer gets up, and starts to move extremely slowly, as if awakening into an afterlife. She takes off the blue costume used in the last combat scene. Left with a minimalist black outfit, the aesthetics contrast sharply with the elaborate costumes of the previous scenes. Although Tatjana just "died" on stage, she now lives and moves on in Oxana's dancing solo.

Dancing the past in the present tense, Chi re-imagines what Barbakoff's past may have been and thus transcends the historiography from which she drew information about her. The choreography allows for multiple interpretations: is this a dream, a glimpse of the fourth dimension, a vision? To me, the scene embodies what Dolan calls "utopian performatives," ${ }^{19}$ for Chi enacts into the performative timespace of "now" the possibility of Barbakoff's survival and/or afterlife, and inscribes her memory as a dynamic process to be acknowledged and appreciated collectively and individually. In this scene, Oxana Chi repeats movement motifs from the whole piece, assembling fragments from earlier sequences in a seamless choreography. This time however, she dances in slow motion, inducing a dreamlike feeling, giving the audience the chance to re-experience her movements at a different pace. Even the kick and fight movements which were executed so swiftly in the Struggle scene, are now in slow motion. The gracefulness of the swaying torso; the smooth floating of the arms, sometimes evoking the Tai Chi figure known as caressing the clouds; and the Javanese hand postures diffuse a soft haze over the tragic ending of narrative.

Just as a clock slows down time when it is set in motion - as physics experiments have shown ${ }^{20}$ - so does the temporality of Through Gardens, relying on the choreographic motion of the dancer. A mise en abyme, this final scene performs a postmemorial choreobiography of memory: perforMemory folds itself over, as a perforMemory of perforMemory. The deceleration of the pace leaves a mnemonic imprint of the whole choreography on the audience. It almost makes me feel as if I am witnessing what a

\footnotetext{
${ }^{19}$ Dolan, Utopia in Performance, 5.

${ }^{20}$ Capra, The Tao of Physics, 170.
} 
corporeal search for historical traces may be like. It renders the impression that Oxana, in that moment, is reaching out to the memory of Tatjana, which she creates as she performs, a diasporic spidering producing the thread of memory as it goes, a memory2go.

What does Oxana Chi's play with pace express about hegemonic timelines and alternative storytelling? By choosing to "cite" her own movements, and let phrases recur, as if memorized, yet at an altered pace, the choreographer shows how a slight alteration of tempo may impact the whole narrative and perspective of storytelling. In dominant western historiography on the Holocaust, or let's say in the biography of Tatjana Barbakoff, a dead dancer cannot rise again. Motionless beings do not come back to motion or life, and movements from the past can not be reiterated. The process of inviting chronology into her choreobiography, and eventually transcending it, also bears affinities with indigenous tools of storytelling. For instance, Jacqueline Shea Murphy has noted how the dramaturgy in the piece No Home but the Heart refers to historical chronology and dates, while questioning linear time and overlapping time periods in order to transmit other knowledges about the colonization of the Americas. ${ }^{21}$ Similarly, Oxana Chi's dramaturgy refers to historical markers of the $20^{\text {th }}$ century while re-mixing them.

The title of the scene, "New Moon," hints at a cyclic type of temporality, and invites one to reconsider the whole piece through a new lens, a cyclic, seasonal, non-linear temporality. To witness this scene is to leave the linear thread that seemed to hold the performance together. Instead, the dancer unravels a multi-textured sense of time, and allows the audience to re-assess each scene as part of a cycle, and as a cycle itself. Time here becomes circular. The dancer, who is inspired strongly by her visits to the Asian continent, expresses how her relation to time was impacted as a young German leaving the west for the first time:

India was quite an important experience for me, because I found a particular freedom for my choreography and dance which really matters to my choreography. Namely, that I can treat time as I wish to. My movements need a wealth of time, and I want to deeply savor each movement - and this is what India taught me something which may have gone lost in Europe, or which may never have existed in the first place. ${ }^{22}$

Inspired by the experience of another relation to spacetime, especially in the performance realm, Chi is strongly interested in a flexible approach to time, which becomes a process-based parameter in the hands of the choreographer. Time relativity is demonstrated in the cyclic temporalities of Through Gardens. Cyclic relations to time pervaded most Hindu and Chinese cosmologies a long time before reaching western

\footnotetext{
${ }^{21}$ Shea Murphy, The People Have Never Stopped Dancing.

${ }^{22}$ Chi, interview [My translation].
} 
physics. Cyclic time connects the self to its environment, to the cosmos. Here one may also think of Chatterjea's analysis of Indian choreographer Chandralekha in relation to time:

[Movements] are not fixed in the physical time that binds us to routine, but happen in metaphysical time, cosmic, memory time, when in one blink, a whole era, millions of years can be said to have passed by. ${ }^{23}$

This is the feeling emanating from the "New Moon" sequence, and from Through Gardens as a whole. In the scene of the Chinese Dress described in the last chapter, OxanaTatjana puts on a costume suggesting Barbakoff's relation to her mother's silks. The memory or search or imagination of the mother may echo Chi's own biographical relation to a mother's presence/absence. Both beings co-exist in the dancing body: the $20^{\text {th }}$ century and the $21^{\text {st }}$ century dancer. Physical time, cosmic time and memory time juxtapose against perforMemory a biography that dominant dance historiography often fails to account for. A pirouette, or a turn of a hand becomes a timeframe in which either a few minutes or several years of Tatjana Barbakoff's life have passed. Thus, cyclic time contests western linear time, and its corollary of (past) cause and (present) effect.

Oxana Chi's signature use of live-music, and the elaborate collaboration with artists who compose and improvise for her choreographies, also plays a role in shaping cyclic time. The dance, almost always in conversation with one or more instruments, usually shapes the manufacturing of time: the choreography determines when a sequence starts and when it ends. Within these cues given to the musicians, cycles of dance and music evolve according to the energy of the moment. This happens for instance in the version of the Birth evoked at the beginning of the chapter, where the musician mimics the sounds of a heartbeat. The increasing velocity of the hearbeat-guitar must happen in a fine-tuned concordance with the intensity and pace of the dancer's movements. Although the movements do not have to exactly match the music or vice-versa, the sense of time passing for the dancer within her costume is in tune with the musician's percussive playing. Without a classical one, two, three count, the artists synchronize with each other, as the dancer bursts out of the cloth and the guitarist pauses. A new cycle of motion and music may begin, and so does time move throughout the piece.

In an e-mail addressed by Oxana Chi to hang and piano musician Laszlo Moldvai, dated January $1^{\text {st }} 2010$, the choreographer clearly expresses the interrelation between circularity, time, choreography and music in Through Gardens:

${ }^{23}$ Chatterjea, Butting Out, 62 . 
Since the dance sequences continuously repeat themselves, and spin almost like a whirligig, there remains much freedom of interpretation for the audience.

(Da sich die Tanzsequenzen immer wiederholen, wie ein Kreisel sich quasi im Kreis drehen, bleibt den Theaterbesuchern viel Raum für eigene Interpretationen. ${ }^{24}$

Furthermore she mentions the idea of circular time, or a time circle ("zeitlicher Kreis"), revealing her desire to choreograph a non-linear dramaturgy, which should be sustained by the music composition-improvisation. Indeed, the circular motion of time is reflected in the circular movements embedded in the cyclic conception, a point I will come back to later.

Deploying her tremendous skills in ballet techniques such as pirouettes and tour fouettés, Oxana Chi's dance is also strongly embedded in Africanist techniques and aesthetics. ${ }^{25}$ Her storytelling mixture of dance, live-music, and dramatic expression corresponds to what Zenenga calls African Total Theater. ${ }^{26}$ Also, her above quoted reflection on time suggests that "[t]ime is a factor, but enough time rather than a set amount of time," a feature of Africanist dance, according to dance scholar Kariamu WelshAsante. ${ }^{27}$ Welsh-Asante theorizes seven common features, or "senses" that characterize Africanist dance (in which she also includes certain developments of ballet, jazz and modern dance). "Repetition" is one of these senses. Asante suggests that an Africanist use of repetition works through an intensification of movements. Thus, the repetition of a movement carries its transformation through the modulation of its pace, or emotional quality, or execution.

The use of repetition in Through Gardens struck me as particularly powerful and fascinating. When the dancer repeats a phrase of movements, the repetition is always in itself a transformation and an intensification, moving towards a climactic resolve, especially in the scene of the Celebration and of the Struggle. Here, the repetition turns hypnotic, it pulls the audience into it. The celebratory pirouettes and jumps, or the resistive kicks and swings of the arms, are repeated as if to show that memory is circular. Increasing the precision and the emotionality of the patterns conveys the feeling of a rushing flow of time, a storm through which the dancer consistently navigates kinesthetically.

\footnotetext{
${ }^{24}$ Chi, "E-Mail an Laszlo Moldvai, 01.01.2010"; Oxana Chi published the e-mail herself in the catalogue Chi, Tanzende Erinnerungen, 2011.

${ }^{25}$ For an elaborate analysis of Africanist influences in American ballet, see Dixon Gottschild, Digging the Africanist Presence in American Performance.

${ }^{26}$ Here I refer to the aesthetic paradigm defined in Zenenga, "The Total Theater Aesthetic Paradigm in African Theater."'

${ }^{27}$ Asante's search for common features does not mask the complex diversity that marks the multitude of dance styles produced on the African continent, nor their own distinctions between traditional and contemporary forms. See Welsh Asante, "Commonalities in African Dance," 150.
} 
Through Gardens performs a cyclic memory2go in which conventional delimitations between past, present, and future are disrupted. The dancer perforMemories a dynamic engagement with the epistemology of a historical figure, generating a corporeal spacetime in which notions of historical time and geographical space coalesce into the performing body. The performance epitomizes a cyclic approach to choreobiography, and allows the audience to circle, step by step, the perforMemory of Tatjana Barbakoff.

\subsubsection{Instant time in Parole, Parole, Parole}

When I first came across Farah Saleh's work through the piece Ordinary Madness, I hesitated over whether or not it dealt with memory, since it obviously performed the present reality of Occupation and its impact on Palestinian daily life. However, all the works discussed here intervene in the past from a present position, and none of them can be truly understood within the temporal frame of linear progress. Now that I reflect upon my interview with Farah Saleh, I note that she did not use the historical term "Nakba." Is it because memory is an ongoing preoccupation in Palestine? I interpret the solo Parole, Parole, Parole, as well as the group work Ordinary Madness, as works of perforMemory. But they do not engage with ancient memory, but rather the memory of the last day, or the last hour, or even the last second. In this sense, time, in Farah Saleh's dance, feels instant.

Her dance sculpts a time that is imperative, instantaneous, detached from its fore- and after. In Parole, Parole, Parole, dancer and audience occupy one timespace/spacetime. When I witnessed it, Saleh did not dance on the stage, rather she danced across the whole room occupied by the spread out audience. I felt a bitter irony in watching the mostly European citizens "forcefully displaced" by her dance, in a more or less voluntary interaction. Some audience members had to make space for her, as she walked on her hands closer and closer to them. Others stuck to their spot and took in her kinesthetic message.

Because of the extreme proximity between performer and viewers, I felt that time flowed differently, almost like conversational time, but a conversation in which one party the audience - sometimes remains silent or motionless. When I witnessed the piece at the Tanzquartier Vienna, Saleh expressed a difficulty in connecting with the audience. However, with regards to other contexts, she has stated that the solo made her feel that she was "being with the people and feeling things with them, and making them feel things, and they were transmitting things to [her]." ${ }^{28}$ This suggests the abolition of spatial and

\footnotetext{
${ }^{28}$ Saleh, interview.
} 
temporal separations between the audience and the performer. By entering into intimacy with the audience, she wraps them into her spacetime, and transmits the idea that the performance does not exist independently from its witnesses. The gracefulness of the body, reflecting years of practice in contemporary and traditional European and Oriental dance styles, produced smooth waves of motion. Sometimes, the body collapsed, as if falling into a timeless gap.

The piece also involves the simulation of a Skype conversation between Farah Saleh and a distant lover. Because of the Wall and checkpoints, realities that split up the physics and psyche of Palestinian citizens, the spacetime of a loving relationship is virtual. The lovers, separated by geopolitical frontiers, communicate through Skype. While her supposed lover, close to her heart, is out of reach, she is extremely close to strangers, and dances within this unexpected spatial intimacy. Reminiscent of contact improvisation, her way of interacting with the audience underlines the distance between her and the physically absent lover.

As in the choreobiographical work of Oxana Chi and Chantal Loïal, Farah Saleh's dance reclaims individual agency from the anonymity of hegemonic narratives. Illustrating the tension of memory politics in Palestine, Hanan Ashrawi writes in her foreword to Birthing the Nation:

As I sit in my home in Ramallah, the sights, sounds, and smells of the Israeli attack bombard my senses: helicopters, bombs, bullets, gas. The conflict that shapes this book is sadly alive and indeed booming louder than ever. News broadcasts around the world almost daily report the rising death toll. This sinister numerical game, whereby Palestinian victims of Israeli fire are daily given as $x$ numbers killed and $y$ numbers wounded, reduce our humanity to a series of abstractions. The victims' names, identities, dashed hopes and shattered dreams are nowhere mentioned. ${ }^{29}$

PerforMemory counters the dehumanization of historical abstraction. This resonates with my own memory of learning about the Shoah in school, and missing my relatives' names and images in the vast narrative, and feeling like history was a missile thrown at me. The more zeros added to the books' count, the deeper I would feel that "history" nullified the humans behind the numbers. To perforMemory allows us to reunite various timespaces within the moment of the performance, to interweave information about what may have preceded the traumatic event, and the protagonists' daily issues and realities. And yet, Farah Saleh's political dance is also about...love, as she pinpointed in the interview:

For this miniature in general my intent is to make people feel this possibility of love, that very human simple thing that can happen when people are close. And how easy I can do it with people thats very close to me, me personally and the person I love...

\footnotetext{
${ }^{29}$ Kanaaneh, Birthing the Nation, xi.
} 
[across] this huge gap and distance, not really physical distance but political distance, where I cannot reach this person. ${ }^{30}$

The distance she speaks of is not only a spatial one, but a temporal one, a distance shaped by waiting, longing and lingering - as performed in the piece. Although this piece is the shortest of the solos discussed here, it stretches time outwards from the hegemonic clocks of news and geopolitical chronologies. Farah Saleh dances conflict, but also and maybe mostly gestures of love in times of war. Her perforMemory is sensuous, as if sensuality may heal the wounds of the present, retrieve an imagined past or dream the possibility of a more tender future.

\subsubsection{The ripples of time in They Call You Venus}

When Chantal Loïal dances the pain and joys of Black women, is she Venus? Is she Chantal? Is she both, as she says in the interview? Performance allows for those boundaries to be blurred, and for this actual blurring not to confuse, but rather produce a new meaning, and to make a statement about the continuities between present and past racism in France. They Call You Venus traces the true story of Sawtche, also known as Sarah Baartmann or the Black Venus. In contrast with Chi's search for traces (Spurensuche), and her reclamation of Barbakoff's vital role in cultural memory, this piece centers a historical figure who is often cited in black and postcolonial studies. While Barbakoff's dance art inspired many painters, sculptors and photographers in the 1920s1930s, the story of Sawtche's deportation and enslavement found its way into literary and artistic engagements in the later $20^{\text {th }}$ century, although these often work with images and texts written by the very people who oppressed them. It seems that her story is emblematic of the violent intersection of racism, sexism and capitalism produced against bodies positioned as Black and female. In an analysis of Elizabeth Alexander's 1990 Venus poem collection, Samantha Pinto writes that "Baartman is large, in Elizabeth Alexander's text; she is her own world, her own system of reference, even as she is limited by another set of meanings." ${ }^{31}$

Loïal also creates her own world, on stage, and moves at the critical border between referring to a history of racism and the racism of history, and tracing her own epistemology. The solo form highlights the centrality of the performer as "her own system of reference." This materializes in a choreography that comes across as waves of movements and time. Within this oceanic choreography, I identify three parts: the humiliation, the celebration and the commemoration.

\footnotetext{
${ }^{30}$ Saleh, interview.

${ }^{31}$ Pinto, Difficult Diasporas, 60.
} 
Time floats in this piece. The dancer's body often moves slowly, allowing the audience to be drawn into the story and into the folds of time. At the beginning of the piece, the light design conveys the feel of exhibition and display, as Loïal appears, like a living display, in squares of light. She takes her time. Motion is sometimes extremely slow: for instance her hands cover her body protectively at the height of her chest and genitals, she moves them, delicately, raises them in front of her, until the outstretched arms point diagonally to the upper sides, then reaches back behind her, as she interlocks her fingers, bends her knees and leans her upper body towards the ground. Still in the same stream of slow motion, she raises herself, turns, side-facing the audience, until the simultaneous decentering of the pelvis releases the locking of the hands. This floating quality recurs in various sequences. The search for fluidity matters to Loïal:

With a work on slowness, the Venus dance took a streaming character, showcasing the fluidity of movement, as if in progressing through an aquatic environment. Below, implicit as a watermark, African[ist] dance is always around, folds into, melts into the movement, rediscovers itself in a contemporaneous aesthetic.

(Avec un travail sur la lenteur, la danse de la Vénus a pris un caractère coulé, mettant en valeur la fluidité du mouvement, comme une évolution dans un espace aquatique. Derrière en filigrane, la danse africaine jamais bien loin, se plie, se fond dans le mouvement, se redécouvre dans un esthétique contemporaine. $)^{32}$

The fluidity of her motion influences the temporality, which also feels aquatic, channeling a sense of rippling time as the story unfolds. Her body keeps undulating, as the choreography stitches elements of Afro-Caribbean styles, traditional western alignment and floor work techniques known as "modern dance" and ballet. Episodes of rising energy, such as the scene when she shivers more and more intensely, resolve into a release of tension, time bending over itself.

"I am woman, I am black, I am myself!"...with this loud statement, Chantal Loïal ends the sequences dealing with the humiliation and oppression of Venus' body and self, and enters into a spirit of celebration. The soundtrack is now South African, and Loïal proudly and joyfully swings the arms, stomps the feet and moves in a contemporary blend of African and Caribbean dance styles. A former company member of the Ballet national du Congo and Ballet Théâtre Lemba, she brings to the stage a proficiency in both Central and West African styles. The hands that were often bound in the last scenes are now released, free to flex. Each finger possesses agency, as seen when she performs the Africanist motif of the finger tracing a vertical descending line along the body.

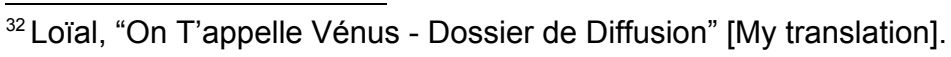


In her artist statement, ${ }^{33}$ Loïal mentions her will to produce an entire life within a unit of time, place and space. It reminds me of the "rules of theatrical dramaturgy" hammered in by literature teachers in my French school time. However, it is interesting how Loïal deviates from these rules, or actually uses "the master's tools" to tell a story I was never allowed to hear in school. She performs a choreobiographic time unity. Time ripples, as waves of motion and emotion allow the audience to travel across centuries and places, from the $18^{\text {th }}$ century to the $21^{\text {st }}$ century, from South Africa to France over the Caribbean. The unity only resides within her body performing in the now.

\subsubsection{The fugitive time in Choc(s)}

According to an Indigenous oral tradition, the world began with a woman falling from the "skyworld." The story is told as follows by Robin Wall Kimmerer, environmental professor and enrolled member of the Citizen Potawatomi Nation:

She fell like a maple seed, pirouetting on an autumn breeze. A column of light streamed from a hole in the Skyworld, marking her path where only darkness had been before. It took her a long time to fall. In fear, or maybe hope, she clutched a bundle tightly in her hand. $[\ldots]^{34}$

In Choc(s), Christiane Emmanuel seems to fall from the sky, in a less bucolic and more neoteric fashion, immersed in a science-fiction soundtrack. To me, she evokes the imagery of a time out of time. At the beginning of the piece, the dancer hangs high up in the air above the stage, in a vertically oriented fetal curl. Slowly, she stretches her body out and opens her eyes, as if coming (back) to consciousness, and soon begins a dynamic walk that transforms into a sprint. Her expansive leg and arm movements make her airwalk sometimes seem like she is rolling, swimming or flying through the air. In the artist statement, she refers to the piece as the scanning of her memory, in search of referentiality:

I am crossing through my memory and thinking of all the big dates of history and to all of those who fought, so I am clinging on. ${ }^{35}$

She may be clinging onto the diasporic condition that emerged in the last chapter. Her words suggest the intricacy of historical time and a contemporary location. Not only does she clings to a rope but she often clings to pieces of cloth, or to the ground on which she crawls and rolls. In this solo, the performer often seems to encounter obstacles. Maybe

\footnotetext{
${ }^{33}$ Loïal.

${ }^{34}$ Kimmerer, Braiding Sweetgrass, 3.

${ }^{35}$ Emmanuel, "Choc(s) - Artist Statement."
} 
her dancing limbs embody the suffering, loss and alienation generated by an ongoing colonial regime on the island of Martinique.

The solo Choc(s) dissolves chronological demarcations between the past of slavery and the present embodied struggle against oppression. The dancer-choreographer binds together elements from task-based choreography, contemporary idioms and traditional steps of Cuban rumba and Martinican bèlè, in the corporeal quest for a memory that may sustain the body into the present. The piece deals with the burning matter of the protest that led millions of people to block the economy in 2009 and 2011. Running through the streets of Martinique island, citizens protested against the economic structure characterized by the slave masters' descendants' continuing monopoly over the majority of resources, and the astronomic costs of food and accommodation. The history of social protest in Martinique bears many stories erased in hegemonic memory transmission, yet sometimes retrieved through oral memory. For instance, Christiane Chivallon collected oral testimony about the 1870 revolt against slave owners in southern Martinique. In an important work reflecting on the construction of the memory of slavery in Martinique, she centers the role of embodied memory which "cannot be detached from the body," which she calls "mémoire incorporée," arguing that:

[...] this memory becoming body renews the circuits of being "against": against command, against the plantation-system, against power, against inequalities, against official narratives $[\ldots] .^{36}$

In Choc(s), Christiane Emmanuel also seems to constantly bump against a force that stops her, and to run against time, and to move in protest against the societal structure of capitalism. The scenography supports the choreographic message and evokes the white collar world order. At first we see a wall of large, white shirts. At center stage, a pile of white shirts form a circle. Once the dancer lands on stage, a video projection transforms the whole stage environment into a cityscape, marked by a strong riff. The pile of shirts now resembles a volcanic crater, reminding me of the volcano in Palestinian-Martinican Widad Amra's poetry (see chapter 2). Christiane Emmanuel keeps running, searching, within this new grayish network-like environment. Although she dances a rush and run, she often takes her time, as do Chantal Loïal and Oxana Chi. Gestures extend into a long stretch of time.

The temporality of this solo makes me think of the realms of futurity and fugitivity, such as those found in Tina Campt's analysis of what she calls an "alternative visual archive of the black diaspora." Campt speaks of the "performance of a future that hasn't yet

\footnotetext{
${ }^{36}$ Chivallon, L'esclavage, du souvenir à la mémoire - Contribution à une anthropologie de la Caral̈be, 532 [My translation].
} 
happened, but must" and looks out for "strategies of diasporic survival" in unexpected places such as passport pictures. ${ }^{37}$ Emmanuel performs these strategies in Choc(s), when she spends much time running, in the air or on the ground, as if time was an aspirated fluid, moving in the fragile spacetime. In a choreographic quest for balance, for something to hold onto, for a space or timeframe to stand on/into, she performs the harsh search for stability and safety. The use of aerial work epitomizes the ambivalent relation of the performer to conventional time and space coordinates.

"Images of Skywoman speak not just of where we came from, but also of how we can go forward," ${ }^{38}$ says Kimmerer, and so do Emmanuel's Earth- and Skyworld bend the linear timeline of Martinique's geopolitics. Choc(s) collapses the hegemonic narrative of a postslavery society. Moreover, it grips onto what is behind, and attempts to attain, through performance, a timespace ahead of her own subject located in the equation of the $21^{\text {st }}$ century Caribbean.

\subsubsection{The swirling time in Impressions}

If time were a musical figure, in this piece it would be a staccato. The solo engages with the impact of Wan-Chao Chang's memory from her years home away from home. Questioning how these memories affect her new daily life and return to Taiwan, the piece works through a choreography that seems to unfold layers of time. The title, Impressions, suggests that Wan-Chao Chang digs into the imprints left by memory within her body to render a sense of time that is physically past but mentally and bodily present, thus influencing her motion in contemporaneity.

The sequences follow each other in staccato-like fashion, but the dance movements remain mostly fluid. The hands float on the surface of time. Hands flow gently through the air, in a remix of Javanese dance techniques. They often reach out, trying to grab something, as if there was an invisible support to hold onto within the motion of time, or as if the dancing hands could hold onto time itself, and stop it from fleeing. Towards the end of the piece, hands also appear as a video projection, and the dancer plays with the image, projecting the shadow of her hands onto the video representation of her hands, reminiscent of the Javanese wayang kulit art. The self moving in the now thus enters into touch with the hands moving in another dimension, be it past or present, reaching for each other. As in Emmanuel's Choc(s), time here is fragility, and equilibrium is the remedy.

Time can also be a precious memory, a location in space and time that the dancer tries to hold in her hands. So is the prop, the scarf that may be a thread of diasporic memory

\footnotetext{
${ }^{37}$ Campt, "Black Feminist Futures and the Practice of Fugitivity."

${ }^{38}$ Kimmerer, Braiding Sweetgrass, 5.
} 
that she moves with, within and without. In one brief sequence, the scarf will even capture the saxophone of the accompanying musician. The scarf entangles the instrument, the body, the movements and sounds, almost arresting time.

The "millions of years before and after us" and "millions of places" around us, as suggested in Chung-Hing's poem which opens this chapter, overlap each other in Chang's performance. Rhythm plays an important role, especially when the music carries the movements in a lively manner. Stepping, sometimes leaning the arched back behind herself, isolating the shoulders, even running, all these movements harmonize with the dynamism of the piece. Nevertheless, at times the dancer takes the time to pause, to decelerate the pace, as the music goes on. In these sequences, her movements evoke a movie still.

The stretch of time indeed feels cinematic, with Chang's coming and going through the performance venue. She could be wandering in flashbacks of her past, or debating in which spacetime she wants to and can stay. The body seems to be struggling between leaving something behind (a place, a situation, a memory) and running back after it. With only two or three steps, the dancer could be jumping back and forth from the USA to Taiwan, from Taiwan to Indonesia, from one layer of her life to another, trying to reunite these moments in a performative way and instant.

At one point, Wan-Chao Chang starts spinning on her own axis, using the technique of dervish dancers. In Beijing Opera tradition, performers walk in a large circle to indicate narratively that they are traveling a long distance. Here Chang sticks to the small circle of her self, and yet her dance leaves a swirling trace in the air, and conveys the impression of an intense journey, be it a geohistorical, emotional or mental one. Wan-Chao Chang dances the motion of time at a microscopic scale. Scientist Carlo Rovelli has described the apparently peaceful and clear water surface of a lake as "the rapid dance of myriad of minuscule water molecules." 39 Wan-Chao Chang's perforMemory combines calm, fluid body energy with dynamic, agile motion and control over each and every muscle. I cite Rovelli because he uses the metaphor of dance to explain the movement of time, space and the nature of spacetime according to quantum physics:

Every cubic centimeter of space, and every second that passes, is the result of this dancing foam of extremely small quanta. ${ }^{40}$

The solo Impressions can help us understand kinesthetically what this dancing foam may look and feel like. As quanta matter, it moves beyond the notion that time and space exist

${ }^{39}$ Rovelli, Reality Is Not What It Seems, 183.

${ }^{40}$ Rovelli, 192. 
independently from each other, or move in a linear fashion. The dramaturgy resists the linearity that structures most historiographical projects of western narrative domination.

Time - and its measurement, as we know, is a social construct which varies from society to society. Chang dances Impressions of time as it inhabits her being. She performs within a swirling temporality, she clings onto the imprints left over time on her body. She connects, through movements, the Impressions of the past as they swirl into her present. Her perforMemory bridges the gaps between remembering (other times), wishing (to be somewhere else), and being, dancing, continuing to live and create.

(En)countering hegemonic narratives involves addressing the conceptions of time underlying them. Scratching beneath the surface of dominant historical discourses, one finds western norms of time, space, or spacetimes. I have tried to show how each solo performs and is informed by a different notion of time. ${ }^{41}$ To perforMemory involves addressing what time is and how dance comments on, challenges and transforms notions of linear, chronological time, which in turn impacts memory transmission. I argue that each dancer works with a different approach to memory, as reflected in the various positionings described above. Paradoxically, I find myself undertaking what Jill Dolan describes as the difficult task of the performance scholar, namely "to document a complicated process of engagement with a live event whose presence I can only trace as I remember it in the future." ${ }^{" 2}$ Although these pieces live from their liveness, it is only afterwards that I try to translate them into words. The remembering "in the future" inevitably diverts from the multi-sensory experience in the spacetime of the performance. While Tina Campt encourages us to "expand our sensorial engagement" with photography, for instance by trying to listen to images of black diasporic refusal and survival, ${ }^{43}$ my conceptualization of perforMemory challenges us to also move beyond the mere visual realm of dance. Paying attention to the multisensorial qualities of the performances, I proposed an interpretation focusing on dimensions of time as experienced in the works. Dancing the past in the present tense, the performers all move at the crossroads of time, space and emotion. These elements are no longer distinctive categories, rather they (e)merge on stage, generating memory2go as a new spacetime dimension. By stretching the definitions, functions and motions of time, the dancer-choreographers resist the very temporalities that simplify, silence or suppress their stories. They perforMemory a present presence, and generate a spacetime made of multiple textures, shapes, and paces. Through dance, they (re-)invent how the moving body may metaphorically and materially intervene into

\footnotetext{
${ }^{41}$ Here I am also reminded of a university reading, in which each chapter describes a world with a different conception of time: Lightman, Einstein's Dreams.

${ }^{42}$ Dolan, Utopia in Performance, 15.

${ }^{43}$ Campt, "Black Feminist Futures and the Practice of Fugitivity"; Campt, Image Matters, 2017.
} 
and transform postmemorial discourses and practices, physically, epistemologically, ontologically, and phenomenologically.

\subsubsection{The quantic dance of memory: moving through and beyond past, present and future}

To move through the world of performing arts is to experience the whirlwind of the multiple paces and textures of time. On stage, it becomes particularly clear and intense to wonder what experiencing time means. Earlier this year, on February $16^{\text {th }} 2017$, I initiated and co-curated - with Oxana Chi - a performance night at Dixon Place Theater in Manhattan. One of our goals was to promote visibility of the perspectives of Black women, and especially lesbian/queer ones during Black History Month, and we included ourselves in the line up. I was particularly excited to perform new work: the New York premiere of my short solo Homesong, consisting of spoken words and saxophone.

I remember waiting in the backstage spacetime before the show. Rosamond S. King, a poet, performer and tenured humanities professor is about to perform. As nervousness and concentration bubbles start to inflate and fill up the air, she evokes how every minute "feels like an eternity" before performing. I agree, feeling the same way: lingering on these small islands of waiting time, a few minutes ahead of show time, each passing second seems to stretch into a long, infinite moment. This feeling makes me reflect upon how subjective time is, how a second is not a mathematical, intangible unit of time, but rather a bubble that floats and carries one along different paths, at varying paces, depending on the winds of personal emotion, situation and position. The stretched time of waiting backstage contrasts so sharply with the intense, sky-rocketing time feeling of stage performance. Once I step onto the stage, performing a text or playing an instrument, I feel swallowed by a hurricane of time, and now suddenly time rushes and I focus on performing at an appropriate pace. It is a conscious effort to modulate time, while the intensified bodily production of adrenalin, serotonin, dopamine, tends to accelerate speech or play rhythm. The seconds that seemed eternal a few minutes ago in the backstage time/space, now ripple so fast...and I try to catch them with each pause of breath. I perform my text, my song, alone, or accompanying Oxana Chi, and I leave the stage feeling detached from my usual time senses. When we toured I Step On Air, I realized how 45 minutes of performance spacetime have an entirely different feel from a 45 minute rehearsal.

Strangely, with each show, the performance felt shorter, although we timed it, and did not alter the duration. It felt as though time was shrinking. This surely had to do with 
experience, with the ease that comes with repeating a work, with traveling through the performance several times. Like the familiarity that comes with having walked an itinerary several times, I could now wander through the piece at a different pace. What still feels like one of the most challenging tasks to me, but is refined through practice and experience, is to not walk through the whirlwind without bending time, and to stick with your route. Surfing on the non-linear time feel on stage, while staying precisely in tune with the measured clock time - because you do not want to play 30 minutes or 1 minute of saxophone for sequence $A$, if during rehearsal you agreed that sequence $A$ should be about five minutes. I learned this art and science of timing from Oxana Chi's precise coaching during rehearsals. This experience helped me to understand how time does not only move forward from past to present to future, but rather shifts from one cognitive state to another. Time is a matter that we can craft. While humans seem to move through set units of seconds, minutes, hours and days, they actually move through waves of emotion, through positioning in space, through evolving environments and through various levels of consciousness, all of this at stake in how humans sense time and how time senses affect humanity.

\subsubsection{Dancing right here right now: from ephemeral to epiphenomenal time}

In ancient China, the "hsiang yin" was a clock that indicated the passing of time through the burning of incense, the ashes of which eventually revealed a philosophical or poetic text or koan. ${ }^{44}$ I read about it in the work of Korean-born philosopher Byung-Chul Han, who explains how the incense-clock measured time by filling the air with fragrance, thus materializing how time can become space. ${ }^{45}$ If time scents, can dance fill the stage with the fragrance of memory? The performances discussed here reunite the notion of time and space within a performing body. In perforMemory, time becomes space, and memory becomes the motion of time in space, as the dancers imagine and embody alternative ways of relating to time and memory.

A plurality of other examples could be cited to illustrate non-western conceptions of time and memory transmission, for instance American Indigenous practices of sand painting and their temporary temporality, which Teshome Gabriel takes as a starting point to reflect upon erasure as a practice of memory. ${ }^{46} \mathrm{I}$ mentioned in the introduction that many performance and dance scholars have defended the ephemerality paradigm, while others defend the idea of the body as an archive. Scholars such as Julia Wehren in

\footnotetext{
${ }^{44}$ The author develops an interesting reflection about time as a fragrance. See Han, Duft der Zeit.

${ }^{45}$ Han.

${ }^{46}$ Gabriel, "Ruin and The Other."
} 
Germany or Rebecca Schneider in the USA make clear that performance cannot be restricted to its presumed disappearance and ephemerality. However, their engagement with the relation between performance and history/memory focuses on practices of choreographic or theatrical re-enactments. While my analysis is interested in the actual enactment of memorial discourses and practices through performance, I share Schneider's enthusiasm for the resilience of performance, away from the ephemerality paradigm:

When we approach performance not as that which disappears (as the archive expects), but as both the act of remaining and a means of re-appearance and "reparticipation" (though not a metaphysic of presence) we are almost immediately forced to admit that remains do not have to be isolated to the document, to the object, to bone versus flesh. ${ }^{47}$

Schneider refutes the assumption that performance disappears, choosing to focus instead on what remains. The various temporalities described above, born out of my own reading of the choreographies, resist the disappearance of the performing body in the narrow corridor of linear time. They show how the dancing body leaves traces across spacetimes, and how to perforMemory amounts to creating a multiplicity of spacetimes for memories to unfold. If we agree that the body stores memory - across millenniums of generations and millions of kilometers - then it becomes utterly urgent to think corporeal practices beyond the realm of ephemerality.

The dancers' understanding of their body as a channel for a memory retrieved from other generations, locations and dimensions is underlined by the conversations presented in the next chapter. Dancers also use their bodies as a channel for contemporary interventions within historical definitions, even within the definition of what history is, in order to affect sociopolitical change. For example, Farah Saleh worked on a project entitled "Archive of Gestures," which she presented during a residency at The Center for Humanities at Brown University in 2016. In an interview given around that time period, she explains:

I'm investigating the idea of artist as archivist. The body contains counter-archives or counter-narratives to the official narrative. [...] My question is: how can artists contribute to change by problematizing social and political memories? I'm interested in latent stories or invisible stories of Palestinian history that were never officially archived or deliberately obscured. I'm archiving the gestures of the actors of these stories using historical archives that were documented, personal testimonies, and imagination. ${ }^{48}$

\footnotetext{
${ }^{47}$ Schneider, Performing Remains, 101.

${ }^{48}$ Saleh and Bindler, Free Advice and an Interview with Farah Saleh.
} 
Her words return us to a leitmotif of this book, namely that bodily performance, in this case dance, does not only represent, but actually contributes to the process of accessing and creating knowledge about the past from a present standpoint. I have tried to trace how this extends to other contexts, from Palestine to the USA, from the memory of slavery to the Holocaust. I could cite other reflections by the dancers, such as Oxana Chi's argument that past and present times cannot be thought of as strictly separated. ${ }^{49}$ The idea of the artist as archivist is inherent to Chi's entire repertoire, and her use of dance to perforMemory silenced narratives, and to choreobiograph Tatjana Barbakoff in Through Gardens, or May Ayim in I Step On Air.

In the latter case, I had the chance to accompany her perforMemory in various settings, often academic ones all across Germany, as well as in Turkey, the USA and India mostly in plenary sessions for feminist events. Everywhere, the audience expressed how deeply the contribution impacted them, for it enriched, supplemented, or even countered the conventional forms of knowledge transmission which they were used to in the academy. The analysis of audience reception could constitute a full research project of its own, and could help assess the long-term impact of dance on its viewers and how the memory of it stays within the body, but this is beyond the scope of my research. Often, we introduced the performance with a talk in which we delivered key information about May Ayim's biography. We listed publications and achievements, told of her travels, challenges and engagement. After a short break, Oxana Chi slipped into the role of the dancer. Thus, she juxtaposed a more conventional form of biographical storytelling to the choreobiographical process that marks most of her current repertoire. Similarly, when I attended Through Gardens, it was often contextualized by a preliminary talk or interview (given, for instance, by historian Günter Goebbels, who has been researching archives on Barbakoff for over twenty years). Oxana Chi's choreobiographic process works through an epistemology that relies both on the linear, chronological knowledge of history, and on the non-linear, performative spacetime of her own sense of a dancing being in contemporary Germany. Choreobiography can be non-linear, and subvert the idea that past, present and future are successive markers on a timeline. Success, struggle and search (for inspiration or liberation) are sites of corporeal investigation not only in relation to 1920 s/1930s dance historiography, but also in relation to her $21^{\text {st }}$ century reality.

Another point of entry for understanding how dance bends hegemonic timelines is to reflect upon non-western structures of time, as transmitted through embodied memory. Here, I am not only thinking about Black or Africanist knowledge systems. Earlier I suggested that Through Gardens rests on cyclic time - which may have to do with Chi's

\footnotetext{
${ }^{49}$ Chi, interview.
} 
interest in and knowledge of Indian and South East Asian arts and cultures. I find that the cyclic dramaturgy of Through Gardens bears affinities with the structure of the dance of Shiva. This dance is described in an Exploration of the Parallels between Modern Physics and Eastern Mysticism as follows:

The Dance of Shiva symbolizes not only the cosmic cycles of creation and destruction, but also the daily rhythm of birth and death which is seen in Indian mysticism as the basis of all existence. At the same time, Shiva reminds us that the manifold forms in the world are maya - not fundamental, but illusory and everchanging - as $[\mathrm{s} /$ ]he keeps creating and dissolving them in the ceaseless flow of dance. ${ }^{50}$

Through the performative cycles of Tatjana Barbakoff's successes and struggles, and the framing of birth and death within a circular narrative pattern of dance, Through Gardens displays the "ceaseless flow of dance," and lets Tatjana Barbakoff (re-)appear and (dis-)appear. The dramaturgy flows, as do the movements, in their seamless connecting to a rich source of techniques originating in various geographies and histories, from ballet to kung fu and Javanese to modern dance. Here again, I am reminded of the motif of a wind, or a breeze that carries this chapter on time. In a cycle, there is not necessarily a beginning or an end. The scene of the New Moon - which by its very title evokes the lunar cycle - re-frames Barbakoff's death, by infusing it with life. This dramaturgic move allows for the idea of an afterlife, seldom found in dominant narratives of the Holocaust.

In another aspect of "sites of memory," ${ }^{51}$ André M. Zachery's Afrofuturist perforMemory lets linear time implode in his reflection upon alternative ways of thinking, living and performing African diasporic identities. Like Digital Middle Passage, the work Hidden Tracks belongs to the series Untitled Distances. It "looks at the African diaspora practice of the 'Ring Shout' as a spiritual time vessel - holding past, present, and future simultaneously in a single gesture." ${ }^{2}$ The idea of a time vessel in one way or another is meaningful for all the pieces discussed here. PerforMemory is a process that enacts not only other times and spaces, but even more so other ways of relating to time, space and their interrelation. Zachery's solo Digital Middle Passage disrupts the linearity of what Michelle M. Wright calls the "Middle Passage Epistemology." It brings to life a live diasporic, non-linear motion. I find it particularly striking to look at Zachery's work through the lens of Wright's scholarship on the Physics of Blackness, which offers a visual metaphor of spacetime:

\footnotetext{
${ }^{50}$ Capra, The Tao of Physics, 242.

${ }^{51}$ Morrison, "The Site of Memory."

${ }^{52}$ Zachery, "Untitled Distances."
} 
If the spacetime of the Middle Passage Epistemology can be represented by a line (or an arrow), then the postwar epistemology [...] should be represented as a circle with many arrows pointing outward in all directions. This nicely sums up the argument of Physics of Blackness: in any moment in which we are reading/analyzing Blackness, we should assume that its valences will likely vary from those of a previous moment. The circle denotes the "now" of the present moment, and the arrows represent all the spacetimes that intersect with that "now." 53

Sitting in the audience to watch Zachery's work is to witness the constant transformation of Blackness. The term "valence," used by Wright, originates in the realm of physics to describe the motion of electrons, but it is also used in psychology in relation to emotions. Zachery's dance opens up existential questions about the valences of Black perforMemory. It incites us to ask how Black bodies interact with the past, and with each other in the present, and how they find the physical and emotional power to move towards the future. Moreover, I find the metaphor of the line and the circle of utmost relevance to the work of Zachery and his Renegade Performance Group. In the specific case of Digital Middle Passage, the dancer actually traces a line by traversing the middle space of the stage (starting from the right and ending to the left, from the audience's perspective), yet circularity represents the key element throughout the choreography. In the soloist dancer, I see an arrow flying high and low, out and back, to the circular motion of spacetime. Circular motion - to which I will come back in a later part of this chapter - is the infinity of a journey in which the performer consistently reaches out to ancestral legacies and millennial fantasies, however irresistibly anchored in the performative "now." "Now" is the reference point of what Wright calls "Epiphenomenal time," ${ }^{54}$ it is the present spacetime in which Blackness is situated. I was inspired by the way Wright derives her theorization of Epiphenomenal time from an ingenuous interweaving of literary criticism, phenomenological philosophy, quantum physics and diasporic critique centered on Black memory.

What is most appealing about Wright's inclusion of Epiphenomenal time is her emphasis on the agency of a contemporary subject, whose existence is determined by the interrelation of the multiple dimensions of Black identity. Wright does not reject linear time conceptions, rather she argues for a combination of chronological linearity - which acknowledges a traumatic history - and Epiphenomenal time - which allows for complex, colliding and colluding definitions of subjectivity - to be able to define, or understand ontologies of Blackness. Her work focuses on literary examples, and she does not visit the world of performing arts in her fascinating theoretical odyssey into Blackness. Yet, I find that Epiphenomenal time may be clearly understood through stage performance, in the

\footnotetext{
${ }^{53}$ Wright, Physics of Blackness, 20.

${ }^{54}$ Wright, Physics of Blackness.
} 
dancing bodies' execution of movements in the time and space of now. I argue that performance, and more specifically dance, are primordial sites of realization for Epiphenomenal time, and that the dancescapes of perforMemory can shape our understanding of the various textures of temporality. The multiple "strands" 55 of perforMemory's time are not only a metaphor for identity, they also speak to a material breadth of dance styles and movements. I find Wright's theory particularly attuned to Zachery's work, including the piece Untamed Space which is premiering as I am about to publish. However, in light of my interpretations of time above, I find that the swirling time in Impressions also lets arrows pierce out of the circle, and that a salient example of Epiphenomenal time can be found in the instant time of Parole, Parole, Parole, just to give two examples. Therefore I remain open to the possibility of extending its validity outside of the scope of Black diaspora, to other realms of identity. In any case, it appears that to perforMemory right here and right now is more Epiphenomenal than ephemeral.

\subsubsection{Intensity as the spacetime of perforMemory}

In the changing atmosphere of perforMemory's spacetimes, intensity seems to be the constant that holds the dance of quantic memory together. If the dancing body is a home, intensity is the wind that breezes through its spatiotemporal, emotional, kinesthetic windows. I propose intensity as the epistemological and ontological framework of perforMemory in relation to spacetime. And simultaneously, intensity is the key feature of live performance, which fades away with an audiovisual recording, or a literary description, or a notation of a dance. The timescapes of perforMemory, as I have tried to suggest above, are the result and the source of non-linear time modes and counterhegemonic narratives. Connecting this to the reflections in the previous chapter on space and the dancing body as a home, my research leads us to understand dance as the practice of moving beyond ideas of past, present and future, or what Ella Shohat calls a "teleological" world conception that "segregates" temporality and spatiality. ${ }^{56}$ The spacetime of a danced perforMemory becomes a referential unit for the expression of memory.

PerforMemory anchors the body in the performative now and may combine linear and Epiphenomenal time. The dancers do refer to historical events, traumata and facts such as the Holocaust, the Transatlantic Slave Trade, the Nakba, the racist-colonialist complex. Yet, they associate these referential markers to a self-referentiality embedded in their performing body. Inspired by Michelle Wright's discussion of quantum physics, I turned to

\footnotetext{
${ }^{55}$ Wright, 83.

${ }^{56}$ Shohat, Taboo Memories, Diasporic Voices, 15.
} 
quantic conceptions of spacetime to reflect on dance...to find that physicists sometimes describe the motion of spacetime as a dance. The earlier mentioned "dancing foam" 57 imagery chosen by Carlo Rovelli suggests that time and space do not exist independently from one another, or as abstract entities or measure units. This is why Rovelli and other scientists like to say or write that there is actually no such thing as time, or the passing of time as western theory and socialization teaches it.

At the extremely small scale of the quanta of space, the dance of nature does not develop to the rhythm kept by the baton of a single orchestral conductor: every process dances independently with its neighbors, following its own rhythms. The passing of time is intrinsic to the world; it is born of the world itself, out of the relations between quantum events that are the world and that themselves generate their own time. ${ }^{58}$

While Rovelli speaks of dance, Frank Capra also describes the dance of the matter as a cosmic dance and takes the example of Shiva's dance:

Different particles develop different patterns in their dance, requiring different amounts of energy, and hence have different masses. [...] Thus, not only matter, but also the void, participates in the cosmic dance, creating and destroying energy patterns without end. For the modern physicists then, Shiva's dance is the dance of subatomic matter. ${ }^{59}$

So it is all dance! Does this suggest that our environment is per se the ephemeral, ever renewing interaction of particles of microscopic spacetime? Or that ephemerality does not really exist, and therefore it is absurd to call the art of dance ephemeral? Refuting the ephemerality of dance also makes the case for its capacity to tell history, and to acknowledge the role of the (moving) body in the production and transmission of cultural memory. Beyond the metaphoric eye blink and the poetic imagery of dance, I find a deeper connection between the movement of spacetime and dance. In my interpretation of the multidimensional temporality emerging out of seven solos, intensity, rather than ephemerality is the core. As suggested above, I read in the works of the seven dancers various manifestations of non-linear time. In their works, I see the motion of time in cycles, waves, pulses, ripples. I see instantaneous, fugitive, suspended time. These motions do not travel along a past-present-future continuum.

The performances contemporize the past. To perforMemory amounts to producing memory-as-you-go, or memory2go, a memory intimately and intensely bound to the moving body. In the interaction of muscles, time, and space, the dancers generate their own spacetime of intensity in which cultural memory can become visible and experienced.

\footnotetext{
${ }^{57}$ Rovelli, Reality Is Not What It Seems, 192.

${ }^{58}$ Rovelli, 178.

${ }^{59}$ Capra, The Tao of Physics, 245.
} 
These spacetimes are what Dipesh Chakrabarty would call a time knot. Chakrabarty describes linear time as straightened time knots, referring to the imagery and vocabulary of time in his first language, Bengali:

Time, as the expression goes in my language, situates us within the structure of a granthi; hence the bengali word shomoy-granthi, shomoy meaning "time" and granthi referring to joints of various kinds, from the complex formation of knuckles on our fingers to the joints on a bamboo stick. ${ }^{60}$

In the repertoire of perforMemory, the shomoy-granthi or time joints physically connect kinesthetics and history. When memory is located and performed within the body and its movement, perforMemory moves at the physical junction between time knots and body articulations. Therefore, new concepts of spacetimes become possible, as they are created by the performance itself.

Because the body is political, connecting corporeal presence to the contemporaneous agency of the moving subject is political. This helps me to demonstrate my main argument, namely that by anchoring memory to the body, perforMemory strongly politicizes memory. When the bodies moving and the stories they are telling stem from diasporic perspectives and processes, the dance becomes a mode of resistance countering hegemonic historiography. Dancing the past in the present tense not only allows for the "politicization of memory," ${ }^{61}$ it is a fundamental way to achieve it. PerforMemory thus counters erasure of the bodies and their stories, as the dancing bodies leave a swift trace, visual yet invisible, temporary yet unalterable.

Dance as resistance operates from the resilience of intensity, and accomplishes an epistemic transformation of our cognition of time and space, actually renewing cognition itself by creating performative timescapes, and performance as a spacetime of intensity. As noted earlier, intensity bears affinity with intensification. Repetition as intensification transforms the repetition of a movement into the intensity of an emotion, an intentional and intensive knowledge transmission. This can be seen in Oxana Chi's use of modulation of pace in spinning and fighting (back), Zufit Simon's and Chantal Loïal's shuddering, Farah Saleh's alteration of daily gestures and intimacy, André M. Zachery's repetitive spiraling and diving, Wan-Chao Chang's searching and twisting.

On this thesis' journey with story-hunters and dancing lions, each chapter is a window onto the dancescapes of perforMemory. Following the introduction, the second chapter discussed memory as a site of movement. In the third chapter, the dancing body appeared as a diasporic home. In this chapter, I carved out timescapes of perforMemory and proposed the idea of intensity as a spacetime of perforMemory. Moving forward in this

\footnotetext{
${ }^{60}$ Chakrabarty, Provincializing Europe, 112.

${ }^{61}$ hooks, "Choosing the Margin as a Space of Radical Openness," 155.
} 
endeavor I will now engage with the material and metaphorical physicality of perforMemory. If dancing the past in the present tense is so intense, it has much to do with the actual dance movements that belong to the repertoire of perforMemory. 


\subsection{The Moves of PerforMemory: Shaping the Dancescapes}

After my diasporic journey, I returned to Berlin in the spring of 2016 to complete my doctoral program. As I was completing my dissertation, I designed and taught a class called "Performing Memory: race, gender and diaspora in cultural discourses and practices" at Humboldt-University. One of the hallmarks of the seminar was the involvement of dancers. The outcome earned me the Teaching Award, First Prize, from my Humanities Faculty (Fakultätspreis für die Lehre). The students fed a copious blog on Tumblr with their written and audiovisual contributions on the topics of memory. ${ }^{62}$ Meanwhile, digital social media kept me connected to the distant New York City's dancescapes. They gave me a regular glimpse, albeit on screen, into the work of the many dancers whose work I appreciated. It was in that time and space, away from New York, that I came to fully appreciate Instagram, which I had started using during a Boot Camp for the Performing Arts at the New York Foundation for the Arts (NYFA) undertaken as a member of Oxana Chi's company. Browsing Instagram felt like stepping onto a platform where "diasporic spidering"63 came to life. Some pictures performed the memory of the dance world I was dearly missing, both as a spectator and as a protagonist. One of the persons I enjoy watching on Instagram is Candace Thompson, who founded the Dance Caribbean Collective (DCC). One day, she posted a picture of her solo Of Circles and Bright Colors. The photo transported me back to the live experience of the performance, which I attended in the summer of 2015, during the first edition of the DCC Festival New Traditions....A flow of smooth movement, a graceful alignment, a whirlwind of colorful energy. The Instagram post included a caption:

Floating. Dance can be so much about creative illusions but we have a real ability to shift energy, harness power and realize new collective existences. How will you use that gift today $?^{64}$

Performers do "use the gift" indeed. Dancers-choreographers do not merely execute a set of movements imagined by someone else. They interpret movements which they have carefully selected themselves, through conceptual processes, and/or through creation and

\footnotetext{
62 "Performing Memory."

${ }^{63}$ George-Graves, "Diasporic Spidering."

${ }^{64}$ Thompson, "Of Circles and Bright Colors."
} 
improvisation in the recurrent rehearsal spacetime. They present their self-in-presence to the audience, performing movements with the intent of expressing an aesthetic creation, a political message, an emotional evolution. Foremost, they are acutely aware of the interrelation between physical performance, societal environment and social transformation. Thompson's words carry the belief that dance should not merely be seen as a space of representation, but also as a time_space of action. When dealing with traumatic memory, dancers can "shift energy" in order to address and transmit cultural memory without inducing the re-traumatizing of themselves or the audience. ${ }^{65}$

The seven solos of perforMemory demonstrate the ability to "harness power" through dance. They combine the search for aesthetic quality and the critical inquiry into sociopolitical concerns. The topics of women's history, diasporic migration, coloniality, discrimination, healing, social and personal transformation build a repertoire of perforMemory. The dances also intervene into power structures of memory-making in a way similar to Ananya Chatterjea's understanding of dance as intervention:

Dance images [...] despite their impermanence, have energy and the power of liveness, spirit, and the fiery passion of their creators' politics. They shore up in other but vital ways the project of decolonization, creating aesthetic frameworks that are permeated with an interventionary politics, working not solely in reaction to hegemonic structures, but generating beauty and power that, while creating specific kinds of pleasure and value, resists reinscription into reigning dominant constitutions. ${ }^{6}$

I find that all these solos embody the duality of beauty and power described by Chatterjea, without subscribing to mainstream definitions of them. ${ }^{67}$ Their empowering figures, stories and forces live within the moving presence of the performer. In the spirit of critical dance studies, I would like to now ground the interpretation of dancing bodies in their materiality ${ }^{68}$ In doing so, I try to move beyond the visual realm, and follow instead what Jacqueline Shea-Murphy calls "a dance studies model, with it attention to corporeality and the energies and agencies engaged by bodies moving, within particular frames and contexts, in time and space." ${ }^{69}$ In this quotation, Shea-Murphy illuminates the role of the body's agency in dance, in which I see a meeting point between gender and performance studies.

In this section, I focus on turning, jumping and crossing as corporeal practices through which the performers shape the dancescapes of memory. This choice is largely inspired by my analysis of Through Gardens, which serves as a thread throughout the inquiry.

\footnotetext{
${ }^{65}$ Hirsch, The Generation of Postmemory, 161. See discussion of this in my chapter "Memory Dancescapes."

${ }^{66}$ Chatterjea, Butting Out, 135.

${ }^{67}$ Although André M. Zachery claims that he is not interested in the beauty of movement. Zachery, interview.

${ }^{68}$ On this, see also Martin, Critical Moves.

${ }^{69}$ Shea Murphy, The People Have Never Stopped Dancing, 8.
} 
Obviously, the performers all engage in a very complex array of movements. Thus, I do not mean to restrict their work or to say that these are the only movements of perforMemory. Rather I propose this reading as a way to connect the physical and conceptual realm of movement in the production and transmission of cultural memory. The questions I try to answer here are: what are the movements of perforMemory? Which corporeal tools do the dancers use to shape the dancescapes of memory? How do they physically intervene into cultural discourses and practices of memory-making?

\subsubsection{Turning}

\subsubsection{Spinning selves}

In a frenzied, festive atmosphere, Oxana Chi dynamically embodies the successes of Tatjana Barbakoff in a whole-bodied engagement in the scene of the Celebration (Das Fest). Because the scene actually features the three sets of movement theorized here (turning, jumping and crossing across the stage, sometimes simultaneously), I find it emblematic of the corporeality of perforMemory. Turning is certainly a structuring movement of the scene. Spinning on her own axis, the dancer nimbly executes turns. Some of them are drawn from ballet, such as the pirouettes en retiré - meaning that a thigh is withdrawn high in second position. On the blog "Ballet Bag," which provides an insight into ballet techniques, the pirouette spin is described as follows:

A complete turn of the body on one foot. The supporting foot can be either on pointe or demi-pointe, with the working leg positioned sur le cou-de-pied, in arabesque, à la seconde, in attitude, etc. Legs give the impulse from a deep plié in preparatory position, arms control the turning speed and the head is the last part of the body to turn away from an imaginary "spotting" point and the first to hit the point again once the body completes the turn. ${ }^{70}$

The description suggests the complexity of this spinning technique, which is usually performed by cis-men, according to blog founders Emilia Spitz and Linda Uruchurtu. Chi destabilizes the gender roles associated with the technique. She also spins on her own axis while reaching from one corner of the stage to the other, as if propelled by an energizing force that allows her to move in spins, rather than progressing in a straight linear fashion. Often, she breaks conventions by softening the rigidity of ballet lines, thus "giving ballet a fresh spin," as goes the motto of the above cited blog.

\footnotetext{
${ }^{70}$ Spitz and Uruchurtu, "Bag of Steps: Turns."
} 
The dancer sometimes uses, as a starting or ending point of the spin, a figure reminiscent of the attitude pose in ballet vocabulary. Sometimes her body wraps itself in the turn, as if embracing itself. In this position, the dancer stands on one leg, her foot flat à terre, the other leg lifted back with the knee bent. One arm on the side of the lifted leg is curved over the head, the other arm is extended to the side. According to the educational glossary of the American Ballet Theatre, the attitude was originally derived from a $16^{\text {th }}$ century bronze statue representing a dynamic, flying, Mercury with wings on its feet. ${ }^{71}$ The Mercury deity stands for gatekeeping between the worlds, and is known to be a patron of the arts, success, and commerce. Therefore it is interesting that Chi reframes the ballet attitude in her choreobiography of Tatjana Barbakoff, and uses a figure connected to success to express and celebrate the historical dancer's achievements. The performative turns and spins of Oxana-Tatjana chart a whirlwind of emotions, rendering what this stage of her life may have felt like. As mentioned earlier, Barbakoff gained increasing recognition as a dancer in the 1920s and 1930s, performing in cabarets as well as in renowned venues such as the Schauspielhaus Düsseldorf, or opera theaters and city halls across Europe. After her performance on October $26^{\text {th }}, 1924$ at the Königsberg City Hall, the newspaper Ostpreußische Zeitung reported as follows:

Deepest internalizing in sharpest cultural state is what we found in Tatjana Barbakoff. Spirit and energy at the peak of their possibilities. What is ravishing in Tatjana Barbakoff's dance, is her being's release, the peaceful abstraction from the world of demands and laws that accost us from afar. One stands as hypnotized under the irresistible influence of this dancer.

(Tiefste Verinnerlichung in schärfster Kulturfassung fanden wir bei Tatjana Barbakoff. Geist und Energie auf dem Gipfel ihrer Möglichkeiten. Was an Tatjana Barbakoff entzückt, das ist das Erlöste ihres Daseins, die selige Entrücktheit über die Welt der fremd an uns herantretenden Forderungen und Gesetze. Wie hypnotisiert steht man unter dem unwiderstehlichen Einfluss dieser Tänzerin. $)^{72}$

This excerpt emphasizes the energetic realm surrounding Barbakoff's expressionist dance, a quality found in Chi's contemporary piece Through Gardens, which also emits hypnotic energy, especially in the circular dynamic of the Celebration scene. Without representing specific times and places, or other markers of memory related to the $20^{\text {th }}$ century, the choreography suggests how Tatjana Barbakoff became an influential dancer, and a source of inspiration for many well-known artists. The sequence seems itself like a painting set into motion, a warm feast for the senses in the tones of red, green and yellow.

The dancer also uses half-turns to re-turn her body frontally towards the audience, which could be interpreted as a connection between reaching back into the past and

\footnotetext{
71 "Attitude."

${ }^{72}$ Cited in Goebbels, Tatjana Barbakoff, 13 [My translation].
} 
looking forward, or what metaphorically lies ahead. Here one may also think of the Sankofa, the Akan symbol of a bird looking back to draw the knowledge necessary to move forward. In this case, the spinning movement of perforMemory is also the starting point for a narrative turn away from hegemonic discourses on the Holocaust. This highly dynamic scene of Through Gardens embodies the movement of turning as an act of life, of overcoming obstacles, of advancing towards a goal, and therefore inscribes a precious step in the choreobiography of Barbakoff. Interestingly, Oxana Chi uses diverse forms of turns throughout her current repertoire. In the piece Neferet iti discussed in chapter three, Chi ends the piece with seven minutes of continuous spinning, reminiscent of dervish rituals. Here, turning feels meditative and healing. It concludes the performative quest for the pharaoh's roots and routes. The turn bears the texture of a wave flowing across the timescapes of memory, disrupting the coloniality of hegemonic time_spaces. Wan-Chao Chang also makes use of the dervish technique, sticking more closely to the original technique while Oxana Chi transforms it.

My reading of spinning can also be applied to André M. Zachery's Digital Middle Passage. Turns are omnipresent in Zachery's corporeal language. When he spins and turns on stage, in this case, he collapses the conventions of Middle Passage narratives, bridges their fallacies, and amplifies its scope and dimensionality. He grounds his work in the knowledge of Afrodiasporic history, yet deconstructs what has been written about it, and reconstructs it as cathartic experience only bound to the body moving live on stage. Spinning may be a tool of empowerment, an energy that carries the body across past, present and future. Sometimes, Zachery spins in a capoeira-like fashion, a wave seems to go through his torso as he spirals repeatedly on his own axis, in a very flexible use of the back and hips. Other times the spinning goes with a sinking to or rising from the floor, and unearths the vertical dynamic of his turns. At one point, Zachery starts on his knees and turns on his own axis as he gets up with arms reaching towards the ceiling. This brief moment of rapid turn, entailing a hint of ballet or so called "modern" dance technique, however, resolves immediately in Africanist aesthetics. The body collapses on a flexible spine, the knees and upper body are closer to the floor, as if bending under a heavy load, or leaning over a barrel. The turn also marks an interruption in the slow motion pace preceding and following it.

At times the dancer rotates in both directions within a luminous circle, a moon-like image projected onto the floor center stage. His hand affixed to the ground is the axis on which he pivots, as if his body was the arrow of a time traveling clock. The performances Through Gardens and Digital Middle Passage are embedded in a spiraling motion, whether it is momentous for Oxana Chi, or recurrent for André Zachery. Turning here epitomizes the idea of intensity as a performative spacetime. 


\subsubsection{Circling memory}

Circularity is also a strong motif in Christiane Emmanuel's Choc(s). The circle inhabits her whole repertoire, for she often draws from the Martinican "traditional" dance named bèlè, which is structured as a circle, as she explains in her interview (see next chapter). In relation to $\operatorname{Choc}(s)$, she also emphasizes the circle:

And [in] this piece we are actually in a dynamic of 'going around in circles,' I run always in the same position, always facing forward, never facing back, I reroute, I return myself, I turn around to run, still forward, in the opposite direction, but it is always a race going in circles. So I ask: am I bored, am I going around in circles, am I searching for something else? It all depends on the audience and how they understand it.

(Et dans la pièce justement nous sommes dans une dynamique de tourner en rond, je cours toujours dans le même sens toujours face et jamais de dos, je détourne, je me détourne, je me retourne pour courir face dans l'autre sens, mais c'est toujours une course en rond. La question que je pose: est-ce que je m'ennuie, est-ce que je tourne en rond, est-ce que je cherche quelques chose ? Tout dépendra du public, comment il recevra la chose. $)^{73}$

The race in circles varies in pace and intensity. At first, Emmanuel is running around the piles of shirts in a circular shape resembling a volcanic crater stacked center stage. This circles us back to the first chapter, which opened with Palestinian-Martinican author Widad Amra's metaphor, "We are on a volcano and we are a volcano." ${ }^{74}$ Emmanuel's race around and dwelling into the volcano-like crater could be the embodiment of Amra's poem. The dancer blurs the boundaries, obviously racing on the volcanic island of Martinique, while performing herself in a magmatic flow. At times she seems lost, disorientated, conveying a feeling of disorientation that recollects Sara Ahmed's phenomenological definition: a feeling that "shatter[s] one's sense of confidence in the ground or one's belief that the ground on which we reside can support the actions that make a life feel liveable." 75 The actions at stake here are the efforts necessary to come to terms with the colonial legacy that pervades and poisons the island's socioeconomic structures up to the present. Emmanuel explains that she choreographed the piece in the context of the political uprisings of 2011 , when people protested on the streets against the economicsocial-racial inequalities. ${ }^{76}$ To fully understand her dancing race, one also needs to know that street demonstrations in Martinique, such as the carnival-bound street marches and dances, often entail running. As I experienced it, not the slow marching, but the actual racing up and down the hilly landscapes of the city's capital binds its participants together,

\footnotetext{
${ }^{73}$ Emmanuel, interview [My translation].

${ }^{74}$ Amra, Le Souffle Du Pays. Nabd El Jayzirah, 13 [My translation].

${ }^{75}$ Ahmed, Queer Phenomenology, 157.

${ }^{76}$ Emmanuel, interview.
} 
in a synergetic dynamic of autonomy and liberation. In light of my earlier description of the fugitive time characteristic of the solo, the run also carries the legacy of the imagery of slaves running away from the plantation, especially when the dancer runs vigorously, progressing in large strides across the stage, and sometimes turning around as she faces invisible obstacles that prevent her from running further.

It is also interesting to note how Emmanuel's choreography echoes patterns found in Caribbean visual arts. Here I think for instance of the strategies of "erring, opacity, circumvention, diversion, regeneration, provocation, metaphormosis" ${ }^{\prime 77}$ to use Emmanuelle Bermude's words in her reading of Martinican visual artist Patricia Donatien-Yssa. Dancer Christiane Emmanuel impersonates those processes in her performance. ${ }^{78}$ The piece Choc(s) works through these strategies of resisting coloniality and capitalism in a negotiation of the curvilinear element. The dancer runs in circles, meaning that her race has neither a beginning nor an end. The circle is a leitmotiv in Africanist performance traditions, explains Nadine George-Graves:

In these traditions, dancers stand in a circle to symbolize the communal experience. With no front or back or head or rear, the circle is inherently non-hierarchical. Everyone can see and be seen. It also creates a sacred liminal space in which transformations can occur. When one or two people step into the center of the circle she/he/they take on the energy from the others. They shine as individuals by stepping out of the group while remaining a part of it, supported by it. Often when a semicircle or arch is presented on stage, it is to include the audience as the completion of the circle. ${ }^{79}$

In my research, the performers are alone on stage, yet they still rely on the circle's multiplicity. And Christiane Emmanuel indeed experiences transformation within the circle. When she digs into what seems like a pile of white shirts, she unearths colorful pieces of clothes that she puts on successively on top of one another. The result is an expressionist tableau, an unusual collage on her own body. Her new costume mixes up a western "male" suit with the popular and colorful aesthetics of the female market workers. The costume transformation induces a movement transformation: now Christiane Emmanuel sways the hips, and tentatively switches to the register of Caribbean traditional dances. The circle, place of clothing mutation, becomes the space of a corporeal metamorphosis.

Curvilinearity is one of the main features of Kariamu Welsh-Asante's theorization of Africanist dance. In the words of Asante, "[t]here is power in the circle, the curve, the round, supernatural power if you will." ${ }^{80}$ The rotation described earlier, in Through

\footnotetext{
77 "errance, opacité, contournement, détournement, régénération, provocation, métarmophose," Yung-Hing, Art Contemporain de La Caraïbe, 175 [My translation].

${ }^{78}$ See the interview for Christiane Emmanuel's reflection about choreographing a piece about the painting "La Jungle" by Wifredo Lam. Emmanuel, interview.

${ }^{79}$ George-Graves, Urban Bush Women, 142.

${ }^{80}$ Welsh Asante, "Commonalities in African Dance," 146.
} 
Gardens and Digital Middle Passage, is a vessel of energy. The movements are set at specific moments of the choreography, suggesting a sense of dynamism, power, progression. Besides rotating on themselves, both choreographers also make use of the circle. Circling and circulating energy, Oxana Chi for instance traces half-moon crescents with her arms. Within the cyclic time dramaturgy, the scene of the Celebration is essentially structured as a circle. Often times, Chi also runs in circles, but also backwards, and her circular race is not disorientated at all, on the contrary, it is a clear, decisive progression (although sometimes backwards) through the stages of Tatjana Barbakoff's achievements. The circle is materialized solely by her movements, thus when she dances a full circle, she creates an abstract open space where her imagination and the fantasy of the audience can meet. André M. Zachery also performs curvilinearity. His circle too is one of power, even more so when he dances within a round moonlight projection spotlight. The circle is truly ritual here, even if, in the Digital Age, the ritual is performed by a lone dancer remote from the group. Maybe the group is present-absent, in the invisible spirits surrounding the dancer. Chantal Loïal also associates rotation and celebration. She concludes the scene representing the posthumous return of Sawtche's spirit to South Africa with a double circle: she sweeps through the stage spinning on her own axis, tracing circles with her hands and pelvis in the air, as well as marking a curvilinear trajectory. When she reaches the point at which she started the circle, she disrupts the circularity at the sudden appearance of the skull prop. This makes clear that the circle stood for positivity. The dancer embodies the quantic dance of memory, a joyful choreobiography in which not only the body's skeletal remains return to the homeland, but a lively body, a black woman moving live on stage.

The theatricality of dance works without words. Celebratory atmospheres can be channelled through movements. In my perception, the circle disrupts the usually rectangular shapes of concert stages. Scenographic and choreographic circles transform the spaces into imagined locations. It is through the power of imagination that we see the circle that they trace as they spin and loop around. This connects to circling as an epistemological tool: dancers can approach and reach memory through circularity and curvilinearity.

Rotation of the self on itself or the self circling the stage, is a vital movement of perforMemory. Through rotating torsos and rotating shapes, the performers imagine and materially inscribe curvilinearity into the spacetime of the stage. The circular quality of the performative "now" or Epiphenomenal time discussed earlier in reference to Wright ${ }^{81}$ is a three-dimensional reality in these works of perforMemory. Performative turns let memory

${ }^{81}$ Wright, Physics of Blackness. 
become a shifting, malleable, transportable matter, a memory2go. Here, to perforMemory takes the shape of turning, and spinning on one's own axis. This brings together the arguments made so far, namely that memory is a site of movement (chapter two) in which the dancing body can turn into a diasporic home (chapter three) by being intensely present within the present spacetime (chapter four, section 1).

\subsubsection{Jumping}

Jumping requires power. The power to contract and release specific muscles. Jumping also enacts power, when a jumping body conveys force and liberation. When Chantal Loïal represents the confined Sawtche, the jump is a movement through which the body frees itself from bondage - maybe symbolized by the tight use of her head wrap to bind her chest. Here the jump is less a matter of reaching a spectacular height, as in classical ballet, but rather a search for a connection to the ground, in the spirit of Africanist dance techniques. It is a stomping-jumping, when the feet successively hit the ground and march on the spot, as torso and head drop and rise with increasing power and speed. This figure requires a precise synchronicity of all body parts. The dancer also makes a festive use of the jump. Still in the celebratory spirit mentioned above, she performs various types of jumps in the sequence depicting the restitution of France to South Africa, or the return of Venus to Sawtche. Loïal's dance reflects training in both West and Central African styles, with the jumps originating in West African techniques, in which the body lengthens through the arms and legs. Sometimes she aligns one jump after the other, deploying a variety of jumps that all serve the theatricality of joyfulness and celebration. ${ }^{82}$

Jumping is also festive in Oxana Chi's Celebration sequence discussed earlier in relation to spinning. A complex jump consists of the dancer jumping backwards, throwing the waist back and simultaneously reaching forward with the hands, all of this without interrupting the flow of the circular choreography. Here the jumps are integrated into the curvilinear trajectory. The constant changeover between spinning and jumping creates a very dynamic and intense atmosphere. Chi also deploys an Africanist jump inspired by the imagery of a Senegalese bird, in which the body reaches out through all its extremities. Chi actually uses jump techniques throughout her current repertoire. In Neferet iti, in I Step On Air, and most recently in Psyche, she undertakes jumps at key moments of the performance, often inducing empowerment. Jumping across the stage, Chi's moves consciously break down rigid linear narratives and build up new possibilities of relating to

${ }^{82}$ Thank you to one of my proofreaders, Judy Pritchett, for suggesting a reference I did not know of: CaponiTabery, Jumping for Joy. 
history. She may also be jumping over the obstacles of traumatic memory, bridging silenced narratives to inspire a transformative spirit, spurring on political awareness and stimulating social healing. For both Loïal and Chi, the jumps enact the willpower, strength and determination of the protagonist to be in charge of her own story and body, and of the body as a story.

Jumping is intensity. It is a movement of perforMemory in the sense that it epitomizes the body's capacity to be present and the present as tension (and release). When Zufit Simon jumps in all about nothing, she makes use of a very strong core, and channels the energy from the torso upwards in a rushing movement of rising. Jumping is a repetitive figure here too, sometimes occupying only a brief space time. Sequences of jumps are repeated, with arm variations, the arms sometimes reaching back, sometimes extended to the ceiling. Simon uses quick, intense jumps to move forward, for instance when she is on the floor, her upper body leaning backwards, supported by the hands and legs raised forward above the ground. Sometimes she hops in a pas-de-chat like fashion, traversing the stage like a joyous being animated with youthful energy. Or she jumps laterally, bending the elbows and knees simultaneously, or jumps and releases by catching an imaginary force in the air. She can also jump and throw her bent legs backwards. All of these jumps stem from a personal impulse, a choreography conveying the impression of spontaneity, of the transitory nature of emotions passing by. Jumping queers one's relation to body and self.

Jumping defies gravity. A jumping dancer counters gravity, traveling for a brief timespace to and from the earth-ground. The jumps in Digital Middle Passage turn the stage into a place of departure and return. Rather than returning to Africa to search for traces of history, as Saidiya Hartman does in the novel Lose your Mother, ${ }^{83}$ the dancer departs and returns to the dance floor, the soil, at his own pace and within the performative spacetime. In a TEDx talk, gravity is summed up poetically by physics scientist Kelly Holley-Bockelmann:

And so what gravity is at its core, is just the response of moving matter to all those dimples in the universe. [...] We are in space time. If a gravitational wave passes by, we are going along with it, we are waving too, because we are a part of the universe..$^{84}$

As André Zachery jumps up and down, tuning his body to the sound and gravitational waves of the space, he seems to rebound on the dimples of spacetime. Physics are inherent to Zachery's physicality. His own technique of Physical Propulsion, as he calls it,

\footnotetext{
${ }^{83}$ Hartman, Lose Your Mother.

${ }^{84}$ Holley-Bockelmann, "TEDx Talk: The Spacetime Symphony of Gravitational Waves."
} 
was devised out of his proficiency in the Flying-Low technique codified by David Zambrano, which uses spiraling as the base for jumping:

The class utilizes simple movement patterns that involve breathing, speed and the release of energy throughout the body in order to activate the relationship between the center and the joints, moving in and out of the ground more efficiently by maintaining a centered state. There is a focus on the skeletal structure that will help improve the dancers' physical perception and alertness. ${ }^{85}$

In his class description, Zambrano further mentions the physical principles of cohesion and expansion, which can clearly be seen in Zachery's coherent core and expanding energy. His relationship to the floor is intensely mobile. Jumping, or propelling himself to and from the floor, he enacts power, performing the ability of dancers to "harness" power as evoked in Candace Thompson's Instagram post cited earlier. She, like Zambrano, speaks of shifting energies, and this is precisely what is at stake in Zachery's jumping tools. Zambrano's Flying-Low becomes Zachery's "Flying High and Low." The personal appropriation of the technique devised by a contemporary dancer on his own posttraumatic body becomes a means of impersonating the movements of post-traumatic Blackness.

What does Zachery's use of a flying technique express about the perforMemory of chattel slavery? Digital Middle Passage, and more specifically the jumps, may be interpreted in light of the tale of the Flying Africans. Prevalent in African-American popular culture, the tale describes how enslaved Africans used metaphysical powers to fly back to Africa. Depending on the context, the flight has sometimes been interpreted as a metaphor, in which the slaves' spirits fly back, be it through physical death (suicide), or through a metaphysical, spiritual, extraordinary reality. Considering this ambiguous relationship to death and liberation, Soyica Diggs Colbert defines the flight as a paradigmatic black movement. In her essay on the myth of "Flying Africans," she

considers the depictions of Flying Africans as black performances and more particularly black movements, paying particular attention to the way the depictions of flight enact a performance and imply other meanings of movement, including political and geographical. [...] Although the implications shift over time and across geographic locations, the negotiations with the freedom drive and the death drive persist in depictions of Flying Africans. ${ }^{86}$

In order to examine how the tale of Flying Africans affects and reflects Black culture, the author analyzes literary and oral works, such as Toni Morrison's Song of Solomon and music by Kanye West and the Parliament Funkadelic. Although it appeared in the

\footnotetext{
${ }^{85}$ Zambrano, "Flying-Low - Dance Technique."

${ }^{86}$ Diggs Colbert, "Black Movements," 130.
} 
anthology Black Performance Theory, her brilliant essay however does not include dance productions as a source of analysis. The dance solo Digital Middle Passage is paradigmatic of the performance of "flight" as Black diasporic mobility, as a tool to attain physical and psychic liberation, and beyond. The audience experiences the spacetime of the jumping body, re-framed in the context of a performative engagement with the memory of the Middle Passage. When Zachery jumps and flies "high and low," he physically enacts the possibility for the body to defy laws of geophysical and geopolitical gravity. Here there is no slave ship, no space ship, only the body as a vessel of memory. Thus, I interpret Zachery's jump-flight not merely as a Black movement, but as a paradigmatic movement of perforMemory. His jumps, like those of Chantal Loïal and Oxana Chi, draw energy from ancestral grounds, and float above any attempt to reduce and narrow one's identity.

The role of jumping in these works makes me wonder if there is a Black diasporic jumping cultural motif that stands for celebration and liberation across time and space. Reading my work on jumping, dance expert Judy Pritchett (Frankie Manning Foundation) brought to my attention the work of Gena Caponi-Tabery, which explores the role of jumping in 1930s African-American culture. ${ }^{87}$ It made me ask: is there an echo between Afro-European Oxana Chi's use of jumps (albeit based in ballet techniques) to chorebiograph the successes of Tatjana Barbakoff in hostile 1920s-30s Europe in Through Gardens, and the flourishing jump element in 1930s Black culture in the USA? Looking at "jumping" jazz, athletics and basketball, Caponi-Tabery writes that in the 1930s, African-Americans "transformed the jump, a historical gesture of celebration and defiance, into a cultural exclamation point." 88 To me, this also rings true for André Zachery's contemporary (meta)physical search for elevation in the $21^{\text {st }}$ century. Also, as the author notes, the relation between jumping and African-American culture does not begin in the 1930s, as it can be found, for instance, in ringshout dance worship of the $19^{\text {th }}$ century. ${ }^{89}$ In any case, the dances of perforMemory, and particularly the Black diasporic dances, seem to reflect across the spacetimes of Black diasporic cultural practices Caponi-Tabery's argument that reaching up through the air on stage may correspond with aspiring to, or accessing social and political elevation. ${ }^{90}$ Indeed, I would take her argument a step further (or higher), by suggesting that jumping in these contexts demarcates bodies not only from the material ground and sociopolitical constraints, but also signifies reaching for a realm beyond conventions of calendar time and geographical space.

\footnotetext{
${ }^{87}$ Caponi-Tabery, Jumping for Joy.

${ }^{88}$ Caponi-Tabery, 144.

${ }^{89}$ Caponi-Tabery, 154.

${ }^{90}$ Caponi-Tabery, xv.
} 
The performances addressed here testify to the body's capacity to become not only a tool of representation but an actual site of subversion, challenging dominant sociopolitical relations and mainstream configurations. Participating in dance and movement classes, from Afro-Haitian to Kukuwa over to kung fu and capoeira, I learned to sense through my own body the intense training required in order to become proficient in certain forms of corporeality. Yesterday for instance, in synchronicity with my writing topic, the Kukuwa ${ }^{91}$ class involved a lot of jumping. The dynamic cycle helped me release the tension accumulated over several hours of computer-writing. I reveled in the jumps, trying to improve my movement quality. I simultaneously strove to improve the verticality of the jump - thus involving more energy from the lower body and abdominals - and its materiality, to make it look and feel as "light" as possible - requiring a flexible engagement of the knees and other joints. In the brief spacetime I spend in the air, seeing my flying self in the mirror, time and space feel so intense that it is not relevant whether I jump high, or long. I sense power, intensity and a complex relation to gravity.

In jumping, or moving oneself, the self may connect to a deeply located intelligence generated within the body. This recognition is fundamental to understanding how the body can be not only the conduit, but also the source of sociopolitical intervention, as argued by dancer-scholar Ananya Chatterjea:

I want to insist on perceiving the body as intelligent and multivalent, which subverts the traditional distrust of the body in much of European or Western discourse. I also want to assert the body's proactive role in political and cultural commentary, locate intellect within the body, and recognize how the articulations of the intelligent body are chiseled through the fine and intense training modes used by these choreographers. ${ }^{92}$

Power, intensity and gravity play a particular role in perforMemory. In the context of hegemonic ascriptions of bodies to racial and gendered categories, and the consequent negation of their power, jumping inscribes the body into agency. It places diasporic subjectivities in different relation to time and space. This movement of perforMemory indicates how the performers use kinesthetics as a refined medium to embody and express social critique and to imagine and enact other realities or ways of moving through it. Jumping is a liberating movement of perforMemory. It liberates the body from the constraints of time and space as defined within conventional western physics and humanities. It liberates the dancing body from hegemonic narrations. Jumping from one

\footnotetext{
${ }^{91}$ Kukuwa is a movement class developed by a Ghanaian dancer, Ellen Kukuwa, now taught and trademarked in the fashion of techniques such as Pilates and Limon. Her daughter Cassandra Nuamah teaches it in New York City: a lively variation of movement sequences, combining traditional and contemporary dances from all over the African continent. See the website Kukuwa, "Kukuwa."."

${ }^{92}$ Chatterjea, Butting Out, 25.
} 
story to another, back and forth from present self to past selves, dancers' jumps bridge abyssal gaps of absence in western historiography, digging out millennial possibilities, realities and energies.

\subsubsection{Crossing}

A blizzard blankets New York as I write these words. Rolling and growling sounds rush out of the alleys through which the air makes its way. Snow storms sometimes sweep over the city, forcing it to slow down, to relax, or even to freeze materially and economically. The powerful winds transform the space they traverse, reminding humans that their interaction with the environment is bound to forces that can never be entirely controlled or countered. The blizzards, like diasporic moves, are forces of displacement.

At times, Wan-Chao Chang's dance reminds me of a tree balancing in the wind. Her body seems to swing to the rhythm of the memories that come and go within her. In the swirling spacetime of her solo Impressions, she moves as if shaken by the wind, sometimes gently, sometimes violently. The head often counterbalances the body's weight, leaning from one direction to the other. The arms trace a circle around her head that ends in a dropping of the lower body and flexed elbows. The hands reach out to the ceiling, as if gathering imaginary threads. The scarf worn around her neck, flowing around her hands, echoes the fluidity of her movements.

In these Impressions, as in other works of hers, the stage becomes a meeting place for the plurality of dance styles she learned and stored in her body memory. When she crosses the stage, she uses a range of techniques, although altered. Reflecting her training in Javanese classical dance, the dancer at times meanders gently through the stage. The body shifts weight, the upper body twisting, the knees bend alternately, one foot stepping backwards after the other while the opposite arm reaches forward. Waves of qi go from the shoulders to the delicate hand poses. The pulling of the scarf and the other movements are rooted in the Gambyong dance style. ${ }^{93}$ Sometimes her ballroom years resurface, in the jiggling shoulders and the hopping way she crosses the stage laterally, and her training in Chinese folk dance also re-emerges at time. Her experience as a dancer in the Ballet Afsaneh company flows into the piece too, when she picks single dance elements from the historical countries of the so-called Silk Road, such as the dervish spins. Other times she sweeps across the floor, constantly shuffling back and forth, turning the intimate stage into a large space to be wandered through.

\footnotetext{
${ }^{93}$ Cahyaningtyas, "The Gambyong Dance."
} 
Gloria Anzaldúa asserts: "The places where I lived left an impact on my psyche, left a mark on every cell of my body." "W4 Wan-Chao Chang's solo of perforMemory collects the places where she lived, and translates the embodied memory of these places into a dynamic relation to the current spatiality of the stage. Activating each cell of her dancing body, the artist re-connects to her memory and renders corporeal impressions of it. She brings to life Anzaldúa's vision of the body as a "geography of self," mapped in Anzaldúa's drawing as the overlapping of a body's veins and a territory's streets. ${ }^{95}$ This drawing also echoes Christiane Emmanuel's dance against the backdrop of a digital scenography, a projected map in which the streets eventually overfill with a red fluid. In Chang's choreography however, national borders are transcended. Instead, cultural influences merge within the dynamic assemblage of the dancing body. ${ }^{96}$

In contrast to Wan-Chao Chang, Farah Saleh handles the border within one territory or nation. Her work is preoccupied with the physical borders that divide the Palestinian territory as much as with the impact of these borders on emotional subjectivity. Parole, Parole, Parole is a solo of transitions between places and emotions. The dancer constantly evolves from one spot to another, dis/placing and displaying the body. The first transition is smooth, for the dancer enters the performance space with the audience. She briefly goes through the room as more audience members enter. Holding a bundle of flowers in her hand, her walk is abruptly interrupted when she bumps into one of the venue's walls. She remains there, separated from her "lover" by this physical obstacle. The audience sees her from behind, in a tragic pose that may also suggest the body searches that Palestinian citizens must regularly undergo at checkpoints, when they wish to travel across the country. The body drops, hesitantly searches for balance, and is animated by a wave going through each body part. In the artist statement found on the website of the Miniatures Officinae institution which supported the first iteration of the piece, she reflects upon geopolitical obstacles to love:

In Palestine, love and the act of loving are not always that easy. And it is even more complicated when a Palestinian from Gaza falls in love with someone who is not from the strip. Someone from Ramallah for instance, sister city, not (yet) twin. Is the love story between Gaza and Ramallah im/possible? ${ }^{97}$

This translates into a site-related performance in which she interacts with the audience and with the venue. When she bumps against the wall, she embodies the geopolitical

\footnotetext{
94 Anzaldúa, Light in the Dark/Luz En Lo Oscuro, 77.

${ }^{95}$ Anzaldúa, 30.

${ }^{96}$ For an interesting discussion of Anzaldúa's concept of geographies of selves in relation to choreography and identity-making, see the recent thesis Dava D. Hernández, "Dancing Mestizaje: The Choreodramas of The Guadalupe Dance Company."

${ }^{97}$ Saleh, "Note D'intention. Parole, Parole, Parole" [My translation].
} 
constellation and the physical borders restricting the freedom of movement - and of loving. When she cannot cross the space, the flowers become the ones who travel, as she turns her back to the audience and throws them across the room, in a tragicomic mix of marriage ritual and resistance. Here she also refers to the graffiti artist Banksy, whose stencil on the Israeli wall is reproduced in the performance venue. It depicts a street protester who, instead of throwing stones like the Intifada youth, is ready to throw a flower bundle.

The interest in the interrelation between love, physical distance and digital connection also makes me think of the work of the Post Natyam collective, "a transnational, webbased coalition of dance artists whose work triangulates between art-making, activism, and theory." 98 What the Post Natyam collective and Farah Saleh have in common is the deployment of dance across geocultural boundaries, and the Post Natyam members add to it the will to queer borders, gender and dance practices. Borderlands are marked by the intricacy of physical and emotional boundaries, as Anzaldúa reminds us:

A border is a dividing line, a narrow strip along a steep edge. A borderland is a vague and undetermined place created by the emotional residue of an unnatural boundary. It is in a constant state of transition. ${ }^{99}$

In Saleh's performance, the wall of the TanzQuartier Vienna becomes the narrow strip along which Saleh strives to move...on her hands. By reversing the verticality of her body, she conveys a feeling of difficulty, of struggle in expressing the "emotional residue" of her love relationship. Her performance seems to engage with the confluence of geographical borders and psychic boundaries, crossing the minds of those living under Occupation. If the body cannot move freely across the border, it finds other ways of transgressing it.

While in Ordinary Madness, Saleh choreographed the interrelationships of individuals within the group, this time the performer is alone, even the beloved "other" is absent, and the only beings in proximity are the audience. The dancer plays on this proximity, for instance when walking on her hands, she gets so close to audience members that they feel the need to move across the space. However she returns in the opposite direction, which leads them to move back to their original spot. She approaches certain attendees extremely closely, mimicking the gesture of a being assessing its fellow beings. Apart from certain cues, there does not seem to be a predefined plan for the trajectory of the dancer. Rather, she engages with the site, and with the audience. Dancer-scholar Aimée Cox maintains that through choreography a body may inform, or transform the spatiality of its surroundings:

\footnotetext{
${ }^{98}$ Chatterjee et al., "Post Natyam Collective"; See also: Chatterjee and Lee, "'Our Love Was Not Enough': Queering Gender, Cultural Belonging, and Desire in Contemporary Abhinaya."

${ }^{99}$ Anzaldúa, Borderlands, 25.
} 
Choreography suggests that there is a map of movement or plan for how the body interacts with its environment, but it also suggests that by the body placement in a space, the nature of that space changes. ${ }^{100}$

Saleh's choreography influences how the viewers place themselves in the venue, despite or because it works through site-specific and audience-specific improvisation. Like in contact improvisation, her dance is all about intimacy, and about crossing: people, borders, space. She transforms the space from a regular theatrical setting into a place where performer and viewers inhabit a common location. Attending the performance in Vienna, I sensed that Saleh did not easily connect to the audience. ${ }^{101}$ However, the performance expressed the will to transition, to be open to affinity in a hostile environment. Parole, Parole, Parole translates daily preoccupations of Palestinian citizens into the embodied memory of a performer's dancing body. PerforMemory here is a source of knowledge and meaning-making, just like the theoretical references used to make sense of performances.

In the movements of perforMemory, dancers connect the strands of identity as shaped by memory, emotion, space and time. Diagonal moves challenge the convention of western reading that moves from left to right or from front to back. A performer moving in diagonals traverses the whole stage without fully facing, nor turning one's back, to the audience. The diagonal may trace counter-hegemonic directions urgently needed by all those who want to move away from capitalism, patriarchalism and occidentalism. In the context of perforMemory, the diagonals also materially enact what "multidirectional memory" ${ }^{102}$ may look like.

In Through Gardens, Oxana Chi makes a broad use of the space. In the scene of the Journey, she uses diagonal trajectories, or diagonal movements to cross the stage-world. A video projection shows Wayang Kulit figures, puppets used on stage in Indonesia to depict historical events and comment upon sociopolitical issues. As the video ends and the stage lights dim, the dancer returns to the stage in a new costume. The puppets on the screen are mirrored by her silhouette detaching from the dark. Standing at the back left corner of the stage, she follows the paths of light as they appear and disappear diagonally, in zigzag shapes. Her steps are reminiscent of Tai Chi walking exercises, in which one slowly steps one foot after the other in order to regulate the yin-yang balance in the body. She adds another dimension to this technique, by letting an almost imperceptible energy circulate through her body, a flow which animates her arms. Thus, she seems to be a puppet hanging in the air which is being moved by external forces. In

\footnotetext{
${ }^{100}$ Cox, Shapeshifters, 29.

${ }^{101}$ Saleh, interview.

${ }^{102}$ Rothberg, Multidirectional Memory.
} 
this fashion, she travels across the whole stage in diagonal lines, finally reaching the top right corner. The performer crosses world borders in a few steps and a few minutes, but conveys the feel of a prolonged journey, because of the diagonal use of space, and because of her use of time, namely moving in extremely slow motion.

This trip may represent Tatjana Barbakoff's migration from Latvia to Germany at the beginning of her career. However if the scene is understood in a non-linear interpretation of space time, as suggested earlier in this chapter, it may also stand for all of Barbakoff's voluntary journeys and forced displacements. Consequently, I also see it as Barbakoff fleeing from Germany in 1933 and eventually criss-crossing France, going from one hiding place to another, attempting to escape the fascist persecution she was exposed to as a Chinese-Jewish-Latvian dancer performing sociopolitical critique. It may also tell of the dancer's dreamed travels from China to Europe. The scene may therefore be interpreted as a linear reading of the piece's dramaturgy, as much as a disruption of it. Each time she reaches the end of a light path, a newly lit diagonal appears for her to step into. To zigzag across the stage is to reach the borders of the stage. This spirals back to the bridge motif discussed in the chapter on diaspora. Tatjana Barbakoff's dance art itself was described in relation to bridges, as suggested by this German press article from Die Deutsche Zeitung edition from October $17^{\text {th }}, 1925$ :

Barbakoff's dances were dreams. Her face, her play of features, moving within its own self, without the intention to enter in contact with us in the audience. Dreamlike. Her dances [were] also magic bridges, tying one silent moment to the other. And standing on this bridge, there was she, the dancer: what was her life expression in relation to the infinity stretching behind her?

(Die Tänze der Barbakoff waren Träume. Ihr Gesicht, ihr Minenspiel, so ganz in sich selbst bewegend, so ganz ohne jeden Willen mit uns im Zuschauerraum in Verbindung zu treten. Traumhaft. Ihre Tänze auch zauberische Brücken, von Stille zu Stille geschlagen. Und auf dieser Brücke stand die Tänzerin: was war ihr Lebensausdruck vor der Unendlichkeit, die hinter ihr sich spannte?) ${ }^{103}$

This poetic reflection on Barbakoff's dance also rings true for Chi's contemporary perforMemory of her, and especially her strong use of dance expressionist qualities in Through Gardens. Although neither Barbakoff's nor Chi's dance seems to be always calm, they share a surrealist approach to dance, an endeavor to paint society in dreamlike colors, no matter whether the dream is a sweet one - or not. Dreams are also characterized by the differential spacetime feel that we experience in them. Maybe what all seven dances of perforMemory discussed here have in common is the use of their dances as bridges, between past, present, future, between time and space, between

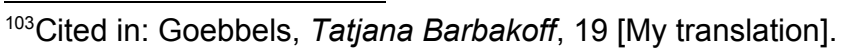


forgetting and reclaiming the past, between understanding and transforming it. Crossing the stage, they bridge millions of years and millions of places of Chung-hing's poem, and create infinite possibilities to find out about, or heal from traumatic histories.

Power is the common thread tying the three movement categories of spinning, jumping and crossing on stage. All these movements do not merely represent power, they wield multidimensional forms of power through embodiment, to paraphrase Zenenga. ${ }^{104}$ As mentioned at the beginning of this book, the dancing body may be a confluence of the intellectual, corporeal, social and economic realms of power. While Zenenga, a scholardancer, maintains that this is true for Zimbabwean performing arts - in contrast to western performing arts $-\mathrm{I}$ argue that all of these performances work towards the simultaneous negotiation and expression of power, regardless of their geographical origins. This connects the arguments made so far, namely that memory is a site of movement (chapter two) where the dancing body can turn into a diasporic home (chapter three) by being intensely present within the present spacetime (chapter four, section 1).

In my search for a connection between the material and the conceptual implications of the dancers' arts of occupying the stage, I demonstrated how they use their bodies as living tools to sculpt dancescapes as their décors for an endeavor to produce and transmit cultural memory. The complex ways in which they process notions of and relations to time and space in their works, suggests that they exert the power to stretch hegemonic time linearity, to mold space, and to ultimately shape the context in which they deal with the past. In this chapter, I also validated the assumption that the dances can provide a live personification of what bell hooks calls "psychohistory." ${ }^{105}$ Spinning, jumping or turning can become a process which takes into account how "historical facts" - such as the trauma of the Holocaust or Transatlantic Slave Trade - have an "impact on our emotional world." The movements of perforMemory thus serve the project of a performative narrativization of cultural memory, in which factual information matters less than embodied emotion.

In her analysis of African-American choreographies, Ann Cooper Albright defines the project of "New Epic Dance" as one that "refuse[s] the static doneness of historical documentation, lifting the black and white printing off the page and imbuing it with the ability to move, shift, and, finally, to transform itself." ${ }^{106}$ The timescapes and the movements of perforMemory meet in the realization of this aspiration. The dancers physically engage their body joints and articulations in relation to the performative

\footnotetext{
${ }^{104}$ See chapter 2 on Zenenga, "Power and the Body," 65.

${ }^{105}$ hooks and Mesa-Bains, Homegrown, 100.

${ }^{106}$ Cooper Albright, "Embodying History," 440.
} 
spacetime, eventually generating choreographies in which there is no immediate distinction between the movement of a body and the movement of time. In this sense, Chakrabarty's metaphoric time-knot or "granthi," 107 becomes corporeally real. Infusing the stage with the power to represent oneself and to share this representation with the audience, the dancers invite us to move beyond the very idea of representation. What remains from this chapter is the idea of intensity as a self-generated spacetime of perforMemory, in which dancers activate multiple tools such as turning, spinning and crossing to dance the past in the present tense.

$\overline{{ }^{107} \text { Chakrabarty, Provincializing Europe, } 112 .}$ 


\section{DANCE DIALOgUeS: IN CONVERSATION WITH...}

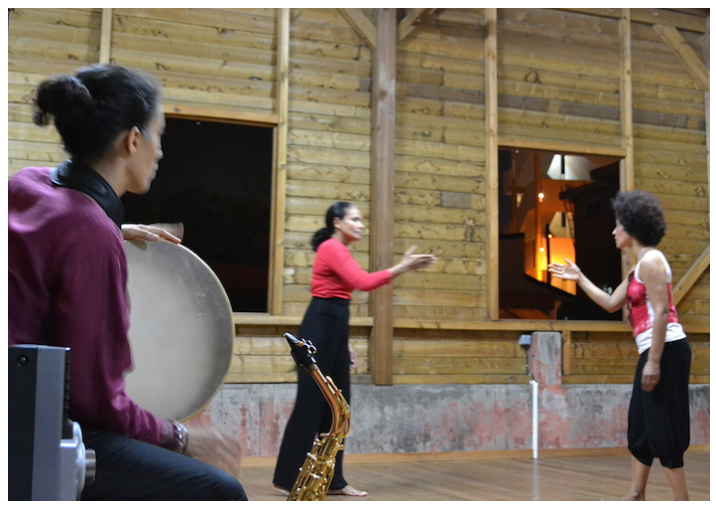

Christiane Emmanuel (left) and Oxana Chi (right) performing The Journey with Layla Zami, (front). La Maison d'Arts, Martinique 2014. Photo: Emilie Alves de Puga

The Journey is a duo choreographed by Oxana Chi in collaboration with Christiane Emmanuel, who hosted Chi as an artist-in-residence at La Maison Rouge/Maison des Arts in Martinique in December 2014. The short piece engages with the dancers' respective experiences as choreographers of color working within the whirlpool of the European cultural production industry. It is a sad, sensual, energetic, humorous work-in-progress. The dancers, full of verve, sometimes stumble, but eventually always land on their own feet and selves, as they journey through more or less difficult memories of their dancing career.

The photograph above depicts the two performers trying to reach for each others' hands. Yet, they will not get to shake hands, because each dancer hypnotically follows the lead of her own hand. The photographer captured the moment when they still seem able to reach for each other, before their bodies shift into the spiraling motion of perforMemory. At the forefront of the picture, you can see me holding a drum, and paying close attention to the dancers' movements. The picture mirrors the research positioning I have come to call an insider without (see introduction). Having had the delight of accompanying the performance on stage with live drum and saxophone sounds, I sat in the optimal position of a participant observer. Although I have not accompanied all seven performers live, I feel a connection to each choreographer interviewed. I was able to conduct and record deep conversations on their intents, aesthetics, trajectories. Thus, the picture is emblematic of the committed, 
corporeal engagement that carried me through this research journey, a journey full of revelations, challenges and achievements.

This final chapter is a journey within the journey, a journey of personal encounters. It could be taken as an art book within the academic book. It includes the transcripts of the conversations I had with each dancer-choreographer. When I was able to, I travelled to the countries where the dancers were currently living and performing at the time. The conversations were held between September 2013 and December 2015 in Germany, France, Taïwan, Martinique, Austria and the USA. Thus, this conversational chapter represents a diasporic spidering in itself, it occupies multiple spacetimes and encompasses, in a way, the multidimensional temporality and spatiality of the research. Most importantly, as announced in the introduction, the chapter simultaneously zooms into and zooms out of the dances of perforMemory. Zoom in, because here you will find detailed reflections on particular aspects of the performers' works. Zoom out, because the performers locate the works within a broader artistic vision and process. Each dancerchoreographer comments upon their solo piece, which is under focus here, and also discusses other works of relevance to perforMemory, or other works that matter to them. It is my hope that this broader conversational scope expands upon the reflections in prior chapters, illuminating the performances in light of the choreographers' artistic intents. The interviews express themes which I have partly addressed in my analysis: inspiration, spirituality, energy, quest, passion and motivation. What all interviews have in common is the expression of the dancer-choreographer's envisioning of their very own universe where memory matters, moving matters and movement moves the matter of memory.

Thanks to the dancers, and thanks to digital technology, I recorded our encounters on video. Here I have placed the interviews in chronological order, not so much to return the reader to linear time, but more to give a sense of the research process, and its evolution. As explained in the introduction, it is a deliberate choice to position these interviews within the main body of the thesis, instead of in an appendix that would push these precious exchanges after the conclusion. In this way I hope to be in harmony with the epistemology described earlier, and with a postpositivist approach to writing. ${ }^{1}$ Here I also think of Patricia Hill Collins' emphasis on "the use of dialogue in assessing knowledge claims," 2 a fundamental posture of Black feminist epistemology. The interviews offer the reader the chance to re-engage with the performances from the perspective of, and in the words of, the dancers. Yet, in my desire to foreground the artists' perspectives on their own work, I am crisply aware of the fact that the interviews are framed by my questions.

\footnotetext{
${ }^{1}$ Green and Stinson, "Postpositivist Research in Dance," 107.

${ }^{2}$ Collins, Black Feminist Thought, 260.
} 
The reader should bear in mind that the interview format, like the writing format, channels the meaning within a narrow words corridor ${ }^{3}$, sometimes limiting the transmission of corporeal experiences. Moreover, my choice to render the interviews as written transcripts inevitably leaves out a vital dimension in the ways people, especially performing artists, transmit meaning. The transcripts erase the body and vocal gestures that the interviewees use to enrich their oral answers with emotional meaning. Reflecting upon practices of interview, the Routledge Memory \& Narrative series' main editor notes the difference between "meaning" and "information" in interview situations:

The oral expressions that interviews document, however, contain more than words arranged into sentences arranged into narratives of varying lengths, an illusion that transcripts foster. Spoken expression is inseparable from emotion and gesture. A context of direct interaction with other people also suffused by emotions shapes what is said as well. Every interview occurs in a process of a physical performance for an interlocutor. ${ }^{4}$

Thus a double-level translation happens here, namely translating body movements into oral words, and translating those into words. Eventually, you will find elements of the "physical performance" in the audiovisual companion to the book. A biographical note precedes each interview, presenting key aspects of the artist's career, with information drawn from their personal websites and resumes.

Here, I also wish to note that I was able to interview four choreographers in their first language, respectively German for Oxana Chi; French for Christiane Emmanuel and Chantal Loïal; and English for André M. Zachery. I hope this helped them to feel comfortable with all my questions! Farah Saleh and Wan-Chao Chang were generous enough to converse with me in English, and Zufit Simon in German, a third language for all three of them whose first languages are respectively Arabic, Chinese and Hebrew. As we moved in this diasporic linguistic interstice, we found a meeting place in a language that is as dynamic and flexible as their dance movements. This also means that four interviews out of seven were translated into English for this book. Maybe this eventually maintains the balance between artists speaking in their first tongues - but inevitably translated in the writing, and artists translating their thoughts directly within the interview process.

Each conversation is different, as you will see I did not have a fixed set of questions to apply to everyone, everywhere, everywhen. Rather, I prepared each interview in relation to my background research, knowledge of the work and the artist. During the course of the conversations, I adapted the questions I had prepared and sent beforehand to the artists,

\footnotetext{
${ }^{3}$ Thank you Lann, for making me think further about this aspect in the interview conception! ${ }^{4}$ Cándida Smith, Art and the Performance of Memory: Sounds and Gestures of Recollection, 2.
} 
in order to be flexible enough to respond to what they shared. This dynamic and fluid interview practice corresponds to the application of the epistemological and methodological orientations outlined in my introduction. It also resonates with the interview principles and best practices recommended by the Oral History Association, especially the necessity to "seek an in-depth account of personal experience and reflections, with sufficient time allowed for the narrators to give their story the fullness they desire."

Because each interviewee connected their repertoire to personal biographies, they confirmed my hypothesis of choreobiography, namely of choreographic practices inextricably enmeshed within their makers' life paths. The interviews also reinforce the idea of an epiphenomenal time perspective seen in the previous chapter, as they combine a linear engagement with repertoire development, together with a situational reflection situated in the "now."

I read throughout the interviews a desire to navigate perforMemory away from any mainstream, exploring, sampling, re-creating alternative currents of resistance, history, oppression and liberation. The performances seem to all have in common their creators' will to re-member and understand painful pasts in order to overcome present inequalities and imagine future realities.

${ }^{5}$ Oral Historian Association, "Principles and Best Practices." I was inspired to use these principles by Conyers, "Shedding Skin in Art-Making." 


\section{1. ...Oxana Chi | 17.09.2013 | Berlin, Germany}

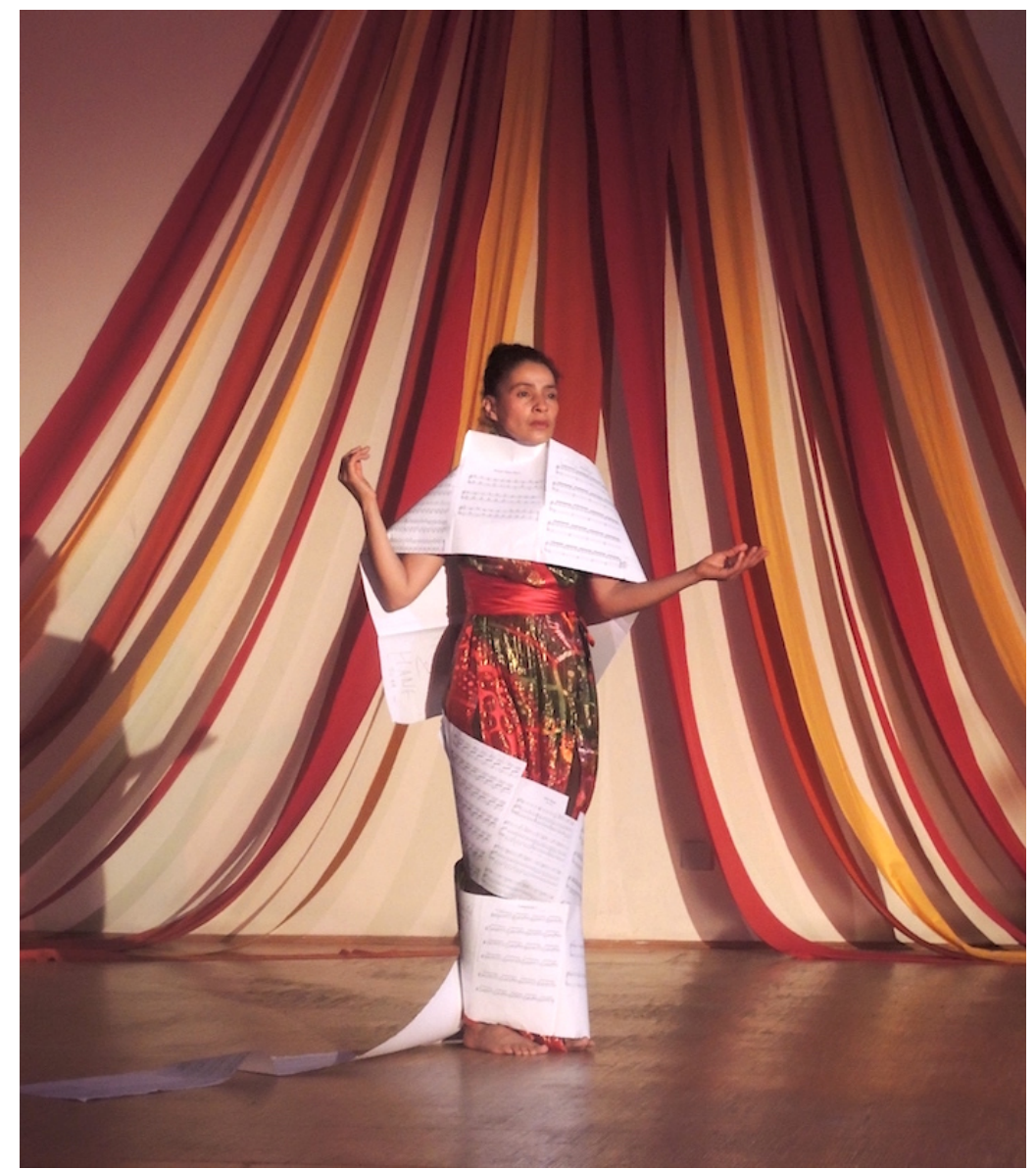

Oxana Chi in Tanz auf der Stelle - Impressions from Through Gardens.

"Nacht \& Nebel" Festival, Berlin, 03.11.2012. Photo: Layla Zami 
Oxana Chi is a choreographer, dancer, filmmaker, curator and publisher. She was born in Germany of Eastern Nigerian and Eastern European descent. As the Founder and Artistic Director of Oxana Chi \& Ensemble Xinren since 1991, she has produced 18 productions including two commissioned works for the Humboldt-University, Berlin. She developed her own style: a transcultural fusion blending elements from traditional and contemporary techniques from West Africa, Europe, Egypt, and South East Asia into a new vocabulary.

Chi has recently performed in France, India, the UK, Indonesia, Germany, Taiwan, Martinique, Turkey, and Singapore. Her work has been shown at venues and events such as Movement Research at Judson Church, Dixon Place NYC, Werkstatt der Kulturen, Ballhaus Naunyn, Maison Heinrich-Heine Paris, Théâtre de Belleville, Societätstheater Dresden, Bronx Academy of Arts and Dance (BAAD!), LaMaMa, University Settlement, and Aliwal Arts Center Singapore. She was featured at arts festivals such as Solo International Performing Arts, Taipei Fringe Festival, Jewish Music and Theater Week Dresden, BlackTinX Performance Festival, Black Herstory Night, Biennale "Passages" Bielefeld, but also at exhibitions such as Homestory Deutschland, EDEWA, and books

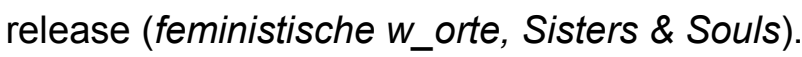

She often performs in the context of feminist events in universities, most recently at NYU Tisch School of the Arts, Tampere University Finland, City University of New York, Rutgers University Philadelphia, Humboldt-University Berlin, Bielefeld University, Mainz University, Yeditepe University Istanbul, and Goldsmiths University London.

Chi is a 2017-2018 Artist-in-Residence at Abrons Arts Center, and has received various awards and grants including the Cité des Arts Residency (Paris), as well as awards and grants from the Berlin City Council for the Arts, Gerda Weiler Feminist Foundation, Fonds Darstellender Künste and Fonds Soziokultur. She received the titles of Filmmaker of Inspiration and Ambassador of Peace at the DOSHIMA 2016 in Jakarta for the movie Dancing Through Gardens. ${ }^{6}$

www.oxanachi.de 
Layla Zami: Oxana, the first time I saw you on stage was during a performance of your dance piece Through Gardens [Durch Gärten]. I was deeply impressed by your very aesthetic style, as well as your political content. Where and how do you draw inspiration for your art?

Oxana Chi: Through my travels. I have been traveling for nearly 31 years, beginning at the age of sixteen I traveled within Europe, and then at the age of twenty I realized that Europe is too limiting for me, and then traveled to India. India was quite an important experience for me, because I found a particular freedom for my choreography and dance, which is extremely important for my choreography. Namely, that I can treat time just as I wish. My movements need a wealth of time, and I want to deeply savor each movement and this is what India taught me - something which may have gone lost in Europe, or which may never have existed in the first place. Then I traveled quite a lot to Indonesia, I went to Taiwan, I went to many islands and countries, in Asia, in the Pacific, in Australia, and also to America. In recent years, I also traveled to Nigeria and Martinique as well. All of these travels have shaped me, and above all, they provided me with a deep inspiration for my work. An inspiration which I cannot find in Europe. This makes my work distinctive.

L: By "my travels" you mean lengthier stays, right? Because in a short one-week trip you cannot find inspiration. So you stayed longer in these places?

O: Yes, for me "traveling" also means that I partially live there, or stayed for a minimum of one to three, or even twelve months. And really tried to immerse myself in the culture, simply to look at things, and also to participate. To study, to educate myself. Yes, that is quite important. So it is not a one-week package holiday, I simply do not do those types of travels.

L: You just told us about your travels, and the inspiration from your travels is clearly visible in Through Gardens. That is the first piece of yours I saw. That day, before your performance, you were interviewed on stage by the historian Susanne Jahn-Manske. Could you tell us a little more about that? I found it a very new, innovative, and communicative way to publicly present historical themes.

O: Yes, as to the inspiration for Through Gardens, I had just returned from China. Another long trip...first I was in Taiwan, then in Hong Kong, then in southern China, and there were many, many images in me, as Hong Kong is incredibly modern and high-tech, and following that I was in southern China, where there were still quite archaic structures 
in rural areas, where they really still tilled the fields with an ox and a plow [shows with a gesture]. The entire atmosphere was like a few hundred years ago, at least that is how I felt. This trip was extremely full of contrasts. Then I returned to Berlin, and it was like falling from paradise into hell. I always feel like this when I return from a trip.

I went, despairingly, to the library, something which I almost never do...and looked at the dance section. There is actually just one small shelf in this enormous library with a few books on it, which are mostly somewhat out-of-date, there's basically nothing contemporary. I was quite frustrated, and thought, "Well, there's nothing here in the dance section, perhaps I'll take a look in the visual arts." I looked through a few books in the visual arts, found them all more or less boring and outdated as well, and then...on all of these dusty bookshelves, at the very, very top, there was a small white book. It completely stood out, because all the other books were grey and dusty, and this small white book simply glowed. I got a ladder - there are these small ladders in the library - and climbed up there, because I am only 1,60 meters, and the book was really over 2 meters high, and I took it down from the very topmost shelf. The cover read: Tatjana Barbakoff, Dancer and Muse. ${ }^{7}$ The picture showed a very, very beautiful woman in a Chinese dress. And it totally spoke to me, it really hypnotized me, [laughs] because I had just looked at all these awful books, which actually had nothing interesting in them, and then suddenly there was this incredibly beautiful cover, and it was a catalogue of the [museum] August-Macke-HausBonn.

I then leafed through the pages and saw that there were many photographs, and much of it felt kindred. I felt a certain affinity to this person, and looked at the kind of performances she had done, and among others, there were "Bali-dance", and Chinese dance, dance styles I also enjoy, therefore I saw parallels to my work. I took the book home and read it through that evening, also something that I normally never do, I don't read, or very rarely. I read the entire book from the beginning to the end. Of course, I came across the terrible fate of Tatjana Barbakoff, well first [l came] across her successes, how she made incredibly beautiful dances, choreographed more than 60 dances, and how thus she achieved great success in Europe. It was also written that she was finally murdered in Auschwitz.

The next day, the next morning I said, "I would like to make a choreography in memory of Tatjana Barbakoff," so I resolved to do this. But actually, it wasn't only my decision or my desire, it was something greater than me. Not my self, but greater than myself. Yes, and that's how I came to choreograph Through Gardens. The title is from a dance that Tatjana performed, a Chinese dance that she performed quite often. 
L: And how did you have the idea of inviting the historian Susanne Jahn-Manske? What does it mean to you to be interviewed on stage by a historian before you dance?

O: The idea of working with interviews before I dance came about because I read a text about Yves Klein. Yves Klein had a period in which he only painted blue paintings, and he had an exhibition with blue paintings, and people asked what the point was, for all had the same format in the same size, and all the paintings looked the same. The exhibition was very badly received, I mean, it was met with absolute lack of understanding. Whereupon, Yves Klein repeated the exhibition with the same paintings, but asked a gallery owner who was very eloquent, to come and introduce the painting: to explain what kind of inspiration was behind the work. And he even went so far as to write different prices under the various paintings - [although] they were all the same. The art dealer then explained, for example, when one stands in front of this painting, one has this kind of a feeling, and that is why this painting costs so-and-so much. Another painting, which had exactly the same format, costs perhaps ten times the price...but this is because when one stands in this particular angle of the gallery and views the image, it is a completely different feeling. That is why it costs so-and-so much. He explained the art, the colors, and so on. I could say, or one could say that he introduced the works of art to the viewers. But it is also possible to say that he manipulated his audience.

I find it extremely important to prepare those who enter a space for that which they are about to see. Because then, the resonance will be very, very good. What happened with Yves Klein - all the paintings were then sold, the large majority of them, although previously no one wanted to see the paintings - that's precisely what I do with art, with my art, with dance. I find it very, very important that those who enter the space are prepared, particularly in Europe or Germany where dance is something that people almost do not know. In Berlin or Germany, people are not as interested in dance anyway, as they are in France or other countries. So it is important to prepare the audience, to tune them into what they are about to watch. For Through Gardens I found it particularly important, and especially began to do this, to give the audience an introduction.

It does not need to be about Through Gardens, but can be a historical introduction/context. For example, Susanne Jahn-Manske told a story that did not really fully have to do with Through Gardens, she told a story about a father and son who hid in a garden in Wilmersdorf [in Berlin, Germany]. So she told of a historical event, that is also related with the Shoah. That was a very, very good beginning - she also told it very, very beautifully, very, very deeply - to prepare the people for what they were about to see: that consequently, a story would be told which would also be told very, very beautifully, but which also has a certain depth, also has a certain sadness, and which also has a huge 
historical relevance for Germany, for Europe, and for the rest of the world. That is why I always do this before my dance performances, that I first give an introduction in order to prepare the audience. I have also noticed that the audience receives it extremely well, that everyone leaves the performance space extremely satisfied, and that no one says, "Oh, that was such an abstract choreography, I didn't understand it at all."

L: We just spoke about Through Gardens, and we'll remain with Through Gardens. In this piece you evoke, in a poetic and complex way, the dancer Tatjana Barbakoff from the 1920s-1930s. I've seen various performances of the piece, and it is your dance art and specifically, Through Gardens, which inspired and shaped my thesis. I am particularly moved that through this piece, you promote an alternative narration of history which emphasizes resistance, and offer a personal practice of remembering, which brings the audience closer to an individual biography. Can you tell us more about Through Gardens with regards to history and memory?

O: Yes, Tatjana Barbakoff. This artist lived in Berlin in the 1920 s and 1930s. She was Latvian-Chinese-Jewish, and moved to Dusseldorf, then to Berlin, and later emigrated to Paris. At first, I was interested in this topic because I took a similar path: I came from Dusseldorf, moved then to Berlin, then to Paris, and finally to Australia and back to Berlin. What's important to say is that I actually didn't choose to create Through Gardens. I didn't think, "I'Il create Through Gardens now." Instead, as for the historical relevance, I didn't think at the time about creating a piece about the Shoah, but as I mentioned earlier, it was something greater than me. I was given the task. And then I thought, "Okay, if I'm given the task, then I'll do it." Then of course I immersed [myself], deeper and deeper, and deeper and deeper...and it was important to me to continually question, and to see how history actually functions in Germany. And who tells history. And how, where, and when history is told.

What I noticed then - but had also previously noticed - is that in dance historiography, only certain people appear, people with whom I cannot identify. Through this work on Through Gardens, I could for the first time identify with a figure, namely Tatjana Barbakoff. Tatjana Barbakoff helped me to call more and more into question: who actually, here in Germany, who actually, here in Europe, who actually in the world writes history, or is allowed to write history. Then it became clear to me that it is extremely important for contemporary artists like myself to write history themselves. And if I don't have the means to write a book, then I must stand on stage and dance this history out. I must add alternatives, or create alternatives to all this mainstream, which actually very, very cunningly narrates a single history, which is very, very limited to my taste. Instead [of this 
mainstream], I must widen the scope, without exclusion. This means that all the voices who have written history should be made audible, and Tatjana Barbakoff belongs to those. "Tatjana Barbakoff" is just a name.

Behind Tatjana Barbakoff, millions of artists stand. Whether they were gassed, whether they are censored in other ways in present times, and cannot work, whether they are never mentioned by the media or in history books, that is not the point. Behind Tatjana Barbakoff there continues to be - all the way into today, and even beyond, into the future - other artists, who have distinctly helped shape our history, who have even created our history, but who are not named. This is why I find it very, very important that I attempt - in my own way, of course - but at least attempt to create alternatives, and to incite other artists to create alternatives to the narrative of history we encounter here. Because I believe that here, a great deal is left out that is actually extremely important.

L: Yes, thank you. That was very insightful. It is quite visible in your pieces that you genuinely demand an alternative historical narrative. In this case, you emphasized the resistance, and that very much moved me, because for example in school [in France and Germany], I was always confronted with medial representations of the Shoah that only show Jewish people as victims. Resistance was not a topic. There is a very important scene in your piece, I think you call it "The Struggle" (Der Kampf). Would you like to speak more about that?

O: Yes, I'd be glad to. When I was a child, I was also confronted often with antisemitic discourses, and a violent language negating the resistance of Jewish people. I find it scandalously shameful that such a thing is even still said. I always paid attention to resistance, for instance with Tatjana Barbakoff. How many years she spent resisting! In Berlin, as she had to flee - and even before National Socialism came to power, she always had themes that focused on political issues. She always sought to view our society critically and to point out injustices in her performances. After her emigration, she still continued to choreograph and to work, even without a residence permit, without a work permit, and still she managed to make it into the newspapers, to make it into art books...and continued performing! That is a very, very strong resistance. Although she was a migrant, although she had to live underground, she still created incredibly beautiful choreographies, still had exquisite costumes...To achieve that, although you are actually being persecuted the whole time and constantly threatened by deportation, I mean, how can you reach that? For this reason, I believe that it is extremely important to show that she fought. 
I worked for very long on the scene "Der Kampf" (The Struggle) in my piece, I am still working on it, because it must become much, much more complex. The Jewish people, well not only the Jewish people, all people who resisted: Sinti and Roma, Afro-Germans, and also all those who simply were not in agreement with the regime, many, many artists who simply did not create mainstream work, and rejected the Heimat-Abendland-Gedusel [patriotic homeland blablabla], were persecuted, and tried to resist. That is simply how it was, and that must be shown. After "The Struggle," there is the [scene of the] New Moon: the hope, because I believe that although Tatjana Barbakoff was put to death, and although so much art was destroyed here in Europe, she still left something here which gives us - me, or you, Layla, or all artists here - a certain strength to keep on going, and a fertile soil from which we can grow. And so I think that, even though she has passed away, she is still active and still resists, and that is also the case with many other artists.

L: Why do you prefer solo dances and solo choreographies? And are there points of contact, or parallels between your personal biography and the figures you perform on stage?

O: Well I danced in a musical once, and the only passages I liked were solos, two solos. All these group sequences, I found them absolutely awful. I always made mistakes, I always somehow danced the wrong steps, and the choreographer was incredibly frustrated, but I couldn't help it. I always made mistakes! Then I thought more about it, and realized that I probably found it uncomfortable to perform the same steps as nine other dancers the entire time. [I realized that] because of my personality - I am an individualist I just somehow had no desire to dance like the other dancers. Then, of course it's also a financial issue: first of all, to employ other dancers as a choreographer costs quite a lot.

Also, I have done a few duos, and noticed that I had to look after the other dancer, yet I am simply very preoccupied with myself. I am quite a self-focused person. So when I dance, I try to pour myself more and more into the dance, and my body...to give everything that is possible to give. And if I must work with other dancers, I won't be able to give on stage what I would like to show. And I won't be able to develop myself the way I want to develop myself, because...I am a seeking person. I seek much in my own self. I can not manage that when I work with other dancers.

That is the first thing, and the other is that I have noticed, when attending dance performances, that I was most touched when a single person was dancing on stage...where I could fully concentrate on one dancer. I always incredibly enjoyed that. There are few group pieces that have moved me in the way that solo works did. I have also often noticed when watching group pieces that I think "I'Il just watch this dancer, or 
that dancer," and then concentrate throughout the entire performance on one figure only. So I understood, more and more over the years, that I simply am not a group dancer, I am a solo dancer. That became clear to me in 1991. I danced my first solo then. And since then I have only danced solos, and am quite pleased with it, because then I can really give everything, and that is important to me.

L: Giving everything...I do see this when you are on stage, and this solo work is most likely reflected in your daily life and in your practice. You train nearly every day, right? In this way you can more freely shape your daily routine, or your training, than when you have to rely upon others, isn't that right?

O: Yes, first of all, I can arrange my time in a way that suits my body. Because it is also important to say this: I have not let myself be choreographed [by others], because here in Europe and in Germany, most people have a very, very different body than I do, and they need different time, they have a different nutrition - all of that does not fit at all with my energy and my body. My body is African, and my energy comes from many places. It's Eastern European, it's Asian... many energies come together, and build my energy. I have quite an individual energy. I also need to treat this energy in a certain way. I call this "housekeeping."

That is why it does not make sense for me to go to dance rehearsals of some dance group, to totally exhaust my energy there, and then to realize that it's too much for me, or that I am totally under-challenged, or whatever. I have always noticed that my energy does absolutely not fit with mainstream, does not fit with a white, western, maledominated society. It simply does not fit. Therefore, I work to my own rhythm, at my own pace. I always told myself that I have plenty of time to learn certain movements. I can not learn them in three years. Maybe I can learn them in twenty years. But then it's still early enough to bring the movement to the stage. For example, what I can do today on stage, I perhaps couldn't do twenty years ago, or not as well as [I can] today. And I continuously add new elements, and new movements from various cultures. It always becomes more dense, because my soul, my body and everything surrounding it, my energies become more dense.

Dance, to me, is a constant development of one's self. It is not one dance technique: classical ballet, modern dance and so on, all of that is not my thing. To me, dance is a very, very complex matter...akin to the soul. It is almost impossible to grasp. I wish to grasp it, of course, but it is impossible to grasp. And so it is important to constantly keep researching, like a scholar...and I can actually only present this work in a solo program. I 
can not expect this of anyone else. Besides, other people have other energies, and other focus in their dance.

Another aspect is that I have worked very biographically in recent pieces. About figures like Tatjana Barbakoff, Nefertiti and May Ayim. Those are figures to whom I have certain affinities. In very different ways, but all of them feel related to me. Not only through a biographical connection, but also through a soul-relationship. Therefore, it is good that I dance solo, because these pieces are extremely important to me, and that is how I wish to show them.

L: We met in Berlin at a public event, where a company named Mémoires Vives [Lively Memory] showed a piece about French colonial racism. In your piece Neferet iti you also deal with colonial structures and discourses. How do you manage to contemporize the past in a way that is as multi-faceted as it is clear?

O: To contemporize the past...Well, past and present are deeply related to each other. I do not see a large rift between past and present. I actually intended to do something about a pharaoh, the thought simply came to me. For me, it was about dancing a [cis-]female personality, in order to bring [cis-]women into the foreground, since women in Europe are always in the background. I told this to a friend, the actress Suheer Saleh. She is Egyptian-German, and she said to me: "Oxana, why don't you do something about Nefertiti? She is a very interesting pharaoh, and that could be quite fascinating." A few days later [in Berlin], I stood in front of a larger than life advertisement picturing [the bust of] Nefertiti, with the legend "Nefertiti...the beautiful migrant of the city." That struck me. I thought, "migration" and "beautiful," in one sentence? In a public space, in Germany? That was a sentence that sounded nearly impossible to me. Because I have never heard such sentences. Certainly not in public spaces, or in the media. When the press reports about migration, it is always as a problem, never as an asset. The poster troubled me, because it became clear to me that migrants are gladly seen as a source of profit [to society], but when it's simply about being fair and living with one another, then migrants are always just seen as a problem. Because of the poster, I decided that I would make something about Nefertiti. When Suheer first suggested it to me, I thought, "Hmm, let's see," and "I'm not sure yet," but when I saw the poster, it became clear. And when I deal with Nefertiti, then of course the first thought is: art looting. ${ }^{8}$ Of course, the topic is extensive, because art looting has to do with nearly all museums in Berlin. Not only in Berlin, also in Europe, or

${ }^{8}$ The bust of Nefertiti is a looted work of art exhibited as major attraction at the Egyptian Museum in Berlin, drawing millions of visitors to the city each year. Egypt has been reclaiming the bust from German authorities for almost 100 years, without success. See Opoku, "Nefertiti in Absurdity." 
America...so art looting is actually a gigantic topic that cannot be captured in one small dance piece. That is why I framed my Neferet iti piece with a focus on details.

I assume that [the statue of] Nefertiti wakes up on the [Berlin] Museum Island, and travels the path back, or that she comes from Egypt and traces the path of her abduction. It was important to me to go at it purely through dance, to depart from dance styles. In this piece, I work with various dance styles that could describe a journey. For this, I additionally studied Raks Sharki [Egyptian oriental dance] with Zadiel Sasmaz, a Turkish dancer, in order to feel my way in, to feel my way deeper and deeper into the movement. The journey actually describes various movement structures, from African to contemporary Hip-Hop, also classical ballet - for the classical ballet is actually an adaption of African movement. All of the leaps, the turns actually come from African countries, often from West Africa. I work through all of these adaptations in Neferet iti.

Because she is a pharaoh, it was also very important to me to create a particular, spiritual, mood. I believe this worked quite well, because the way I combine the dances and choreographies with each other builds up a spiritual energy. And it ends with the Sufi dance, which comes from ancient Muslim cultures. Yes, it mattered to me, to work very choreographically, and yet still politically. It is still political, because before I even begin to dance, I first read a text which I previously wrote. ${ }^{9}$ In this text, I express my opinion about the fact that "Nefertiti" is in Berlin, and my opinion about structures that do not view desecration of graves and art theft as criminal. I speak about this before I begin to dance. Therefore, I deal here, again, with a a political topic, Nefertiti.

L: You just spoke of your dance styles, and how you actually mix different styles. I believe you actually call it "Fusion," you haven't mentioned this word yet, but I have heard you say it before. Can you now tell us more about the process by which you work, and more concretely, how you create your incredibly beautiful performances, which you also always present with live music - which is also relatively rare [in the contemporary dance scene]?

O: Regarding my dance styles, I studied in various countries: with some of the greats like Christine Kono, who was at the Joffrey Ballet School in New York, or with Bu Endang Subono from STSI Solo [Sekolah Tinggi Seni Indonesia Surakarta], and with many different artists, Indonesian, Western...Through these experiences of training, it became clear to me what kind of dance I wanted to create. It also became clear to me that I did not want to create one style of dance. I also studied classical ballet for many years with Yvonne Wendrig from China/Holland. 
At one point it became clear that I no longer wanted to do any of these styles, but instead that I had to develop my own style. Then I began to do "Fusion," an idea of various dance styles, as well as my own input. Some dances I did not even study, some styles are already in me: some Africanist dances, for example. Or "oriental dance," by that I actually specifically mean Samudi and Raks Sharki. I can observe the forms a little, but actually they are already in me. I have developed these various styles into my own "Fusion-Trend" and I use this style in my choreographies. What I do, when I have a theme, I go to the rehearsal room and I improvise. I let movement flow through me. I move, and I move, and I move, and at some point I think: "Yes, this movement is good, and this movement is good..." or "This beginning is nice," or "This middle is nice." It comes to me. I don't really think it up, instead all the styles just come to me...the movement, and the rhythm. And when I move then - I am always alone [in the rehearsal space] - it becomes more and more meditative.

From this meditative language of movement, I perceive how the music should be. First come the instruments, then I know, "there I need a violin," or "a hang would fit well there," or "there a bamboo flute, or a piano." They come one after another, and once I have the instruments, then I consider which musician would be fitting. Then I simply meet with musicians that I know - or don't know - and find out which musical language each one plays, and which ones would fit best with the piece. And then we begin to work in the rehearsal room together. I always work with images, I give them images. I tell them, for example, this is one image: the atmosphere must be very romantic, it must be like a park. Or I tell them, "This must really be brutal, right now we are in World War II. A bomb is about to drop on our house." I give them a mood, and sometimes I also give them composers that I find interesting. What is also important to say is [that] the musicians I work with are also simultaneously composers. They are artists, they create. Not only adapt, but also create: they invent the pieces for my performances. Some pieces are prior compositions, and if I really enjoy one piece, then I say: "Okay, I find this piece very interesting, but could you tailor it to me? It is like a beautiful dress I see, could you alter it so that it fits my shape?" Then they do that as well, and the second part of the process is that I work together with the musicians, and from there the dance emerges.

L: Oxana, you just told us about the process of your work, concretely about how you work together with musicians. I myself had the chance to be on stage with you, and experienced how you work together with others in the piece I Step On Air, which is dedicated to the Ghanaian-German poet, performer, and scholar May Ayim. How was the experience for you, having your performance art involved in scholarly-academic contexts? I would be interested in [hearing about] this. 
O: Yes, I came to the theme of May Ayim through you, because you planned to make a film about May Ayim, and I had just met you then. From 2009 to 2012, I organized the Salon Qi every year in memory of Tatjana Barbakoff, and then in 2011 I had the idea of adding a May Ayim reading as well. Then you prepared texts that you had researched about May Ayim, and offered to give a presentation. I then had the idea of bringing in the actress Suheer Saleh. The two of you worked together and staged an incredibly beautiful lecture-performance, a scenic reading [szenische Lesung], which was half academic, half with presentation, but also theatrical. I programmed it at the Salon Qi. In the audience was Natasha Kelly, who teaches at the Humboldt University at the Gender Studies department, and we presented the reading again in 2012 at Dance Summer 12, a festival which I also organized together with you. In that same year, Natasha Kelly approached me, and commissioned me to choreograph a piece about May Ayim, Panna Cinka and Delia Zamudio, female figures who were great and powerful personalities. I ended up choosing May Ayim and let the other figures flow in, but for me it was really about May Ayim.

That was very well received - and there was the contact to the university. We were then invited to perform it in various universities, at other exhibitions and festivals as well, but also in academic contexts. What was interesting was that it really fit in well there, because they had several presentations and lecturers, and our piece felt like release. It creates a good atmosphere, yet it is academic and complements the academic presentations. It was quite good to collaborate with the universities, and we decided to do it more often. It works well, has a receptive audience....and hopefully it will continue in this way.

L: Oxana, your dance pieces are transdisciplinary, as you mentioned earlier, and you yourself are a multi-talented artist who works with many art forms: choreography, dance, film, video installation, curation, and in addition, you have published texts on your art, which I can analyze for my work. But your heart seems to beat loudest in the dance arts. What is special for you about dance as a form of expression? Particularly with regards to time and space, life and consciousness?

O: It's true, I do like to film. I shot films for a while, and I also regularly write texts, not only about my dance, also about other things. I also love painting, I enjoy going to exhibitions, and have some friends who are painters, I find all of that wonderful. I love art in general. But for me, dance is the queen. Really the absolute greatest of all the arts. For me it is the purest form of art, because in the end, we humans can do without everything. We can do without books, without paintings, without images, we can also do without 
films...but we cannot live without our bodies. It simply isn't possible. Dance really is simply body, soul, heart. All of those are needed, otherwise one can't dance. It isn't possible otherwise. And so for me, it is the greatest of all the arts. That is why I dance. 


\section{2. ...Christiane Emmanuel | 21.02.2014 | Fort-de- France, Martinique}

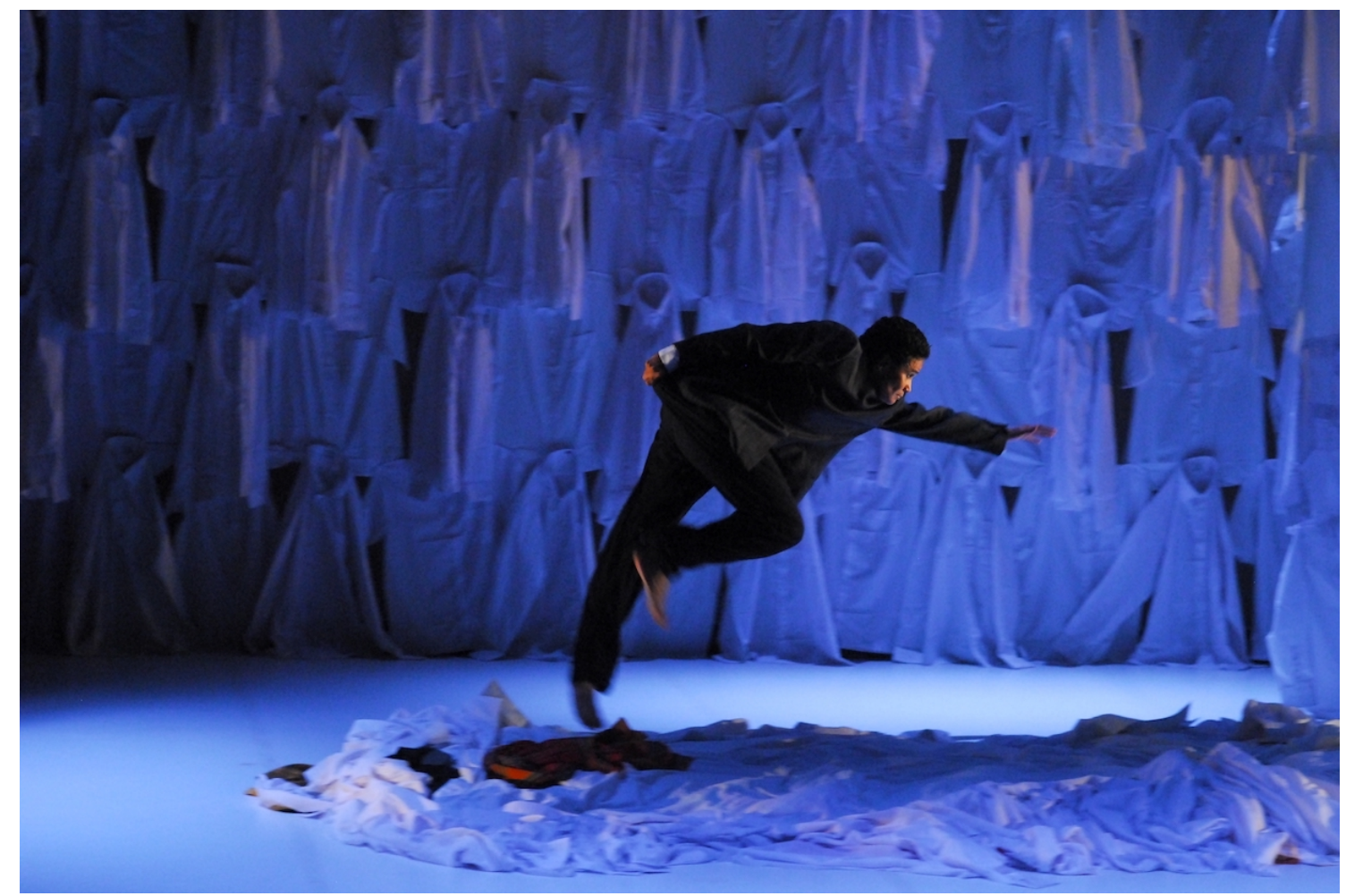

Christiane Emmanuel in Choc(s). Atrium, Fort-de-France, Martinique 2011. 
Christiane Emmanuel is a dancer, choreographer, and dance pedagogue. She created the Experimental Group of Contemporary Dance (GEDC) in 1989, now Compagnie Christiane Emmanuel. Her choreographic language is firmly inscribed in Martinican and Caribbean idiosyncrasy. The company is also enriched by the profile of various artists and choreographers. In 2010, the artist also became the Founding Director of the Maison Rouge/Maison des Arts, a dance socio-cultural center based in her home neighborhood of Fort-de-France, Martinique.

Christiane Emmanuel holds a State Diploma from the Cuban Ministry of Education and Culture, and a State Diploma from the French Ministry of Culture. She studied dance for five years at the Escuela Nacional de Arte (ENA) in La Havana, Cuba, and for two years at the Académie Internationale de la Danse (AID) in Paris, France. She also trained in Dunham Technique, Contact Improvisation, and trained in traditional and contemporary Africanist styles with Elsa Wolliaston, Fred Lassere, Bruce Taylor and Marianela Boan, among others.

As a choreographer, Emmanuel received the "Utopia" Prize for Choreographic Creation (2011) from the Martinique Regional Council for whom she produced commissioned works. Her repertoire comprises 20 productions. The company performed internationally in state theaters, cultural centers and festivals. She has appeared throughout the Caribbean, among other places in Martinique (Tropiques Atrium, Fonds St Jacques Cultural Center, Aimé Césaire Theater); French Guyana (Auditorium de l'EnCRe, Musée des cultures Guyanaises); Guadeloupe (I'Artchipel), St Domingue (Edanco Festival); Venezuela (Caracas Dance Festival); as well as in Burkina Faso (FIDO Festival); and France (Tours National Choreographic Center, Avignon Off Festival).

Since 2016, Christiane Emmanuel has been the President of the Tropiques-Atrium Theater, the largest, state-sponsored performing arts venue in Martinique. She also entered politics and currently leads the Cultural Committee at the Martinican Regional Council.

christianeemmanuelcompagnie.blogspot.com 
Layla Zami: At your talk at the Habitation Clément, you said that you "dig your Martinican self." Can you tell us more? From where do you draw inspiration?

Christiane Emmanuel: It was very clear to me, through my parents' education, that we are first and foremost Martinican [citizens]. Dad himself was immersed in reading Aimé Césaire, Senghor and [was] a fervent supporter of the Martinican cause, so I had a good luggage, a full one, with the "bar code stickers" of Martinique. With this "bar code," I went to study [dance] in Cuba. There, I felt confirmed in the feeling that I am Martinican, and mostly, Caribbean. Drawing on the training I got in Cuba - Afro-Modern Cuban dance, and traditional Cuban dances - and knowing the traditional dances of my own country, I quickly noticed that a local traditional dance is a strong base, a well, a stand on which you can rest, and bounce off in life. This does not mean that my choreographies are strongly influenced by my [Martinican] traditional dances, but there is a base...there is a knowledge of space, well is it inborn or not, is it conscious or not? But things are much easier if you dig [into] both spaces, the contemporary dance "space," and the traditional dance "space." My Martinican self is my forest, my location, the place where I live, the people I socialize with, the political space, the geopolitical space named Martinique, the cultural space, the dense forests of Martinique, the beaches, the inhabitants, the Martinicans themselves...

L: You just got back from Burkina Faso, and your company is now celebrating its $25^{\text {th }}$ anniversary... How was your work received over there?

C: We had a flying start in the year. On January $14^{\text {th }}$, we left for Burkina Faso, upon invitation by a great dancer-choreographer, Irène Tassembedo, who organized the second edition of her festival [Festival International de Danse de Ouagadougou]. [...] Being an optimist, I always knew that one day I would eventually perform in Africa, maybe in a near future, to work with African choreographers who appreciate my work. And it happened! And actually the show I brought there, Jazz Douss, is an encounter between two contemporary dancers and a hip hop dancer, who dance to a [piece of] jazz music [Olé by John Coltrane], but use an element from a traditional dance from Martinique, not as a style, but as a form: the bèlè round. So the piece works around the circle, which is also the shape that jam sessions take, be it hip hop, or jazzmen in a street corner, it is always the same shape...The musicians stand somewhere, and immediately, the audience builds a circle around them, and in the middle the dancers express themselves. Therefore this recalls the traditional dance space arrangement. It was the fortieth death anniversary of [John] Coltrane, and I wanted to go down memory lane, so we brought this piece to Africa. The work was well received, because the audience understood my topic: 
how I used basics - without doing traditional dance on stage - the basics of a spine, the basics of the pelvis, how this pelvis moves in relation to everything that one learned, and which added value to these basics, from this strong culture that flows into a way of being.

At the end of the day, I think that I choreograph our way of being, our way of being in Martinique, ways of moving...I think that unconsciously, it is inscribed in my choreographic dreams and creations...well, maybe it used to be unconsciously, but now I am conscious of it, because it is a recurrent theme! It all depends on the topic, if I am given a topic where one must dance an "i" letter, I think I would swing the "i," because we can not be a straight "i." We have too much to express! Our walk is musical, our body is an orchestra, whether you look at the hips, the feet, the knees, the positions, the posture, the head nods, the gestures, the placing of the hands...we are a complete orchestra, it is all about putting it in symbiosis to make a choreography out of it.

L: Your mentioning of Coltrane resonates with my education, growing up with the sounds of Coltrane's Africa Brass Sessions. And you mentioned the circle, which indeed is recurrent in your work. You mentioned the relation between music and dance. Can you say more about your collaboration with other artistic partners?

C: In the case of Coltrane, the music already existed, since the artist no longer lives...I don't know if he may have enjoyed composing for the company? So in this case, the piece was directly linked to the music of Olé, which is really a very, very beautiful piece. And indeed this music is arranged similarly to a bèlè circle [dance and music style], because each instrument takes its turn of speech, like the tambouyé [drummer], like the bwatè [ti bwa player], the singer [lavwa], the répondè [bèlè choir] and the dancer. ${ }^{10}$ So I found an easy way through the musical space offered by Coltrane. But otherwise in my view, a true choreographic creation must be accompanied, meaning that the choreography must be the main art form, it must be the main statement that one carries.

I have a theme. I work with dancers according to the theme I need to develop, we do workshops, or excursions. For instance for the piece An Kabel pou Lam ${ }^{11}$ dedicated to Wifredo Lam, and inspired by his painting The Jungle, we went out into the forests of Martinique...knowing that the catalyst for Lam to paint The Jungle was the famous walk he took with Aimé Césaire on the Balata road, so I took an excursion with the dancers on that road.

\footnotetext{
${ }^{10}$ The bèlè is a dance and music style found in Martinique and other islands of the Caribbean, transmitted by Afro-descendent people over the generations.

${ }^{11}$ The title means "One Kabel for Lam." The kabel is a traditonal dance step in Martinique.
} 
When I returned to other pieces such as Paroles du bruit du dedans, or Mangrove, or the Petites choses de la vie, or Choc(s), it was first a choreographic creation, and then came the musical creation, the scenography, the costumes, and the light design. Often the scenography arose at the same time as the choreography, since one needs to work within the space arrangement determined by the scenography, or the scenography may become itself a partner, a dancer. So I often prefer to set up the choreography, and then... [the rest].

I have been collaborating with a great genius for years, his name is Jeff Baillard. We have been working in complicity for ten years, so we get to know each other better and better, and we always worked with a high esteem for each other's work, knowing that we both know our trade. What I appreciate about Jeff is his capacity to listen, and his suggestions. It is not someone who tries to persuade me to use a specific soundscore for a certain piece. No, Jeff puts his music, his whole self, his whole musical magical power in favor of the dance.

But I can also mention Sylviane Gody who works with us, Line Backer Bonpin who works with us, Dominique Guédon, my light designer for over ten years. And honestly I can call on other people for specific tasks, but you don't change a winning team. [Laughter]

L: You just mentioned $\operatorname{Choc}(s)$, in which the collaboration with the visual artist Valérie John is essential. Your movements are very aerial, but also grounded, there is a strong dynamic in this regard. The protagonist you embody seems to live in the rhythm between balance and unbalance...

C: This societal upheaval in 2009 , this general strike that affected Martinique for two months...I was out there everyday, I participated in the movement, I watched TV, I listened to the people, I listened to the politicians...It came out from a great impetus and a great hope, but quickly, the house of cards collapsed, the sand castle dripped, the bricks fell apart...[Laughter] I won't say that I was disappointed, for it takes time...the life of a human being is very very short compared to History. History... if you draw a [graphical] curve, a century will be half a millimeter, so you can imagine that a human life is not even a dot on this curve [graph]. So I was shocked [by the politics], to see suddenly setbacks, people turning their shirts around [as the French saying goes], upside down, downside up, "nou mété tout moun d'ako" [Creole for we make everyone sing one song] as the song goes.

So I was shocked. And I started thinking of strong moments in human history, I am not only talking about Martinique, but also the 1789 revolution, the abolition of slavery, civil rights movements, the women's rights movements, in Martinique the 1870 civil uprisings, 
the february 1974 uprisings, the 2009 uprisings. Some things have moved forward...I do not know at what cost, I don't know if there was an exchange of shirts, maybe it is common, I don't know, I was not there. But I keep in mind big names, all these people who fought, who pushed progress forward, who struggled, so there is a hope. I always keep the idea of hope, as I say in the artist statement for $\operatorname{Choc}(s)$ : I cling on, and I hang on to all these memories.

And so when you watch the performance, I start at a height of five meters above the ground, I run, and I recall myself running on the pavement of the main avenue of the Général de Gaulle boulevard...but here, in the performance, I run in the air, I do not know where I am going, I am lost, I run until I collapse out of exhaustion. And in the piece we are actually in a dynamic of "going around in circles," I run always in the same position, always facing front, never facing back, I reroute, I return myself, I turn around to run, still forward, in the opposite direction, but it is always a race going in circles. So I ask: am I bored, am I going around in circles, am I searching for something else? It all depends on the audience, and how they understand it. At one point, stop, we move on.

There is a very beautiful scenography designed by Valérie John, an artist who works with me, we are both great friends, longstanding accomplices. [...] She suggested this wall section that represents the crowd, all these shirts, these 250 shirts hanging on like bodies.And at one point, she set up, ahead of me, a wall section of shirts with collars, and long sleeves....and when I implemented this wall of shirts, I said "Oh no, I can't stand this, it's terrible!". It felt like an obstacle, like authorities that refuse to listen. Therefore when I worked on that piece, the authorities were present, onstage, but I defied them, and I allowed myself to laugh at them, saying "Where are we, where is this all going?" At one point there is also a "pool" made out of white shirts and linens.

When I was choreographing at this specific moment, when I started to put on, and off, the colorful clothes I would find under this pile of white shirts, I recalled a quote by Césaire: "carnaval des autres" (the others' carnival). ${ }^{12}$ Not even the whole sentence, only this expression. When I thought of this sentence, I laughed out loud, as I was dressing up, I was only thinking "carnaval des autres," "carnaval des autres." Those three words extremely motivated me and so I started to play with the dressing and undressing of the colorful clothes [on top of her white costume]. I experimented with this, until I decided that I would keep all these clothes on, heaping and stacking them on top of each other. Questions...

\footnotetext{
12“"mon peuple [...] quand donc cesseras-tu d'être le jouet sombre au carnaval des autres" meaning "my people [...] when will you stop being the somber toy at the other ones' carnival." Maybe Césaire was thinking of his own complicity as a Martinican politician working within a French colonial system. Césaire, "Hors Des Jours Étrangers."
} 
In Choc(s), the number one question was consumption, prices. I find myself dressing up like a consumer, I never have enough, so I accumulate these clothes...out of fear of not lacking tomorrow? Or am I simply a homeless person, who also searches, and is also in the fear of not having enough tomorrow? Or is it a behavioral disorder? There are strong, recurrent identity disorders in Martinique, people not knowing where they are at, or mimicking other cultures that are remote from their own. But I become aware of it, and I say "stop!" I explode into dance, and this pool of clothes becomes the idea of the bèlè circle, because the colors emerge out of it. So it is about the people, the people no longer in a uniform framework, as when we were running up the avenues [during the civil protests], but the people now in a circle, and I dance for it, I say "But wait, we must return to matter, to the basics, we must search within our roots!"

At this point I call in three drummers, Micky Télèphe, Daniel Dantin, Marc Séraline, who play a rumba along to my dance. It starts with a yambú, and it ends with a guaguancó, which are part of the rumba cycle in Cuba. And here I do a phenomenal work, [connecting] my knowledge of traditional African dances, traditional Cuban dances and traditional Martinican dances. I start off with a simple chacha lubafu, to reach a bel siyé, for indeed the ancestor of the bèl siyé is the chacha lubafu. This is only one example, it was actually an array of research into my Caribbeanity if I may say [so], in my "Afro" resources.

So when you speak of aerial, light dances that are also grounded, sure, that's right, but I would speak more of fragility. I walk a fine line.And at the end of the piece, you see that I draw a whole branch of shirts, which may be this fine line...on which cloth pieces appear. They may represent society, or simply the questionings that haunt me, the zombies I draw along with me, what I drag along. I leave it open to the audience - there may be different readings [of the piece] - and I am fine with that, every one may understand what they want, and often these different readings rejoin the choreography.

\section{[Interview break]}

C: So I was telling you that in An Kabel pou Lam and Mangrove, there is no specific [normative] gender. It is more of a "human being" dynamic.Well not human, but rather living being, animal being, vegetal being. At what point are the dancers insects, at what point are they human, at what point are they vegetal? Mangrove is a subaquatic world, An Kabel pou Lam is a night world. When I look at [Wifredo Lam's painting] La Jungle, it is a thick forest, with various skin and light tones, but I see it as a nocturnal space. In both choreographies, there is a back and forth across gender. It is not about men/women. It is 
beyond. But surely in the rest of my repertoire, I do represent [cis-]women and [cis-]men, even when the [cis-]men wear skirts.

L: Let's conclude with a short mention of the beautiful place where we are conducting this interview...

C: My most beautiful dream. Actually when I created this location, when I started planning this space, I called the project "the moving dreams." I had been dreaming of this for more then twenty years: to turn the rooftop into a dance studio. Things moved on...[we are] on the rooftop of the Maison Rouge/Maison des Arts. It is the family house in which I was born, in which I was raised. We were ten children, all raised in this space filled with good spirits, loaded with foolishness, loaded with tricks made to each other. This is really a space that breathed...kindness, joy, cheerfulness, also pain (when you get punished), family spirit, parental love, and the love and respect my parents carried for each other. I say "carried" because Dad died. This year, he would have turned 100 years [old]. Mom is still with us, hopefully for long. They had a very warm and respectful relationship, we were imbued with it, and so it is a joyful house. And I am very glad to have turned it into [the Cultural Center] Maison Rouge/Maison des Arts, here in the neighborhood of the Terres Sainville.

It was a necessity. Musicians sometimes rehearse in one square meter, they work on their instruments. Architects, like us choreographers, are preoccupied with the use of space. They have a room where they work, and plan projects. And I was always in the position of dependency, having to ask for space in locations built for professionals. I don't even want to think of it now. All these small inconveniences led me to look for private funding. And I bought off the family house, without public funding, to turn it into a dance space. Today there are several projects here, including cooperations with the Solange Londas school, for the neighborhood children, and I am surrounded with professional dancers who work here. This is where we are at now. I have built, I believe, a highly cultural place. 


\section{3. ...Chantal Loïal | 01.03.2014 | Paris, France}

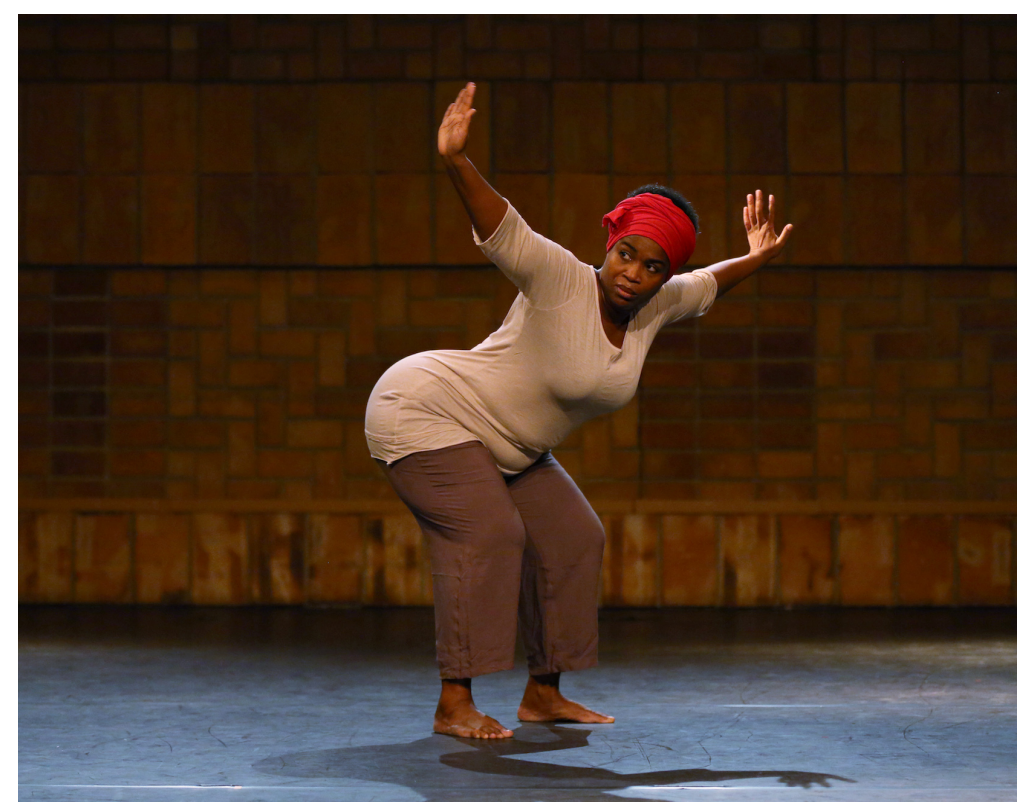

Chantal Loïal in On t'appelle Vénus. Photo: Patrick Berger 
Chantal Loïal is a choreographer, dancer, and pedagogue. Born in Pointe-à-Pître, Guadeloupe (French Caribbean), she arrived in France in 1977. She performed and toured with French, Congolese, and Belgian companies and artists such as National Congo Ballet, Ballet Theater Lemba, Georges Momboye, Tchico Tchikaya, MontalvoHervieu Company, Les Ballets C. de la B., and Raphaëlle Delaunay. Her training comprises traditional Guadeloupian and African styles. She also has a State Diploma in contemporary dance from the French National Dance Center of Pantin.

In 1995, she founded her own dance company, Difé Kako. The group is known for a dynamic blend of modern jazz, West and Central African dance, ballet and Caribbean dances, accompanied by rich live-music, and for their irresistible enthusiasm as dancers and pedagogues. In 2015, she was awarded the Legion of Honor, for her 28 years of contribution to French culture through performances, events, classes and workshops.

The company receives funding from the French Ministry of Culture and the regional offices of Martinique and Guadeloupe, among others. They perform widely across France and the Caribbean. As a solo dancer, Chantal performed at various venues including the Kennedy Center and Maison Française (Washington), Festival d'Avignon, Bolzano Dance Festival, and Théâtre de la Villette (Paris).

www.difekako.fr 
Layla Zami: Good day Chantal, thank you for taking the time for this interview, considering your busy schedule and the premiere of your new show, "Noirs de Boue et d'Obus." Could you tell us more about it?

Chantal Loïal: It's a commemoration of World War I (1914-1918); The Great War. The idea to continue the work I do: to be able to talk about the Caribbean, Africa, and about our roots. Therefore, we are still in this triangle that resides in me since the beginning of my work. The idea is to be able to let the soldiers from the Caribbean, of Africa, the "tirailleurs," "La Force Noire," and France to coexist...to understand how the soldiers met in the trenches, how they fought war, what they endure during the war which was an atrocity. That's somewhat the idea.

\section{L: With four dancers?}

C: There are four performers, only [cis-]women as always - it is a known fact that my work revolves a lot around [cis-]women. There will be three women soldiers who will perform, take us on a journey, and travel through all of the emotions that can be found in this war: fear, anguish, the trenches, the walk, monuments, letters from "les poilus," the wartime godmothers. There will also be excerpts of films which deal with difficult subjects that some of the soldiers have gone through during the war. The ones who refused to go fight were executed. We will have an excerpt of a film inspired by Kubric, and we will have "Le Camp de Thiaroye" by Ousmane Sembène, which covers the poor care given to soldiers, more precisely in terms of food. This movie, which is about the Second World War, corresponds to an excerpt where the "Moi-y'-a dit" language was established, in the First World War, for the Black soldiers, the "tirailleurs" to communicate amongst each other and also with France.

L: Ousmane Sembène is a Senegalese director...and I met you in Martinique where your show On t'appelle Venus was featured. A show, I must say, that moved me very much. I wrote an article about it already back then, it is also a work of memory...

C: It is true that my hobbyhorse is [cultural] memory. On t'appelle Vénus [They Call You Venus] revolves around Africa, but speaks of deportation, the triangular trade, and of a woman who was deported in the 1800s. She's deported simply because the Europeans deemed she had a different body type and ethnic practices. They wanted to make an effigy of her, so much, that when she arrived in England, she was displayed like a circus act, with animals, under the pretext that she had deformed buttocks, well as seen by the 
Europeans anyway. Furthermore, she was mistreated, arrived in England, than France, and found herself exposed, in cold weather, mistreated, sexually abused...and finally died of ailment. Painters wanted to draw her, and that's it. Suddenly, this becomes for France, since it's the naturalists' era, the opportunity to have racial slurs [...]. She will be one of which we refer to when speaking of race.

L: You usually work in a group, whereas this time you presented a solo piece. What is the link between your personal trajectory and this solo? Did you dig in your autobiography to find inspiration?

C: While speaking of Venus, clearly! When a friend of mine, Jacques Martial, [the theater Director] at the Villette [Theater], mentioned it to me, it's because he knew on the one hand that I was working hard on memory, and on the other hand that I was committed to the [topic of] women. He told me: "I think you absolutely need to speak of this woman, there might be a comparison to be made with your body." Indeed, I realized there was a comparison to be made, since I have been working with contemporary choreographers for many years (even if I was using my body with humor), there were always the questions posed by the spectators: "Is this her real butt? Are these her real breasts?", the same questions would be raised when I went abroad. Therefore, it still needs to be addressed today, consequently, in 1802, Venus died, but I was able to come out of it, and to create humor...and the choreographers whom I worked with were interested in depicting that all bodies can dance, and that we need to accept the difference of otherness, but in Venus' era it wasn't what we accepted. This is why there was indeed a parallel to be made between what I was living on stage with the spectators' glance, and what Venus may have lived with the glance of these people who came to the circus, where the glance was pejorative, it was an atrocity. I doubt people of that era realized [this], or how conscious they were of it.

L: I felt you were tapping into that...as a spectator, we slightly are transported to a character of that era watching Venus, in the same breath, it is a contemporary show...

C: I did tap into that, I played on voyeurism, that's for sure. I certainly tried to make people feel uncomfortable. Physically, I was close to Venus, but I still tried to tell her story of suffering, what she may have lived, and to make people uncomfortable, put them in that state. There will always be those who enjoy and those who don't. Bringing up memory will always feel uncomfortable. 
L: You just returned from South Africa where you presented this work. Was it received differently [there] than in France or in the Caribbean?

C: In the Caribbean, we feel close [to the topic], because throughout the show we speak of deportation, of slavery. In the Caribbean, I got very positive feedback, [as a] matter of fact, they said: "And it's a Caribbean [person] doing this show!". We have this story about ship holds - Venus was brought back by boat. For the Caribbean people, it was clear, they got the message, and in the Caribbean, people are very demanding on this subject. In France, it's a bit harder, they felt way more uncomfortable, because they are responsible for what happened. Nelson Mandela had asked for [France to return] Venus' body and bones, so it can come back to South Africa, and that was cause for debate at the French Parliament! There is a situation of uneasiness. In South Africa, on the contrary, there isn't. They re-appropriated the body of Venus; it's their history. Seeing a foreign woman, well from the Caribbean, being able to communicate that, it was wellreceived, people were very touched. As a matter of fact, many have told me: "We feel that you are not from here, to be able to write such a show, and we have never seen Venus' story told this way." It was pretty moving.

L: How did you live it on a personal level, more so in terms of dance, since we spoke much about politics? I remember seeing video clips where you started in the Ballet du Congo, in group work..and now you return to Africa...in a solo.

C: Truthfully, I always used to work more with a group, whether in traditional African ballet or contemporary [European] companies. The idea of going towards a solo felt strange, because in my early years, watching contemporary dance [solos], I would say to myself: "But it's impossible not to share [with others], to be alone [on stage], it's hard to be isolated." Then, aging and gaining maturity, I told myself: "Why not?" It was a challenge to be alone on stage, but then, it fell on my lap as I was spoken to of this subject; it was the perfect timing for a solo. In the end, it's a beautiful experience, because one is left to rely on oneself, to defend a cause, and connect with an audience. Most of the audience members come out of the show crying, or feeling uneasy or screaming, and some are disapproving. The point is, my solo does not leave one indifferent! In South Africa, I was proud and happy to retrace the steps Venus had taken. So far, I have only been to Cape Town, yet I would love to go where her ancestors were, between Cape Town and Port Elizabeth. Personally, it was extremely touching when I got on stage for the first time, in front of students of the university, I thought: "Finally, I am here." It was important for me to present this solo over there. 
L: It is a beautiful story because in the show, in the South African music section, you actually bring her home in a way.

C: In any case I tried to be as close as possible to her story in order for people to understand clearly what had happened, where she left from, how she arrived, what she lived in Europe, and finally, how she left. I also paid tribute to her [posthumous] homecoming. Therefore, I think the idea of "going back" was important. I do hope to go back to Africa and tour cities other than Cape Town.

L: We first started speaking of the Caribbean, but you also have more current themes such as in Zandoli pa tini pat [Lezard has no legs]. ${ }^{13}$ You play with the connection between past and present, since we see Josephine Baker's bananas revisited by [the contemporary pesticide] chlordecone. There are some signs indicating the time period “1802”...

C: The initial idea was to speak of the environment, the garden, the nature. It just so happens that the show was created in the midst of Hurricane Dean in Martinique, in August 2007, if I'm not mistaken. So, in the middle of creation, I said to myself: "No, I can't pass on this." Hurricane Dean was able to bring forth a strong case of chlordecone history on the government level. For 13 or 15 years, we'd been fighting at the Senate and State levels for them to consider this issue, and it's Hurricane Dean that revealed the most about the history of chlordecone. I felt it was important to talk about it, because a year or two before, it had been Josephine Baker's 100th anniversary, which allowed me to make the connection. There were multiple photos and images of Ms. Baker everywhere in France, huge posters of shows about her. Josephine had a Black woman story as well, there was an ambivalence about this worshiped Black woman. There was again another voyeuristic side, which allowed me to continue on this hobbyhorse, on the triangular link of the Caribbean, Europe and Africa, and to be able to dwell on another subject which is in a grave state, the environment. We suffer from health issues due to pesticides. Therefore, linking an internationally known character, who had been used in a Banana context, allowed me to speak of the past of Josephine de Beauharnais with Napoleon, in relation to Martinique and the Caribbean, reverting to Josephine Baker, who had been an international icon in the occident. Painting Josephine Baker as a beautiful banana, and then having a banana rotted by chlordecone, connected us to the past, to the duty

\footnotetext{
${ }^{13}$ Zandoli is a lizard species found in the Caribbean.
} 
memory. That way, the youth stays connected, since our shows are very pedagogical, and the teachers hang on to the environmental themes throughout the school year.

L: You've mentioned a lot of triangular relations on the political, historical and social levels. What is the triangular in terms of dance, which is a mix of Afro-CaribbeanEuropean?

C: My dance's identity is based firstly on Africa and the Caribbean. Indeed, I try to reconnect to movements from Central Africa, which are based essentially on hips and circular body movements, also movements from West Africa, which are more from the Mandingue dance style, with the head, the arms, the body's extremities, the jumps, and the Doople position, which represents a straight arrow statue. It's grassroots work we are developing, which can also be found in the Caribbean, either in Martinique with Bèlè, where we find the slightly different Dooplé position, and in Guadeloupe also. In Martinique, we find a dance that's much closer to West Africa, like in Benin, whereas in Guadeloupe we find something closer to Central Africa, characterized by more hip movements. Let's not forget that both Martinique and Guadeloupe have gained a lot from European styles such as beguines, mazurkas, polkas, quadrille, and court dance, what I call court dances. Often, what I say when teaching is: "[The] lower part of [the body], is Africa, [the] upper part, is France, the whole is creole." It's an expression I developed while working. I use it in my teachings, because there is a specific attitude found in a creole woman, which stems from these different African and European cultures, which in turn becomes creole, it's reinvented, and I try anyway to convey this type of movement. Pointed shoes, arm dresses and haughty head dresses are elements found in creole dance, where we are often "nagging" with hip sways. My work consists of that, in preserving....and quite often to mix it with other knowledge, such as the one brought in by new performers who join the company. Actually, the company has a connecting thread, that we call "Afro-Creole." Obviously, each performer brings their personal artistic baggage, their singular identity, which becomes a plural one within the company. This means that we accept each performer's singularity, while they adapt to the company's body of work. Therefore, these are people interested in the company's choreographic language, its connecting threads and artistic approach, and who want to do African and Caribbean dances. We integrate, for instance, hip-hop, contemporary, classical dances, and let's say, for a lack of better word, "oriental" dance. In general, performers arrive with their personal baggage, which is mixed with the company's baggage. The [scope of the] company is very large. There is movement, but we also use the voice quite a lot, the oral theatrical voice, the singing voice, and we know that in our [Afro-Caribbean] traditions, we 
do not segregate voice, music and dance. We know very well that in both Bèlè [from Martinique] and Léwòz [from Guadeloupe], we find voice, music and dance, it's not distinctive to one area, we all have it, and in Africa it's the same. Everything comes together, tightens up, and this is what I can say about the work I'm developing.

L: This is amazing! How long have you been doing this? You have created a lot of shows.

C: We have ten shows with Difé Kako, we are celebrating our 20 year anniversary in 2015. The idea is to develop and to make the world discover the Caribbean throughout carnivals, balls, dance conferences. The company is about 40 people, with approximately 15 musicians, ranging from percussions, bass, accordion, harmonica, violin...The percussions are West African (Djembe), Caribbean (Bèlè \& Gwoka) and Central African (Ngoma). It's very, very, very diversified and [a] very large [ensemble]. What we find important is the use of a sense of humor. We try to write deep and serious shows while using humor, and not every show is written as such, but mostly are created to speak of important subjects, with a light touch in this world of brutes. [Laugh]

L: It is indeed reflected in your shows. Thank You. Is there anything you would like to add?

C: Thanks to you. The only thing I hope for, is to get the next generation ready, that the youth are interested to keep going and that my company will be around for a long time! 


\section{4. ...Farah Saleh | 11.05.2014 | Vienna, Austria}

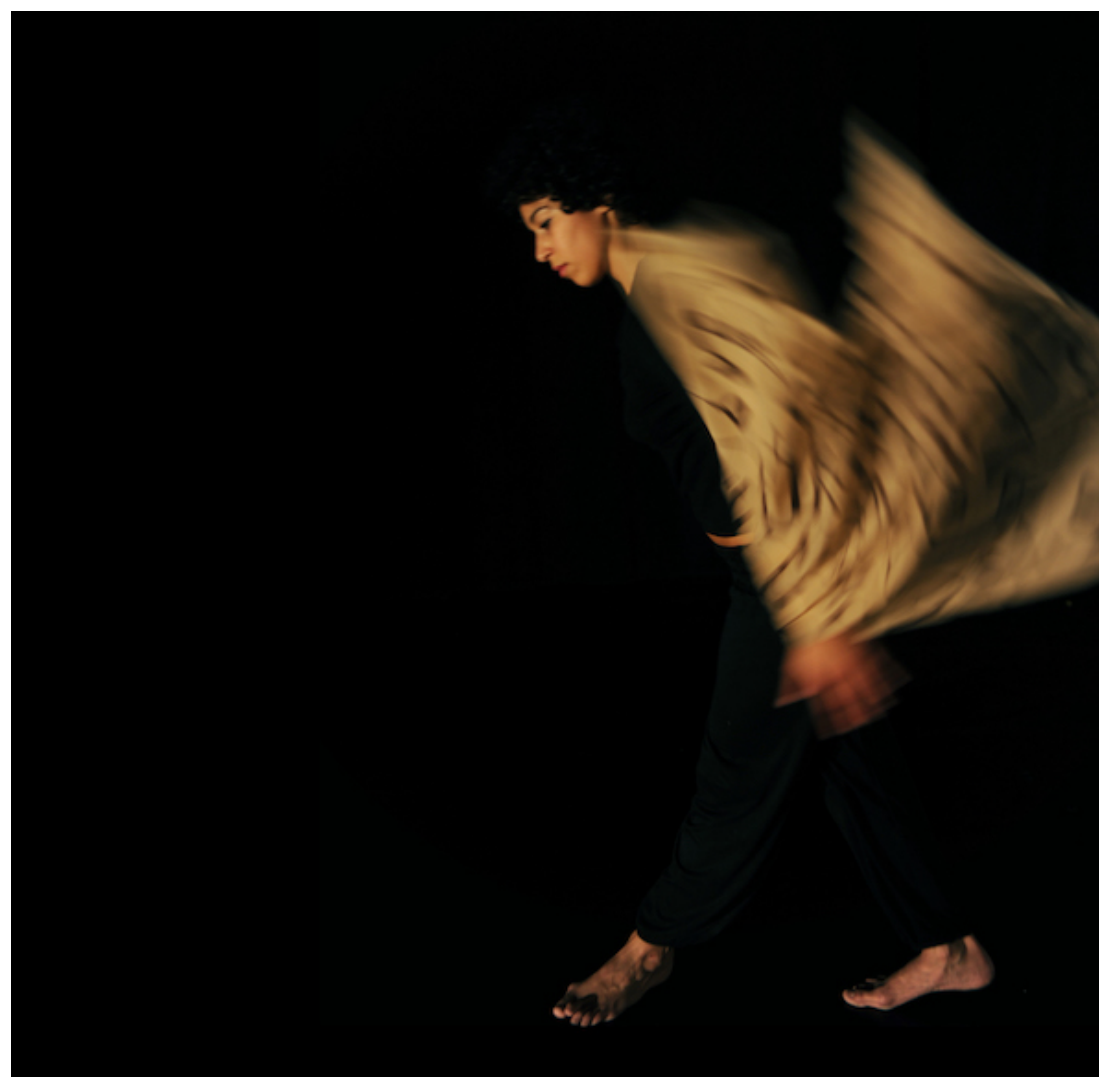

Farah Saleh. Photo: Shareef Sarhan 
Farah Saleh is a Palestinian dancer and choreographer active in Palestine, Europe and the US. She was born in Syria in a Palestinian refugee camp. She has studied linguistic and cultural mediation in Italy, and in parallel continued her studies in contemporary dance. She has been dancing and choreographing with Sareyyet Ramallah Dance Company since 2010, for which she created Ordinary Madness (2013) and Hana and I (2014). She also took part in and toured internationally with Keffiyeh/made in China (2012) and Badke (2013) co-produced by the Royal Flemish Theatre (KVS), A.M. Qattan Foundation and Les Ballets $\mathrm{C}$ de la B.

Since 2010, Saleh has also been teaching dance and coordinating and curating artistic projects with the Palestinian Circus School, Sareyyet Ramallah and the Ramallah Contemporary Dance Festival. In 2014, she won the third prize of the Young Artist of the Year Award (YAYA) for her installation A Fidayee Son in Moscow, and in 2016 she won the dance prize of Palest'In and Out Festival in Paris for the duet La Même. She is currently touring with her latest pieces Free Advice (2015), La Même (2016), and Cells of Illegal Education (2016). In 2016, she was an Adjunct Lecturer at Brown University's Department of Theatre, Arts and Performance Studies, and a Visiting Scholar at the Pembroke Center. ${ }^{14}$ Since 2017, she is a doctoral researcher in the Ph.D. by practice program at the University of Edinburgh, College of Arts.

www.farahsaleh.com

${ }^{14}$ Saleh, "Farah Saleh." 
Layla Zami: I saw a short video trailer of Ordinary Madness on the Internet and I was very touched by the performance. Can you tell us more about it please ?

Farah Saleh: Yes. We worked on Ordinary Madness in 2012/2013, it was a production of Sarrayet Ramallah, a company in Palestine with which I collaborate with since...2010 lets say. The idea of the performance was about the madness that the Palestinian people are living in, from the distorted social relationships that people are having, that are becoming very formal, without any life anymore. So that's why we use a lot of gestures from greetings, and daily life moments and relationships that are very distorted sometimes.

And of course we talk in a very subtle way also about political divisions, internal political division and also the Israeli Occupation in some moments, some jokes here and there. I feel that the performance was thought - when we were making it, me and the dancers - in a very light, light and deep but not in a somber way.

L: So you choreographed the piece.

F: Yes, its a piece by me, it's 50 minutes long, but I like to work with the dancers so there is a lot. It's me who gives the task, personally I think of states, or situations, I would like to see. But it comes through improvisation and tasks with the dancers so there is a lot of input from the dancers and then I put them together in a dramaturgical way so that it would make sense also for the audience.

\section{L: How was the feedback when you showed it in Ramallah?}

F: I showed it in Palestine, in Occupied Golan, in Italy. So in Palestine it was in the West Bank, in many cities and also in Jerusalem. The people liked it and could relate to it because it had lot of gestures and situations that they could relate to. They were interacting...there was also [a] little part where we had interaction, one dancer would go down and kiss someone from the audience and...people, yeah, didn't know what to do...and there were some more intimate moments...but...We thought that some things would shock the audience but somehow they were not very shocking, but the performance brought something new to the stage. So we had interesting reactions from the people. And also in Jenin, in Hebron or in other places where contemporary dance is not common.

L: Yes, because yesterday at the conference you mentioned that you inspire yourself from Palestinian styles but that you make something more personal out of it? 
F: Yes, this was not about Ordinary Madness, it was about Badke, its a BelgianPalestinian co-production, I dance in it, I am just a dancer so of course my input is there but Badke is a transformation of Dabkeh.

L: So in Ordinary Madness, you were not inspiring yourself from Dabkeh movements ?

F: Maybe not Dabkeh in general, but our daily life, Palestinian daily life, Palestinian gestures, greetings. For me, since I taught belly dance in Italy for a long time, its really in my body somehow. So it is there somehow in my style of moving...a lot of movements not only in the belly but with the whole body related to belly dancing.

L: I think "belly dancing" is a wrong translation into English, in French also. Actually it means Dance from the East or something. I think its just Europeans who called it belly dancing, no? Because it actually comes from the hips and the whole body.

F: Yes, it comes from everywhere in the body.

L: You were working with other dancers and you also work as a solo artist. What are the differences for you, how do you feel between working in a group and working as a solo artist?

F: I always had fears about working as a solo, because when I watched, or still watch solos, I feel "Wow!", you have the stage, you have to really be there, do things and be convincing otherwise its really boring or not involving.

My first solo was Parole, Parole, Parole and since the research was all about interaction with people and it was a miniature between 5 and 15 minutes, mine was 9 or 10 minutes, it wasn't difficult at all, I enjoyed it very much. Because there was this interaction with the people I didn't feel me performing for people, but I was being with the people and feeling things with them, and making them feel things, and they were transmitting things to me. So it wasn't as difficult as I thought it would be. It gave me a lot of liberty, freedom. So I liked it.

And working with dancers is also very interesting of course. Sometimes it can be very difficult, because its always about compromise, understanding the balance and knowing where everyone's role is, if its division or collective work...but I like it, I like [them] both.

L: So you want to continue working with both?

F: Yes. 
L: So you just mentioned Parole, Parole, Parole, for instance you're involving the audience, you send flowers to someone, what exactly do you want to reach when you interact [with] the audience, especially in different contexts? Because, as you mentioned in the program notes, this is about how difficult it may be to do something as easy in other contexts as sending flowers to someone, so when you present it here in Vienna, what is your artistic intent?

F: Yeah, for this miniature in general my intent is to make people feel this possibility of love, that very human simple thing that can happen when people are close. And how easy I can do it with people thats very close to me, me personally, and with the person I love... [across] this huge gap and distance, not really physical distance but political distance, where I cannot reach this person. And then from this intimacy, we go to the Skype chat, where for me it's...where people really look for intimacy to talk together, to cook together, or to have sex together but it's not real, there's no real contact. So yes, I intended to try to make them feel this.

But, personally, the Vienna audience are very difficult. For instance, I performed at least ten times in different countries. And the beginning here was difficult because people were talking...they were not staggered in the space like we asked them to. And so they lost the beginning, they missed it completely, this contact. I think, it's what I felt, that many people missed it. And then usually when I have contact with people, I can feel the contact. And I thought I was trying and...not many really continued having it. And then there was a technical problem with the technical guy, he missed the cue...so I had to change the end which didn't work as an end...but overall, I felt that the Austrian audience was particular...but that's fine. It's a new experience!

L: It's interesting because yesterday when I was thinking about the piece, I thought "Well, we're always talking about interacting with the audience, making the audience react" but of course you have to react to the audience so it's always...

\section{F: Both sides!}

L: Would you like to speak about Sandwich Labné?

F: It was the first piece where I was really a co-choreographer with other two dancers from Sarayyet Ramallah. We worked over eight months on this 40 minute piece, it took a long time because dancers at the time were not professional really, not technically wise but payment-wise and everything so they had to work or study, etc., etc. So it was about 
Gaza war. And we were making fun of the humanitarian aid that was arriving after the war and helping the embargo! For us it is helping, and still now, this humanitarian aid is just supportive to the colonial situation in Palestine. It's just a game, it's money...it produces money for them and it makes us more dependent so that we cannot really react and change the situation, it maintains the status quo. That was about it. And it was about the stories of two little girls in the Gaza war that were killed. So through the story, even if it was not narrative at all, but they were coming in and out these girls...dancing, there was no narration. We were eight of the company, it was kind of collective as well, there was a lot of input from everyone, and then we were putting it together and there was the artistic director of the company who was the actual director, even if he wasn't really present! Because it was his idea. The idea of the girls, etc. It was a very interesting process for the group itself, because we had a lot of discussions, not only about dance, but also about the political, social, is it really necessary this humanitarian aid that we have and...so it was very important to build the group, that's now still going. Not only as a group, we're becoming also more independent each one, but it really brought individuals to understand that context which is really important for me. We toured in Palestine, Occupied Golan, again and Jordan, Lebanon. That was Sandwich Labné.

L: So listening to you, I understand the dance as a form of resistance, which is what you are talking about in your conference, is not only for the audience but for you also, right, and for the participating artists?

F: Yeah, especially! That's why for me it's not only about dance production but also about dance education. So for me it starts since you're little, but even if you start when you're older, it's good, that makes you think and feel, understand your emotions more and the surroundings, so that you can change whatever you like, so yeah in that sense it works on the dancers themselves.

L: Because we were talking about the Occupation, and you mentioned that you subscribed to the Cultural Boycott, so how does this materialize in your working process or in your daily art, your daily work?

F: The boycott movement has been growing lately in the past years. And for me it has been bringing results back. Because some Israeli people are thinking about it, they're very worried about it. They're becoming very worried about becoming an Apartheid state which I think we already are - but now because of this movement, because of this campaign and because it is growing, the population in Israel is becoming worried and 
they're thinking - some of them - of changing the situation. Some are even boycotting settlement products - even though for me it's not the settlements which are the problem, or the only problem - but anyway. This is the boycott movement in general, that's economical. It's the Boycott Divestment Sanctions. But in it there is the Cultural and Academic Boycott Campaign and I subscribed to this one. And as much as I believe that art and culture can bring people together or build bridges, as much I think that when you tell people "No! We're not equal, we can not make bridges when we're not equal." and we make as if we are equal and as if things are normal, I believe this "no" can even change things more than these bridges that we pretend to build. So sometimes its tricky because you think "Ah, maybe, if I meet this Israeli artist, or if I see this Israeli performance" in Europe, because me as [a] Palestinian I'm not allowed to go to Israel, and in theory they are not allowed to come to the Occupied Palestinian Territories but they can. There is a small law that doesn't allow them but many Israeli friends of mine come, so it's just as if they don't really want to push themselves to go. Because for me I would be arrested for six months in prison. For them, nothing would happen because nobody has been caught and put in prison [for going to Palestine] since many, many years. But anyway, sometimes I question myself a lot, also. If it's not blocking things from developing. But when I see the results on the ground, I believe, no it's working this campaign, and even Israeli artists are starting to change. Some, yeah, are trying to do things on the ground. So sometimes the "no" also works, not only putting weak bridges or superficial ones.

L: You also organize a contemporary dance festival in Ramallah every year. How do you and participating artists react to the context of the Occupation during the festival ?

F: Since 2006 there is this Ramallah Contemporary Dance Festival which is an international dance festival, so it's Palestinian, Arab and international companies. 5000 international artists came to Palestine in these past nine years and they have been experiencing Occupation themselves as well. Problems on the bridge which is between Jordan and Palestine, it's the border, let's say, that's called the bridge. Problems in the airports, because they're coming to work with Palestinians so we send them invitation letters and sometimes they just take them for two, three hours [ofinterrogation], just because they are coming to dance...to Palestinian audiences. Nothing wrong, but it's a crime. Until now no one was sent back, only some Arab artists didn't get permission, so they did not come. So performances were changing, adapted, unfortunately, but we were trying to find solutions. So yeah, from the border, to the checkpoint that they have to pass, also their sets which they have to pass, sometimes it's a lot of problems, they open everything, they don't allow things, they do allow things, the Israelis...and the war, and the 
people, they see the situation, sometimes they visit refugee camps, that they have to cross, the main checkpoints which is Qalandia and sometimes on Fridays, there are some [...] clashes between young boys throwing stones and Israeli soldiers with really big guns and tear gas...so they see things with their own eyes. And they also meet Palestinians, for the first time some of them, so they don't see the Palestinian on the TV that they always see, the terrorist one or the one covered all over with guns, they see normal people, humans. That's a big step already.

L: I think that's also what's specific about dance, to challenge. What you're saying, TV images, all these things or other media they are giving us something and they don't want us to think at all. And what I like also about your dance is that it's abstract, as with all the choreographers that I am interviewing, they are telling very concrete things but in an abstract way, so that it's more complex. Once I go home, I still think about the performance or maybe I interpret things differently. So this is exactly what the project is about, to show that dance can be empowering or that it can change perception. You also mentioned, when someone asked a question in the conference, you said "Yes, I am talking about Palestine, but also people can see other stories," right, they can project, for instance you said that in Italy some people had different interpretations...

F: Yeah! Also they could relate to the stories of relationships that we were talking about, between men and women, between two men, two women, between a group of people, about superficial greetings and superficial circumstances we sometimes put ourselves in. So yeah, also the emotion that the performance transmits, you feel something, you live a process and you feel the emotions, it's not a final product, you act on emotion, so people feel the emotions themselves, and emotions are universal, not Palestinian emotions and Italian emotions!

L: The last question would be, in which ways does your autobiography, well of course you already talked about your daily context but maybe your autobiography in the sense of the places you lived in, in which ways does it reflect your dance on stage?

F: Well, I was born in Syria, then grew up in Jordan. I lived the first five years of my life in Syria and then seven more in Jordan, and then seven more in Palestine, and then seven more in Italy, and then back to Palestine, but in the period between 2009 and 2014, which are five years, I had a base in Palestine but I had many months also in Europe, in France and in Belgium, and sometimes also in Italy. So for me this kind of continuous movement makes me feel a citizen of the world. I am very much connected to Palestine, 
because it's a cause, so I want Palestine to be free, for its people, and I'm part of its people also, but I believe once Palestine is free, I come back only to my idea of [a] citizen of the world, so I can then go live in Japan, or in India, or...because I feel this world is owned by everyone, not by certain persons, populations or nations. And this is very much reflected in my performances. Because I feel that I am universal or a citizen of the world. As I said before, on the gestures that I use, they come really from daily gestures that you can see on the streets here in Vienna or in Palestine. Same for the situations. It's also because I lived all these situations everywhere and I feel that they exist everywhere and people everywhere are really the same with the different causes that they live for and dedicate their lives for.

L: Thank you, is there anything more you would like to say?

F: No...good luck for your research. 


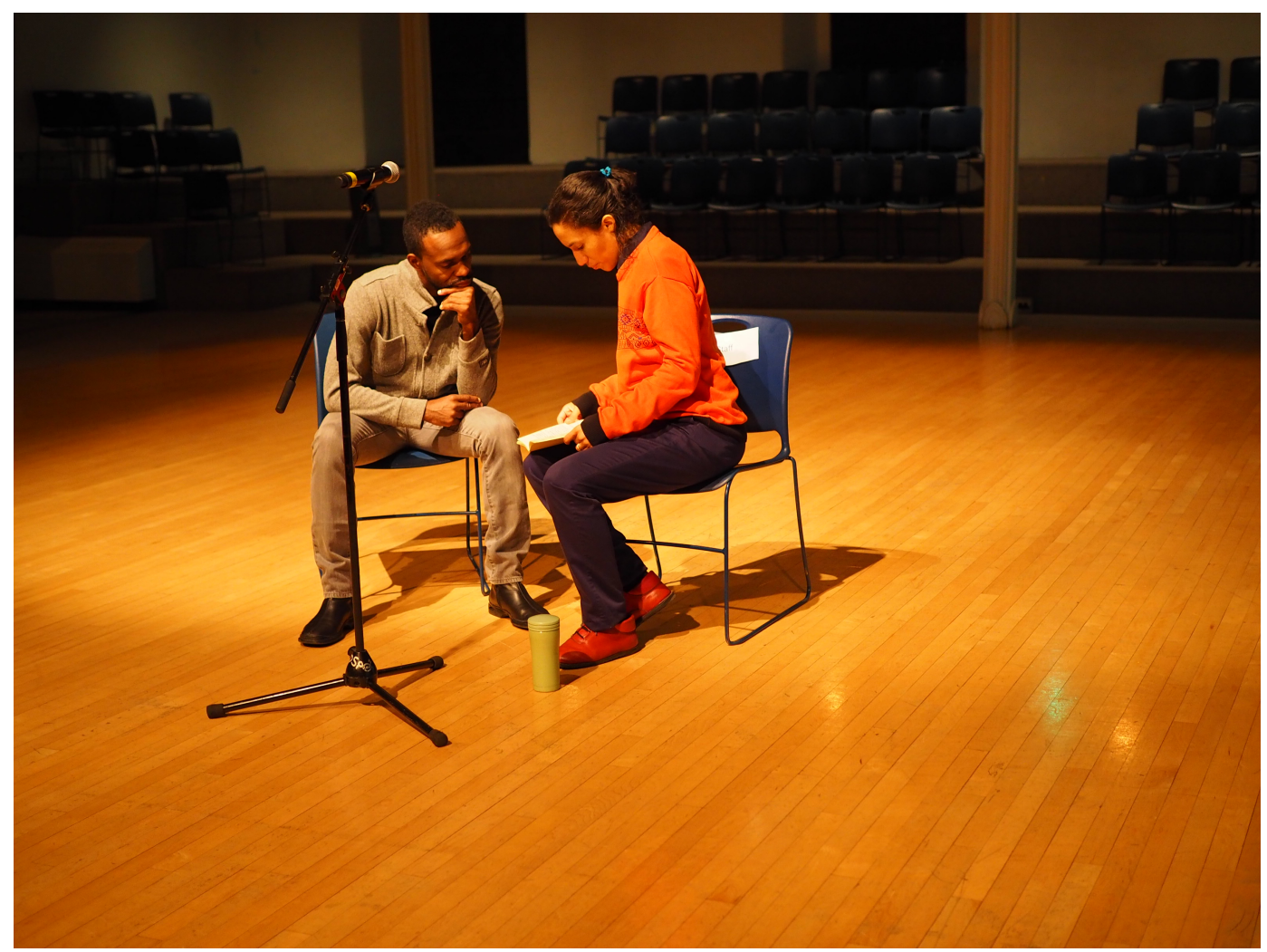

Layla Zami preparing a pre-show discussion with André M. Zachery.

Danspace Project, St Marks Church, Untamed Space premiere, New York, 30.09.2017.

Photo: Oxana Chi 


\section{5. ...Zufit Simon | 30.06.2014 | Berlin, Germany}

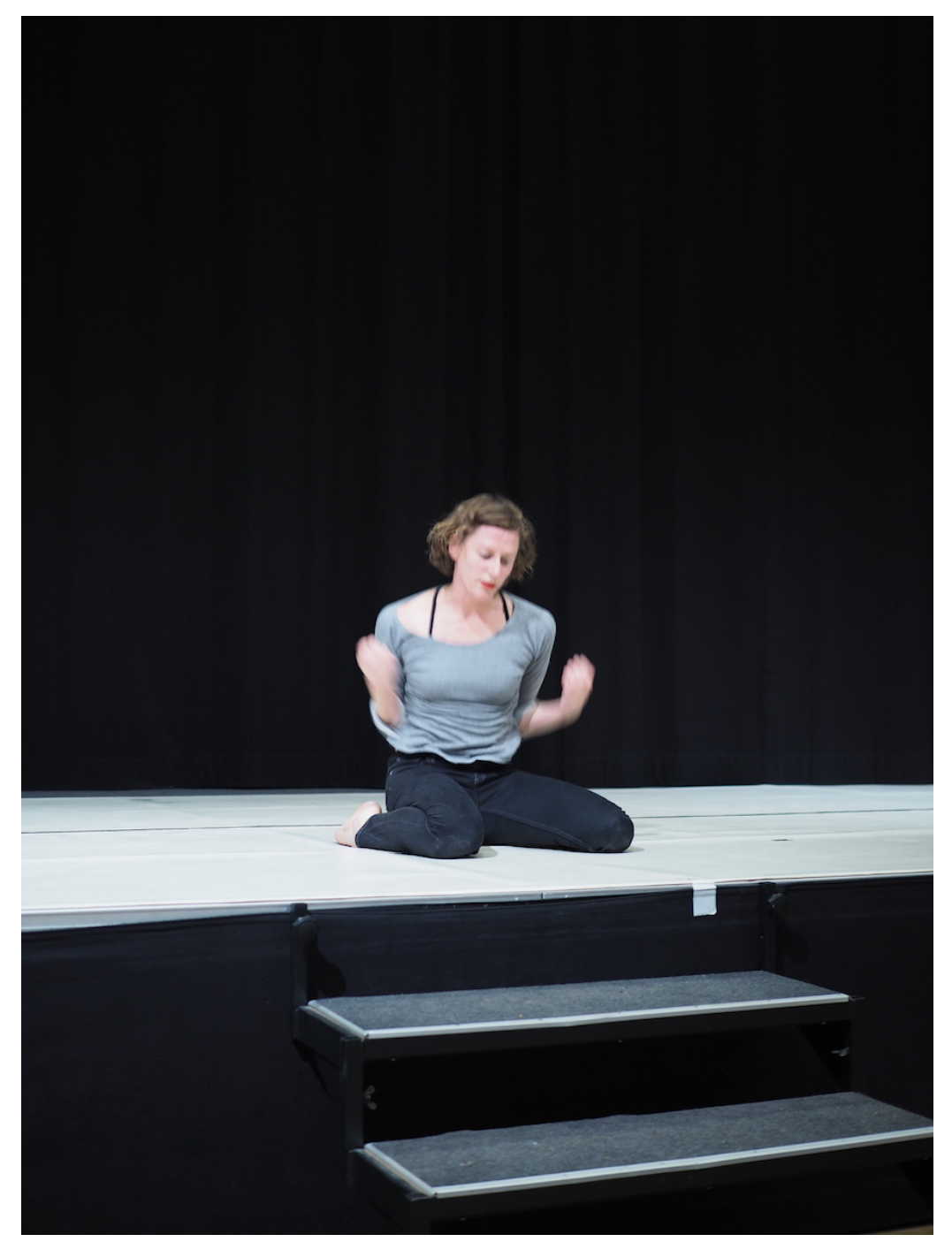

Zufit Simon in all about nothing. Moving Memory Symposium-Festival, Berlin, 21.10.2016. Photo: Layla Zami. 
Zufit Simon is a German-Israeli performer and choreographer born in Israel, living in Berlin. She studied at the Amal Alef Performing Arts School in Israel, and graduated in Contemporary Dance at the University for Music and Performing Arts in Frankfurt on the Main, Germany.

In 2005, she won the third prize of the euro-scene Leipzig for the best German dance solo with fleischlos, and the third prize of the International Choreographers' Competition in Hanover for Meine Mischpuche. Her awards also include the Best German Dance solo (Euro-Scene Leipzig), and the Audience Prize (Vorort-Festival Münster).

As a performer, she worked with Anja Hempel, Christoph Winkler, Marco Santi und Sommer Ulrikson. She has performed at international festivals in Italy, Austria, Tanzania, Poland, France, Czech Republic, Russia and Germany.

In Germany, her work was shown among other places at the festival Tanz im August and selected twice for Tanzplattform Deutschland. She was invited to the German Dance Platform in 2012 with Wild Thing and in 2014 with I LIKE TO MOVE IT. In October 2015, she opened the season of the Theaterhaus Jena with director Moritz Schönecker and the production Die Zofen. Her solo work has received funding from the Hauptstadtkulturfonds Berlin and the Berlin Senate. The piece all about nothing was in residency at the Munich Tanztendenz, as a part of her trilogy un-emotional about the relation between body language, expression and gestures.

www.artblau.de/Simon.html 
Layla Zami: Memory plays an important role in your work, for instance in the piece Meine Mischpuche, you processed your family history in relation to the German past and present. Can you tell more about it?

Zufit Simon: The piece Meine Mischpuche is about relations. Foremost, family relations and memories are a way to produce the piece. Memories are like a bag of emotions that we carry everywhere, no matter where we go, whether we are sleeping or awake...[Memory] is what we always take with us, [it] influences our character, how we act, react. That is something one can never let go of, never get rid of. Meine Mischpuche deals with the chain reaction of emotions within family, about how fragile family relations are. It was a fascinating process, with two other dancers, and it was also a very intensive process, living and working together for about ten weeks. During the process we worked with approximately 1000 [clay] eggs, that somehow contributed, that broke in pieces and are also very fragile. That was also a very exciting process.

L: How long was the work process?

Z: The process was about ten weeks, a long phase of "ups and down."

L: When did you decide that it would be a group work? Did you know it from the start?

Z: I knew from the start that this piece, Meine Mischpuche, would be a group piece with two more dancers. I come from a family of three children, I am in the middle, the "sandwich-child," so it was clear to me that I needed two more dancers to even be able to create different constellations and relations to and with each other. The process ahead of the rehearsals was long, a long preparation process and research. For a long time I had wanted to produce a performance about family relations and about my family story.

L: How do you work in practice? When you have an idea, before collaborating with others, do you improvise in the space?

Z: I started by doing research, I got a stipend for this production and I flew to Israel with a photographer. We interviewed and photographed various people in my family. We also confronted diverse people. It was enthralling to talk about things that were never spoken of before. Very slowly, like an onion peeling, we uncovered layer after layer. My father and his sister talked about memories from their childhood, things they had never discussed before. It was exciting, but also very fragile. 
L: The dance generated change, because you found out through your research what you did not know of before. Did it trigger a new perception, a deeper perception maybe in daily life of how you deal with emotions?

Z: Actually not, it is just a bag that you carry everywhere with you. But my grandmother and grandfather came to the performance, my family came specially from Israel, it was also very interesting and exciting for them. For several months later, they kept discussing it, actually talking about what they had exchanged with each other in the interview. [Laughter].

L: Last month I had the chance to see your solo all about nothing, it was the premiere. This is also about memory, as you wrote in the program notes. But different kinds of emotions, it seems to me...

Z: The solo all about nothing handles emotions, mostly emotions. Memories are actually just a way to create diverse situations, diverse images that inhabit us...our minds...from our childhood or daily life, or emotions that we witnessed in other people. The solo deals with various emotions and moods that slowly rise up and slowly shift. The emotions result [from] the various moods that were developed slowly, that may be interrupted. It is about how emotions may be manipulative, in me, or in the audience.

L: I felt that strongly, because at the beginning, there was a party atmosphere, but then it changed, toppled over, and I did not know exactly when.

Z: The music plays an important role here, the music is consciously also very manipulative. The relation, the gravity between dance and music changes constantly. The music is not only in the background, sometimes the music generates various images that appear and disappear, and so is the dance: it generates images that slowly appear and disappear, the atmosphere switches from one instant to the other.

L: How did you collaborate, did you develop the choreography with music from the start?

Z: The musician accompanied the process quite early, we had a lot of discussions, exchange of ideas, we experimented a lot, in order to use the music consciously as a manipulative tool in some moments in the piece, but not only. We just researched into 
various moods of music. It was a very intensive productive collaboration with the musician Robert Merdzo, we kept working until a few minutes before the dress rehearsal.

L: And now on stage, is there some improvisation?

Z: Some aspects are composed, predetermined, and some are improvised, and it depends on the mood and the moment. Because the piece deals with emotions, one can not pinpoint "after three seconds, you start this and that," or that kind of cue. The perception of temporality can be stretched. There is also a part where we constantly react to each other, like a ping-pong effect between us. I take in some aspect of the music, the musician takes on some of my mood. It keeps going back and forth.

L: We talked about your pieces Meine Mischpuche and all about nothing. How does your solo work differ from group collaborations, in general?

Z: In solo work, where I am myself on stage, communication flows totally differently. I can directly implement, try out something and reflect with myself in the moment. [When] working as two people, then it is also direct communication, "one-on-one," but also the first level of exchange; three people is already a small group. Then there are various elements, various levels in the way one transmits something. Which moods are in the group? Which constellations are there between three people? There are various interpretations and variations. There is not only the work itself, but also the communication and how it flows, which also makes the process productive, rich, and exciting.

L: Is three a difficult number? You also choreographed duos...

Z: Three is already a small group. It is no longer one-on-one. From three onwards, the communication flows like this [hands draw a zig-zag]. Someone understands this way, the other one that way. There are all kind of possibilities.

L: Maybe we can also discuss your solo ich(a)? In this piece you deal with gender stereotypes and you question societal norms of being-woman or being-man, I found that interesting, can you say more about it?

Z: I was in a very long process, for several years I wanted to work with the theme. It was mostly about self-perception: how is one's own body and how is it perceived by society, what is seen as feminine, what is seen as masculine, what is seen as erotic, 
which body parts are erotic, what makes a body erotic. It also relates to media, fashion, different cultures. ich(a) is one of the works that matters the most to me, because it is a theme I have been dealing with for a long time and that had to "boil" for very long, until it could reach the stage, or even the rehearsal room.

It deals with the body, and disassembles it to the basic: flesh. The audience's reception varied strongly between [cis]-men and [cis]-women. I performed it several times and received different feedback each time. The light design allowed me to really watch the audience's faces.

It was a collaborative work with video artist Carlos Bustamante. On stage there were four big flat screens. The piece really deals with body, flesh and blood. It deals with human beings, and their various cognitions, and at the same time I show something personal and see how the audience reacts. I was very surprised by how the reactions differed between [cis]-men and [cis]-women. Many women identified with the piece, with what happens on stage, with the question mark, with the question of what and how one feels as a human being, as a woman, and their body. And the men...for many men it was difficult to watch the piece, to confront me, the body and the flesh.

L: So it probably means that the piece was a success, if your intent was to destabilize and show how gender may be a societal construct.

Z: Yes, well the piece does not contain a statement in itself. It is a question mark. And I had not guessed that the reception would be so different in terms of gender.

L: Where did you perform it?

Z: I performed it here [Uferstudios, Tanzfabrik Berlin] and in Braunschweig and Hannover. Later I performed it again in Berlin. Because my pieces continuously develop further, the process does not stop at the premiere, it is continually developed and reflected further from one show to the other. Therefore the last performances in Berlin were very strong. And also within me many things developed further.

L: There is no spoken language in it, right?

Z: No. It was a conscious choice to not use language, because otherwise it relates directly to a specific culture or country. In the solo all about nothing, I clearly use text and voice, and create various layers...between body language, voice, text content, and facial expression. It all piles up and the elements overlap. They do not create one common image, they do not complement each other, but rather overlap with diverse requirements as a background. 


\section{6. ...Wan-Chao Chang | 05.09.2015 | Taipei, Taiwan}

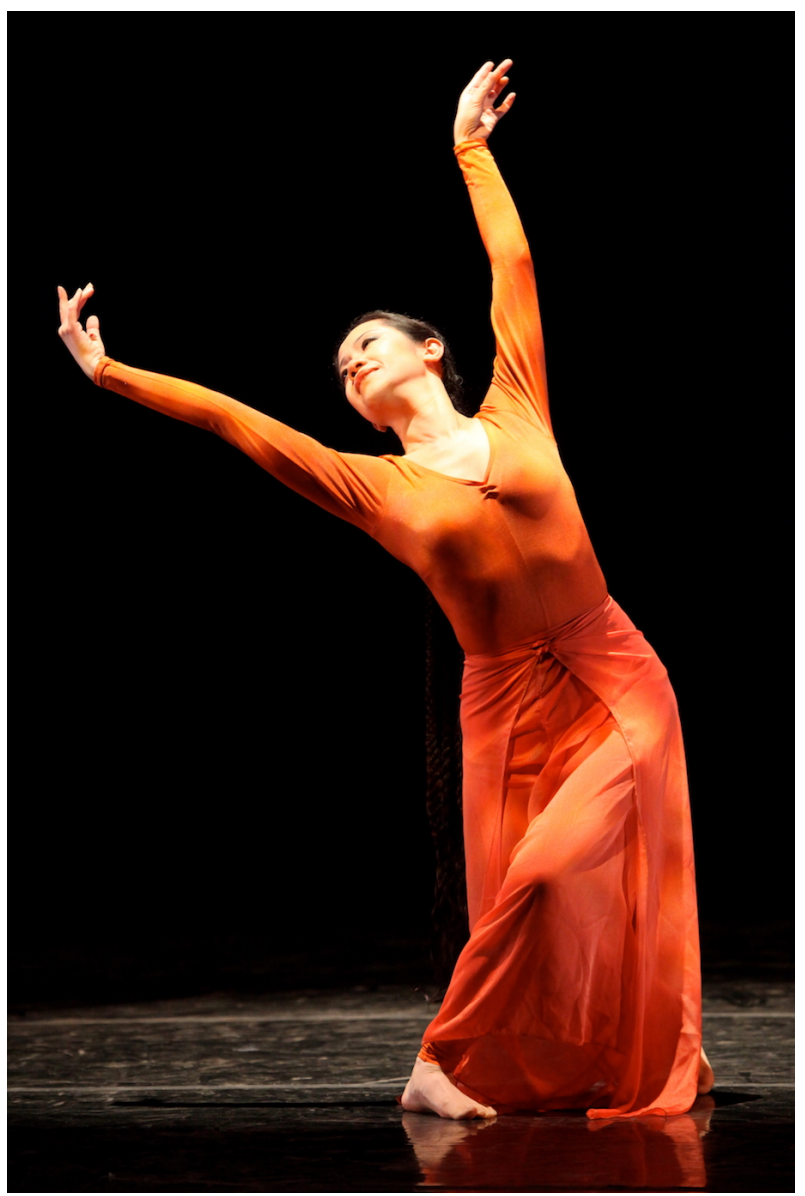

Wan-Chao Chang. Cowell Theater at Fort Mason,

San Francisco, 2011. Photo: Juan Carlos Pometta 
Wan-Chao Chang is a choreographer and dancer who was born and raised in Taiwan, where she is now based. She founded Wan-Chao Dance in 2008, a blend of many virtuoso dance disciplines, giving them a unique character. The company performed at West Wave Dance Festival, San Francisco Ethnic Dance Festival, Cultural Encounters at the de Young Museum, Festival of the Silk Road, Consulate General of the Republic of Indonesia in San Francisco, and Eve's Elixir. In 2010, she received a nomination for Outstanding Choreography by the Isadora Duncan Dance Award (Izzies) for the work Follow the Footprints.

Chang studied music for ten years in college, and studied Chinese Dance at the Guang

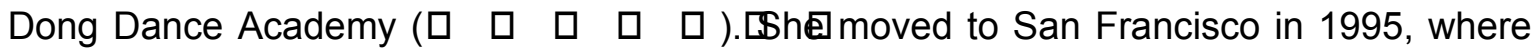
she graduated with a BA Magna Cum Laude in Dance Ethnology (1999) and an MA in Creative Arts (2001) from San Francisco State University (SFSU).

Chang performed with EMBAJE dance company (currently San Francisco State's University Dance Theater), Gadung Kasturi Balinese Music and Dance, Lestari Indonesia, and Gamelan Sekar Jaya. She was also a principal dancer of the Chinese Folk Dance Association, and a founding member and lead dancer at the Harsanari Indonesian Dance Company. As the Dance Director of the Westwind International Folk Ensemble (20002002), she performed throughout the San Francisco Bay Area. In 2005, she joined Ballet Afsaneh as a Principal Dancer, and toured internationally in venues such as the British Museum in London, Museum of Fine Arts, Houston, and in the Persian Iranian New Year Parade in New York.

\section{www.wanchaodance.com}


Layla Zami: Please introduce yourself.

Wan-Chao Chang: Sure. My name is Wan-Chao, last name Chang, Wan-Chao Chang. I call myself an "ethnic contemporary dancer." I founded Wan Chao Dance about, let me count...about six or seven years ago, in 2001 in America. And I was very fortunate to dance and work with many different talented dancers and put [together] some choreographies. Why did I call it "ethno-contemporary?" It's really interesting that I have been learning many, many different styles of dance, because I really am interested in different cultures and their traditional dance. But they have so many different dance vocabularies and body styles, so after dancing [for] about ten years other peoples' dance, I started to think, "What's my own dance?" At that time, there was a dance term, "fusion dance," which started coming out. But I think the dance I want to make is not only a fusion. The dance I want to make, deep inside, is rooted in traditional dance movement, but giving a different meaning, a more contemporary meaning. So I was looking for the terminology - how do I call my own dance style? Because when people asked me "What kind of dance are you doing?" I didn't know how to answer. Actually my husband, Bernard, helped me to find this term, "ethno-contemporary." So I kind of call it "ethno-contemporary dance." And since then, it's been very abundant, and I feel very blessed and, should I say, I've been neutralized with different cultures and many dance communities. Yeah! [Laughter]

L: You mentioned some styles you were learning or cultures you are interested in. Can you name some?

W: Oh yeah, there's a lot, actually! Let me see...Like a lot of kids, I took some dance classes, but very simple, like movement, or so-called ballet, and a little bit of Chinese classical dance. In college here, I started to very seriously learn ballroom dance international style, and I had very, very good teachers. I really appreciated it because I learned a lot. The couple dance, the connections with the partner. But you have to risk you have to dance with another person. What happens if you don't have another good partner to dance with? And so I felt there is something else I want to try. Until there was a day I was invited to perform ballroom dance in a performance. That was an international folklore dance performance. I saw that - wow, there is abundance, there is a Filipino dance, a Balkan dance. So from that time I started to - I was very hungry - take all kinds of dance, and learned Bulgarian, Romanian, Hungarian, East-European, Malaysian and Filipino. Just a little bit. Everything just a little bit. And then, in order to be a good dancer, I started to go back to the ballet... 
L: Did you also learn Iranian dances?

W: Yeah, that's right. That I actually did when I went to America. When I went to America I entered this dance ethnology program. I started to take Indian dance, because there's many dance styles I was very interested in, but it wasn't available in Taiwan at the time. So when I went to America, in addition to taking Flamenco, Indian Dance, Modern, and after class I went to take dance like Russian, Ukrainian, and Indonesian dance. After school, after graduation, I also performed with a Central Asian dance company. I did a bit of Tajik, Iranian, and Afghan and Uzbekistan, that kind of dance. But of course I still continued doing Indonesian dance, because it's very beautiful, and there are very, very articulate dance movements from Indonesian dance. So I think that's my main source: one is Indonesian dance, and another one is Central Asian dance. And probably a little bit of Chinese classical training!

L: Yes, yes it is! I don't know many people with such a great mix.

W: There are actually many of them. But most dancers choose - when they try different styles of dance, they pick the one they really like, and that they feel really touched their heart, and they really devote [themselves] to it. But I was too hungry! [Laughs]. When my Kathak teacher told me, "Oh, you need to take ten years to master it," I thought "I don't have ten years!". I want to take these ten years to do different things as well. So [I have a] lot of influence from different dance styles.

L: And actually I can see this in Keep Her Safe, because they're using several vocabularies.

W: Right. Keep Her Safe is a piece inspired by an incident happening in Indonesia. My parents were born and raised in Indonesia, and later on they moved to Taiwan. So there is some experience - the culture, the history that they are familiar with. When I was a kid I wasn't really connected, until I was an adult, until I was away from home, then I finally got the opportunity - the desire to trace the roots. Of course, I found out - my goodness, I have so many roots I don't know what to pick! But that story really inspired me, that accident that happened. There were two waves of anti-Chinese movements. I wanted to make a piece, not particularly to describe the history of the accident, but a piece inspired by the conflict. Not only by conflicts, but also by peace that we actually can make. Because after 9/11, when I was in America, I really saw a lot of splits. I was struggling - of course we are different, but we are the same, too. We share the same earth, but why do 
we see differences more than we see the similarity? And since then, I started to find the vocabulary that can connect individual cultures. Why did I choose the Indonesian for that piece? That's because at that time, I danced a lot of Indonesian dance, and my dancers were interested in it. And I was very fortunate to have a Gamelan Indonesian musician and Indonesian dancers to work with. That's a great resource! That's why I used Indonesian movement. But I also worked with many different dancers who had never learned Indonesian dance. They came from different backgrounds. That's why for that piece, not only Indonesian dance and Chinese - the main inspiration - but also some other material developed, inspired by those various dance vocabularies. Or the prop, or the music, or whatever they can think about.

L: So you didn't start alone yourself in the rehearsal room? You started from the beginning with people? Or you first started alone?

W: That's a very interesting question. Because usually I choreograph very slowly. I try not to waste my dancers' time, so I try to choreograph some movement before [rehearsal]. But I also realize that - coming from the modern dance class - dancers play a very important role in the creativity process, and it's a powerful resource. It would be such a waste if you don't have space for them to develop. Because what they come out with might be a much better surprise than what you have in mind. So actually there are two ways: I try in the beginning of the process to make the piece, to do a lot of improvisation, or creative exercise, to try to encourage them to come out with something: some gesture, some movement. Or to utilize different props, or space, or interaction with other dancers. That's one way. And another thing is, I try to come up with some movement and teach them, to see how they can take it. Because for dancers who never learned those traditional movements, the result is very different. After I teach them, I have to quickly adjust and find out - how can I make them feel comfortable with this movement? And also not only fit them into the movement I choreograph, but develop the movement to become theirs. That's actually a very challenging process, but I really enjoy that because the result is different from what I had in mind originally. But it has more spice, more...how do I say it? More feeling than what I originally created, so it's good. I also think for the improvisation process, for the dancers it's actually very interesting, because in traditional dancing - we usually just learn steps, we just copy in the beginning. Especially for Asian dance, or the dance that I am familiar with, usually you learn [a] specific dance style, you have specific dance steps, and you don't have much space to improvise. So it's very interesting to see how ethnic dancers struggle with the exercise. But you can tell that when they start to explore the possibility, you're happy for them. Because you see they 
already go beyond the boundary, go out of the box. You see them actually start to develop their own things. I feel very happy that after we work together, some dancers actually start to develop their own form of choreography, or start to do their own work. I think that's really very fruitful. I think that's the creative process - usually not only about my creative movement, but also to do some exercises with dancers to see what's coming out, and then put it together.

L: The solo I Thought Here Is My Home, you mentioned this before we started recording, is a part that could almost be independent from the whole piece, right?

W: Right. Yes.

L: It's your solo, I could say?

W: Yes. I've just combined a solo and a group piece.

L: Oh, the group is also still a part of it?

W: Yes.

L: So I really like this image at the beginning...

W: For the solo work?

L: Yes. The circle. Okay, I don't need to say my interpretation now [laughter], but I could really relate to that, this idea of home, and that you could transport it or take it away. So maybe you want to say something about this. And also about being a solo dancer.

W: Right. I start to answer the first question about identity, home and roots. As I mentioned before, my parents were born and raised in Indonesia, so they moved to Taiwan, but since I was a kid, we have never been identified as Taiwanese. So there was always some division. We have a home - my parents have a hometown in Indonesia, and my hometown is supposedly Taiwan, and I do believe so. But for some reason, people, some people don't really recognize it. It's a very complex issue. I don't want to say it's right or wrong, because there are many aspects from a historical point of view. But from my personal experience at that time, when I was a kid, I was still searching for "Where is my home?". Because it's not China, it's not really Indonesia, and is it Taiwan? Yes, it should be, right? And then I moved to America and became a foreigner, they called it "alien!"

L: Yes, they also called me an "alien."

W: Right! And I devoted many years over there, a lot of my professional network is over there. But still, I was called a "foreigner" and I couldn't stay. Also when we go abroad, people ask us "Show your cultural dance. Show your culture," and then I start to struggle. My culture? Should I show Chinese dance? Well, I'm ethnic Chinese. But I'm not really 
coming from China, right? Should I show the Taiwanese aboriginal? Well, I'm coming from Taiwan, but I'm not aboriginal! Where's my culture? So it was a struggle at that time for me, because I was still searching for roots, and there is a stage where I recognized that, well - how do you define culture, actually? It's the environment I grew up with. Taiwan is the place I was born and raised, [where I spent] spent 30 years before I moved to America. In America I spent 15 years, and in the meantime, I spent a lot of time with different ethnic groups. I danced with them, I dined with them, I played with them, so they are part of my culture. I feel that it's very difficult: I have to split myself. You have "It's your culture" or "It's not." So on stage, "Where is my home?" is the beginning of the process, because I feel that I've always been an alien." At that time I was searching, where is my home? In that piece I feel a little bit lonely, and use a lot of material from Indonesia and China. That was actually the beginning of the source for Keep her Safe, Please! I usually start from a very small piece, and put it together and develop it further. Where is my Home actually is a solo development. Later on, another part became a group piece. The group piece actually works with a live percussionist, and it's very powerful. What I want to say is that, after a journey of searching for the roots, or trying to find the answer, or trying to find what's right or wrong, Black or white, I just want to embrace the colors, embrace the diversity, and just recognize that I have the strength, no matter where I come from. Those are elements which enrich me. In the group piece, different dancers start developing from a solo, until the break. A long tail starts to build up until you can say it's a celebration...different groups just merging together and...bump!

L: We were talking about music just now, so Keep Her Safe, Please! was your first experience working with live music?

W: Not the first time, but it's the first time I created a piece starting from scratch. I mean, the music is basically from scratch. Because I used to work with live music, but basically already composed. So I set the choreography on the composed music, but Keep Her Safe, Please! was the first time I worked with a composer to try to build music for that piece.

L: And you put together Chinese drum with Indonesian Gamelan?

W: Oh yes, right. Those are the two main ethnic groups for the theme. Then I realized, they are all percussion instruments! It's quite interesting, we did not worry about rhythm, that was a good experience. There are so many ways and so many different styles, and the musicians all work differently. 
L: Very different rhythms also, right? The Gamelan music...

W: Very different.

L: Was it Gamelan from Java, or Bali?

W: The instrument is Balinese Gamelan, but the composer [Midiyanto] is Javanese. Midiyanto tried to compose music particularly for the Balinese Gamelan, but with also a flavor of Sundanese, Javanese, or Balinese. I like the composition, it's very beautiful. [...]

L: Talking about your solo, Impressions, would you like to tell us more?

W: Sure. Impressions is a new experiment for me, because it's my new solo work, with another musician who also composed the music. It's also a piece that I created after I moved back to Taiwan. The work environment in Taiwan is very different from America, the Bay Area I used to work in. So when I first came back, I had a hard time to restart, because I didn't know many people here at that time...unlike in the Bay Area, where I had a whole team, a whole cast, a crew I can work with, where I didn't need to worry about stage management, or sound engineer, or lighting designer. But when I moved back to Taiwan I wanted to do something. Even though I came back home I still felt lost, because I felt that my mind and my mindset were still in America. Which is a very strange feeling for me, because I am supposed to feel that I am comfortable here. But I was actually not, and I realized that, after 15-16 years, there is a lot of memory in the past that I couldn't let go of. And I still think about that. So Impressions is a piece where I try to recall those memories from the past, the different segments. It intends to put them together, to call back the memory...like an album. That time, by coincidence, I had the opportunity to work with the musician Klaus Bru, to create this "memory" environment or atmosphere. I feel that in terms of movement, maybe it's a little bit traditional, but with the music, it is a new concept, segment by segment...it's a kind of experimental work for me. I am glad I did that, because after I brought back those memories, now I can say, "Good, I'm glad I did those." And I can move on to try different things.

L: It's awesome. Really great.

W: I finally bring it back to memory? [Laughter].

[...] Solo work is not easy. Especially for the Fringe Festival, you don't have much time to set up. You have to consider your constraints with the set up time and strike time. So you can't really do things as desired. And how can you retain audience attention for 40 minutes? It's very challenging to me. After that I was just exhausted! But actually, 40 
minutes is quite a long piece for solo work. Oxana's piece [Neferet iti] is also 40 minutes, right?

L: Yes, this piece is 35 minutes. She has other pieces which are even longer, like 60 minutes. Indeed, you have to get used to the venue, and exactly like you say, you have to get used to the context, especially with the lighting.

$[\ldots]$

I could really relate to what you were saying about being a migrant, and always feeling "alien," and all of these things, because I have a similar - maybe completely different history - but my family is also mixed from many places, and also I travel. It's interesting what you say about Taiwan, because my family partly comes from Germany, originally part of my family, [which] was Jewish. But now I moved back to Berlin, and my grandparents were German, but I don't feel German. But when I am in France, I also don't feel French. So I could really relate to it, and it's also why I like your dance because I could find my own stories inside it, or [l could] relate to your stories.

W: Yes. I think it's a struggle, because of course you can always say "Everywhere is my home," but deep inside, you always have that question. Also, how people really accept you for who you are - that also matters. At some point, I thought San Francisco-Bay Area was my home - but that's a basic fact that I couldn't stay. I am still a foreigner! And here, after I came back, I still feel that I am a stranger too. A lot of things are still new, or I can never be used to [them] anymore. So I think this constant journey to find inner peace, it's...it's still a topic, it's still a theme that can be developed a lot. Especially in Taiwan, there are so many immigrants here. How do they define, how do they see themselves in a different country. Do they feel that they abandoned their culture? Or how do they embrace their own culture? It's very interesting how a lot of immigrants, when they travel abroad, keep their tradition. They don't want to touch it. It has to be that way.

L: But even the story of Taiwan, right, people come from many different places in China. So I guess it's also - I always feel like here, it's kind of a mix of people.

W: It's a mix - actually it's a mix. "Are you Taiwanese?" That question is always a little sensitive. Why, why do you ask this question? It's just like asking people "Are you American?" I mean, we are human! [Laughter]. We live here now, we do our work here, we contribute ourselves here, so we are local. So why do we have to divide ourselves into differences. But unfortunately there are still differences, there are still conflicts. I think 
people are scared of the unknown, that's why they exaggerate the differences, and they are afraid of that. I think I want to see the similarities.

L: I like that you say that. And I think that dance can bring people together a lot, you know?

W: I hope so.

L: For sure. I believe so.

W: If music can do that, why not dance? It's just a different medium. Some people use artwork, and painting, and dance can be too. We all have [a] different vocabulary, so how can we use this vocabulary to build a sentence that both of us can understand. And both of us feel the same - maybe we don't see this exact same pattern, but the meaning is the same.

L: We understand the same.

W: Right. For dancers, the good thing is: they don't have a language barrier. So I think that's one of the powerful languages we can use. For the diversity, I think it can be a blessing. And also for myself, for example, even though I learned many, many dance styles, there are still certain styles I am more comfortable with. That's my body memory, that's the source when I choreograph movement. But I also like to take different classes, or seek different inspirations, or music, and try to help me to think out of the box, and to develop, to come out from this memory.

$[\ldots]$

W: I try [to deconstruct the dance]. The method I try is: after having this movement, I try to use a different music. Or just no music at all. I force myself to come out - to keep my memory for a certain stage and move on to find different things. It's...how do I say it? Not an easy journey, but when you find something different that belongs to yourself, I think it's a treasure. So, when I think back, I am really grateful for having this opportunity to put [together] those works with those dancers who are open-minded and willing to work with me, and also with those musicians, willing to take risks.

L: But they are also lucky that they worked with you, right?

W: Yeah, I hope so! [Laughter].

L: I like what you said about the treasure. I like that. Memory and treasure. 


\section{7. ...André M. Zachery | 01.12.2015 | New York City, USA}

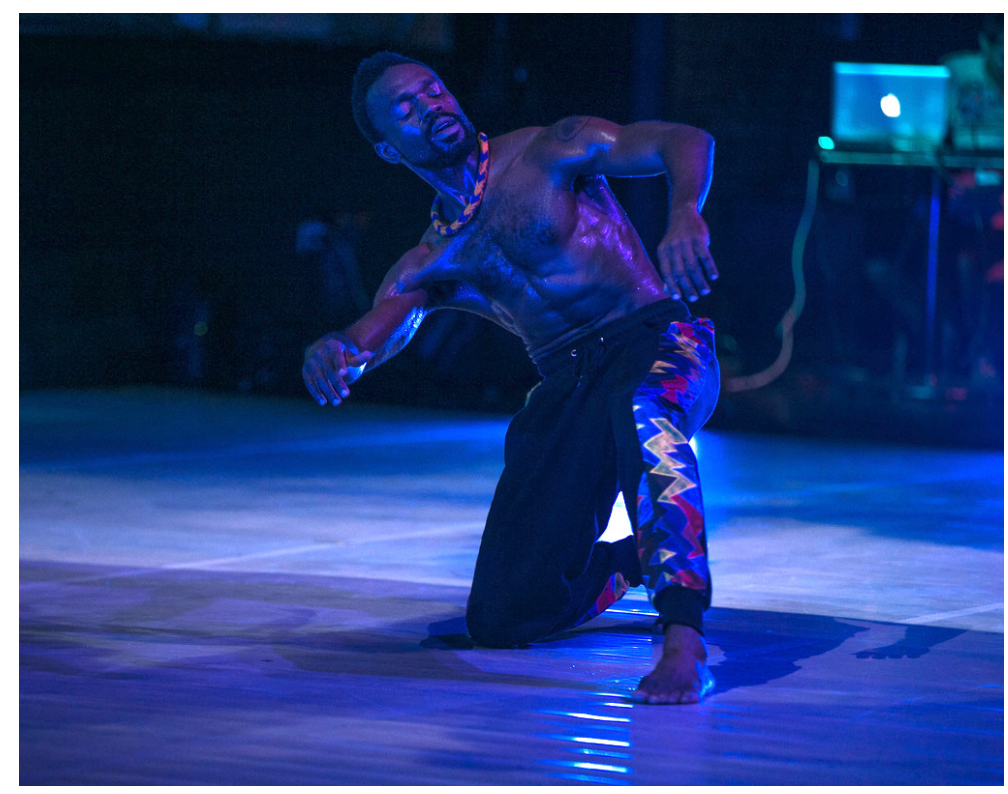

André M. Zachery in Digital Middle Passage, Afrofuturism Series. Irondale Center, New York. November 2015.

Photo: Kearra Gopee 
André M. Zachery is an interdisciplinary artist born in Chicago, USA, partly of Haitian descent, and based in Brooklyn, New York. He holds a BFA from the Ailey/Fordham University program and an MFA in Performance \& Interactive Media Arts from Brooklyn College.

$\mathrm{He}$ is the artistic director of Renegade Performance Group (RPG), a Brooklyn-based dance company exploring Black artistic aesthetics and expressions through dance theatre, visual performance, and film/media. RPG has received several residencies and awards and supports its ongoing work through institutions such as the Jerome Foundation, CUNY/Dance Initiative, the Brooklyn Arts Council, Harlem Stage, the Foundation for Contemporary Arts, Inception to Exhibition (ITE), the Brooklyn Museum, MoCADA, the Bedford-Stuyvesant Restoration Arts Center, Danspace Project, University Settlement, the Irondale Center, The Schomburg Center for Research in Black Culture| New York Public Library, and 3LD Art \& Technology Center.

Zachery has been a creative lead on collaborative teams ranging from music videos, theatre works, films and operas. He has presented research and been a panelist at conferences at Duke University, Brooklyn College, and Massachusetts Institute of Technology. He has curated performance platforms and artists' panels at Danspace Project and the CUNY Graduate Center in New York. ${ }^{15}$

A recipient of the 2016 NYFA Fellowship (Gregory Millard Fellow) in Choreography, he was a guest faculty artist-in-residence at the School of Dance at Florida State University. $\mathrm{He}$ is currently a 2017-2018 Visiting Artist and Guest Professor at Virginia Commonwealth University.

www.renegadepg.com

${ }^{15}$ Zachery, "Renegade Performance Group." 
Layla Zami: Hi André, thank you so much for making time, can you please introduce yourself?

André M. Zachery: I am André M. Zachery and I am the artistic director of Renegade Performance Group. RPG is a Brooklyn-based dance company that has three artistic components: dance theatre, site-specific performance, and film and media. Most recently, the major project that we have been mounting, and [which] just premiered our season, is the Afrofuturism Series. It is a platform where Black culture and aesthetics and practices are being remixed and reimagined through dance and technology and its relationship to $21^{\text {st }}$ century culture and the global diaspora presence of blackness.

L: I was impressed and moved by your performance Digital Middle Passage (DMP), can you tell me more about this piece, how was the process of working on it and what was your intent?

A: The solo DMP was a self-exploratory work that was a true linking of past, present and future ideologies, frameworks, and concepts surrounding my own cultural heritage and my own experiences from traveling, researching, and interactions with experiences of blackness around the globe. The work now asks what those experiences mean to me personally moving forward. In the sense of relating it to the Middle Passage, I wanted to capture the transitory experience of the soon to be enslaved Africans in-between [the] process of literally being autonomous and free to an existence completely defined by subjugation and itemization if you will.

So I am now asking: well, how do we remix that experience to reconsider that moment of transformation for this idea of Afrofuturism? In the sense of relating it to Sun Ra's Space is the Place (the movie where he leaves Earth and he finds another planet to exist in liberation), this solo is about a speculative experience for blackness in the present moment. What is it that, where is it that we can metaphorically go from this state of constant, you know, resistance and revolution within our bodies and in our psyche, to a space where we can define a landscape, or planet, galaxy, atmosphere of an existence independent from whatever circumstances that we had prior, meaning on Earth, or in the United States or wherever you're from in this realm of the diaspora.

And so that's what DMP is really looking at: what does this cocoon-like transition feel like spiritually, physically? What happens to the body, mind and spirit? What is released? Do the ancestors come with you? Do the ancestors guide you? I'm trying [to reclaim] the horrors from the Middle Passage into a moment of self-actualization. In another sense I was thinking the transformation was about submergence into the seas to get permission 
from the ancestors that were lost on the voyage. That I had to literally almost drown myself to find their spirits under the water, to then get permission to move forward.

L: Thank you. I felt that drowning at certain points, I felt it could be so much about the Middle Passage as it could be about the present of a Black man in America. So how do you concretely work when you're in the process of rehearsal, you have this idea. Does the music come at a later point, or do you choreograph first?

A: In the case of DMP, the solo, the music was composed by Ivonne K. Paredes. She is a composer and an MFA graduate of Brooklyn College's Conservatory of Music Composition Program. We met at Brooklyn College and shared similar ideologies on sound and performance. I was really interested in Ivonne's work after I heard it in an electro-acoustic ensemble recital. I thought it was really wonderful, so I approached her about collaborating on this project. I knew she had done some compositions for cello, and I was specifically interested in having a cellist arranged electronically. In this piece, she actually used a lot of her Peruvian roots and cultural traditions to lend to this praxis of intersectionality within Afrofuturism. That it is not solely about people of African descent, but this idea of "How are you taking your own heritage and legacy, and taking with you, and moving forward?". Through our discussions I saw that's a big part of her work as well, so we were able to relate that to the sound. She created the score into three sections, which I really like.

The past few years I have begun working directly with composers - Ivonne and with RPG resident composer Jeremy Toussaint-Baptiste. It is really an intrinsic partnership that builds the work simultaneously akin to the collaborative relationship between John Cage and Merce Cunningham. I'm really interested in creating soundscapes in which the movement is encapsulated. Time and space for me are truly malleable, and it's not something where I'm always concerned [about] building exact counts or placement of movement. But it's like ok, this idea is coming here, and is framed by the sound saying something, here, and I'm interested in moving here, or the piece finalizing with this, so that is the picture [of] how, you know, the path within the relationship to the sound, it's flowing together, it's juxtaposing...I'm informing it, it is informing me and that's how this piece [DMP] was built and most work now I do with composers. I enjoy it and have some really great relationships creatively and personally. I can't really stress enough how incorporating live sound, with the Black body, is under-used presently in performance. It is something you [Layla] and Oxana do that really inspires me. That's something Jeremy and I talk about, you know, I think that I would like to see more choreographers doing, bring[ing] that relationship back. 
L: Yeah, it makes sense. That is one of the aspects I appreciate about your work and Oxana Chi's work. It is true that not many choreographers work with live-music. It also has a cost. It makes such a difference when you have this live interaction.

A: I actually want to talk about that a little bit more. That's actually something I was talking about with [RPG resident composer] Jeremy Toussaint-Baptiste. We realized not many choreographers of color work intimately with a live sound artist in NYC. At least we don't see it happening that much. It's something within our creative relationship we've been doing since we've met.

In one sense it happens on a mass level within social dance and social gatherings, in that, you know the DJ gets on, and the groove is there and magic is happening because it's a shared, intrinsic thing that we [Black people] do. Especially within this realm of dance and performance, the investigations that we're doing with digital music and digital sound in conversation with Black movement, concepts and performance structures we feel offers another perspective to expand on Black artistry. For us this is merely an extension of the traditional relationship from the mother continent with a drum/string/horn orchestra for classical forms of African (specifically West African) dances such as Sabar, Doundounba, Manjani. But now with this idea of Afrofuturism: yeah, ok, in how many ways can we recreate and remix the generation and initiation of this sound?

Black music and Black dance is a synonymous marriage. It continues to produce forms (jazz, hip-hop, reggae, zouk, kompa, soca, house, rock-n-roll, rhythm and blues) that feed an entire hemisphere. There is no separating the two. It's interesting then that the partnership between live sound makers/composers and dance makers of color does not happen regularly! I mean living artists! I'm not talking about dead. That's another thing. I can say I was inspired to see this happening with choreographer Adia Whitaker and rock artist Tamir Kali at AFROPUNK at Harlem Stage.

Within Afrofuturism and the work of RPG, I am really, really interested in contemporary artists across disciplines working together. That is something I would like to challenge more choreographers, older and younger than me, to really consider. We can ask ourselves, Who is a sound artist doing interesting work now, that's pushing something fresh?" and begin to really work there because that is a relationship that will really broaden our art and really bring generations [together]. Looking at AFROPUNK, it exists at an amazing level for Black sound and Black music, whereas Black dance and performance it's not quite at the mass level of appeal independently. So I think there is something that we can [hands connect in a snake-like move] ride with, and build amongst ourselves. Especially Black women composers and sound artists, let's find and support them. Those doing interesting work such as yourself [Layla], we must acknowledge Black 
women's presence within new sound, new music, remixing from our own cultural heritage. That is very important and part of the work of Afrofuturism Series and that should be a part of more choreographers of color moving forward.

L: So while you were talking about this, I was thinking on another totally different level, of Dapline!, where you make another big challenge which was to present a piece with Black male dancing with no sound. You know you had this great [NY Times] review, people were really thrilled by your work, so maybe you want to talk about that. It's a totally different process, you're choreographing a group. You're still dealing with, I feel, memory, time and space, reimagining past imageries of blackness to give new possibilities of imagining for the future but in a totally different way. Also telling the difference between working as a solo artist and choreographing with visual artist LaMont Hamilton.

A: The piece Dapline! was built from a relationship with artist-practitioner LaMont Hamilton and his visual series "Five on the Black Hand Side." ${ }^{16}$ What LaMont really was doing with his photographic project was anthropological work into Black cultural practice. $21^{\text {st }}$ century anthropological work on breaking down African-American or more broadly African diaspora social practices of daily life. I think one of the things for the non-Black person viewing this work is to understand that there is deeper meaning in how we as a people [Black people] move and communicate.

Dr. Brenda Dixon-Gottshild elaborated on this at a Judson Church performance in September 2015. [...] Her artistic explorations show how the Black body moves in a white space or one that is framed by whiteness, versus a space that is really formed by Black experience. Black movement is very different. So the idea of "the Dap" [André simulates a dap with his two hands], for us, for me, living in Brooklyn New York, living on Eastern Parkway and Nostrand, is a gesture of love. Even if it's between two older men doing it, even if it's between two young men doing it, even if it's between two gang bangers doing it. All three of them have just showed love to each other. Usually, from a white frame of context, that is an absolute action of resistance. And that's how we begin to really tell the truth about race society and specifically this country - the United States of America. Dapline! is rooted ultimately in the personal experience of being a Black male in this country. Whether you're a Black male that identifies in a myriad of ways: hetero, trans*, homosexual, gay. Your gender pronoun is not necessarily the issue or the focus, but it's on that shared experience of "Yeah, my body in space moves in a certain way. And I know how it impacts the people with whom I'm sharing space." I feel, and we all feel in our own

\footnotetext{
${ }^{16}$ See Hamilton.
} 
unique ways, the experiences of this in the good, the bad, the sad, the happy, the triumphant. Dapline! is about setting a space for all of these emotions to exist and be translated through this one gesture - dap! Because that fist bump, no matter who does it, is powerful. But especially when two Black fists dap. It's a unifying and empowering experience that is loud! In that sense, we knew there needed to be no "added" sound or other acoustic element besides the rising of the breath, the bodies making contact with the floor and each other. In a way it made them [the Dapline! performers] hyper-aware of each other while in action. It's something that we didn't really need to explain. They just realized it themselves within the movement.

Dapline! is a piece that is very hard for me to watch. We created it quickly, because I mean, what did I need to investigate besides our own lives? If I don't know myself after all these years on earth then there is a problem! It was literally my/our everyday actions with each other as Black men shared openly. Me, LaMont and the rest of the crew, we just decided to open up a conversation and let the world see it. It's something that our mothers have seen, that our sisters that support us and love us, have seen, and have held us and laughed with us, cried with us. Something our fathers, uncles and cousins gave us by birthright. But outside of that, it was something that...for people to see it so un-stylized was eye-opening. And I'm speaking for the non-Black here. For every Black person in the room, they knew what the piece was, and we worked our best to again, not stylize it. It was really stripped away, just be...your experience is real but just be...that became so clear and evident within that [first] group of men that we had, that we were so grateful they embodied. I think that is the real truth in the piece. That it is an honest assessment of our everyday existence. It doesn't need a soundtrack.

Working collaboratively with LaMont, he was able to bring a visual art perspective to help create these frames, these tableaux, and vice-versa: I was able to look at the tableaux that he was using as [a] reference point and say "this is work, how to get into action, how it flips out." From my own readings...l was really into the book Pedagogy of the Oppressed [by Paolo Freire] at that time, and LaMont was heavily taking on the work of Fred Moten. All of these considerations went into the work, all of that was shared with the performers, all of that was given to them whether they read it or not. We simply said, this is what we're thinking about and this is what we're all going to consider. And that simple [dap] gesture, you know, again, I think that's the depth of us as Black men in this diaspora. That head nod or hug...is love. From the oppressive standpoint, it's a tactical action of resistance that can be used to kill us. And that's the truth. But that's the power of our existence in this country, and that's why l'm saying that it's the truth about this concept of race. That's why the piece is hard, and it is heavy, but it's necessary. 
L: You just touched upon a lot of things. I was going to ask you if your Black diasporic heritage is a daily source of inspiration or struggle or both, you totally answered that. I feel that's the power of your work and maybe that has to do with Afrofuturism too. How do we make work that's inspiring to our communities and that speaks in certain codes...Let's say a Black man would see your work and feel that it's about love and it's empowering and still it's relevant, in my eyes, to any audience, whether they are white Americans or not familiar with the US-context at all. Because you know there is body movement, there is emotionality, it's political and people might interpret it in different ways but still it will touch them. It's really interesting what you just said because I feel this was achieved with Dapline!, hearing the feedback from certain white people in the audience who might before have read certain codes in certain kinds of ways before watching the piece. Let's go back to Afrofuturism. You are also a media designer. In Digital Middle Passage, you use projections which you made yourself. Do you want to talk about the interaction between bare, raw movement and the technological realm?

A: As I was mentioning, the Afrofuturism Series was about looking at many forms and iterations of Black cultural practices or African diasporan cultural practices and artistically addressing them in a various contexts, re-imagining them or re-purposing them in new spaces such as a digital realm. One of the things I've said is: how do we access our spirituality through this digital realm? Are we able to still contact our ancestors in this virtual space? How does this happen? In that sense, yes, the framework for all the digital pieces, the digital media within the performed work was really built with this in mind.

I put these considerations into practice when building the technology aspect for the season. I was especially looking at the different viewpoints of how I was able to interact with my own body in the space. By using data from the live-feed to achieve interactivity, through capturing the movement to slightly alter the projected image. It's asking: my body is here in the space, but does one see the same or another body in this virtual realm? Bill $\mathrm{T}$ Jones asked similar questions when he was experimenting with digital media, in the work Ghostcatching. More specifically, how does one translate the experience of the Black body in the virtual realm to the corporeal world? Is the feedback the same?

In the program Untitled Distances, my point of departure was tracing the use and application of iconography and symbolism from the African continent to the American Hemisphere. I started with images of the Bakongo cosmogram which serves as a symbol of the eternal life cycle. Shaped as a cross, kalfou, carrefour or crossroad if you will. Its extension in the Diaspora is especially relevant in the loa vève in Haitian voodoo. In the United States, because so much Africanism was stripped away all we had left to create our eternal life circles were our Black bodies. This is how the ring-shout practices [which 
are referenced in the piece] have survived and become remixed over time in the jazz improvisation jams, doo-wop circles, hip-hop cyphers and especially, dance gatherings. So we have all this imagery and symbolism and now I'm asking can we create that same energy in the virtual space - this idea of a digital ring-shout. Again it's not necessarily having answers. It's asking: what if we just place that there? What happens? I think its this idea (especially within "elite" artistic circles that are mainly cis-white) is that "oh you know, Black people don't really experiment with their cultural..." and myself and many others are responding: Are you sure about that? Even hip-hop itself was an experimentation. Some DJs taking some records to find and isolate the "breakbeat." Even scratching the recording to get the sonic result of the vinyl being skimmed by the rock rhythmically?! That's a laboratory setting if I ever heard of one, you know? In a way they did a one-up on John Cage, who was not a fan of records as music mediums, and instead used the properties of the record as the sound generator itself and not solely the music within it's grooves! [Laughter].

To say that that [the doing and creating of hip-hop by Black people] is not really high art, but then see the constant co-opting of blackness and it being resold in the "high" art market, or the "high" performance realm, is explicitly stating that Black people can be removed even when our artistic innovations, developments, and cultural realities birth these movements. I'm explicitly looking at Black cultural practices through movement, performance, and this digital filter of technology - and I don't know what's gonna come out on the other side! It's going to be received differently from each viewer [on] the other side. Digital media is a space that several choreographers of color use and have used in various ways. For myself it's always an integral part of the artistic process, it's never ever just an aesthetic layer. It is an absolute realm and body in itself that I seek to program to translate and extend the artistic message. Luckily, I had some space at 3LD [Art \& Technology Center in NYC] where I was able to really look at "How are these dancers' bodies and energy interacting with the projections and affecting the space?"

In the other full-length piece, the Inscription Project, there are several interactive moments that translate Black presence and existence. At one point the dancers are creating the digital graffiti with the use of connected devices and the projections are absolutely speaking to what's happening in the space from a literal standpoint and historical standpoint. The work references practices of segregation in the United States like "red lining," and I projected these red lines with which the performers respond to in real-time. I think this is where the application of digital media moves forward from being an aesthetic element to being able to create another context in abstraction. In my personal experience, this again is such a cis-white male realm - especially because of the money that is needed to access this equipment and the time to spend with the education. For me 
now, digital technology in performance will look completely different if you put the equipment in the hands of a queer Thai woman and say "create a piece, you have a year!". It's going to look completely different than what a company like Elevator Repair Service would do with digital work. And I think that this room must be created within our art and performance world to really exist with equity. And it's going to blow their minds up. It really will. People say "everything has been done before." Yeah, everything has been done before, but not everyone's story has been told. I think that's the thing that's so important that I am realizing now. Who is the person that's doing it? Who is the person that's telling it? The story will sound totally different and have [a] totally different meaning from each person and experience from who is allowed to get on the mic or get on the dance floor or get behind the computer and do the work. I'm just playing my part with my own experimentation. I love doing it. I think it's the next step for choreographers: using their own equipment, using their own lenses, cameras, and sound boards. But there must be encouragement to say we can do it. Don't think it's behind your reach. No, you can do it too. I'm doing it, I need someone else to do it too and be like, "Oh ok you do it like that, Im gonna try this..." We need that. We must become our own enablers, say let's just "nerd out" [laughter].

L: Thank you very much André, I think a lot has been said and our time is up. Maybe just one more question that came to my mind while you were talking: you choose really different people to perform together, you have a way of putting together dancers that have very different bodies, aesthetic styles, training as much in Dapline! as in the Afrofuturism Series. I also really like that about your work, do you want to say one more thing about that?

A: Working with performers from different backgrounds, different ways of identifying, different bodies, different techniques, it feeds me. That literally keeps me engaged with how they're going to approach my own movement. In the sense of me being a choreographer, I do have a very specific style that I definitely have developed through a lot of alone time and experimentation. I am then able to relate to somebody and say "Ok, I need you to do this movement." I am not so much a choreographer that needs them to do exactly what I do. I don't need a personal reflection. But I think it's interesting to see all these different responses to what l'm doing and then see them collectively come together and negotiate how they all navigate the space together. What is most important for me and I am not speaking for all choreographers - is that I have to be very clear on my own intentions prior to coming into the space with the performers. So my research, my trajectory with the piece, with the work, about what it is, where it is going and how we get 
there as a group - that always for me has to be refined. Whatever the movement is that comes out is going to be "André." That's where the various leanings and understandings of these different bodies, identities, techniques, come into play. A specific task in Hidden Tracks was this idea of cultural residue. I asked the performer to consider this. "Okay, if someone was to metaphorically trace your path to where you are now from a certain place in your life, what would be the things that you have dropped along your way that have led you to where you are now?" The performer's first response was merely "What?", but then to see each person's interpretation of that is pretty amazing! Another time I created a phrase that I remember, "Struck fear into their hearts" and the performers said, "Wow this phrase is so hard." But then they work tirelessly to get on the material in effect saying, "This is how we're going to negotiate, this is what we're going to do," and I get performers that don't mind doing the dirty work. I get performers that are not interested in being pretty. My work is not interested in saying, "Oh I look so good doing this." I don't care what you "look" like, I'm interested in how you're doing what you [are] tasked with in the space. That's most interesting for me. I am beyond honored and lucky to work with each one of them, past, present and future. 


\section{TURNing OUt: TRANSFORMING THE Body INTO A SPACETIME OF RESISTDANCE}

It's hard to stop rebels that time travel...

Janelle Monáe ${ }^{1}$

The music video to the song Q.U.E.E.N. opens with this phrase, spoken by a voice that greets incoming visitors to the "Living Museum." As they step into a white box-like gallery space, they find the bodies of political artists on display, "legendary rebels" that have been "frozen into animation." 2 The visitors take a look at the bodies of lead singer Janelle Monáe and her band Wondaland, who seem suspended in time. The narrating voice goes on, and explains that the "Time Council" has been "hunting the various freedom movements that [the band] Wondaland disguised as songs, emotion pictures and works of art." ${ }^{3}$ Two of the visitors liberate the displayed bodies; by playing a vinyl of their own music, they animate the band back into life. A mise-en-abyme happens here, as the first beats coming from the vinyl are actually the beginning of the music video's soundtrack. Janelle Monáe slowly regains her corporeal agency, starts singing the song and dancing, as does her band, which begins to move and play music.

This scene epitomizes the power of perforMemory in postmemorial times. It suggests the possibility of a complex relation between art and resistance, between physical and political movements, between archival and performative practices of cultural memory. If music can destabilize power relations by conveying emotional and political meaning, so dance performances can intervene into hegemonic narratives, and bring a memorial status quo into movement. The above cited statement suggests that the ability to propel oneself across time - moving back and forth between past, present, and future - invigorates the capacity to rebel against hegemonic power. The seven dancing protagonists of my research do not only invite their audiences to "time travel," they incite them to re-imagine the very consistency of time.

\footnotetext{
${ }^{1}$ Monáe, Q.U.E.E.N

${ }^{2}$ Monáe.

${ }^{3}$ Monáe.
} 
Thus, perforMemory is a corporeal intervention into western hegemonic discourses and practices of history and geography.

Much time has flown by since I began this research, and the artists keep moving forward, on stage, and in the space/time of their careers. Farah Saleh is herself now pursuing a doctorate under the auspices of the "PhD by practice" program at the University of Edinburgh, College of Art, and is a mother. Oxana Chi is now based in New York, and is developing her latest piece, Psyche. In the performance, she deals with her own embodied memory, in a quest to grasp, process and access knowledge of the soul's essence. Chi performed excerpts of Psyche at the HAU Theater in Berlin as part of the M(a)y Sister Festival, as well as at the Fall 2017 Season Opening for Movement Research at Judson Church in Manhattan. She is also a 2017-2018 Artist-in-Residence at the Abrons Arts Center. There, we began collaborating on her new piece, called Jazz Feeling, made up of a duality between her dancing body and my saxophone sounds. We are scheduled to present a first composed-improvised iteration of the piece at Triskelion Arts Center, Muriel Schulman Theater, in January 2018. In the fall of 2017, in New York, I also had the pleasure of witnessing André Zachery's newest work in the Afrofuturism Series, called Untamed Space, and of facilitating a pre-performance talk with him at the Danspace/St. Mark's Church premiere. In this 75 minute ode to the survival of Black bodies, Zachery and the three female dancers Candace Thompson, Nehemoyia Young and Kentoria Earle traverse the strategy of marooning across space (Haiti, Southern USA, Chicago) and time (slavery to the $21^{\text {st }}$ century). Meanwhile, Zachery is also a Guest Professor and Artist-in-Residence at Virginia Commonwealth University, 100 miles northwest of one of the largest historical maroon communities (on the site of the Great Dismal Swamp) in the United States.

In this research, I tried to show how selected solo dance productions generate a performance that not only represents, but actually enacts perforMemory from a contemporaneous perspective, or the process I call perforMemory. Through my readings of selected works by seven choreographers, I demonstrated how they respond to what bell hooks calls "the need to create spaces where one is able to redeem and reclaim the past, legacies of pain, suffering, and triumph in ways that transform present reality." ${ }^{4}$ Consequently, I emphasized the empowering aspect of the dances. I validated the hypothesis that dance can contribute to "a politicization of memory" and to a "remembering that serves to illuminate and transform the present." ${ }^{5}$ As a reader, I invited you to travel with the dancing rebels of perforMemory through memory as a site of movement, through diasporic dance moves, and through intensity as a spacetime of

\footnotetext{
${ }^{4}$ hooks, "Choosing the Margin as a Space of Radical Openness," 154.

${ }^{5}$ hooks, 155.
} 
memory. I argued that the place the dancers call home is the body they inhabit, and its electricity is the vitality they put in setting their body-homes into e_motion. I also showed how the performances dance the past in the present tense, moving audiences forward through diasporic dancescapes. I defined perforMemory as a mobile memory2go, and highlighted spinning, jumping, and crossing as three corporeal sites of connection between physical and conceptual resistance. Thus, I aimed to show how the dancers not only become whom they imagine, to paraphrase Marquié, ${ }^{6}$ but also re-imagine how to become a human, a narrative, a story, a motion, a memory.

Additionally, the research moves one step further. What the thesis, taken as a whole, demonstrates is that the dances of perforMemory transform memory matter, body energy, space and time. I explored the ways in which the performances shift conventions of linear time, physical space, home, and identity to perform counterhegemonic memories, and thus intervene in dominant modes of collective memory transmission. Therefore, the seven solos in my repertoire of perforMemory epitomize the feat of a political corporeal rebellion that moves fluidly across spacetime, and eventually generates new forms of storytelling that may help us to understand, and transcend, traumatic memories. While bell hooks speaks of the possibility to choose the "margin" as a space of radical openness," I find that the dancer-choreographers no longer accept being confined to the margins, rather they move on center stage, shifting the very definition of margin and center. They create these spaces on stage, and within themselves. Dancing, they permanently transform their own reality through kinesthetics, and transform the audience's relation to reality by propelling past memories and future possibilities into the present timespace of the performance.

A common element linking the seven solos addressed here, as well as other works by these choreographers, is that they move within a triangle connecting life, resistance, and memory (as an archival and a performative practice). For instance, in the choreobiography Through Gardens, Tatjana Barbakoff earns an afterlife on stage through the contemporary body of Oxana Chi. While Barbakoff's figure can mostly be found in paintings and museums, Oxana Chi embodies her story in her former realm of expression, the dance stage. Barbakoff was murdered in Auschwitz, a place that strangely enough, people visit like a "museum" today. Chi transforms the concert dance stage into a space of memory, where contemporary audiences may engage with the past in relation to her, as well as their own contemporary issues and perspectives. In They Call You Venus, Chantal Loïal embodies the story of Sawtche, whose actual, bodily remains were on display in a French museum until 1974 . The performance returns corporeal agency and dignity to a historical

\footnotetext{
${ }^{6}$ Marquié, Non, la danse n'est pas un truc de filles !, 101.

7 hooks, "Choosing the Margin as a Space of Radical Openness."
} 
figure, and liberates her narrative from a double containment, the violence inflicted on a body that was exhibited alive as well as posthumously. The relation between racismcolonialism, gender and exhibition is also integral to Oxana Chi's piece Neferet iti, mentioned in the third chapter on diaspora. In Digital Middle Passage, André M. Zachery personifies historical and contemporary Black diasporic journeys, representing the capture, but also enacting the survival of his ancestors throughout slavery, and his own contemporary survival in a Black body in the USA. In all about nothing, Zufit Simon addresses traumatic violence, and uses at times large, energetic, and at times microscopic motions to process the emotions stored in her body. In Parole, Parole, Parole, Farah Saleh centers love and life as resistance against an oppressive geopolitical context. When physical borders impede individual mobility, and thus the possibility of a relationship, her dance, playing with balance, creates intimacy with the audience, which nonetheless remains quite rigid in contrast with the flow of her movements. In Choc(s), Christiane Emmanuel races, in the air and on the ground, searching for stability on an island marked by historical and contemporary racial oppression. In Impressions, WanChao Chang dances the memories of her life, embracing movement as a way to connect past, present and future moments into one spacetime. All these works suggest that perforMemory cannot be frozen in a "Living Museum," rather they reify the possibility of a "Living Archive," as understood by Aicha Diallo, and as discussed in the first chapter. They perform remembering using imagination as a tool to blur the boundaries between past, present and future, and between the visual and other realms of cognitive perception. Through the live art of dance, perforMemory keeps the remembering, and its audience, alive.

The dances of perforMemory attempt to counter the physical and political immobility that dominant systems enforce on minoritized subjects. In them, perforMemory represents an emotional, rather than a factual connection to memory. Furthermore, they embrace the dancing body as a site and source of constant, and conscious transformation. This is a quality specific to dance, as noted by dancer-choreographer and scholar Hélène Marquié, for whom dance is a "perpetual metamorphosis," in which the body "plays with gravity, spatiality, temporality, directionality, senses, and the self's relationships to the world." Marquié helps us to understand how in molding of these variables, the body acquires the capacity to transform itself, in awareness of itself. I addressed these parameters in relation to the dancing body as a vector of memory, and explored how the postmemorial aesthetics and kinesthetics of the dancer-choreographers transform memory, and how

\footnotetext{
${ }^{8}$ Diallo and MID Redaktion, The Living Archive. See my discussion in the chapter "Memory dancescapes."

${ }^{9}$ Marquié, Non, la danse n'est pas un truc de filles!, 98 [My translation].
} 
this may in turn shift consciousness for the performer as well as for someone sitting in the audience.

In order to offer a differentiated reading of selected performances, I placed my personal interpretations in conversation with the artists' interviews, as well as such various sources as performance, memory and dance theory, decolonial and/or feminist research, a TEDx talk on quantum physics, theological reflections on time, and $20^{\text {th }}$ century novels on love from a gay African-American perspective, and on memory from the perspectives of Holocaust survivors. Furthermore, I linked readings of performances dealing with such various topoi as the Holocaust, chattel slavery, Nakba, Maafa and with displacement in general. These final pages do not constitute the ending of my reflections on perforMemory. In future research, I am interested in addressing new questions, or further developing certain aspects, such as the physicality and materiality of perforMemory, or the connection between gender and non-linear time. It would also be important to assess audiences' reception to the pieces, for instance with a focus on the range of emotions involved in the reactions to perforMemory, and how this relates to embodied memory. It would also be interesting to compare group and solo works, in order to explore convergences and divergences in individual and collective performances of memory.

In the very first pages of this book, I wrote about the Stolperstein, the commemorative stone placed for the Chinese-Jewish-Latvian dancer Tatjana Barbakoff in front of the Renaissance Theater in Berlin, a stone that inscribes into physical space the memory of the time when she used to perform there. In their linking of time and space, of memory, geography and history, these types of stones incite passersby to pause and read names and information about individuals killed by the Nazis. The stones literally influence the urban choreography of passersby, provoking them to watch their steps, walk around the stones or stop and look at the ground. The stones, like the performers, shape the public timescape of memory. Many questions remain to be excavated, like memory, stone by stone, step by step. A few days ago, a Berlin news story reported that construction workers digging out grounds for a sports space accidentally found a gigantic swastika engraved under the lawn. The swastika is originally a Hindu symbol misused by the Nazi regime, and now systematically associated with the European Holocaust in western contexts. The massive swastika, made out of concrete, seems to be the remnant of a Nazi monument. The (outer, external part) of the monument was removed, its foundation remained. What does this finding say about the grounds that I, or we walk or dance on? How may it comment on the timescape in which perforMemory takes place?

What a non-coincidence that I end up concluding this book in the South of France, on a journey with Oxana Chi, in the footsteps of Tatjana Barbakoff. We have been invited to present a lecture-performance on December $9^{\text {th }}, 2017$, at a dance symposium on the topic 
of mobility, choreographic careers and gender, as part of the Cannes Dance Festival organized by the University of Nice Sophia-Antipolis. Oxana Chi performed an excerpt from Through Gardens, starting with the scene of The Journey. I introduced the performance with a brief musical prelude played on the chalumeau instrument, and gave a talk highlighting biographic and choreographic parallels between Chi and Barbakoff. Our journey was accompanied by Silvia Wojczewski, a graduate research assistant who is conducting a thesis on Afro-German mobility, in which both Oxana Chi and I feature as research subjects/protagonists. What a quick transition between earning a doctorate and becoming myself a subject of doctoral research. In New York and in France, I realized that I was not only a French Jew of color, but also an Afro-German...maybe I'll tell this story in a book one day. After the conference, we spent a short time in Nice, the city where Barbakoff was arrested by the Gestapo in January 1944. We could feel her soul accompanying our every step, along the magical ocean blue, into the Georgian puppet theater, and through the Chagall Museum and its palm trees. We reflected upon the role of dance as a practice of historiographical survival. I was reminded of what Oxana Chi said to me in our 2013 conversation at the beginning of my research:

[...] I believe that although Tatjana Barbakoff was put to death, and although so much art was destroyed here in Europe, she still left something here which gives us - me, or you, Layla, or all artists here - a certain strength to keep on going, and a fertile soil from which we can grow. And so I think that, even though she has passed away, she is still active and still resists, and that is also the case with many other artists. $^{10}$

What this quotation suggests to me is the importance of survival as a trope of resistance: resistance of bodies to immobility/death, resistance of souls to trauma, resistance of knowledge to erasure. The piece Through Gardens gives Tatjana Barbakoff an embodied, afterlife in perforMemory, without re-enacting her choreography or biography, but rather enacting the possibility of her presence. These words also resonate with my other readings, including Audre Lorde's reflections on survival, which remind "those of us who live at the shoreline" that being alive should be celebrated as a triumph when you "were never meant to survive" centuries of oppression and systemic violence. ${ }^{11} \mathrm{I}$ also think, in the context of the Americas, of Alejandro Murguia's reflections on his Mexican-NativeCalifornian genealogy in relation to history. He deconstructs the very notion of historical victory, preferring the idea of survival:

\footnotetext{
${ }^{10} \mathrm{Chi}$, interview.

${ }^{11}$ Lorde, "A Litany for Survival."
} 
History - as the saying goes - is written by the victors, never by the vanquished. I am neither of the victors nor the vanquished. If anything, I am of the survivors - the curious survivors who have brooded on the past and wondered about the future. ${ }^{12}$

The words of Oxana Chi, Audre Lorde, and Alejandro Murguía hint at memory as a source of power, a site of inspiration for contemporary struggles. All these statements also share the will to move beyond the dual perpetrator/victim paradigm. Because they divert from a linear, chronological reading of traumatic memory, they connect to what I have tried to highlight in my repertoire of perforMemory. This spirals back to the opening of this thesis and the question of positioning in relation to storytelling. Survival helps us to understand the historiography and epistemology of trauma as a constellation that is more complex than a mere distinction between perpetrators and victims, victors and vanquished, hunters and lions. If memory can be a "site of resistance,"13 the spine of perforMemory is resistDance, at least in my interpretation of the works and words of the dancerchoreographers. The artists of perforMemory merge dance and resistance, generating what I call resistDance: a live art of survival, characterized by presence across generations of trauma. Luckily, not only trauma and concrete survive across memoryscapes, humans also do. To perforMemory then, is to be in the intensity of the dancing instant, and to perform the conscious possibility to transform one's body into a timespace of resistDance.

How to conclude a work on the topic of ongoing movement? Memory, like life, quantum matter, and dance, keeps on moving. Embarking on diasporic journeys, I traveled with choreographers who dig, sink into, jump towards, and reach out to memory. Moving with and within distinct aesthetics, cultural backgrounds and intentions, they share a common goal: to clear the grounds of memory in order to define subjectivities firmly anchored in the present, and already moving towards the future. As I write the final words of my book, many images come to mind. Dancers gracing the stage with movements infused by power, versatility, subtlety and creativity. Bodies jumping, falling, spinning, arms and legs wandering in all directions, diving into or rolling on the ground. Arms and legs tracing instant drawings on an airy canvas. Cores inflating and shrinking. Hands floating, joining, shaking, caressing. Faces playing all the arpeggios of the known human emotional scales - and beyond. Humans gathering and parting. Not only do humans stand on the shoulders of those who preceded them, they sometimes dance on the grounds shaped by the steps of their predecessors. Hopefully, the dances of perforMemory may help humanity to stop shipwrecking itself against the burdens of its past, and to start levitating through galaxies of cultural legacies.

\footnotetext{
${ }^{12}$ Murguía, The Medicine of Memory, xiv.

${ }^{13}$ hooks and Mesa-Bains, Homegrown, 110.
} 


\section{BIBLIOGRAPHY}

Ahmed, Sara. Queer Phenomenology: Orientations, Objects, Others. Durham: Duke University Press, 2006.

- The Cultural Politics of Emotion. New York: Routledge, 2004.

Ahmed, Sara, Claudia Castañeda, Anne-Marie Fortier, and Mimi Sheller, eds.

Uprootings/Regroundings: Questions of Home and Migration. Oxford: Berg, 2003.

AK Forschungshandeln, ed. InterdepenDenken: Wie Positionierung und Intersektionalität forschend gestalten. wissen_bewegen. Berlin: w_orten\&meer, 2015.

Ali, Kazim. Orange Alert. Essays on Poetry, Art, and the Architecture of Silence. Poets on Poetry. Ann Harbor, Michigan: University of Michigan Press, 2010.

Allain, Paul, and Jean Harvie, eds. The Routledge Companion to Theatre and Performance. New York: Routledge, 2014.

Allen, Zita. "What Is Black Dance?" In The Black Tradition in American Modern Dance, edited by Gerald E. Myers, 22-23. Durham: American Dance Festival, 1988.

Amra, Widad. Le Souffle Du Pays. Nabd El Jayzirah. Paris: L'Harmattan, 2010.

Angelou, Maya. And Still I Rise: A Book of Poems. New York: Random House, 1978.

Anzaldúa, Gloria E. Borderlands - La Frontera. 3rd ed. San Francisco: Aunt Lute Books, 2007.

- Light in the Dark/Luz En Lo Oscuro: Rewriting Identity, Spirituality, Reality. Edited by AnaLouise Keating. Durham: Duke University Press, 2015.

Anzaldúa, Gloria E., and AnaLouise Keating, eds. This Bridge We Call Home: Radical Visions for Transformation. New York: Rootledge, 2002.

Anzaldúa, Gloria E., and Cherríe Moraga, eds. This Bridge Called My Back: Writings by Radical Women of Color. New York: Kitchen Table, Women of Color Press, 1981.

Appadurai, Arjun. "Archive and Aspiration." Archive Public (blog). https://archivepublic.wordpress.com/texts/arjun-appadurai/

Asantewaa, Eva Yaa. "Hamilton and Zachery at University Settlement's Performance Project." Infinite Body (blog), July 31, 2015.

http://infinitebody.blogspot.com/2015/07/hamilton-and-zachery-at-university.html Assmann, Aleida. Der lange Schatten der Vergangenheit: Erinnerungskultur und Geschichtspolitik. München: Beck, 2006. 
—. Erinnerungsräume: Formen und Wandlungen des kulturellen Gedächtnisses.

Kulturwissenschaften. Munich: C. H. Beck, 2006.

"Attitude." American Ballet Theatre (blog).

http://www.abt.org/education/dictionary/terms/attitude.html

Ayim, May. Blues in Schwarz-Weiss. Berlin: Orlanda Frauenverlag, 1995.

Baldwin, James. Just above My Head. (1. 1978). London: Pinguin Books, 1994.

Ballé Moudoumbou, Marianne. "Erste Annäherung zu Maafa." In InterdepenDenken: Wie Positionierung und Intersektionalität forschend gestalten, edited by AK Forschungshandeln, 112-33. wissen_bewegen. Berlin: w_orten\&meer, 2015.

Bernabé, Jean, Patrick Chamoiseau, and Raphaël Confiant. Eloge de La Créolité. Paris: Gallimard, 1989.

Boyarin, Daniel, and Jonathan Boyarin. Powers of Diaspora: Two Essays on the Relevance of Jewish Culture. Minneapolis: University of Minnesota Press, 2002.

Boyarin, Daniel, Daniel Itzkovitz, and Ann Pellegrini, eds. Queer Theory and The Jewish Question. Lesbian, Gay, and Bisexual Studies. New York: Columbia University Press, 2003.

Bragin, Naomi. "Shot and Captured: Turf Dance, YAK Films, Nad the Oakland, California, R.I.P. Project." The Drama Review 58, no. 2 (Summer 2014): 99-114.

Brah, Avtar. "Diaspora, Border and Transnational Identities." In Feminist Postcolonial Theory. A Reader, edited by Reina Lewis and Mills, 613-34. Edinburgh: Edinburgh University Press, 2003.

Bruns, Claudia. "Antisemitism and Colonial Racism: Transnational and Interdiscursive Intersectionality." In Racisms Made in Germany, edited by Wulf D. Hund, Christian Koller, and Moshe Zimmermann, 99-121. Racism Analysis, Yearbook 2. Berlin: Lit, 2011.

Bruns, Claudia, Asal Dardan, and Dietrich, Anette, eds. "Welchen der Steine du hebst" Filmische Erinnerung an den Holocaust. Berlin: Bertz+Fischer, 2012.

Butler, Judith. Bodies That Matter: on the discursive limits of "sex." New York: Routledge, 1993.

- Gender Trouble: Feminism and the Subversion of Identity. New York: Routledge, 1990.

- Parting Ways: Jewishness and the Critique of Zionism. New York: Columbia University Press, 2013.

Cadeau, Valérie. "Chantal Loïal - La diversité par la mise en danse du corps." Point d'Afrique, Mai-Juin 2011. 
Cahyaningtyas, Alexia. "The Gambyong Dance: A Small Intro." Cahyaningtyas (blog), January 22, 2011. https://acahyaningtyas.wordpress.com/2011/01/22/thegambyong-dance-a-small-intro/

Campt, Tina M. "Black Feminist Futures and the Practice of Fugitivity." Barnard Center for Research on Women, July 10, 2014. http://bcrw.barnard.edu/videos/tina-camptblack-feminist-futures-and-the-practice-of-fugitivity $/$

- Image Matters: Archive, Photography, and the African Diaspora in Europe. Duke University Press, 2012.

—. Listening to Images. Duke University Press, 2017.

Other Germans: Black Germans and the Politics of Race, Gender, and Memory in the Third Reich. Social History, Popular Culture, and Politics in Germany. Ann Harbor, Michigan: University of Michigan Press, 2005.

—. "The Crowded Space of Diaspora: Intercultural Address and the Tensions of Diasporic Relation." Radical History Review 83 (2002): 94-111.

Cándida Smith, Richard, ed. Art and the Performance of Memory: Sounds and Gestures of Recollection. Studies in Memory and Narrative 13. Oxfordshire: Routledge, 2002. Caponi-Tabery, Gena. Jumping for Joy: Jazz, Basketball, and Black Culture in 1930s America. University of Massachusetts Press, 2008.

Capra, Fritjof. The Tao of Physics: An Exploration of the Parallels between Modern Physics and Eastern Mysticism. 5th ed. Boston: Shambala, 2010.

Carter, Julian. "Embracing Transition, or Dancing in the Folds of Time." In Transgender Studies Reader 2, edited by Susan Stryker and Aren Z. Aizura, 2nd ed., 130-43. New York: Routledge, 2013.

Castro Varela, María do Mar, and Nikita Dhawan. "Europa Provinzialisieren? Ja, Bitte! Aber Wie?" Femina Politica 2, no. 2009 (2009): 9-18.

Césaire, Aimé. “Hors Des Jours Étrangers." In Ferrements. Paris: Points, 2008.

Chakrabarty, Dipesh. Provincializing Europe: Postcolonial Thought and Historical Difference. Princeton: Princeton University Press, 2008.

Chang, Wan-Chao. I Thought Here Is My Home. San Francisco: CounterPULSE, 2009. https://www.youtube.com/watch?v=30mLm8-OxbQ

_. "Impressions." Wan-Chao Dance. Accessed March 26, 2017. http://www.wanchaodance.com/Performance.htm

_. "Wan-Chao Dance." Wan-Chao Dance. Accessed March 26, 2017. http://wanchaodance.com

_. Interview by Layla Zami. Taipei, September 5, 2015. 
Chatterjea, Ananya. Butting Out: Reading Resistive Choreographies Through Works by Jawole Willa Jo Zollar and Chandralekha. Middletown: Wesleyan University Press, 2004.

Chatterjee, Sandra, and Cynthia Ling Lee. “'Our Love Was Not Enough': Queering Gender, Cultural Belonging, and Desire in Contemporary Abhinaya." In Meanings and Makings of Queer Dance, edited by Clare Croft, 45-65. New York: Oxford University Press, 2017.

Chatterjee, Sandra, Cynthia Ling Lee, Shyamala Moorty, and Anjali Tata. "Post Natyam Collective." Post Natyam Collective - Process, Praxis, Performance. http://www.postnatyam.net/

Chi, Oxana. "E-Mail an Laszlo Moldvai, 01.01.2010." In Tanzende Erinnerungen Mémoire dansée. Femmage an die Tänzerin Tatjana Barbakoff. Katalog zur Ausstellung des Salon Qi 2011 in Berlin und in Paris, edited by Oxana Chi, 12-13. Berlin: Self-Published, 2011.

. "Neferet iti - Reloaded." UnGehörig. Humboldt-University, November 2016. . Oxana Chi. Video, September 17, 2013.

. "Oxana Chi Dance Art." Oxana Chi. Accessed March 26, 2017. http://oxanachi.de , ed. Tanzende Erinnerungen - Mémoire dansée. Femmage an die Tänzerin

Tatjana Barbakoff. Katalog zur Ausstellung in der Galerie Gondwana im Rahmen von Salon Qi. Berlin: li:chi e.V., 2011.

. "Von Hier Nach Dort - I Step On Air." In Sisters and Souls. Inspirationen von May

Ayim, edited by Natasha A. Kelly, 201-15. Berlin: Orlanda, 2015.

_. Interview by Layla Zami. Berlin, September 17, 2013.

Chi, Oxana, and Layla Zami. Durch Gärten Tanzen (Dancing Through Gardens).

Documentary. li:chi, 2014.

Chivallon, Christine. L'esclavage, du souvenir à la mémoire - Contribution à une anthropologie de la Caraïbe. Esclavages. Karthala, 2012.

Chung-hing. Chants de Thé. Paris: Delatour, 2012.

Clifford, James, Lawrence Grossberg, Cary Nelson, and Paula Treichler. "Travelling Cultures." In Cultural Studies, 96-112. New York: Routledge, 1992.

Cole, Teju. Open City. New York: Penguin Random House, 2012.

Collins, Patricia Hill. Black Feminist Thought: Knowledge, Consciousness, and the Politics of Empowerment. 2nd ed. New York: Routledge, 2000.

. "Learning from the Outsider Within: The Sociological Significance of Black Feminist Thought." In The Feminist Standpoint Theory Reader - Intellectual and Political Controversies, edited by Sandra Harding, 103-25. New York: Routledge, 2004. 
Conyers, Liana D. "Shedding Skin in Art-Making: Choreographing Identity of the Black Female Self Through Explorations of Cultural Autobiographies." Master of Fine Arts Thesis, University of Oregon, 2012.

https://scholarsbank.uoregon.edu/xmlui/bitstream/handle/1794/12380/Conyers_oreg on 0171N_10368.pdf?sequence=1

Cooper Albright, Ann. "Embodying History: Epic Narrative and Cultural Identity in African American Dance." In Moving History / Dancing Cultures. A Dance History Reader, edited by Ann Dils and Ann Cooper Albright, 439-54. Durham: Wesleyan University Press, 2001.

Cooper, Julie E. "A Diasporic Critique of Diasporism: The Question of Jewish Political Agency." Political Theory 43, no. 1 (2015): 80-110.

Coorlawala, Uttara. "Ananya and Chandralekha - A Response to 'Chandralekha: Negotiating the Female Body and Movement in Cultural/Political Signification." In Moving History / Dancing Cultures. A Dance History Reader, edited by Ann Dils and Ann Cooper Albright, 398-403. Durham: Wesleyan University Press, 2001.

Cox, Aimee Meredith. Shapeshifters: Black Girls and the Choreography of Citizenship. Durham: Duke University Press, 2015.

Cvetkovich, Ann. An Archive of Feelings: Trauma, Sexuality, and Lesbian Public Cultures. Durham: Duke University Press, 2003.

Cyrulnik, Boris. Je Me Souviens. Textes Essentiels. Le Bouscat: L'Esprit du Temps, 2009. Dava D. Hernández. "Dancing Mestizaje: The Choreodramas of The Guadalupe Dance Company." Master of Arts, Texas Woman's University, 2015. http://poar.twu.edu/xmlui/bitstream/handle/11274/7027/Hernandezc2.pdf? sequence $=1$ \&isAllowed $=y$

DeFrantz, Thomas. Dancing Revelations: Alvin Ailey's Embodiment of African American Culture. Durham: Duke University Press, 2006.

DeFrantz, Thomas F., and Anita Gonzalez, eds. Black Performance Theory. Durham: Duke University Press, 2014.

DeFrantz, Thomas, and Tara A. Willis. "Black Moves: New Research in Black Dance Studies." Edited by Thomas DeFrantz and Tara A. Willis. The Black Scholar 46, no. 1 (2016).

Desmond, Jane C. "Engendering Dance: Feminist Inquiry and Dance Research." In Researching Dance - Evolving Modes of Inquiry, edited by Sondra Horton Fraleigh and Penelope Hanstein. Pittsburgh: University of Pittsburgh Press, 1999.

, ed. Meaning in Motion: New Cultural Studies of Dance. Durham: Duke University Press, 1997. 
Diallo, Aïcha, and MID Redaktion, eds. The Living Archive: Kulturelle Produktionen Und Räume. Berlin: Heinrich-Boell-Stiftung, 2013.

http://heimatkunde.boell.de/tags/living-archive-kulturelle-produktionen-und-raeume

Diawara, Manthia. "Conversation with Edouard Glissant Aboard the Queen Mary II (August 2009)." In Afromodern: Journey Through The Black Atlantic, 59-63. Liverpool: Tate Publishing, 2010.

Diggs Colbert, Soyica. "Black Movements: Flying Africans in Spaceships." In Black Performance Theory, edited by Thomas F. DeFrantz and Anita Gonzalez, 129-48. Durham: Duke University Press, 2014.

Dixon Gottschild, Brenda. "Dance Is a Message in a Cultural Envelope. Urban Bush Women, Jant-Bi, and Diasporan Dialogues." Brenda Dixon-Gottschild. Writer on Dance and Culture, 2009.

http://brendadixongottschild.files.wordpress.com/2010/07/dance-is-a-message-in-acultural-envelope.pdf

- Digging the Africanist Presence in American Performance: Dance and Other Contexts. Contributions in Afro-American and African Studies 179. Westport: Greenwood Press, 1996.

_. "'Racing' in 'Place': Dance Studies and the Academy." Duke University, 2015. http://humanitiesfutures.org/papers/racing-in-place-dance-studies-and-the-academy/ - The Black Dancing Body: A Geography From Coon to Cool. 1st ed. New York: Palgrave-Macmillan, 2003.

Dolan, Jill. Utopia in Performance: Finding Hope at the Theater. Ann Harbor, Michigan: University of Michigan Press, 2005.

Drenker-Nagels, Klara, Günter Goebbels, and Hildegard Reinhardt. Tatjana Barbakoff (1899-1944) - Tänzerin und Muse. Edited by Verein August-Macke-Haus. 43. Bonn: August-Macke-Haus, 2002.

Ellis, Nadia. Territories of the Soul: Queered Belonging in the Black Diaspora. Durham: Duke University Press, 2015.

El-Tayeb, Fatima. European Others: Queering Ethnicity in Postnational Europe.

Difference Incorporated. Minneapolis: University of Minnesota Press, 2011.

_ Undeutsch. Die Konstruktion Des Anderen in Der Postmigrantischen Gesellshaft. Bielefeld: transcript, 2016.

Emmanuel, Christiane. "Choc(s) - Artist Statement," 2011.

_. "Rencontre." Conference presented at the Exhibition LAM CESAIRE PICASSO, Habitation Clément, Martinique, December 15, 2013.

—. Interview by Layla Zami. Fort-de-France, February 21, 2014. 
Etoke, Nathalie. Melancholia Africana: L'indispensable Dépassement de La Condition Noire. Coll. Mémoires Du Sud. Paris: Editions du Cygne, 2010.

Fabre, Geneviève E. "The Slave Ship Dance." In Black Imagination and the Middle Passage, edited by Maria Diedrich and Henry Louis Gates, Jr., 33-46. W.E.B. Du Bois Institute. Oxford: Oxford University Press, 1999.

"Facing the Nakba." Jewish Voice for Peace, https://jewishvoiceforpeace.org/facing-thenakbal

Fischer-Lichte, Erika. Ästhetik Des Performativen. Frankfurt a.M.: Suhrkamp, 2004.

Foster, Susan L. "Choreographies of Writing." Performed Lecture presented at the Susan Foster! Susan Foster! Bodies of Work : 3 Lectures : Performed, Pew Center for Arts \& Heritage, Philadelphia, March 22, 2011. http://danceworkbook.pcah.us/susanfoster/choreographies-of-writing.html

, ed. Corporealities: Dancing Knowledge, Culture and Power. New York: Routledge, 1996.

. Reading Choreography: Bodies and Subjects in Contemporary American Dance. Berkeley: University of California Press, 1986.

_ . "Worlding Dance: An Introduction." In Worlding Dance, edited by Susan L. Foster, 1-13. Studies in International Performance. NYC: Palgrave-Macmillan, 2011.

Fox, Robert Elliot. "Diasporacentrism and Black Aura Texts." In The African Diaspora: African Origins and New World Identities, edited by Isidore Okpewho, Carole Boyce Davies, and Ali A. Mazrui, 367-78. Bloomington: Indiana University Press, 1999.

Fuentes, Marisa J. Dispossessed Lives: Enslaved Women, Violence, and the Archive. Philadelphia: University of Pennsylvania Press, 2016.

Gabriel, Teshome. "Ruin and The Other: Towards a Language Of Memory." Teshome Gabriel - Articles \& Other Works (blog). Accessed February 9, 2016. http://teshomegabriel.net/ruin-and-the-other

Gebske, Jennifer. "Performativität zwischen Zitation und Ereignis. Vergleich der Performativitätsbegriffe von Judith Butler und Erika Fischer-Lichte." Magisterarbeit, Friedrich-Alexander-Universität, 2009. https://opus4.kobv.de/opus4fau/files/1593/MagisterGebske.pdf

George-Graves, Nadine. "Diasporic Spidering: Constructing Contemporary Black Identities." In Black Performance Theory, edited by Thomas F. DeFrantz and Anita Gonzalez, 33-44. Durham: Duke University Press, 2014.

, ed. The Oxford Handbook of Dance and Theater. Oxford: Oxford University Press, 2015. 
- Urban Bush Women: Twenty Years of African American Dance Theater,

Community Engagement, and Working It Out. Studies in Dance History. Madison:

University of Wisconsin Press, 2010.

Glissant, Edouard. Le Discours Antillais. Paris: Seuil, 1981.

Goebbels, Günter. Tatjana Barbakoff: eine vergessene Tänzerin in Bildern und

Dokumentaten. Düsseldorf: Freundeskreis Kulturbahnhof Eller e.V., 2009.

Gopinath, Gayatri. Impossible Desires: Queer Diasporas and South Asian Public Cultures.

Perverse Modernities. Duke University Press, 2005.

Green, Jill, and Susan W. Stinson. "Postpositivist Research in Dance." In Researching

Dance: Evolving Modes of Inquiry, edited by Sondra Horton Fraleigh and Penelope

Hanstein, 91-123. Pittsburgh: University of Pittsburgh Press, 1999.

Ha, Kien Nghi, ed. Asiatische Deutsche. Vietnamesische Diaspora and Beyond. Berlin:

Assoziation A, 2012.

. "Die Fragile Erinnerung Des Entinnerten." Bundeszentrale für politiche Bildung,

October 23, 2012. http://www.bpb.de/apuz/146985/die-fragile-erinnerung-desentinnerten?

. "Macht (T)raum(a) Berlin: Deutschland Als Kolonialgesellschaft." In Mythen, Masken Und Subjekte. Kritische Weißseinsforschung in Deutschland, edited by Maureen Maisha Eggers, Grada Kilomba, Peggy Piesche, and Susanne Arndt, 10517. Münster: Unrast-Verlag, 2009.

. "People of Colour." In Rassismus Auf Gut Deutsch. Ein Kritisches

Nachschlagewerk Zu Rassistischen Sprachhandlungen, edited by Adibeli NdukaAgwu and Lann Hornscheidt, Transdisziplinäre Genderstudien 1:80-84. Wissen \& Praxis 155. Frankfurt a.M.: Brandes \& Apsel, 2010.

—_. "Rostock-Lichtenhagen: Die Rückkehr Des Verdrängten." Heinrich-Boell-Stiftung, January 9, 2012. https://heimatkunde.boell.de/2012/09/01/rostock-lichtenhagen-dierueckkehr-des-verdraengten

Hall, Stuart. "Cultural Identity and Diaspora." In Colonial Discourse and Postcolonial Theory, edited by Patrick Williams and Laura Chrisman. New York: Columbia University Press, 1994.

Hamilton, LaMont. LaMont Hamilton. Accessed July 4, 2017. https://www.lamonthamilton.com/

Han, Byung-Chul. Duft der Zeit. Ein philosophischer Essay zur Kunst des Verweilens. 12th ed. $x$ texte. Bielefeld: Transcript, 2015.

Hardt, Yvonne. "Engagement with the Past in Contemporary Dance." In New German Dance Studies, edited by Susan Manning and Lucia Ruprecht, 217-31. Chicago: University of Illinois, 2012. 
Harry J. Jr Elam. The Past as Present in the Drama of August Wilson. Ann Arbor: University of Michigan Press, 2006.

Hartman, Saidiya. Loose Your Mother: A Journey Along the Atlantic Slave Route. New York: Farrar, Straus and Giroux, 2007.

—. "Venus in Two Acts." Small Axe 12-2, no. 26 (June 2008): 1-14.

Hayes, Jarrod. "Queering Roots, Queering Diaspora." In Rites of Return: Diaspora Poetics and the Politics of Memory, edited by Marianne Hirsch and Nancy K. Miller, 72-87. New York: Columbia University Press, 2011.

Hirsch, Marianne. The Generation of Postmemory: Writing and Visual Culture After the Holocaust. Gender and Culture. New York: Columbia University Press, 2012.

Hirsch, Marianne, and Nancy K. Miller. Rites of Return: Diaspora Poetics and the Politics of Memory. Gender and Culture Series. New York: Columbia University Press, 2011.

Holley-Bockelmann, Kelly. "TEDx Talk: The Spacetime Symphony of Gravitational Waves." TEDx Talk, Nashville, May 23, 2016. https://www.youtube.com/watch? $\mathrm{v}=\mathrm{DTKGAE} 4 \mathrm{voNM}$

hooks, bell. "Choosing the Margin as a Space of Radical Openness." In The Feminist Standpoint Theory Reader - Intellectual and Political Controversies, 153-59. New York: Routledge, 2004.

- YEARNING: Race, Gender, and Cultural Politics. Boston: South End Press, 1990. hooks, bell, and Amalia Mesa-Bains. Homegrown. Engaged Cultural Criticism. Cambridge, MA: South End Press, 2006.

Hornscheidt, Lann. "Aber wie soll ich das denn machen? Interdependenkend forschen: Methodologische und Methodische Handlungsvorschläge." In InterdepenDenken: Wie Positionierung und Intersektionalität forschend gestalten, edited by AK Forschungshandeln, 194-212. wissen_bewegen. Berlin: w_orten\&meer, 2015.

_. feministische w_orte: ein lern-, denk- und handlungsbuch zu sprache und diskriminierung, gender studies und feministischer linguistik. Vol. transdisziplinäre genderstudien. 5 vols. wissen \& praxis 168. Frankfurt a.M.: Brandes \& Apsel, 2012.

—. "Postkoloniale Gender-Forschung: Ansätze Feministischer Postkolonialer Studien." In Schlüsse/werke Der Postcolonial Studies, edited by Alexandra Karentzos and Julia Reuter, 215-28. Wiesbaden: Springer VS, 2012.

Hornscheidt, Lann, and Susanne Baer. "Transdisciplinary Gender Studies: Conceptual and Institutional Challenges." In Theories and Methodologies in Postgraduate Feminist Research: Researching Differently, edited by Rosemarie Buikema, Gabriele Griffin, and Nina Lykke, 165-79. London / New York: Routledge, 2011. 
Ingrisch, Doris. Wissenschaft, Kunst Und Gender. Denkräume in Bewegung. Image 44. Bielefeld: transcript, 2012.

John, Valérie. "De lieu en lieu(x)." In L'Art à l'épreuve du lieu, edited by Dominique Berthet, 127-38. Histoire et Idées des Arts. Paris: L'Harmattan, 2004.

Johnson, E. Patrick, and Ramón H. Rivera-Servera, eds. Blacktino Queer Performance. Durham: Duke University Press, 2016.

_ , eds. Solo/Black/Woman. Scripts, Interviews, Essays. Evanston: Northwestern University Press, 2014.

Kanaaneh, Rhoda Ann. Birthing the Nation: Strategies of Palestinian Women in Israel. Berkeley: University of California Press, 2002.

Kapitan, Alex. "Ask a Radical Copyeditor: Black with a Capital 'B." Radical Copyeditor (blog), September 21, 2016. https://radicalcopyeditor.com/2016/09/21/black-with-acapital-b/

Karentzos, Alexandra. "Postkoloniale Kunstgeschichte: Revisionen von Musealisierungen, Kanonisierungen, Repräsentationen." In Schlüsse/werke Der Postcolonial Studies, edited by Alexandra Karentzos and Julia Reuter, 249-66. Wiesbaden: Springer VS, 2012.

Katrak, Ketu. Contemporary Indian Dance: New Creative Choreography in Indian and the Diaspora. Studies in International Performance. New York: Palgrave-Macmillan, 2011.

Kelly, Natasha A. Afrokultur: Der Raum zwischen gestern und morgen. Berlin: UnrastVerlag, 2016.

Kilomba, Grada. Plantation Memories: Episodes of Everyday Racism. Münster: UnrastVerlag, 2008.

Kimmerer, Robin Wall. Braiding Sweetgrass: Indigenous Wisdom, Scientific Knowledge and the Teachings of Plants. Minneapolis: Milkweed, 2013.

Klüger, Ruth. weiter leben. Eine Jugend. Göttingen: Wallstein, 1994.

Kukuwa, Ellen. "Kukuwa." Kukuwa, www.kukuwafitness.com

Küppers-Adebisi, Adetoun. "Nationalisierung interdepenDenken." In InterdepenDenken: Wie Positionierung und Intersektionalität forschend gestalten, edited by AK Forschungshandeln, 134-47. wissen_bewegen. Berlin: w_orten\&meer, 2015.

Kusser, Astrid. Körper in Schieflage: Tanzen Im Strudel Des Black Atlantic Um 1900. Bielefeld: transcript, 2013.

Kwan, SanSan. Kinesthetic City: Dance \& Movement in Chinese Urban Spaces. Oxford University Press, 2013.

Laframboise, Sandra, and Michael Anhorn. "The Way Of The Two Spirited People: Native American Concepts of Gender and Sexual Orientation." Dancing to Eagle Spirit 
Society (blog). Accessed July 4, 2017.

http://www.dancingtoeaglespiritsociety.org/twospirit.php

Landsberg, Alison. Prosthetic Memory: The Transformation of American Remembrance in the Age of Mass Culture. New York: Columbia University Press, 2004.

Lauré al-Samarai, Nicola. "Inspirited Topography. Über/Lebensräume, Heim-Suchungen

und die Verortung der Erfahrung in Schwarzen deutschen Kultur- und

Wissenstraditionen." In Mythen, Masken und Subjekte. Kritische

Weißseinsforschung in Deutschland, edited by Maureen Maisha Eggers, Grada

Kilomba, Peggy Piesche, and Susanne Arndt, 2nd ed., 118-34. Münster: Unrast-

Verlag, 2009.

Lepecki, André. Exhausting Dance: Performance and the Politics of Movement. New

York/London: Routledge, 2006.

- Singularities: Dance in the Age of Performance. New York: Routledge, 2016.

Lespiaux, Sophie. "Durch Gaerten, une performance musicale et chorégraphique d'Oxana

Chi." Une Chambre à Soi (blog), November 24, 2014.

http://sophielespiaux.blogspot.de/2014/11/durch-garten-une-performance-

musicale.html

Levy, Daniel, and Natan Sznaider. Erinnerung im globalen Zeitalter: Der Holocaust.

Frankfurt a.M.: Suhrkamp, 2001.

Lightman, Alan. Einstein's Dreams. London: Vintage, 2004.

Lin, Yatin. "Kinesthetic City: Dance and Movement in Chinese Urban Spaces by SanSan

Kwan (Review)." Dance Research Journal 46, no. 1 (April 2014): 129-33.

Lockward, Alanna. "Diaspora." In Rassismus Auf Gut Deutsch. Ein Kritisches

Nachschlagewerk Zu Rassistischen Sprachhandlungen, edited by Adibeli Nduka-

Agwu and Lann Hornscheidt, Transdisziplinäre Genderstudien 1:56-71. Wissen \&

Praxis 155. Frankfurt a.M.: Brandes \& Apsel, 2010.

Loïal, Chantal. “On T’appelle Vénus - Dossier de Diffusion.” Compagnie Difé Kako, 2015.

http://www.difekako.fr/wp-content/uploads/DOSSIER-VENUS-WEB-0717.pdf

Lorde, Audre. “A Litany for Survival." In The Black Unicorn: Poems, 1978.

_. "Foreword to the English Language Edition." In Showing Our Colors: Afro-German

Women Speak Out, edited by May Opitz-Ayim, Katharina Oguntoye, and Dagmar

Schultz. Amherst: University of Massachusetts Press, 1992.

—. Zami: A New Spelling of My Name. New York: Persephone Press, 1982.

Lori L. Tharps. "The Case for Black With a Capital B.” New York Times, November 19, 2014.

Lykke, Nina. "This Discipline Which Is Not One: Feminist Studies as a Postdiscipline." In Theories and Methodologies in Postgraduate Feminist Research: Researching 
Differently, edited by Rosemarie Buikema, Gabriele Griffin, and Nina Lykke, 137-50. London / New York: Routledge, 2011.

Mandel, Naomi. Against the Unspeakable: Complicity, the Holocaust, and Slavery in America. Cultural Frames, Framing Culture. Charlottesville: University of Virginia Press, 2006.

Marquié, Hélène. "Le genre, un outil épistémologique pour l'historiographie de la danse." In Actes du colloque international, edited by Roxana Martin and Martina Nordera, 211-22. Université de Nice-Sophia Antipolis: Honoré Champion, 2009.

- Non, la danse n'est pas un truc de filles! Essai sur le genre en danse. CULTURE DANSE. Toulouse: Editions de l'Attribut, 2016.

Martin, Randy. Critical Moves: Dance Studies in Theory and Politics. Durham: Duke University Press, 1998.

McCarren, Felicia. French Moves: The Cultural Politics of Le Hip Hop. New York: Oxford University Press, 2013.

Mignolo, Walter D. Local Histories/Global Designs: Coloniality, Subaltern Knowledges, and Border Thinking. 2nd ed. Princeton: Princeton University Press, 2012.

Mohanty, Chandra Talpade. "Crafting Feminist Genealogies: On the Geography and Politics of Home, Nation, and Community." In Talking Visions: Multicultural Feminism in a Transnational Age, edited by Ella Shohat, 485-500. New York: New Museum of Contemporary Art MIT Press, 1998.

Monáe, Janelle. Q.U.E.E.N. Atlantic Records, 2013. https://www.youtube.com/watch?v=tEddixS-UoU

Morrison, Toni. Beloved: A Novel. New York: Vintage Books, 2004.

."The Site of Memory." In Inventing the Truth. The Art and Craft of the Memoir, edited by William K. Zinsser, 183-200. New York: Houghton Mifflin, 1998.

"Moving Memory - International Symposium-Festival." Performing Memory: Interventions (blog), 2016. http://movingmemoryberlin.tumblr.com/event2016

Muñoz, José Esteban. DISIDENTIFICATIONS. Queers of Color and the Performance of Politics. Cultural Studies of the America, vol. 2. Minneapolis: University of Minnesota Press, 1999.

Murguía, Alexandro. The Medicine of Memory: A Mexica Clan in California. Austin: University of Texas Press, 2002.

Nduka-Agwu, Adibeli, and Lann Hornscheidt, eds. Rassismus auf gut Deutsch. Ein kritisches Nachschlagewerk zu rassistischen Sprachhandlungen. Vol. Transdisziplinäre Genderstudien 1. wissen \& praxis 155. Frankfurt a.M.: Brandes \& Apsel, 2010. 
Nelson, Alondra. "AfroFuturism: Past-Future Visions." Colorlines: Race, Culture, Action, Center for Third World Organizing, 1, no. 3 (Spring 2000): 34-37.

_. "The Factness of Diaspora. The Social Sources of Genetic Genealogy." In Rites of Return - Diaspora Poetics and the Politics of Memory, edited by Marianne Hirsch and Nancy K. Miller, 23-39. Gender and Culture Series. New York: Columbia University Press, 2011.

Okach, Opiyo. "Cleansing." Gaara Projects. Accessed November 1, 2016. http://www.gaaraprojects.com/cleansinggaara.htm

Omise'eke, Natasha Tinsley. "Black Atlantic, Queer Atlantic: Queer Imaginings of the Middle Passage." GLQ: A Journal of Lesbian and Gay Studies 14, no. 2-3 (2008): 191-215.

Opoku, Kwame. "Nefertiti in Absurdity: How Often Must Egyptians Ask Germans for the Return of the Egyptian Queen?," June 28, 2011. https://www.modernghana.com/news/314307/1/nefertiti-in-absurdity-how-oftenmust-egyptians-as.html

Oral Historian Association. "Principles and Best Practices." Oral History Association, 2009. http://www.oralhistory.org/about/principles-and-practices/

Oyěwùmí, Oyèrónkẹ. The Invention of Women: Making an African Sense of Western Gender Discourses. Minneapolis: University of Minnesota Press, 1997.

Paris, Carl. "Reading 'Spirit' and the Dancing Body in the Choreography of Ronald K. Brown and Reggie Wilson." In Black Performance Theory, edited by Thomas F. DeFrantz and Anita Gonzalez, 99-114. Durham: Duke University Press, 2014.

"Performing Memory." Blog. http://movingmemoryberlin.tumblr.com/

Petrowskaja, Katja. Vielleicht Esther. Berlin: Suhrkamp, 2015.

Phelan, Peggy. Unmarked: The Politics of Performance. New York: Routledge, 1993.

Pinto, Samantha. Difficult Diasporas: The Transnational Feminist Aesthetic of the Black Atlantic. New York: New York University Press, 2013.

Plate, Liedeke, and Anneke Smelik, eds. Performing Memory in Art and Popular Culture. Routledge Research in Cultural and Media Studies 48. New York: Routledge, 2013. Quayson, Ato, and Girish Daswani. "Introduction - Diaspora and Transnationalism: Scapes, Scales, and Scopes." In A Companion to Diaspora and Transnationalism, edited by Ato Quayson and Girish Daswani, 1-26. Oxford: Blackwell Publishing, 2013.

Quijano, Aníbal. “Coloniality and Modernity/ Rationality." Cultural Studies 21, no. 2 (2007): 168-78. 
Ramón H. Rivera-Servera. Performing Queer Latinidad: Dance, Sexuality, Politics.

Triangulations. Lesbian/Gay/Queer. Theatre/Drama/Performance. Ann Harbor, Michigan: University of Michigan Press, 2012.

Rossen, Rebecca. Dancing Jewish: Jewish Identity in American Modern and Postmodern Dance. Oxford University Press, 2014.

Rothberg, Michael. Multidirectional Memory: Remembering the Holocaust in the Age of Globalization. Cultural Memory in the Present. Stanford: Stanford University Press, 2009.

. "W. E. B. Du Bois in Warsaw: Holocaust Memory and the Color Line, 1949-1952." The Yale Journal of Criticism 14, no. 1 (2001): 169-89.

Rovelli, Carlos. Reality Is Not What It Seems: The Journey to Quantum Gravity. New York: Riverhead, 2017.

Saleh, Farah. "Farah Saleh." Vimeo. Accessed March 26, 2017. https://vimeo.com/user13826099

—. "Note D'intention. Parole, Parole, Parole," December 2012. http://miniatures.officinae.fr/parole-parole-parole-farah-saleh/

_ . "On Art Production as a Form of Daily Protest." Tanzquartier Vienna, September $5,2014$.

—. Interview by Layla Zami. Vienna, June 30, 2014.

Saleh, Farah, and Nicole Bindler. Free Advice and an Interview with Farah Saleh. Thinking Dance, April 27, 2016. http://thinkingdance.net/articles/2016/04/27/FreeAdvice-and-an-Interview-with-Farah-Saleh

Schneider, Rebecca. Performing Remains: Art and War in Times of Theatrical Reenactment. NY: Routledge, 2011.

Schwab, Gabriele. Haunting Legacies: Violent Histories and Transgenerational Trauma. New York: Columbia University Press, 2010.

Scolieri, Paul A. Dancing the New World: Aztecs, Spaniards, and the Choreography of Conquest. Latin American \& Caribbean Performance Series. Austin: University of Texas, 2013.

Sharpe, Christina. In the Wake: On Blackness and Being. Durham: Duke University Press, 2016.

Shea Murphy, Jacqueline. The People Have Never Stopped Dancing: Native American Modern Dance Histories. Minneapolis: University of Minnesota Press, 2007.

Shehadeh, Raja. "Palestinian Choreographer Finds Expression in Modern Dance." AlMonitor - The Pulse of the Middle East, April 15, 2013. http://www.almonitor.com/pulse/originals/2013/04/ordinary-madness-ramallah- contemporarydance-festival.html 
Shohat, Ella. Taboo Memories, Diasporic Voices. Next Wave. New Directions in Women's Studies. Durham: Duke University Press, 2006.

Simon, Zufit. "All about Nothing." Art Blau - Zufit Simon. Accessed March 26, 2017. http://www.artblau.de/Simon.html\#all\%20about

—. Interview by Layla Zami. Berlin, May 11, 2014.

Sirri, Lana. "Führt geografische und religiöse Positionierung zu Ausschluss?

Feministische akademische Wissensproduktion hinterfragen." In InterdepenDenken:

Wie Positionierung und Intersektionalität forschend gestalten, edited by AK

Forschungshandeln, 158-71. wissen_bewegen. Berlin: w_orten\&meer, 2015.

Spitz, Emilia, and Linda Uruchurtu. "Bag of Steps: Turns." The Ballet Bag (blog), October

31, 2009. http://www.theballetbag.com/2009/10/31/bag-of-steps-turns/

Straus-Ernst, Lou. "Bei Tatjana Barbakoff." Die Weltwoche. May 25, 1934.

Taylor, Diana. The Archive and The Repertoire: Performing Cultural Memory in the Americas. Durham: Duke University Press, 2003.

Thompson, Candace. "Of Circles and Bright Colors." Instagram, November 23, 2016.

Thurner, Christina, and Julia Wehren, eds. Original Und Revival: Geschichts-Schreibung Im Tanz. Materialien Des Instituts Für Theaterwissenschaft Bern (ITW) 10. Bern: Chronos, 2010.

Tighe, Claire. "Middle Passage in Twenty Minutes: The AFROFUTURISM Series."

Culturebot - Maximum Performance, November 10, 2015.

http://www.culturebot.org/2015/11/24930/middle-passage-in-twenty-minutesrenegade-performance-groups-the-afrofuturism-series/

Tillet, Salamishah. Sites of Slavery: Citizenship and Racial Democracy in the Post-Civil Rights Imagination. Durham: Duke University Press, 2012.

Trouillot, Michel-Rolph. Silencing The Past: Power and the Production of History. Boston: Beacon Press, 1995.

Walcott, Derek. "The Sea Is History." In Selected Poems, 137-39. New York: Farrar, Straus and Giroux, 2007.

Walkowicz, Karolina. Die Kampfkunst-Tänzerin. Der Gender Diskurs Im Interkulturellen Vergleich Des Tanzes. Marburg: Tectum Verlag, 2010.

Wehren, Julia. Körper als Archiv in Bewegung: Choreografie als historiografische Praxis. TanzScripte 37. Bielefeld: transcript, 2016.

Welsh Asante, Kariamu. "Commonalities in African Dance: An Aesthetic Foundation." In Moving History / Dancing Cultures. A Dance History Reader, edited by Ann Dils and Ann Cooper Albright, 144-51. Durham: Wesleyan University Press, 2001. 
Wright, Michelle M. "Others-from-Within from Without: Afro-German Subject Formation and the Challenge of a Counter-Discourse." Callaloo 26, no. 2 (Spring 2003): 296305.

- Physics of Blackness: Beyond the Middle Passage Epistemology. Minneapolis: University of Minnesota Press, 2015.

Yung-Hing, Renée-Paule, ed. Art Contemporain de La Caraïbe: Mythes, Croyances, Religions et Imaginaires. Paris: HC, 2012.

Zachery, André M. "Artist's Journal: Futurity and the Containment of Blackness in TwentyFirst-Century Performance." Theater - Yale School of Drama 46, no. 3 (2017): 6282.

—. "Physical Propulsion." Brooklyn Studios for Dance, 2016. Accessed April 24, 2016. http://bksd.org/event/flying-low-andre-zachery/2016-04-26/

- "Renegade Performance Group." Renegade Performance Group. Accessed March 26, 2017. http://www.renegadepg.com/untitled-distances.html

_. "Untitled Distances." Renegade Performance Group. Accessed March 26, 2017. http://www.renegadepg.com/untitled-distances.html

_. Interview by Layla Zami. New York, December 1, 2015.

Zambrano, David. "Flying-Low - Dance Technique." David Zambrano (blog). http://www.davidzambrano.org/?page id $=279$

Zami, Layla. "Dancing the Past in the Present Tense - Queer Afropean Presence in Oxana Chi's Dancescapes." Lambda Nordica Postcolonial Queer Europe, no. 2-3 (2017): 126-50.

_. "Ein all_zu_täglicher Tag*." In InterdepenDenken: Wie Positionierung und Intersektionalität forschend gestalten, edited by AK Forschungshandeln, 72-83. Berlin: w_orten\&meer, 2015.

—. "Mit Oxana Chi Durch Gärten." Nah \& Fern. Das Kulturmagazin Für Migration Und Partizipation, 2010.

. "Oxana Chi von Zopf bis Fluss: Transkulturelle Tanzkunst und alternative Geschichtsschreibung." In The Living Archive: kulturelle Produktionen und Räume, edited by MID Redaktion and Aicha Diallo, 52-61. Berlin: Heinrich-Boell-Stiftung, 2013. http://heimatkunde.boell.de/2012/12/18/oxana-chi-von-zopf-bis-flusstranskulturelle-tanzkunst-und-alternative

. "Oxana Chis Tänzerische Wissensschaffung: Biographische Erinnerung an Tatjana Barbakoff Aus Feministischer Perspektive." In Sichtbar Unsichtbar. Geschlechterwissen in (Auto-)Biographischen Texten, edited by Maria Heidegger, Nina Kogler, Ursula A. Schneider, and Annette Steinsiek, 259-74. Gender Studies. Bielefeld: transcript, 2015. 
_. "Rendre sur scène son corps à Sawtche." Madinin'Art. February 2011.

_. "Research Diary - Unpublished Manuscript," 20172013.

_. "Tanzkunst als lebendige Erinnerung: Oxana Chis performative Erinnerung an Tatjana Barbakoff." In Neues Judentum - altes Erinnern? Zeiträume des Gedenkens, edited by Dimitrij Belkin, Lara Hensch, and Eva Lezzi, 267-88. Berlin: Hentrich\&Hentrich / ELES, 2017.

Zenenga, Praise. "Power and the Body: Revisiting Dance and Theatre Aesthetics of Resistance in the Academy." Dance Research Journal 43, no. 1 (2011): 65-69. . "The Total Theater Aesthetic Paradigm in African Theater." In The Oxford Handbook of Dance and Theater, edited by Nadine George-Graves, 236-51. Oxford: Oxford University Press, 2015. 